Cristina Aparicio

\title{
ANÁLISE DA RESPOSTA ESPECTRAL DE ESPÉCIES DE MACRÓFITAS.
}

Tese apresentada ao Instituto de Biociências da Universidade de São Paulo para a obtenção de título de Doutor em Ciências na área de Ecologia de Ecossistemas Terrestres e Aquáticos.

Orientadora: Marisa Dantas Bitencourt

São Paulo 2007 


Aparicio, Cristina
ANÁLISE DA RESPOSTA ESPECTRAL
DE ESPÉCIES DE MACRÓFITAS.
Número de páginas
Tese (Doutorado) - Instituto de
Biociências da Universidade de São Paulo.
Departamento de Ecologia de Ecossistemas
Terrestres e Aquáticos.
1. Sensoriamento Remoto 2.
Macrófitas 3. Resposta espectral
I. Universidade de São Paulo. Instituto de
Biociências. Departamento de Ecologia de
Ecossistemas Terrestres e Aquáticos.

\section{Comissão Julgadora:}

Welington Braz Carvalho Delitti

Prof(a). Dr(a).

Gregório Cardoso Tápias Ceccantini

Prof(a). Dr(a).

Dalton de Morisson Valeriano

Prof(a). Dr(a).

Arnildo Pott

Prof(a). Dr(a).

Marisa Dantas Bitencourt

Prof(a). Dr(a).

Orientador(a) 
Dedico a minha família: Lourdes, Olival e Ricardo Aparicio. 
"Jesus voltou-se então para seus discípulos: Portanto vos digo: não andeis preocupados com a vossa vida, pelo que haveis de comer; nem com o vosso corpo, pelo que haveis de vestir. A vida vale mais do que o sustento e o corpo mais do que as vestes. Considerai os corvos: eles não semeiam, nem ceifam, nem têm despensa, nem celeiro; entretanto, Deus os sustenta. Quanto mais valeis vós do que eles? Mas qual de vós, por mais que se preocupe, pode acrescentar um só côvado à duração de sua vida? Se vós, pois, não podeis fazer nem as mínimas coisas, por que estais preocupados com as outras? Considerai os lírios, como crescem; não fiam, nem tecem. Contudo, digo-vos: nem Salomão em toda a sua glória jamais se vestiu como um deles. Se Deus, portanto, veste assim a erva que hoje está no campo e amanhã se lança ao fogo, quanto mais a vós, homens de fé pequenina! Não vos inquieteis com o que haveis de comer ou beber; e não andeis com vãs preocupações. Porque os homens do mundo é que se preocupam com todas estas coisas. Mas vosso Pai bem sabe que precisais de tudo isso. Buscai antes o Reino de Deus e a sua justiça e todas estas coisas vos serão dadas por acréscimo. Não temais, pequeno rebanho, porque foi do agrado de vosso Pai darvos o Reino. Vendei o que possuís e dai esmolas; fazei para vós bolsas que não se gastam, um tesouro inesgotável nos céus, aonde não chega o ladrão e a traça não o destrói. Pois onde estiver o vosso tesouro, ali estará também o vosso coração."

Lucas, 12:22-34, Bíblia. 


\section{Agradecimentos}

Agradeço a Deus, em primeiro lugar, que me deu cada suspiro desde que nasci.

Agradeço a minha família, pelo apoio constante, e aos amigos que sempre me amaram sem cobrar nada em troca.

Agradeço a minha orientadora, que além do apoio acadêmico, confiou em minha capacidade e criatividade ao longo desses anos de doutorado, e foi uma amiga sempre presente nos momentos de dificuldade.

Agradeço ao Prof. Timothy John Malthus, por ter me orientado e colaborado para minha tese, durante minha estada na Universidade de Edimburgo, Escócia, ao Christopher MacLellan, que me auxiliou no aprendizado do manuseio dos instrumentos espectroradiométricos.

Agradeço aos professores Sérgio Tadeu, Marcelo Pompêo, Evlyn Novo, Irineu B. Junior, José Galizia Tundisi, Sidney M. Thomaz, que me apoiaram ao longo deste estudo.

Agradeço aos amigos que me ajudaram com seu carinho e amizade ao longo do processo de doutoramento: Gilsom, Cristiane, Juliana, Márcio Nascimento, Lúcia, Adrian, Joana, Fátima, Susan, Stephen, Ângela, Cleber, Helton, Rosângela e cada amigo do meu coração. Também agradeço a todas as pessoas da igreja Presbiteriana do Butantã, que sempre estiveram de braços abertos para me acolher.

Agradeço à Universidade de São Paulo, ao Instituto de Biociências e ao Departamento de Ecologia pela oportunidade de desenvolver esse doutorado.

Agradeço às agências financiadoras CAPES, FAPESP e à Pró-Reitoria de PósGraduação da USP, que possibilitaram a execução deste estudo através do apoio financeiro. 


\section{RESUMO}

A discriminação de espécies de macrófitas através de Sensoriamento Remoto vem de encontro à necessidades econômicas e sanitárias geradas pelo aumento dos conglomerados urbanos e seus danos aos ambientes aquáticos continentais. A ausência de pesquisa básica relacionada à obtenção de respostas espectrais específicas tem dificultado a discriminação das espécies de macrófitas infestantes, em imagens multiespectrais. Objetivos: Tendo o conhecimento das necessidades de pesquisa básica nesta área, este estudo tem como objetivos analisar a resposta espectral de espécies de macrófitas, buscando sua distinção, e comparar a reposta espectral do Infravermelho Próximo (IVP) às características anatômicas espessura da folha, espessura do parênquima esponjoso, proporção do parênquima esponjoso na folha, e proporção de espaços aéreos no parênquima esponjoso. Metodologia: Para atingir os objetivos, foram coletados dados espectroradiométricos de espécies de macrófitas. Num primeiro momento foi testada a distinção entre duas espécies em imagem orbital. Em seguida, foram realizados diversos experimentos em laboratório, os quais foram posteriormente analisados matematicamente buscando suas relações. Foi também realizado o estudo anatômico de folhas de cinco espécies de macrófitas, cujos valores foram comparados com a resposta espectral no IVP. Resultados: O banco de dados de respostas espectrais gerado foi comparado inter e intraespecificamente, e foram usados descritores matemáticos para verificar as possibilidades de diferenciação. As folhas com máxima, média e mínima reflectância de cinco espécies escolhidas por serem mais importantes em infestações foram analisadas anatomicamente e foram calculados os valores da espessura da folha, espessura do parênquima esponjoso, proporção do parênquima esponjoso na folha, e proporção de espaços aéreos no parênquima esponjoso. Conclusões: Os descritores utilizados para analisar as respostas espectrais se mostraram eficientes na separação entre as espécies estudadas em laboratório. Dentre eles, o que mostrou melhores resultados para a distinção entre espécies foi o índice da Posição do Limite Vermelho. As características anatômicas obtidas com o uso de microscopia confocal e de luz possibilitaram a discriminação das espécies. Além disso, foi possível verificar que as características anatômicas analisadas foram altamente correlacionadas com a Reflectância de algumas das espécies na região do IVP.

Palavras-chave: Sensoriamento Remoto, Macrófitas, Resposta espectral, Anatomia, Parênquima esponjoso. 


\begin{abstract}
The differentiation of macrophytes species using Remote Sensing is recommended in a world where the economy and healthy are being highly injured by the increased number of urban population and their damages to the aquatic environments. The lack of the basic research related to the acquisition of spectral signatures of species has been raising difficulties on the discrimination of them in multispectral images. Aims: Knowing this lack of basic research, this work has the goals of analyze the spectral signatures of macrophytes species, looking for its differentiation, and compare spectral the reflectance in the Near Infrared (NIR) region of the Electromagnetic Spectrum with the anatomic variables: thickness of the leaf, thickness of the spongy mesophyll, percentage of the spongy mesophyll in the leaf, and percentage of the aerial spaces inside this mesophyll. Methodology: To reach these goals, it was collected spectroradiometric data of macrophytes species. Primarily it was tested the differentiation between two species in an orbital image. Afterward, it was carried out some laboratory experiments, which were mathematically analyzed looking for their relationships. Then, it was accomplished the leaves anatomical studies of five macrophytes species, whose values where compared with the spectral signature in the NIR region. Results: The initial spectral signatures database was compared inter and intra-specifically, and it were used mathematical descriptors to verify the possibilities of species differentiation. Leaves with maximum, medium and minimum reflectance of five species chosen because of their importance on infestations, was anatomically analyzed and it were calculated the values of the thickness of the leaf, thickness of the spongy mesophyll, percentage of the spongy mesophyll in the leaf, and percentage of the aerial spaces inside this mesophyll. Conclusions: The descriptors used to analyze the spectral signatures denote efficiency in the differentiation of macrophytes species in laboratory. Among them, the one that has been showed the best results for the species differentiation was the Red Edge Position. The anatomical characteristics achieved with confocal and light microscopy made feasible to differentiate the species. Besides that, it was possible to verify that the analyzed anatomical characteristics were highly correlated with reflectance in some species in the NIR region.
\end{abstract}

Key-words: Remote Sensing, Macrophytes, Spectral signature, Anatomy, Spongy Parenchyma. 


\section{Índice}

INTRODUÇÃO GERAL E APRESENTAÇÃO

OBJETIVOS

CAPÍTULO I - UTILIZAÇÃO DE DADOS DE IMAGENS DE SATÉLITE PARA LOCALIZAÇÃO E SEPARAÇÃO DE ESPÉCIES DE MACRÓFITAS NO RESERVATÓRIO BILLINGS, SÃO PAULO

I.1 - INTRODUÇÃO

I.2 - PROCEDIMENTOS METODOLÓGICOS

I.3 - RESULTADOS E DISCUSSÕES

I.4 - CONCLUSÕES

I.5 - CONSIDERAÇÕES FINAIS

I.6 - AGRADECIMENTOS ESPECIAIS

CAPÍTULO II - OBTENÇÃO DE RESPOSTA ESPECTRAL DE ESPECIES DE MACRÓFITAS EM LABORATÓRIO

II.1 - INTRODUÇÃO 26

II.2 - PROCEDIMENTOS METODOLÓGICOS 30

II.3 - RESULTADOS E DISCUSSÕES

II. 4 - CONCLUSÕES 44

II.5 - CONSIDERAÇÕES FINAIS 45

II.6 - APÊNDICE 46

CAPÍTULO III - ESTUDO DO ESTRESSE HÍDRICO DE FOLHAS DE MACRÓFITAS QUANDO SUBMETIDAS A EXPERIMENTOS DE LABORATÓRIO 56 III.1 - INTRODUÇÃO 
III.2 - PROCEDIMENTOS METODOLÓGICOS 58

III.3 - RESULTADOS E DISCUSSÕES 59

$\begin{array}{ll}\text { III. } 4 \text { - CONCLUSÕES } & 64\end{array}$

CAPÍTULO IV - DISTINÇÃO ENTRE ESPÉCIES DE MACRÓFITAS ATRAVÉS DO ESTUDO DE SUAS RESPOSTAS ESPECTRAIS 65

IV. 1 - INTRODUÇÃO

IV.2 - PROCEDIMENTOS METODOLÓGICOS 68

IV.2.1 - Intensidade média nas Faixas espectrais de interesse 69

IV.2.2 - Comprimentos de onda nos picos de reflectância dentro das faixas $\quad 69$

IV.2.3 - Posição do Limite Vermelho ou REP (Red Edge Position) 70

$\begin{array}{ll}\text { IV.2.4 - Índices entre faixas } & 71\end{array}$

$\begin{array}{ll}\text { IV.3 - RESULTADOS E DISCUSSÕES } & 72\end{array}$

$\begin{array}{ll}\text { IV.3.1 - Intensidade média nas Faixas Espectrais de interesse } & 73\end{array}$

IV.3.2 - Comprimentos de onda nos Picos de Reflectância dentro das Faixas 76

$\begin{array}{ll}\text { IV.3.3 - Posição do Limite Vermelho } & 78\end{array}$

IV.3.4 - Índices entre faixas $\quad 83$

$\begin{array}{ll}\text { IV.4 - CONCLUSÕES } & 85\end{array}$

CAPÍTULO V - UTILIZAÇÃO DE ANÁLISES ANATÔMICAS MICROSCÓPICAS PARA EXPLICAR ALTERAÇÕES NA RESPOSTA ESPECTRAL DE ESPÉCIES DE

$\begin{array}{lr}\text { MACRÓFITAS } & 90\end{array}$

V.1 - INTRODUÇÃO 90

V.2 - PROCEDIMENTOS METODOLÓGICOS 95 
V.2.1 - Medidas radiométricas

V.2.2 - Medidas anatômicas

V.3 - RESULTADOS E DISCUSSÕES

100

V.3.1 - Análises anatômicas

100

VI.3.2 - Análises conjuntas dos dados anatômicos e espectroradiométricos 106

V.4 - CONCLUSÕES 116

V.5 - AGRADECIMENTOS ESPECIAIS

V.6 - CONSIDERAÇÕES FINAIS

V.6 - APÊNDICE

Análises conjuntas dos dados anatômicos e espectroradiométricos

CAPÍTULO VI - UTILIZAÇÃO DE MODELAGEM PARA SIMULAR A RESPOSTA ESPECTRAL DE EGERIA DENSA DE ACORDO COM A PROFUNDIDADE 131

VI.1 - INTRODUÇÃO

VI.2 - PROCEDIMENTOS METODOLÓGICOS

VI.3 - RESULTADOS E DISCUSSÕES

VI.4 - CONCLUSÕES

CAPÍTULO VII - CONCLUSÕES E CONSIDERAÇÕES FINAIS 


\section{INTRODUÇÃO GERAL E APRESENTAÇÃO}

A Ciência de se obter conhecimento sobre objetos apenas através da Radiação Eletromagnética (REM) por eles refletida, absorvida ou transmitida é conhecida como Sensoriamento Remoto. Desde as primeiras décadas do século passado muito se tem feito no sentido de aprofundar os conhecimentos sobre a composição química e estruturas internas dos objetos remotamente sensoriados, buscando entender como interferem na interação destes com a REM. O uso de Sensoriamento Remoto auxilia a inferir informações através das respostas espectrais de alvos de interesse. Uma especial atenção tem sido dada à vegetação por conta de sua importância para a vida na Terra e, assim, muito do conhecimento sobre respostas espectrais da vegetação já foi obtido. As recentes pesquisas nessa área têm buscado diferenciar as espécies vegetais apenas através de sua resposta espectral.

Os Sensores Remotos se diferenciam principalmente pelas resoluções: espectral (largura das faixas espectrais) e espacial (área do terreno coberta por um pixel na imagem), e podem estar localizados em satélites (sensores orbitais), em plataformas aéreas ou podem ser portáteis. Quanto maior for o número de faixas espectrais, melhor a resolução espectral, e quanto menor for à área de visada coberta, melhor a resolução espacial. As especificações dos sensores orbitais e aéreos devem ser requeridas conforme o tipo de estudo a ser realizado, sendo necessário identificar as melhores resoluções espacial e espectral que respondam adequadamente às questões envolvidas em cada estudo. 
A tecnologia de sensores remotos, especialmente os orbitais, está em constante desenvolvimento, em busca de atender o maior número possível de áreas do conhecimento. Para a Limnologia (área onde se inclui o estudo das macrófitas), algumas faixas espectrais são especialmente indicadas, como as faixas do Visível (400 nm a $700 \mathrm{~nm}$ ) e Infravermelho Próximo ou IVP (700 nm - 1300 nm) do Espectro Eletromagnético.

Nessa tese, os objetos de estudo são os vegetais que vivem em sistemas aquáticos continentais, com folhas imersas, flutuantes ou emersas, também conhecidos como hidrófitas ou macrófitas aquáticas ou, como doravante serão denominadas, macrófitas. Os sistemas aquáticos continentais são ecologicamente complexos, especialmente em regiões tropicais com alta biodiversidade (Esteves 1998). Diversos estudos têm sido realizados nesses ambientes, dirigidos ao monitoramento de alguns parâmetros bióticos e abióticos (Henry, 1999). Entretanto, estes estudos demandam muito tempo e têm custo elevado para o meio acadêmico, especialmente no Brasil (Carvalho et al., 2003; Martins et al., 2003), um país onde esses sistemas abarcam grande extensão territorial.

Com o aumento da população mundial e das necessidades energéticas, monitorar e controlar infestações por macrófitas consome muito tempo e dinheiro. Os grandes aglomerados urbanos, por sua vez, aumentam a eutrofização de corpos d'água, tornando ainda mais complexos seu monitoramento e controle. Por esta razão, as infestações por macrófitas tem sido um problema constante, especialmente em Reservatórios Artificiais utilizados para fins hidrelétricos ou de abastecimento, fato que tem causado danos aos 
equipamentos geradores de energia elétrica, além de comprometer a qualidade da água e gerar problemas de Saúde Pública.

Ao longo das últimas décadas, muitos pesquisadores têm dirigido seus esforços para aperfeiçoar metodologias que possam gerar resultados baseados no uso de Sensoriamento Remoto para estudar sistemas aquáticos continentais, despendendo menos tempo e recursos financeiros (Thomaz e Bini, 2003; Jakubauskas, 2002; Ritchie e Cooper, 2001; Welch e Remillard, 1988). O Sensoriamento Remoto tem sido cada vez mais utilizado nos dias de hoje, em função principalmente de gerar imagens extensas que possibilitam o estudo de corpos d'água de tamanhos variados, e tem trazido bons indicadores ao monitoramento e ao controle ecológico desses corpos d'água. Algumas pesquisas têm sido realizadas com a finalidade de mapear infestações por macrófitas utilizando Sensoriamento Remoto. Os estudos que envolvem o uso de imagens de satélite ou fotografias aéreas para o mapeamento e monitoramento de macrófitas são os mais comuns, e se iniciaram há algumas décadas.

Para a análise dos resultados obtidos com Sensoriamento Remoto têm sido utilizadas diferentes técnicas de manipulação de dados, incluindo o uso de índices e métodos de classificação, obtidos tanto de fotografias aéreas como de imageadores aéreo e orbital, multi ou hiperespectrais (Mathew et al., 2003; Vasconcelos e Novo, 2003; Schmidt e Skidmore, 2003; Waldron et al., 2001; Jakubauskas, 2000; Smith et al., 2000; Waldron et al., 2001; Everitt et al., 1999; Jago et al., 1999; Lehmann e Lachavanne, 1997; Malthus e 
George, 1997; Malthus et al. 1997; Palombo e Bitencourt-Pereira, 1992; Remillard e Welch, 1992; Abdon, 1989). No Brasil, alguns estudos utilizando Sensoriamento Remoto foram iniciados nos anos 90 (Bitencourt-Pereira, 1992; Palombo \& Bitencourt-Pereira, 1992), com o intuito de melhorar as análises das infestações, restringindo-se ao mapeamento e monitoramento das infestações e não ao estudo direto da resposta espectral de espécies, (Graciani e Novo, 2003; Lima e al., 2003; Vasconcelos e Novo, 2003; Abdon e Meyer, 1989).

Além da escolha das resoluções (espacial e espectral) é preciso considerar também as condições atmosféricas em que o alvo esta sendo observado. Em relação às macrófitas há diversos fatores que podem interferir na resposta espectral proveniente das diferentes formas de vida (Alberotanza, 1999; Peñuelas et al., 1997; Lehmann e Jaquet, 1994). O crescimento e desenvolvimento das espécies no habitat aquático estão condicionados às características químico-físicas do corpo d'água, incluindo fatores tróficos e a iluminação disponível (Zheng et al., 2002; Dekker et al. 1991; Milton, 1987; Ackleson e Klemas, 1986; Kirk e Tyller, 1986; Bukata et al. 1983; Kirk 1983; Smith e Baker, 1981; Davis e Brinson, 1980). Essas características afetam as respostas espectrais registradas tanto pelos sensores orbitais como por sensores in situ e em laboratório. Para estudar estes fatores é necessário que haja coletas de dados de qualidade da água, bem como da resposta espectral das espécies (Han e Rundquist, 1994 e 2003). 
No caso de macrófitas aquáticas, para facilitar a compreensão de sua resposta espectral é conveniente dividi-las conforme sua posição no corpo d'água: 1) Macrófitas com Folhas Emersas ou ao nível da água, que incluem todas as espécies enraizadas ou não que apresentam folhas imersas; 2) Macrófitas com Folhas Submersas, que incluem todas as espécies cujas folhas permanecem imersas na água. Quando analisados por Sensoriamento Remoto, esses grupos de macrófitas sofrem interferências diferentes do ambiente em que vivem. Em ambos os casos a resposta espectral da água e seus elementos dissolvidos; a influência do fundo do corpo de água; a densidade de folhas, idade e condições ecológicas de um modo geral dos indivíduos são fatores importantes para a análise da resposta espectral obtida em ambiente natural. A diferença das espécies submersas é que elas estão envolvidas pelo corpo d'água e portanto sua resposta espectral dependerá também da profundidade em que se encontram (Malthus et al. 1997). Cálculos matemáticos envolvendo índices e derivadas têm sido comumente utilizados para filtrar interferências e localizar variáveis importantes para a melhor descrição das respostas espectrais dos alvos (Lillesand e Kieffer, 2000; Malthus e Dekker, 1995; Goodin, 1993).

Para se aumentar a acurácia dos dados obtidos, é preciso investigar pormenorizadamente em quais faixas espectrais existe a possibilidade de separação de uma espécie vegetal da outra. Desse modo, análises espectroradiométricas, laboratoriais e de campo, precisam ser realizadas para os alvos de interesse. Contudo, são muito recentes os estudos que contemplam análises que auxiliam a distinguir espécies ou gêneros vegetais, ou mesmo hábitos de vida, no caso de macrófitas. Efetivamente não foram encontrados 
estudos relacionados à diferenciação de macrófitas por Sensoriamento Remoto, razão que motivou esta tese.

Para se estudar as macrófitas, leva-se em conta o fato de que as respostas espectrais da vegetação seguem um padrão similar nas diferentes faixas do espectro eletromagnético. Algumas destas respostas estão relacionadas principalmente com pigmentação e com a anatomia foliar das espécies. Desse modo, a hipótese dessa tese é de que é possível utilizar o Sensoriamento Remoto para identificar parâmetros característicos de espécies de macrófitas. Assim, esta tese busca identificar em que medida as variações observadas no espectro eletromagnético podem auxiliar na distinção entre espécies de macrófitas, tanto através do uso de análises matemáticas de suas respostas espectrais, como através da comparação dessas respostas com a anatomia da espécie como sugerem os estudos feitos por Gates et al. (1965). 


\section{OBJETIVOS}

Para testar a hipótese da possibilidade de distinguir macrófitas através de sua resposta espectral, a tese foi dividida conforme seus objetivos específicos para as etapas do estudo. Os objetivos são:

- Demonstrar o uso de Sensoriamento Remoto Orbital para a distinção de macrófitas, incluindo uma espécie aquática;

- Coletar as respostas espectrais de diferentes espécies de macrófitas em laboratório, segundo metodologia desenvolvida para tal, de modo a obter a resposta espectral de doze diferentes espécies de macrófitas;

- Analisar os espectros obtidos de modo a buscar a diferenciação entre as espécies. Serão utilizados quatro diferentes tipos de descritores para essa análise, que são: a intensidade média na faixa espectral, os pontos de inversão em cada faixa, o ponto do Limite Vermelho e Índices entre faixas;

- Comparar as respostas espectrais das espécies estudadas com análises anatômicas de suas folhas, sendo elas: altura foliar, altura da câmara do parênquima esponjoso, e áreas preenchidas por ar dentro dessas câmaras; 
- Utilizar a resposta espectral de uma macrófita submersa para inferir a variação de suas respostas espectrais conforme a profundidade da coluna d'água, através de modelagem matemática.

Todas as etapas do estudo contaram com o apoio do Prof. Dr. Timothy J. Malthus, representante do NERC (Natural Environment Research Council) e Diretor do EPFS (Equipment Pool for Field Spectroscopy - EPFS), e parceiro de projetos desenvolvidos no LEPaC-Sensoriamento Remoto, do Departamento de Ecologia do Instituto de Biociências da Universidade de São Paulo. A identificação e o depósito das excicatas em herbário foi providenciado pelo grupo coordenado pelo prof. Marcelo Luis Martins Pompêo.

Para facilitar a exposição do grande número de dados obtidos, esta tese foi dividida em capítulos, de modo que os objetivos específicos pudessem ser contemplados. Essa divisão também visa facilitar a publicação de artigos científicos para a exposição dos resultados à comunidade científica.

No Capítulo I foram mostradas análises realizadas com dados obtidos de imagens de satélite, a partir das quais foi possível diferenciar duas espécies de macrófitas e duas amostras de água diferentes. Estas análises mostram o quão útil pôde ser o Sensoriamento Remoto neste caso, mas mostram principalmente a necessidade de se obter estudos de espectroradiometria de alvos. Assim, os capítulos seguintes exibiram dados aprofundados 
sobre a resposta espectral de macrófitas, visando colaborar para o aumento da acurácia de estudos realizados com Sensoriamento Remoto orbital ou de plataformas aéreas.

No Capítulo II foram detalhados os procedimentos para a realização dos experimentos de obtenção das respostas espectrais das espécies em laboratório, expondo inclusive as dificuldades e soluções encontradas para as etapas desenvolvidas. Também é apresentado o banco de respostas espectrais gerado.

Como complementação ao desenvolvimento dos procedimentos de tomada de dados espectroradiométricos de macrófitas em laboratório, foi realizado um experimento sobre o estresse hídrico a que as folhas foram submetidas durante os experimentos. Os resultados se encontram no Capítulo III.

A possibilidade de se diferenciar macrófitas foi bastante explorada. No Capítulo IV as respostas espectrais obtidas foram analisadas através de diferentes descritores, com a finalidade de verificar as possibilidades de distinção entre espécies.

Partindo-se da premissa de que a estrutura foliar influencia na resposta espectral das macrófitas, principalmente no intervalo do Infravermelho Próximo, foi realizado um estudo das propriedades anatômicas das folhas das macrófitas, visando identificar quais delas mais influenciam a resposta espectral das espécies estudadas. Os resultados se encontram no Capítulo V. Esse estudo foi feito através de microscopia Óptica e Confocal, e 
contou com a colaboração do Professor Gregório Cardoso Tápias Ceccantini, do Departamento de Botânica do Instituto de Biociências da USP, e seus alunos.

No Capítulo VI foi explicada e demonstrada a utilização de modelagem matemática para inferir a resposta espectral de uma macrófita submersa, através do programa Quantum, de simulação de fótons na transferência radiativa na coluna d'água e na interferência com as camadas de folhas de macrófitas.

As conclusões finais do estudo são mostradas no Capítulo VII. 


\section{CAPÍTULO I - UTILIZAÇÃO DE DADOS DE IMAGENS DE SATÉLITE PARA LOCALIZAÇÃO E}

SEPARAÇÃO DE ESPÉCIES DE MACRÓFITAS NO RESERVATÓRIO BILlings, SÃo PAULO.

\section{I.1 - INTRODUÇÃO}

Um dos problemas mais comuns em reservatórios construídos para fins hidroelétricos é a sua eutrofização. Quando os nutrientes atingem altas concentrações, as macrófitas, sejam emersas ou submersas, infestam o corpo d'água e podem alterar a qualidade da água, dificultar a navegação, e causar prejuízos ao funcionamento adequado dos geradores. Além disso, as infestações podem ocasionar sérios problemas de saúde pública, pois algumas espécies de macrófitas podem servir de habitat para insetos que são, com freqüência, vetores de enfermidades de transmissão indireta, como é o caso da malária, dengue e febre amarela.

Em reservatórios com as dimensões dos que existem no Brasil, o monitoramento das infestações por macrófitas é especialmente dificultado devido à necessidade de extensos trabalhos de campo, o que pode ser amplamente facilitado pelo a necessidade do uso de Sensoriamento Remoto. As análises com Sensoriamento Remoto Orbital para macrófitas são similares aos utilizados para vegetação terrestre, respeitando-se as restrições devidas às características peculiares de cada espécie, e as alterações que podem ocorrer na reflectância 
derivadas da mistura da assinatura da espécie com o corpo de água sob os indivíduos, com a água que os rodeia ou com o fundo do lago que os contém.

As características espectrais dos vegetais em geral, incluindo as de macrófitas, estão em sua maioria relacionadas à absorção da Radiação eletromagnética (REM) pelos pigmentos na região do visível (400 a $700 \mathrm{~nm}$ ), à reflectância da REM na região do Infravermelho Próximo ou IVP (700 - 1200 nm) em função da estrutura celular, e à absorção pela água na região do Infravermelho Médio (1200 - 2500 nm). A resposta espectral dos vegetais em geral é bastante singular e depende, portanto, tanto da qualificação e quantificação dos pigmentos presentes, quanto do conhecimento da estrutura celular e do conteúdo de água presente nas folhas (Lillesand \& Kiefer, 2000).

A Figura I.1 mostra a comparação entre as curvas espectrais típicas dos principais alvos da superfície terrestre: águas, solos e cobertura vegetal (Lillesand \& Kiefer, 2000). 


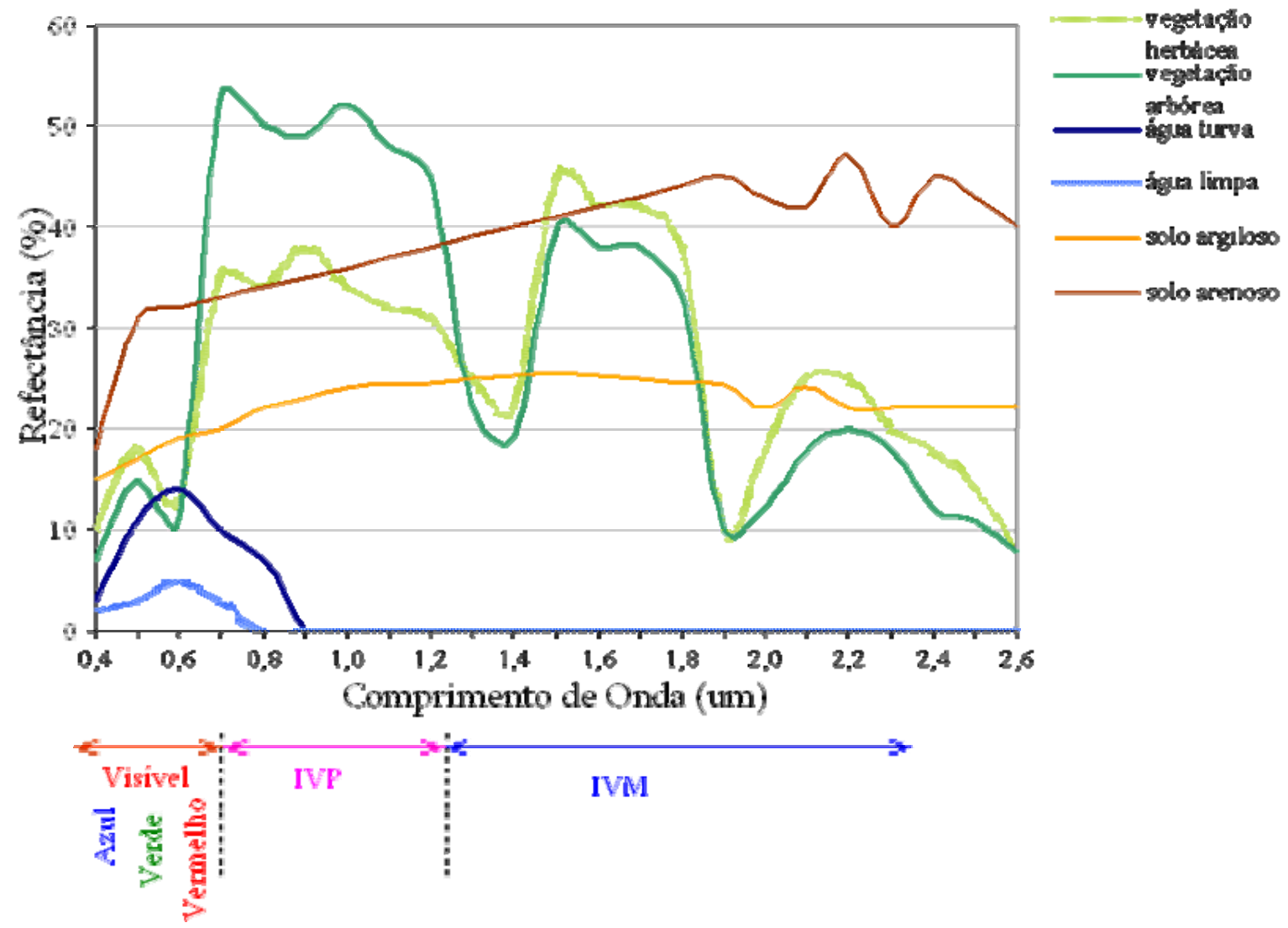

Figura I.1 - Respostas espectrais típicas dos três principais alvos terrestres: águas, solos e coberturas vegetais. (Adaptado de Lillesand \& Kiefer, 2000).

Pode-se observar, pela figura, que a água absorve em todas as faixas do Visível, mas principalmente no Infravermelho Próximo e Médio. No Visível, os particulados em suspensão são responsáveis pela reflexão de energia, como mostra a curva de água turva. A radiação emergente dos corpos d'água se deve ao espelhamento causado pelos elementos em suspensão na água (Kirk, 1996), e também pela reflexão especular na superfície da água.

A cobertura vegetal, por sua vez, apresenta uma curva característica nas faixas do visível e do infravermelho próximo e médio, variando de intensidade conforme a densidade de 
folhas verdes. No Infravermelho Próximo (IVP - 700nm a 1300nm) a cobertura vegetal reflete mais quanto mais folhas verdes tiver, como mostram as curvas de vegetação herbácea e arbórea, pois a reflectância neste caso depende da estrutura anatômica das folhas (Gates et al. 1965). Outros elementos característicos de cada alvo vegetal e que podem interferir na reflectância são tricoma, cutícula, cera, entre outros.

Palombo \& Bitencourt-Pereira (1992) identificaram Pistia stratiotes e Eichhornia crassipes (Mart.) Solms, que infestavam o reservatório Rio das Pedras no Complexo Billings, utilizando imagens da série Thematic Mapper Landsat. Ficou evidente a distinção de ambas as espécies na faixa do IVP desse satélite, que tem uma resolução espectral semelhante e uma resolução espacial de 30 metros. Apesar da nítida separação entre estas espécies, resta ter o conhecimento de se o sistema de fato é capaz de distinguir as espécies, e em que condições.

Os avanços tecnológicos das últimas décadas melhoraram as resoluções espaciais, espectrais e temporais dos sensores remotos orbitais, possibilitando diversos estudos de mapeamento e monitoramento de espécies de macrófitas (Abdon et al. 1989, BitencourtPereira 1992, Palombo e Bitencourt-Pereira 1992, Remillard e Welch 1992, Lehman et al. 1994 e 1997, Lehman e Lachavanne 1997, Malthus e George 1997, Malthus et al. 1997, Alberotanza et al. 1999, Everitt et al. 1999, Dekker 2001, Jakubauskas e Peterson 2002, Waldron et al. 2002, Graciani e Novo 2003, Lima et al. 2003, Mathew et al. 2003, Vasconcelos e Novo, 2003). Os resultados encontrados até o momento são encorajadores, 
mas ainda são necessários muitos estudos para elucidar a aplicação de Sensoriamento Remoto a esses alvos (Malthus e George 1997).

O objetivo deste capítulo é testar a possibilidade de diferenciação entre uma espécie de macrófita emersa, uma espécie submersa, e duas amostras de qualidade d'água coletadas no Complexo Billings, em uma imagem do satélite IKONOS-2, mostrando as limitações dos estudos orbitais na diferenciação das espécies.

\section{I.2 - PROCEDIMENTOS METODOLÓGICOS}

O estudo foi realizado no Complexo Billings, a partir de dados obtidos do satélite IKONOS-2, com 4 metros de resolução espacial, com faixas espectrais do Visível (Azul, Verde e Vermelho) e do Infravermelho Próximo (IVP). Para aferir o posicionamento dos pontos do GPS com a imagem foi preciso refinar o ajuste da imagem à verdade de campo. O erro médio quadrático do georreferenciamento nesse caso foi de $9 \mathrm{~m}$.

Em novembro/2004 e fevereiro/2005 foram identificadas as espécies Mayaca fluviatilis e Pistia stratiotes em duas áreas distintas do Complexo Billings: no Rio Grande foi encontrada a infestação por $P$. stratiotes e em uma lagoa marginal do Rio das Pedras foi encontrada a infestação por indivíduos de $M$. fluviatilis. Especialmente para as análises da macrófita submersa $M$. fluviatilis as imagens IKONOS são as mais apropriadas, pois permitem a melhor delimitação do alvo, já que a resolução espacial é de $4 \mathrm{~m}$, maior que a 
do CBERS-2, de 20 m. O lago em questão é raso, e a profundidade não chega a dois metros, com disco de Secchi marcando profundidade aproximadamente igual a zero em todos os locais, e uma grande abundância de indivíduos de $M$. fluviatilis.

As respostas espectrais de cada espécie foram analisadas a partir de amostragens de pixels identificados com a presença das macrófitas, na imagem IKONOS-2. As faixas utilizadas, neste caso, foram as Faixas Azul (1), Verde (2), Vermelho (3) e InfravermelhoPróximo (4), todas com 4 metros de resolução espacial. O mesmo procedimento foi realizado para dois locais com qualidade d'água diferentes. Os dados de qualidade d'água foram coletados em novembro/2004 e gentilmente cedidos pela Dra. Viviane Moschini Carlos e pelo Professor Marcelo Luis Martins Pompêo.

A metodologia consistiu na tomada de posições geográficas dos locais onde as espécies são encontradas, na extração dos valores espectrais dos pixels correspondentes na imagem IKONOS-2, em cada faixa espectral, e na análise matemática desses dados buscando a diferenciação entre os alvos. Foi realizada uma análise multivariada do tipo Análise de Correspondência com dados não padronizados, para confirmar a separabilidade dos dados em relação às Faixas Espectrais utilizadas.

As imagens multiespectrais do satélite IKONOS-2, foram utilizadas para a extração das repostas espectrais das duas espécies encontradas, através da conversão dos Números 
Digitais em Radiância e depois em Reflectância, utilizando o Coeficiente apropriado para a imagem IKONOS-2 (Bowen 2002).

Levando-se em conta que uma das espécies é submersa, foram também analisadas duas amostras de água com diferentes concentrações de substâncias opticamente ativas, visando verificar a possibilidade de diferenciá-las da espécie submersa. Os dados de qualidade d'água foram coletados em novembro/2004. Os valores das reflectâncias das macrófitas foram comparados com os das duas amostras de água, através de uma Análise Multivariada do tipo Análise de Correspondência com dados não padronizados.

\section{I.3 - RESULTADOS E DISCUSSÕES}

A imagem Composição Colorida com faixas do satélite IKONOS-2, são mostradas na Figura I.2. O Complexo Billings está inserido na Grande São Paulo, mais especificamente nas cidades de São Bernardo do Campo e Diadema. 


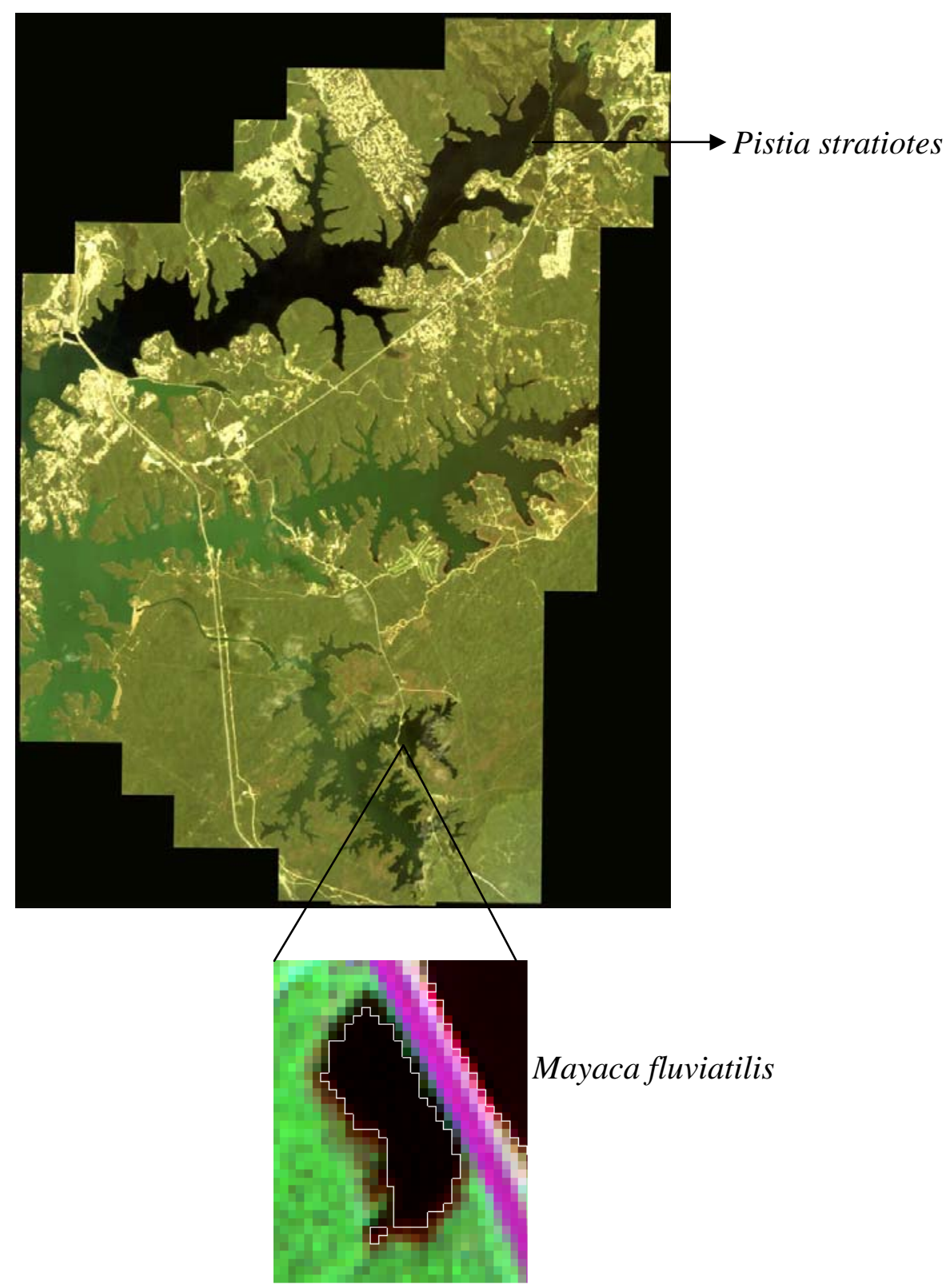

Figura I.2: Localização das áreas onde se encontrou Pistia stratiotes (Rio Grande) e Mayaca fluviatilis. (Riacho Grande), Complexo Billings - Grande São Paulo.

Assim, para comparar com a literatura, foram aferidas as curvas espectrais de cada espécie utilizando a reflectância média das faixas espectrais do sensor. As curvas espectrais obtidas para Pistia stratiotes (Figura I.3) mostraram valores de reflectância proporcionalmente bem maiores do que os outros alvos. Os valores mais elevados foram encontrados nas faixas do verde e infravermelho próximo (IVP). 


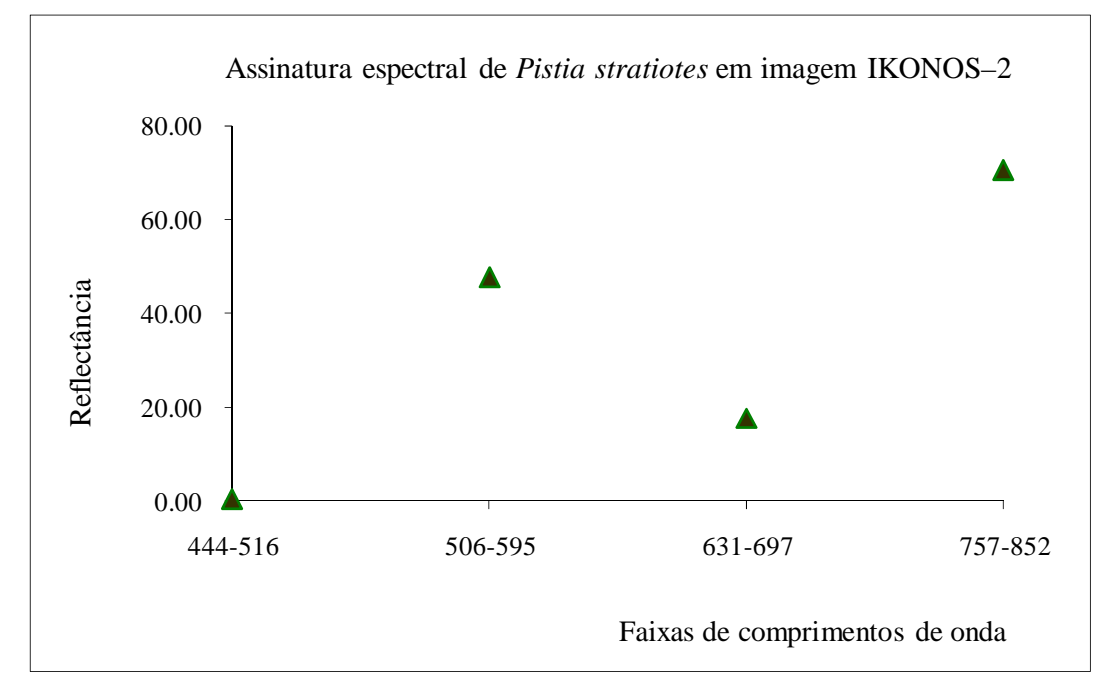

Figura I.3: Resposta espectral de Pistia stratiotes em imagem do satélite IKONOS-2.

Em Palombo \& Bitencourt-Pereira (1992), a curva obtida para esta espécie também mostra um valor maior no IVP que no Verde, mas neste caso a Reflectância no IVP foi menor do que no estudo realizado, podendo ser devida a vários fatores, como variações na densidade e fisiologia da população presente.

A espécie Mayaca fluviatilis apresentou reflectância muito baixa em todo o espectro, o que era esperado por estar coberta por uma coluna de água em vários pontos. O maior valor foi encontrado na faixa do IVP (Figura I.4). 


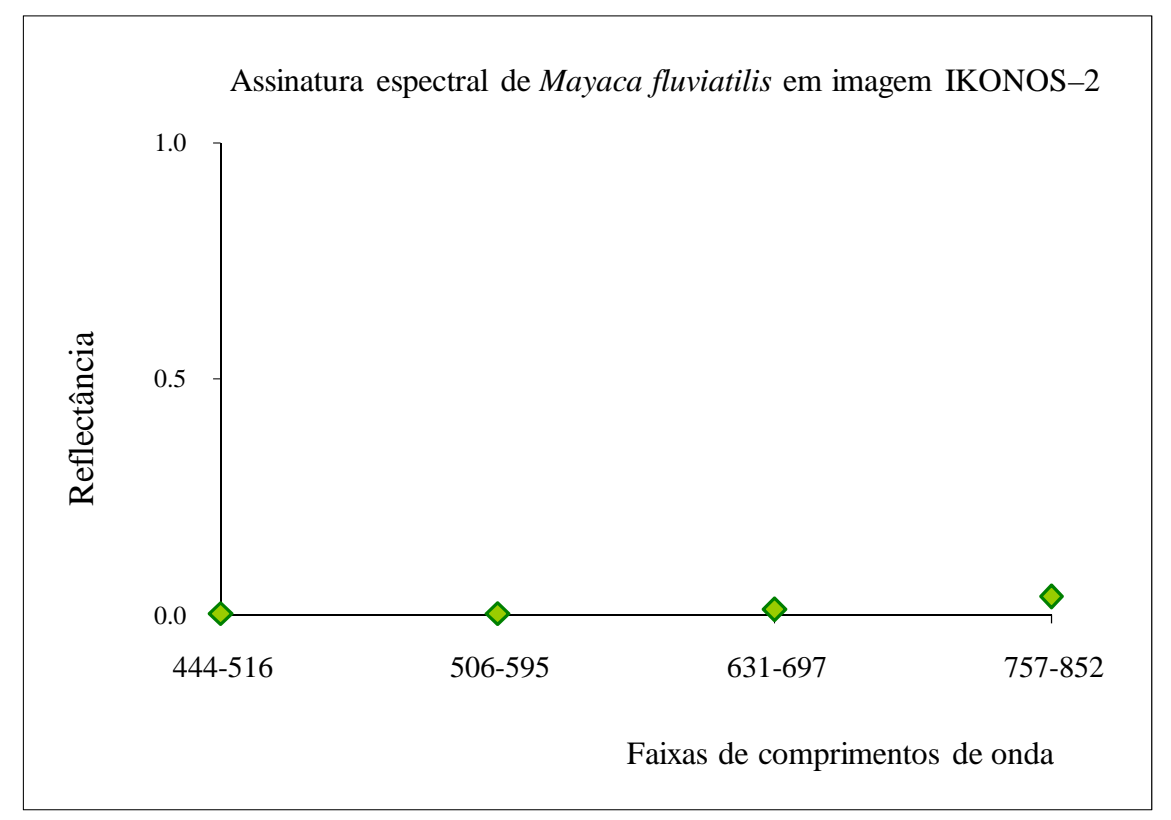

Figura I.4: Resposta espectral de Mayaca fluviatilis em imagem do satélite IKONOS-2.

A água absorve totalmente os comprimentos de onda do Infravermelho Próximo, o que se pode observar na Figura I.5, e absorve parcialmente no Visível, dependendo neste caso das substâncias opticamente ativas em suspensão. Pode-se observar pela figura seguinte que as amostras de reflectância referentes ao Riacho Grande, no Complexo Billings, apresentam valores de reflectância superiores do que as do Rio Grande. 


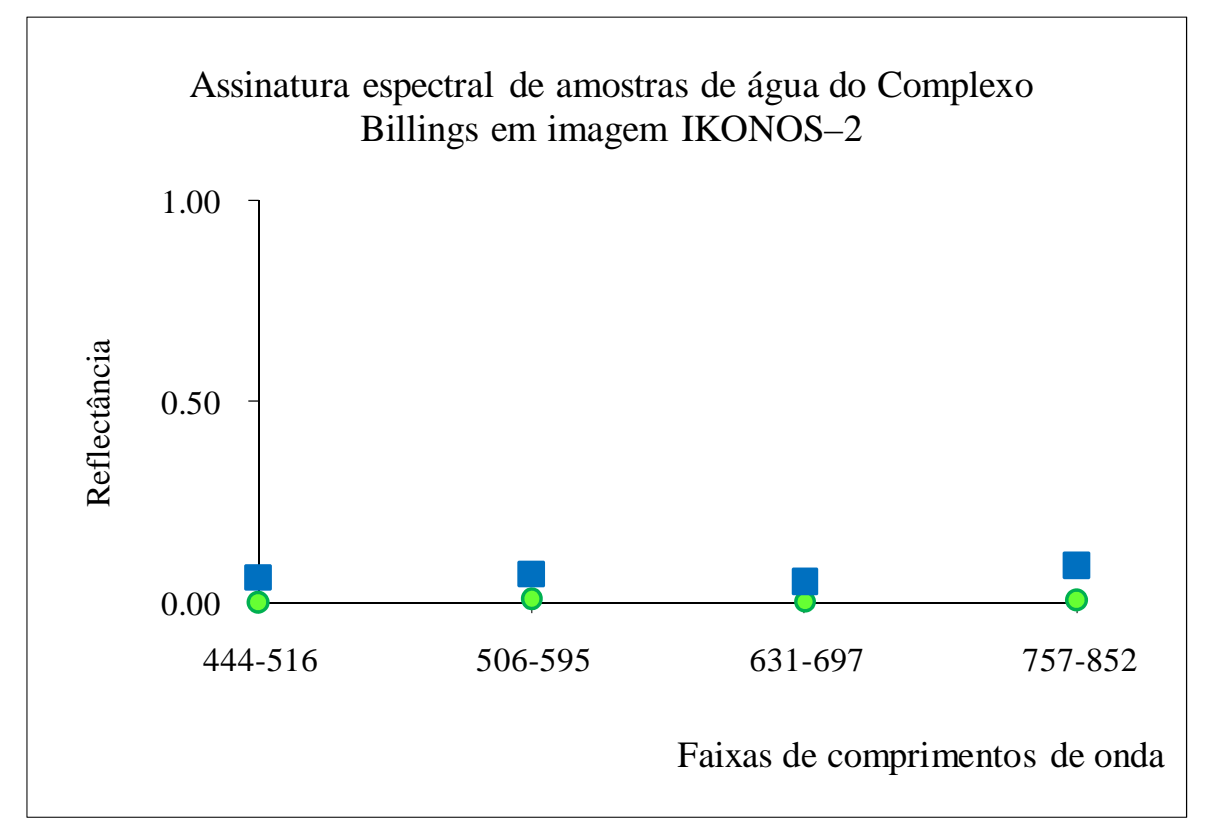

Figura I.5: Resposta espectral de diferentes amostras de água em imagem do satélite IKONOS-2. Em azul está a resposta da amostra de água do Riacho Grande, e em verde a amostra de água do Rio Grande.

Isso pode ser explicado pela maior quantidade de matéria sólida total comumente encontrada no Riacho Grande (Tabela I.1).

Tabela I.1: Concentrações de nutrientes, material em suspensão, clorofila, feofitina e sólidos totais das coletas do Projeto Billings - FAPESP. Dados gentilmente cedidos por Viviane Moschini Carlos.

\begin{tabular}{|l|cccccc|}
\cline { 2 - 7 } \multicolumn{1}{c|}{} & $\begin{array}{c}\text { Prof. } \\
(\mathrm{m})\end{array}$ & $\begin{array}{c}\text { MST } \\
(\mathrm{mg} / \mathrm{l})\end{array}$ & $\begin{array}{c}\text { MSO } \\
(\%)\end{array}$ & $\begin{array}{c}\text { MSI } \\
(\%)\end{array}$ & $\begin{array}{c}\text { Chl-a } \\
(\mathrm{ug} / \mathrm{l})\end{array}$ & $\begin{array}{c}\text { Feof } \\
(\mathrm{ug} / \mathrm{l})\end{array}$ \\
\hline Rio Grande & 0 & 4.6 & 86.96 & 13.04 & 20.32 & 7.75 \\
& 2 & 5 & 84 & 16 & 12.08 & 15.99 \\
& 4 & 4.4 & 90.91 & 9.09 & 20.32 & 6.96 \\
\hline Riacho Grande & 0 & 12.2 & 93.44 & 6.56 & 38.45 & 7.42 \\
& 2 & 13 & 90.77 & 9.23 & 36.25 & 13.97 \\
& 4 & 12.4 & 91.94 & 8.06 & 40.64 & 6.81 \\
\hline
\end{tabular}


A Análise de Correspondência entre os dados permitiu diferenciar as amostras através da análise dos dois primeiros eixos, e mostrou as faixas espectrais do IKONOS-2 que mais influenciaram cada amostra (Figura I.6). Assim, a faixa IVP determinou a separação entre as áreas estudadas com macrófitas presentes ou ausentes.

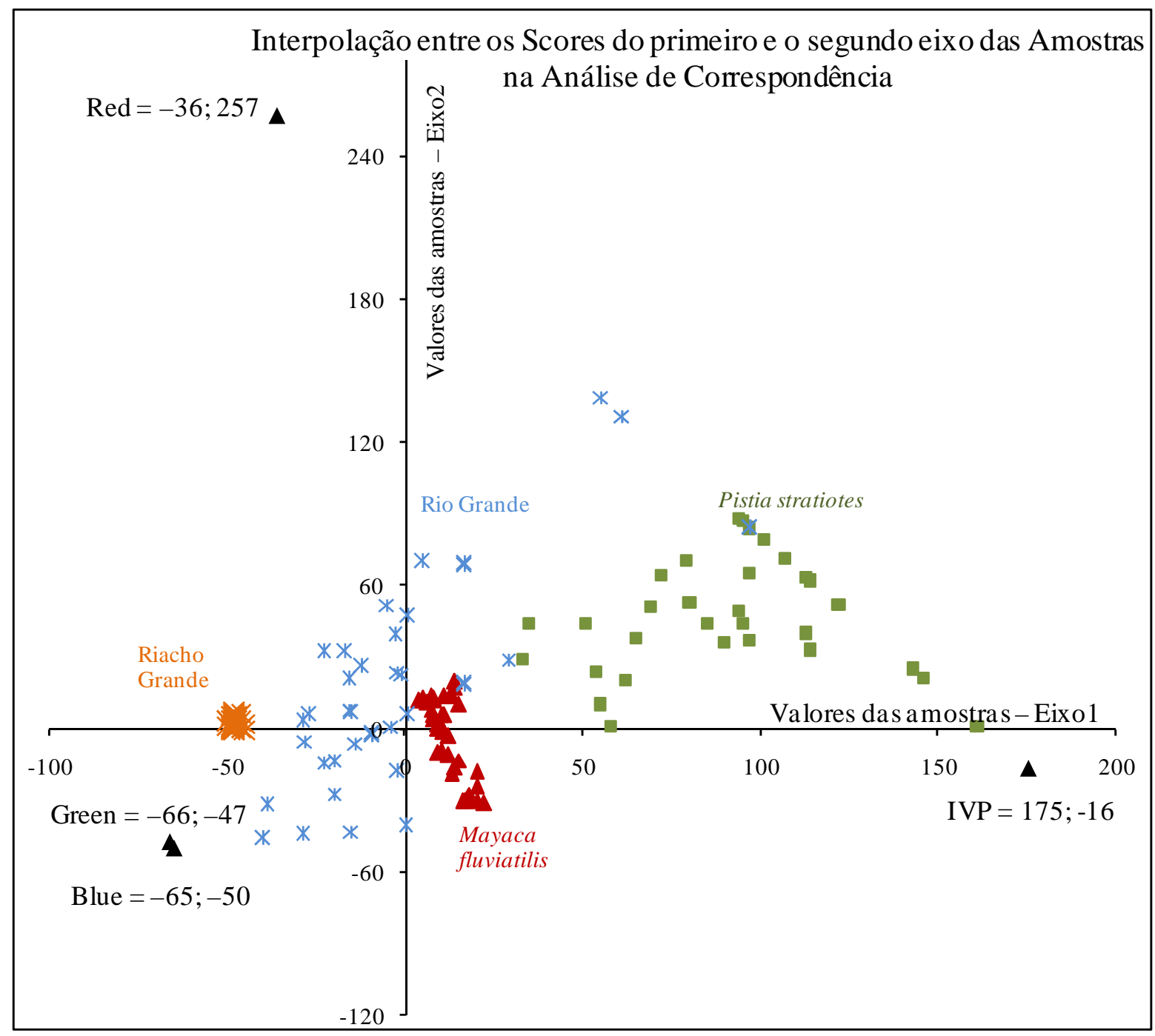

Figura I.6: Interpolação entre os valores obtidos do primeiro e segundo eixo das amostras na Análise de Correspondência. Observa-se a posição de cada conjunto de pontos amostrais, e a intensidade da interferência de cada faixa espectral do IKONOS-2 nas amostras estudadas. 


\section{I.4 - CONCLUSÕES}

Os resultados desse trabalho confirmam a capacidade de imagens multiespectrais do IKONOS-2 distinguirem macrófitas emersas principalmente na faixa do infravermelho próximo. Quanto às macrófitas submersas, a detecção foi possível através de uma análise multivariada. Nesse caso também foi a faixa do IVP a que deu a melhor separação. As imagens do IKONOS-2, na faixa do visível, não propiciaram uma boa separação entre os alvos porque mesmo tendo uma alta resolução espacial, o sensor não é habilitado com alta resolução espectral.

\section{I.5 - CONSIDERAÇÕES FINAIS}

O conhecimento necessário para se distinguir macrófitas através de Sensoriamento Remoto é ainda escasso, e é necessário haver a coleta de um número maior de espécies, e ter-se o conhecimento de quais faixas do espectro permitem a melhor diferenciação de cada uma delas.

Para estudar espécies de macrófits com Sensores Orbitais é necessário definir previamente qual sensor é mais adequado para analisar cada uma. A pré-definição das resoluções dos Sensores orbitais é importante pois depende das espécies encontradas no local de estudo e da área por ela(s) coberta(s). Um satélite como o IKONOS-2 tem sensores com resolução espectral similar às dos satélites LANDSAT, SPOT e CBERS-2. Entretanto, 
há grandes variações de resolução espacial entre os sensores nesses satélites. Assim, para estudos de infestações em áreas menores ou não homogêneas (onde há mistura), o uso de imagens de melhor resolução espacial, como o IKONOS-2 e o SPOT pode gerar resultados mais acurados. Por outro lado, para utilizar imagens CBERS-2, por exemplo, são necessárias áreas de, no mínimo, 60 m × 60 m, infestadas com uma mesma espécie.

Considerando-se a largura das faixas espectrais, seria apropriado o uso de sensores com alta resolução espacial e espectral também, onde fosse possível delimitar melhor os alvos de estudo. Essa necessidade já tem sido atendida em muitos países onde há ampla aplicação do Sensoriamento Remoto em plataformas aéreas que carregam sensores hiperespectrais e que propiciam a cobertura de áreas relativamente extensas para os estudos. Malthus e George (1997) mostram um desses estudos, realizado na Grã-Bretanha, onde já é comum o uso de aviões portando sensores hiperespectrais para estudos de geologia e ecologia.

Em função de os processamentos serem realizados com a finalidade de identificar nas imagens as espécies encontradas in situ, possibilitando assim o manejo e monitoramento das espécies envolvidas, deve-se considerar dois aspectos principais relacionados à melhora na acurácia dos resultados. O primeiro envolve o trabalho de campo, no qual é possível coletar dados com o uso de espectroradiômetros, instrumentos com sensores que coletam informações detalhadas em faixas espectrais de interesse. $\mathrm{O}$ segundo aspecto envolve experimentos em laboratório, a partir dos quais pode-se verificar 
as respostas das espécies sem os fatores que interferem em sua resposta nos sensores orbitais, como a influência da atmosfera e a presença de outras espécies no local de estudo. Tendo-se o conhecimento das respostas espectrais sob diferentes condições, os resultados obtidos com satélites podem fornecer resultados cada vez mais acurados e menos exploratórios.

\section{I.6 - AGRADECIMENTOS ESPECIAIS}

Ao Prof. Marcelo Luis Martins Pompeo, pela imagem IKONOS-2 e apoios de campo e no reconhecimento das espécies, à Prof. Viviane Moschini Carlos pelos dados de qualidade da água, e ao Prof. Sérgio Tadeu Meirelles pela orientação nas análises matemáticas. 
CAPÍTULO II - OBTENÇÃO DE RESPOSTA ESPECTRAL DE ESPECIES DE MACRÓFITAS EM LABORATÓRIO.

\section{II.1 - INTRODUÇÃO}

A interação da radiação eletromagnética (REM) com qualquer alvo pode auxiliar a inferir muita das características físicas e químicas dos mesmos. Esta interação se manifesta pela reflectância que é registrada por sensores específicos de cada faixa espectral. Para o estudo de vegetais vivos, as faixas espectrais de maior interesse são as do visível e do infravermelho.

A Figura II.1 mostra a curva espectral típica da vegetação e os fatores determinantes da reflectância e absorção das folhas nas diferentes faixas do espectro (Lillesand \& Kiefer 2000). 


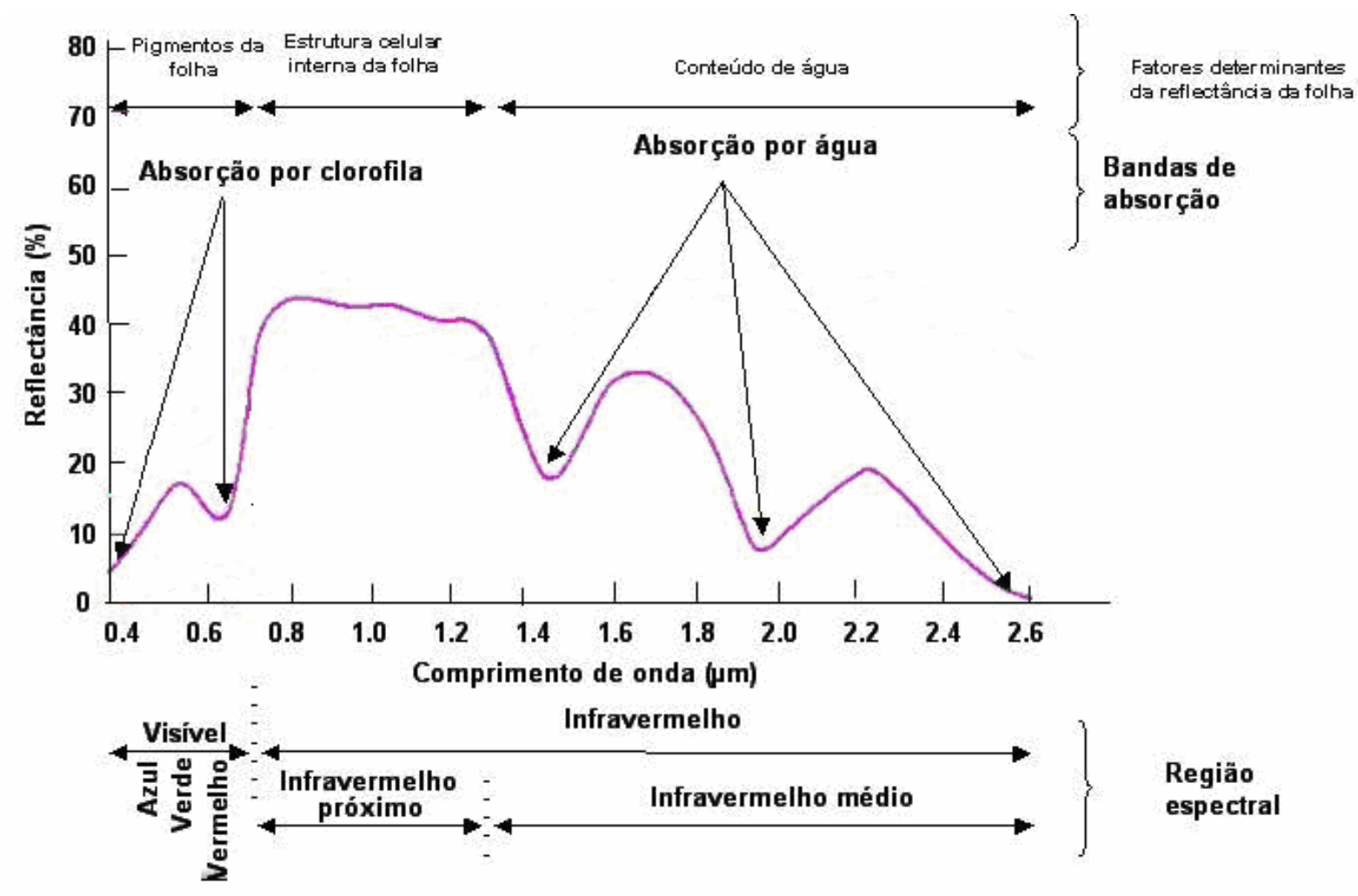

Figura II.1 - Fatores determinantes da reflectância e absorção da vegetação (Adaptado de Lillesand \& Kiefer, 2000).

No Visível a vegetação apresenta baixa reflectância em função da absorção da Radiação Eletromagnética pelos pigmentos presentes nas folhas (Figura II.2). Especialmente na região do Vermelho e do Azul há uma forte absorção da clorofila, o que pode ser visualizado na Figura II.1 como baixa reflectância. O pico de reflectância em na região do Verde é o responsável pela cor verde da maioria dos vegetais em seu estado saudável e fotossinteticamente ativo (Gates et al. 1965). 


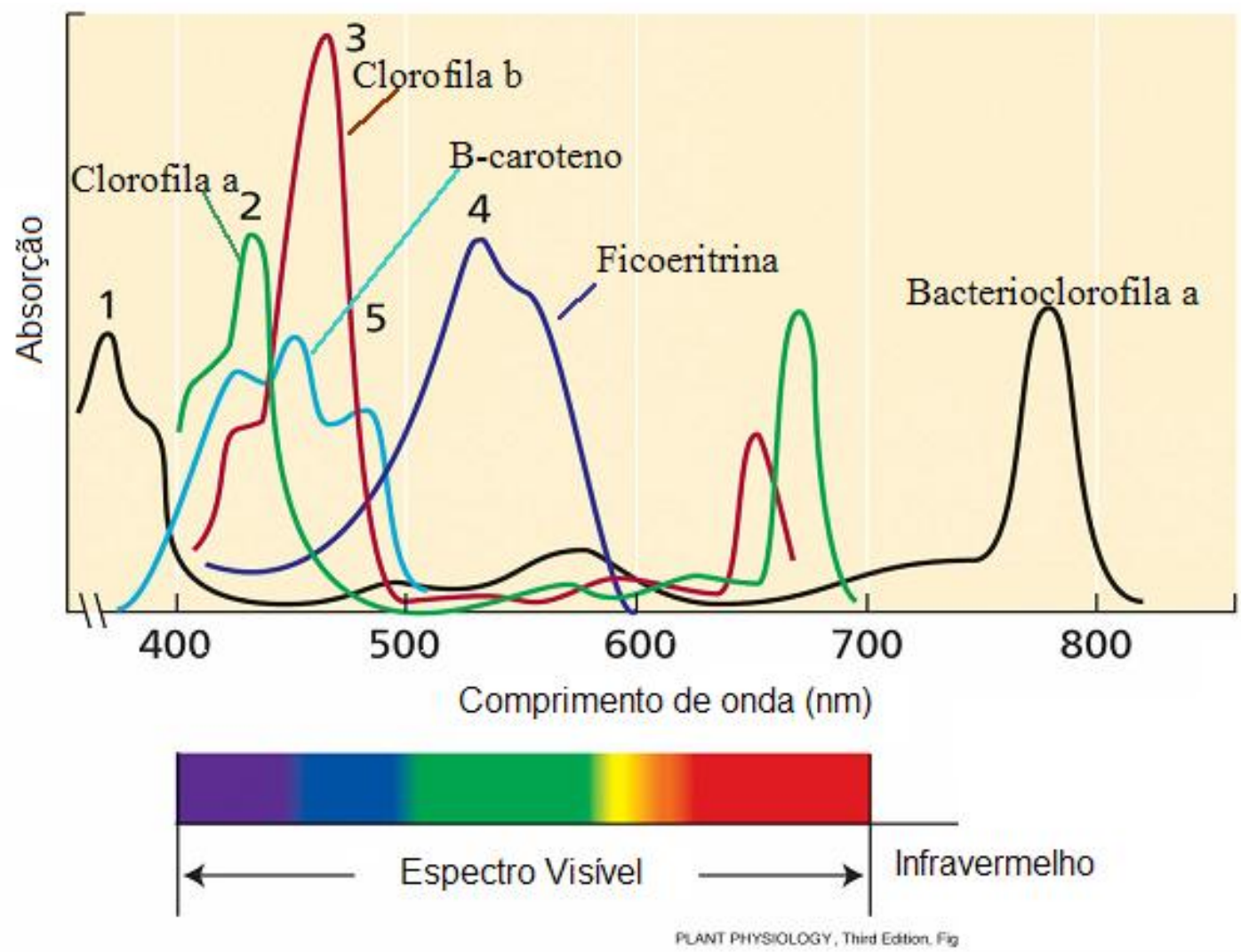

Figura II.2: Absorção da Radiação Eletromagnética pelos pigmentos. In: Taiz e Zeiger 2002.

Diante do exposto, para minimizar as freqüentes incertezas das decisões tomadas com o uso de imagens de satélite, seria desejável que se pudesse acessar um banco de respostas espectrais dos alvos de interesse, antes de se fazer qualquer interpretação. Entretanto, por não haver esse dado disponível para macrófitas aquáticas, fez-se necessário nesta tese levantar o maior número possível de respostas espectrais de espécies diferentes. Isso é possível através da utilização de espectroradiômetros dotados de sensores que captam a radiação emergente do alvo em diferentes faixas espectrais. Assim, utilizando-se um espectroradiômetro e sob certos cuidados especiais, que serão mencionados 
posteriormente, é possível construir as curvas espectrais dos alvos de interesse, tomando-se dados ao longo do espectro eletromagnético. O procedimento experimental mostrou-se semelhante ao apresentado recentemente em Cho e Skidmore (2006), mas a metodologia levou em conta as limitações tecnológicas, as peculiaridades de cada espécie, e as condições ambientais, de conformidade com os objetivos do estudo.

Medidas de reflectância em macrófitas podem ser feitas a partir de: Folhas, Indivíduos ou Densidade de Indivíduos, conforme a espécie e o objetivo do estudo. Para se utilizar folhas, estas devem ser grandes o suficiente para preencher a área de visada mínima do espectroradiômetro, o que não é possível para todas as espécies. Entretanto, a tomada de dados radiométricos dos indivíduos como um todo também é importante porque reflete a influência da arquitetura (ângulos e formatos das folhas) da planta, e inclui a reflectância de todas as outras estruturas da planta.

O objetivo deste trabalho foi o de coletar a resposta espectral de folhas de espécies de macrófitas emersas e submersas, em laboratório, com o intuito de fornecer um banco de dados de macrófitas e gerar os dados necessários para testar a distinção entre as espécies. Também foram comparados os resultados obtidos entre folhas e indivíduos dessas espécies. 


\section{II.2 - PROCEDIMENTOS METODOLÓGICOS}

A escala de análise para macrófitas, contempla quatro níveis: Folha, Indivíduo, População e Comunidade. As análises que podem ser realizadas em cada escala variam em função dos sensores e das tecnologias disponíveis, podendo ser assim resumidas:

1 - Folha - Análise anatômica e química (pigmentos, composição da cutícula) das folhas; 2 - Indivíduo - Análise da resposta espectral do indivíduo como um todo, incluindo todas as estruturas no campo de visada do sensor, e análise da idade das folhas;

3 - População - Análise da variabilidade de respostas espectrais dentro de uma mesma população, análise do substrato, e análise de condições eco-fisiológicas dos indivíduos; e 4 - Comunidade - Análise de diferenciação e misturas entre espécies.

Para cada variação de escala da vegetação, deve ser escolhido o sensor adequado, que deve considerar a área de visada e as resoluções espectral e espacial. Assim, as análises com Sensores orbitais possibilitam respostas nas escalas de Comunidade e População; e as análises com Sensores in situ e em laboratório possibilitam análises com Indivíduos, Folha e População.

O número de espécies envolvido na análise foi o maior possível, considerando-se a disponibilidade de localização e coleta das espécies para a realização do estudo. As macrófitas utilizadas foram coletadas em diferentes locais. Os locais de coleta incluíram os reservatórios e lagoas marginais do Complexo Billings, da Represa Guarapiranga, e os lagos 
do Jardim Botânico e da Universidade de São Paulo, onde os indivíduos foram coletados e/ou identificados com a colaboração do professor Marcelo Luis Martins Pompêo. As espécies estudadas foram: 1) Folhas emersas ou ao nível da água: Eichhornia crassipes (Mart.) Solms, Eichhornia azurea Kunth, Pistia stratiotes (L), Heteranthera reniformis Ruíz \& Pav., Salvinia molesta D.S.Mitch., Nymphaea mexicana Zucc., Limnobium laevigatum (Willd.) Heine e Myriophyllum brasiliense Cambess.; e 2) Folhas Imersas: Egeria densa Planch., Cryptocoryne beckettii Thwaites ex Trim., Echinodorus bleheri Rataj (1970) e Hygrophila polysperma T.Anderson.

Uma série de cuidados padrão foi tomada para padronizar os experimentos, de modo a haver o menor erro possível entre as medidas, aumentando a acurácia dos resultados. Para cada espécie com folhas emersas ou ao nível da água (com exceção de $M$. brasiliense), foram coletadas 10 folhas, em 10 indivíduos diferentes, de modo a se obter uma amostra populacional. Na impossibilidade de realizar as medidas para 10 folhas, foram feitas as medidas para o número de folhas disponíveis. Assim, no caso das submersas e de M. brasiliense houve variação no número de folhas / grupo de folhas em função das características peculiares de cada espécie. Procurou-se manter um equilíbrio em relação às idades das folhas amostradas, de modo que foram escolhidas folhas maduras, nem muito jovens, nem muito velhas.

Em relação à padronização dos experimentos, todos foram realizados em câmara escura, com as mesmas freqüências, intensidades e ângulos da iluminação artificial, e com 
os mesmos posicionamentos das folhas e dos indivíduos em relação ao sensor. Desse modo, procurou-se minimizar os erros o máximo possível. As análises de reflectância foram realizadas com uma lâmpada mista tungstênio-halógena de $1000 \mathrm{~W}$, disposta a cerca de 120 $\mathrm{cm}$ e $45^{\circ}$ de inclinação em relação ao alvo. A distância e altura do Sensor variou de 5 a 10 cm conforme o tamanho da folha, em função da área de visada. O equipamento utilizado para a tomada de dados foi um espectroradiômetro da marca Ocean Optics modelo USB2000, com resolução espectral de $0,38 \mathrm{~nm}$, e fibra óptica com abertura de $24,3^{\circ}$. O raio raio da área de visada pôde ser calculado em função da Altura do Sensor e do ângulo da fibra óptica utilizada (vide Figura II.3). A placa de referência utilizada foi a Kodak Gray Color .

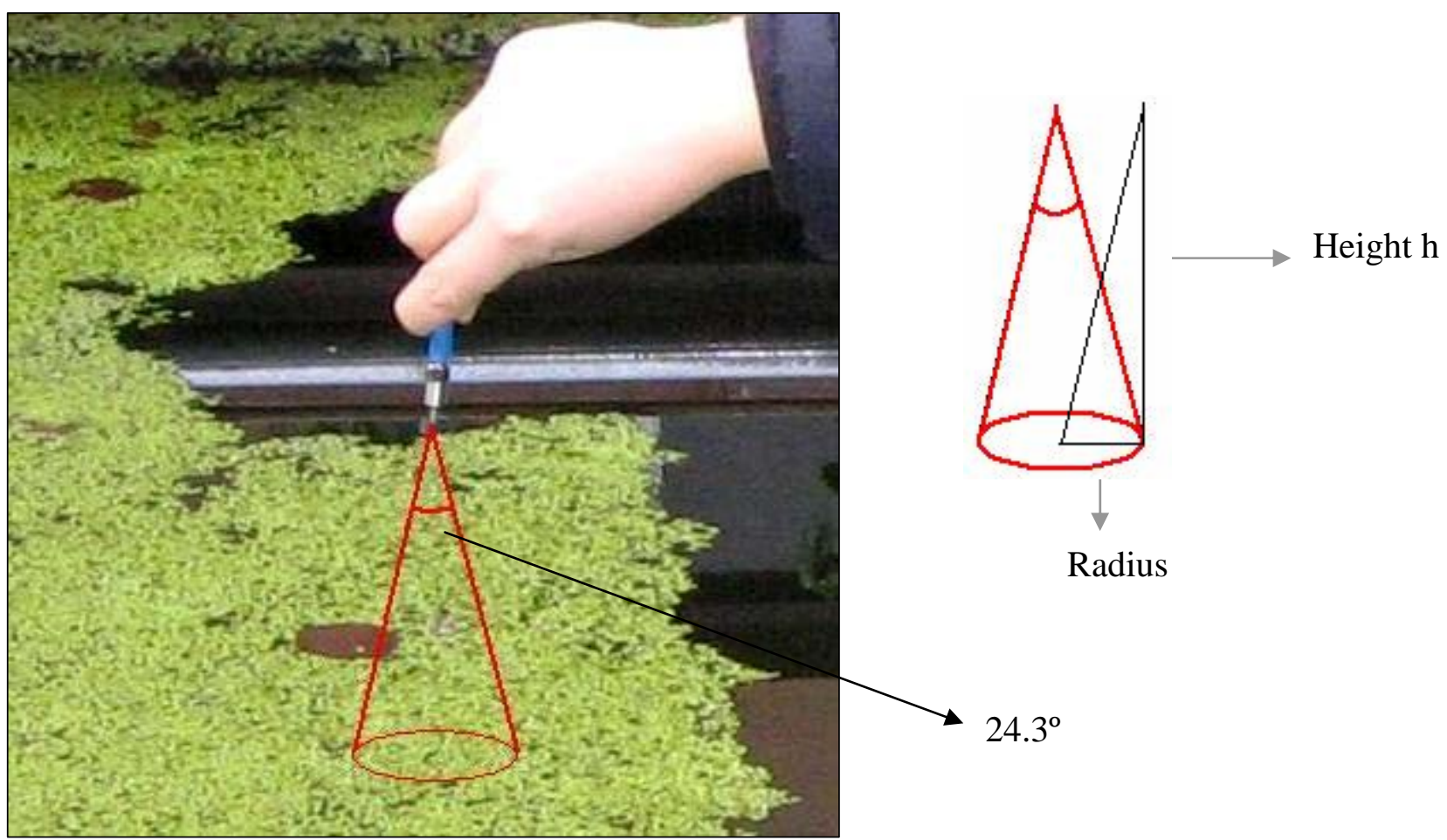

Figura II.3: Ilustração da área de visada da fibra óptica do sensor Ocean Optics, utilizada para os experimentos, cujo ângulo de abertura é de $24,3^{\circ}$. 
Para as medidas espectroradiométricas com as folhas, estas foram retiradas do caule, secas com papel absorvente que não deixa fibras, e as medidas foram tomadas rapidamente, com as folhas esticadas horizontalmente, sobre um fundo preto. As folhas foram aplainadas por pesos de ferro revestidos com o tecido preto fosco, para excluir possibilidades de reflexão especular devido a diferentes ângulos de incidência. Para algumas espécies, pelo fato de as folhas serem muito pequenas, as medidas foram realizadas apenas com conjuntos de folhas.

$\mathrm{Na}$ escala Foliar, foi analisada a influência dos espaços aéreos das macrófitas estudadas na resposta espectral da mesma no Visível e no IVP. Na escala de Indivíduo, foram comparadas as respostas espectrais de folhas isoladas e dos indivíduos completos, em cada espécie (Figura II.4). No nível "População", foi realizada a comparação entre respostas espectrais de diferentes indivíduos da comunidade. 


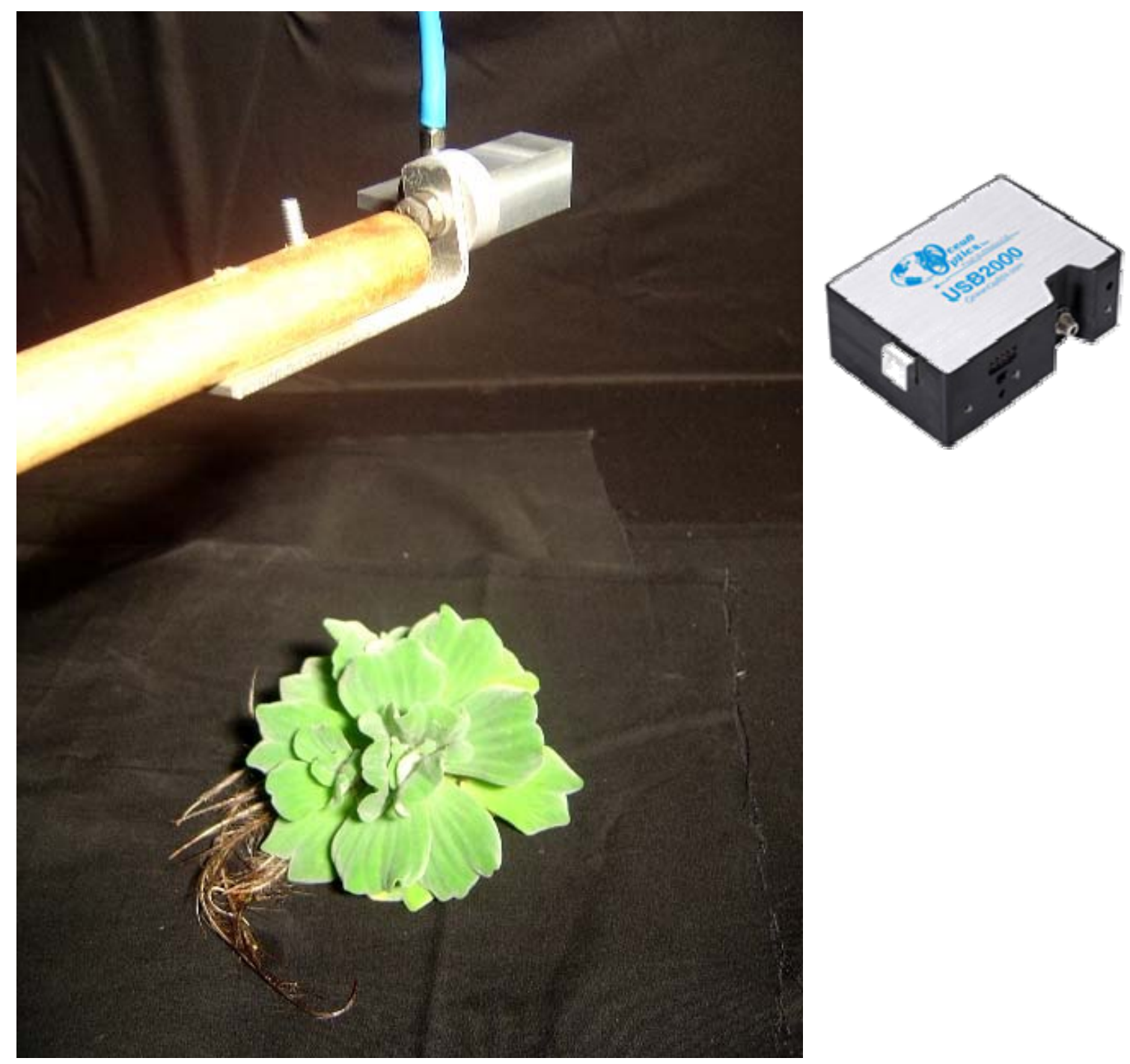

Figura II.4: Experimento em laboratório, e instrumento de medidas USB2000. 


\section{II.3 - RESULTADOS E DiSCUSSÕES}

As respostas espectrais de cada folha medida, e para cada espécie, são mostradas nas Figuras que se encontram ao final do Capítulo, no item Apêndice, de modo a facilitar a compreensão da leitura. Os espectros de reflectância das folhas mostraram variações principalmente na intensidade, intra-especificamente, mas também nos picos de reflectância das faixas, inter-especificamente.

As variações de intensidade intra-específica ocorrem especialmente devido ao fato de haver variações na pigmentação e na estrutura das folhas, em suas condições fisiológicas das folhas, e outros fatores pertinentes às suas diferenças naturais. Outros fatores são a influência da proporção de partes da planta na área de visada em relação à área total (Jakubauskas et al. 2000); a influência da anatomia de caule, raízes, pêlos, e outras estruturas das espécies envolvidas; e a influência da reflectância especular proporcionada pela angulação das estruturas envolvidas na reflectância do indivíduo, mesmo que tenham os esforços tenham sido dirigidos no sentido de aplainar as folhas para manter o padrão das medidas.

Por isso, apesar de ser importante, a intensidade não pode ser tomada como principal descritor das espécies. Entretanto, observou-se que pode haver características pertinentes a cada espécie como, por exemplo, as posições dos pontos de inversão. Assim, 
outros descritores foram testados e os resultados podem ser conferidos no Capítulo IV. As respostas espectrais de todas as espécies analisadas podem ser observadas na Figura II.5.

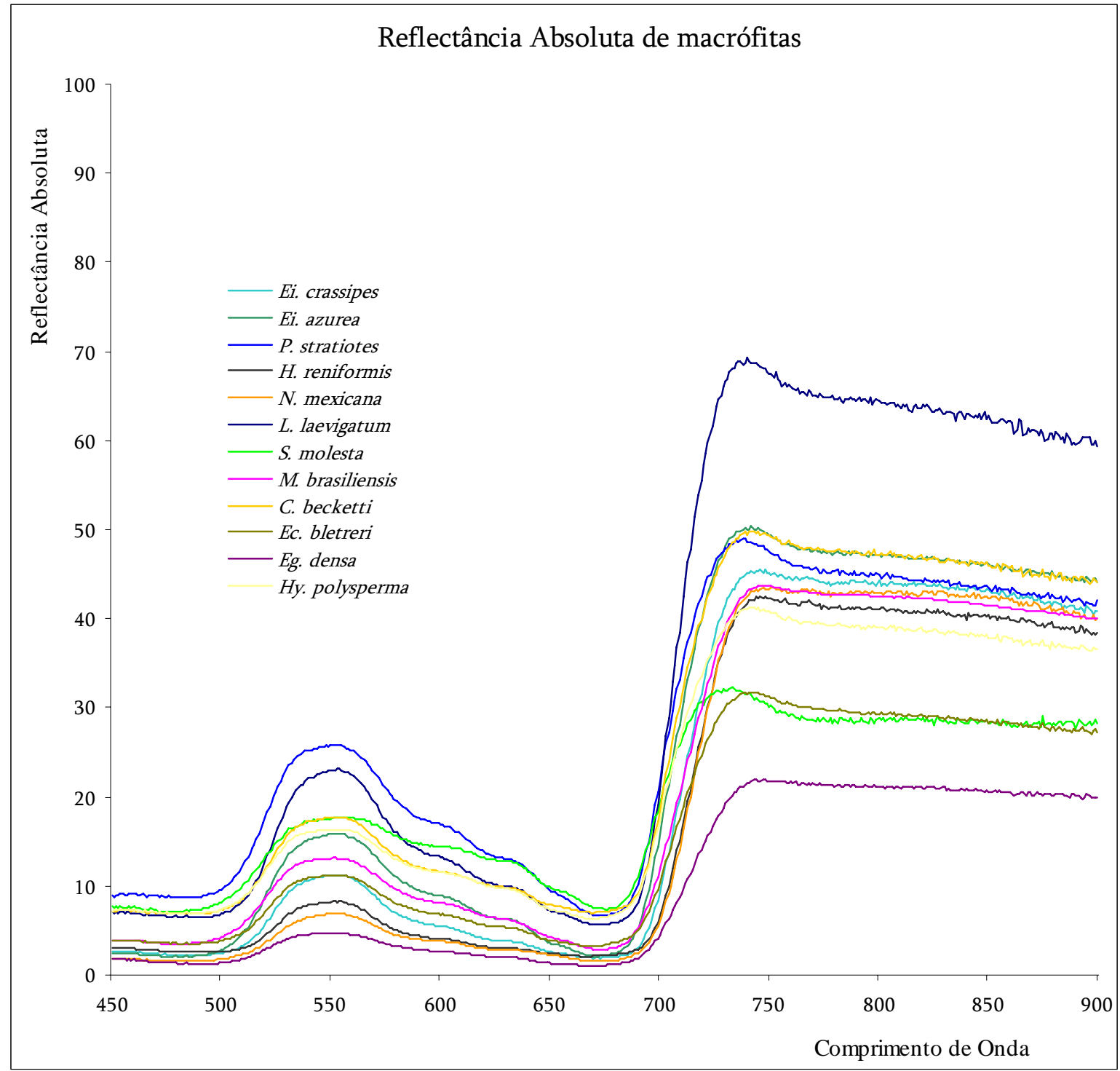

Figura II.5: Resposta espectral média das espécies de macrófitas analisadas (Limnobium laevigatum, Eichhornnia crassipes, Ei. Azurea, Pistia stratiotes, Myriophyllum brasiliense, Nimphea mexicana, Hetheranthera reniformis, Salvinia molesta, Cryptocoryne beckettii, Echinodorus bleheri, Egeria densa, Hygrophila polysperma).

Os valores de reflectância máxima e mínima nas faixas de comprimento de onda do Visível (Azul, Verde e Vermelho) e do Infravermelho Próximo, para cada uma das espécies, estão na Tabela II.1. O coeficiente de variação mostrou que no Azul e no Vermelho há maior variação dos valores de reflectância das espécies estudadas. 
Tabela II.1: Valores de Reflectância (\%) máximos e mínimos de espécies de macrófitas em cada Faixa de Comprimento de onda.

\begin{tabular}{|l|r|r|r|r|r|r|r|r|}
\multicolumn{1}{l|}{ Reflectância (\%) } & Azul Máx & Mín & Verde Máx & Mín & Vermelho Máx & Mín & IVP Máx & Mín \\
\hline Ei. crassipes & 6,94 & 1,70 & 14,10 & 4,64 & 4,88 & 1,46 & 49,08 & 37,31 \\
\hline Ei. Azurea & 15,33 & 1,26 & 24,84 & 4,85 & 11,58 & 1,27 & 54,64 & 35,92 \\
\hline P. stratiotes & 21,36 & 6,10 & 30,23 & 12,92 & 17,24 & 4,62 & 48,00 & 41,68 \\
\hline S. molesta & 17,14 & 4,28 & 24,17 & 7,96 & 16,34 & 5,30 & 38,57 & 20,24 \\
\hline H. reniformis & 4,96 & 1,86 & 10,15 & 3,11 & 3,46 & 1,57 & 44,04 & 37,38 \\
\hline N. mexicana & 4,21 & 1,30 & 8,79 & 3,00 & 3,64 & 1,27 & 45,89 & 39,14 \\
\hline M. brasiliense & 10,31 & 2,83 & 15,84 & 5,98 & 8,37 & 2,31 & 46,13 & 38,83 \\
\hline L. laevigatum & 17,99 & 3,13 & 30,31 & 8,71 & 14,45 & 2,77 & 74,13 & 56,58 \\
\hline Eg. densa & 3,37 & 0,80 & 5,60 & 2,19 & 2,54 & 0,66 & 25,45 & 16,54 \\
\hline C. beckettii & 11,95 & 4,70 & 19,01 & 9,96 & 10,76 & 4,24 & 54,25 & 35,61 \\
\hline Ec. bleheri & 7,58 & 2,69 & 12,72 & 5,81 & 6,06 & 2,48 & 36,28 & 19,88 \\
\hline Hy. polysperma & 14,85 & 4,99 & 20,22 & 8,08 & 13,89 & 4,64 & 48,44 & 29,71 \\
\hline Média & 11,33 & 2,97 & 18,00 & 6,43 & 9,43 & 2,72 & 47,08 & 34,07 \\
\hline Desvio Padrão & 5,75 & 1,63 & 7,85 & 3,05 & 5,08 & 1,53 & 11,24 & 10,64 \\
\hline Coef. Variação & 0,51 & 0,55 & 0,44 & 0,47 & 0,54 & 0,56 & 0,24 & 0,31 \\
\hline
\end{tabular}

Foram calculadas as diferenças de reflectância entre os valores máximo e mínimo em cada faixa e também a variância dentro da faixa (Tabela II.2).

Tabela II.2: Diferenças entre os valores de Reflectância (\%) máximos e mínimos de espécies de macrófitas em cada Faixa de Comprimento de onda, e Variância da Reflectância dentro do grupo de folhas/indivíduos amostrados, para as Faixas de Comprimento de Onda.

\begin{tabular}{|l|c|c|c|c|cc|cc|}
\cline { 2 - 9 } \multicolumn{1}{c|}{} & $\begin{array}{c}\text { Azul: } \\
\text { max-min }\end{array}$ & Variância & $\begin{array}{c}\text { Verde: } \\
\text { max-min }\end{array}$ & Variância & $\begin{array}{c}\text { Vermelho: } \\
\text { max-min }\end{array}$ & Variância & $\begin{array}{c}\text { IVP: } \\
\text { max-min }\end{array}$ & Variância \\
\hline Ei. crassipes & 5,24 & 0,65 & 9,46 & 4,97 & 3,42 & 0,55 & 11,77 & 10,28 \\
\hline Ei. Azurea & 14,07 & 4,05 & 19,99 & 23,23 & 10,32 & 4,13 & 18,73 & 28,68 \\
\hline P. stratiotes & 15,26 & 7,27 & 17,31 & 18,12 & 12,62 & 7,51 & 6,32 & 2,92 \\
\hline S. molesta & 12,85 & 5,37 & 16,20 & 16,16 & 11,03 & 5,57 & 18,34 & 31,57 \\
\hline H. reniformis & 3,10 & 0,27 & 7,04 & 2,83 & 1,89 & 0,18 & 6,66 & 4,50 \\
\hline N. mexicana & 2,91 & 0,22 & 5,78 & 1,57 & 2,38 & 0,27 & 6,75 & 3,67 \\
\hline M. brasiliense & 7,48 & 1,94 & 9,87 & 7,14 & 6,06 & 1,91 & 7,30 & 6,73 \\
\hline L. laevigatum & 14,87 & 6,21 & 21,60 & 21,24 & 11,68 & 5,61 & 17,55 & 41,17 \\
\hline Eg. densa & 2,57 & 0,25 & 3,41 & 0,83 & 1,88 & 0,22 & 8,91 & 9,66 \\
\hline C. beckettii & 7,26 & 2,70 & 9,05 & 5,02 & 6,52 & 3,15 & 18,64 & 47,52 \\
\hline Ec. bleheri & 4,89 & 1,04 & 6,91 & 3,16 & 3,57 & 0,86 & 16,39 & 31,43 \\
\hline Hy. polysperma & 9,86 & 4,17 & 12,14 & 8,91 & 9,24 & 4,08 & 18,73 & 34,32 \\
\hline
\end{tabular}


No azul, a variância mínima das amostras foi a de $N$. mexicana, e a máxima foi a de $P$. stratiotes. No verde a mínima foi de Eg. Densa, e a máxima foi de Ei. azurea. No vermelho a mínima foi de $H$. reniformis e a máxima foi de $P$. stratiotes. No IVP a menor variância foi a de $P$. stratiotes e a máxima foi de L. laevigatum. Lembrando que a pigmentação é a que exerce maior influência no visível, pode-se explicar a maior variância de $P$. stratiotes, cujas folhas variam mais em coloração, e portanto em pigmentação, do que as outras espécies. A maior variância de $L$. laevigatum (Tabela II.12) no IVP pode ser explicada em função de haver maior variação na espessura das folhas que nas outras espécies e, portanto na proporção de ar no interior das folhas.

Em resumo, os valores de reflectâncias variaram consideravelmente dentro da espécie, o que pode ser considerado normal já que nenhuma folha é idêntica à outra. Mas, mesmo entre as espécies, as variações nos valores de reflectância não tornam possível diferenciar com segurança uma espécie da outra (Figura II.6). Por este motivo foram testados outros modos de diferenciálas (Capítulo IV). 


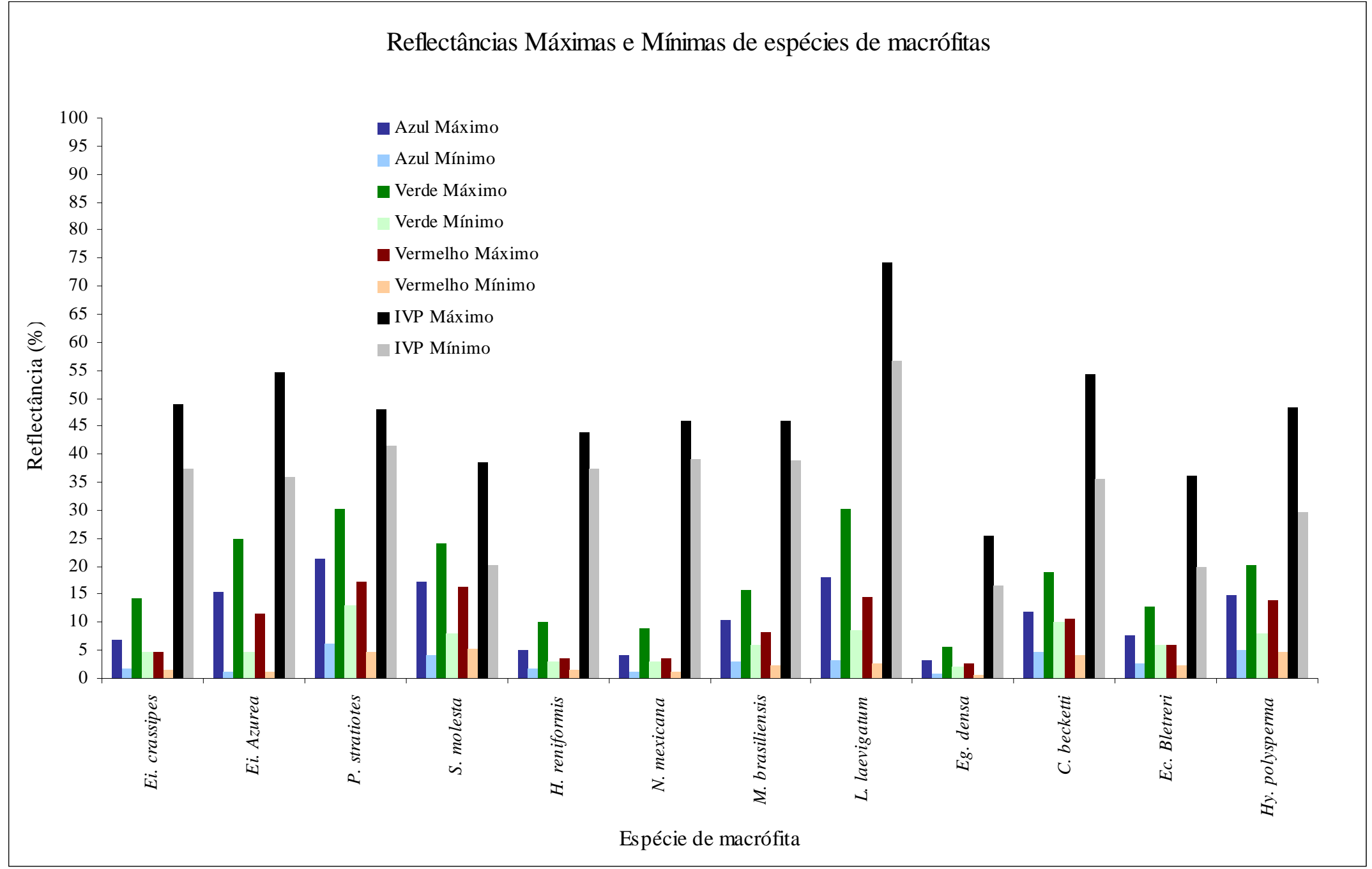

Figura II.6: Reflectâncias máximas e mínimas de espécies de macrófitas nas Faixas de Comprimento de Onda de interesse (Limnobium laevigatum, Eichhornnia crassipes, Ei. Azurea, Pistia stratiotes, Myriophyllum brasiliense, Nimphea mexicana, Hetheranthera reniformis, Salvinia molesta, Cryptocoryne beckettii, Echinodorus bleheri, Egeria densa, Hygrophila polysperma). 
Em relação à análise dos indivíduos inteiros (folhas, caules, raízes), os resultados se encontram também no Apêndice. As comparações entre as reflectâncias médias das folhas das espécies e do indivíduo como um todo se encontram nas figuras seguintes.

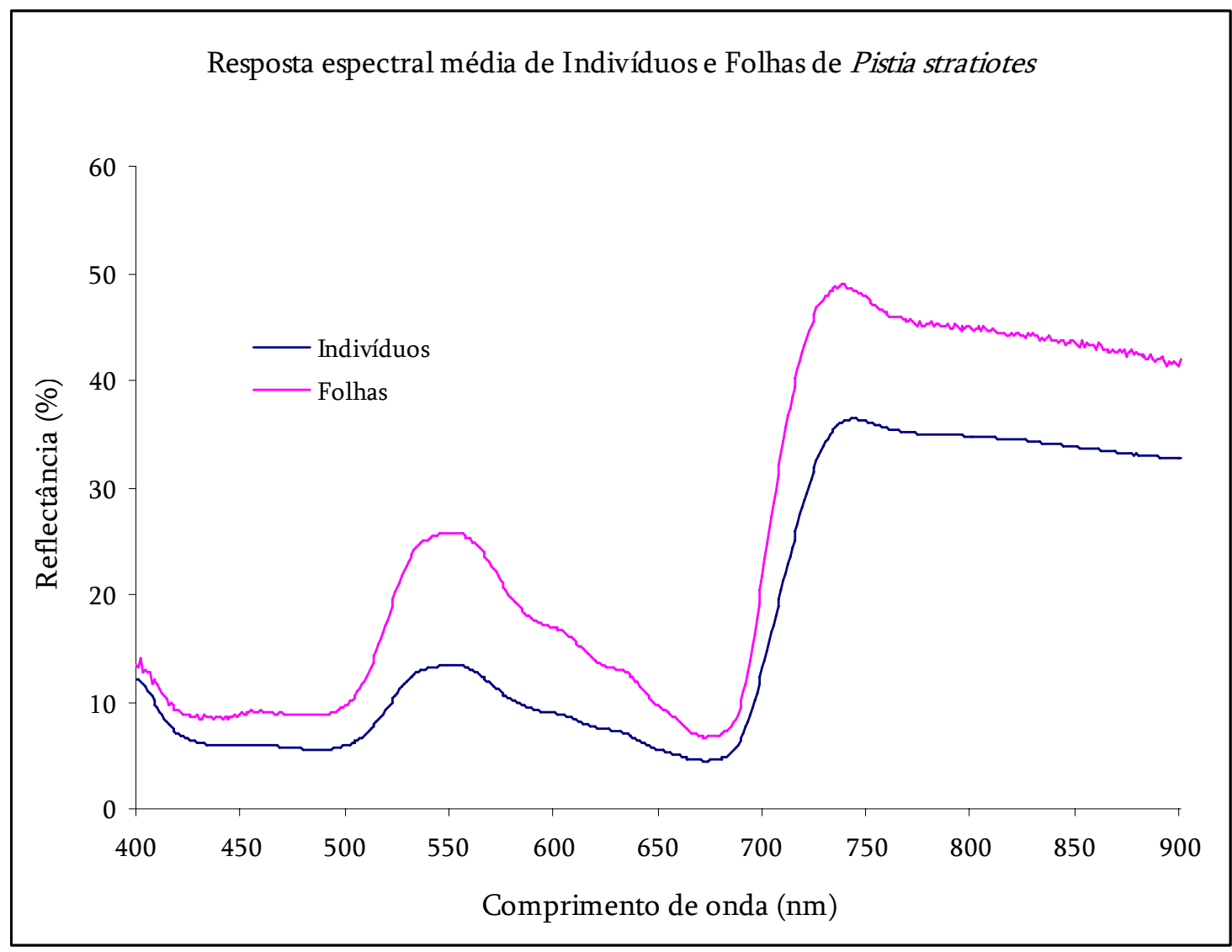

Figura II.7: Comparação das respostas espectrais de $P$. stratiotes, obtidas a partir de folhas (média de 10 folhas) e de três diferentes indivíduos (média de quatro ângulos diferentes). 


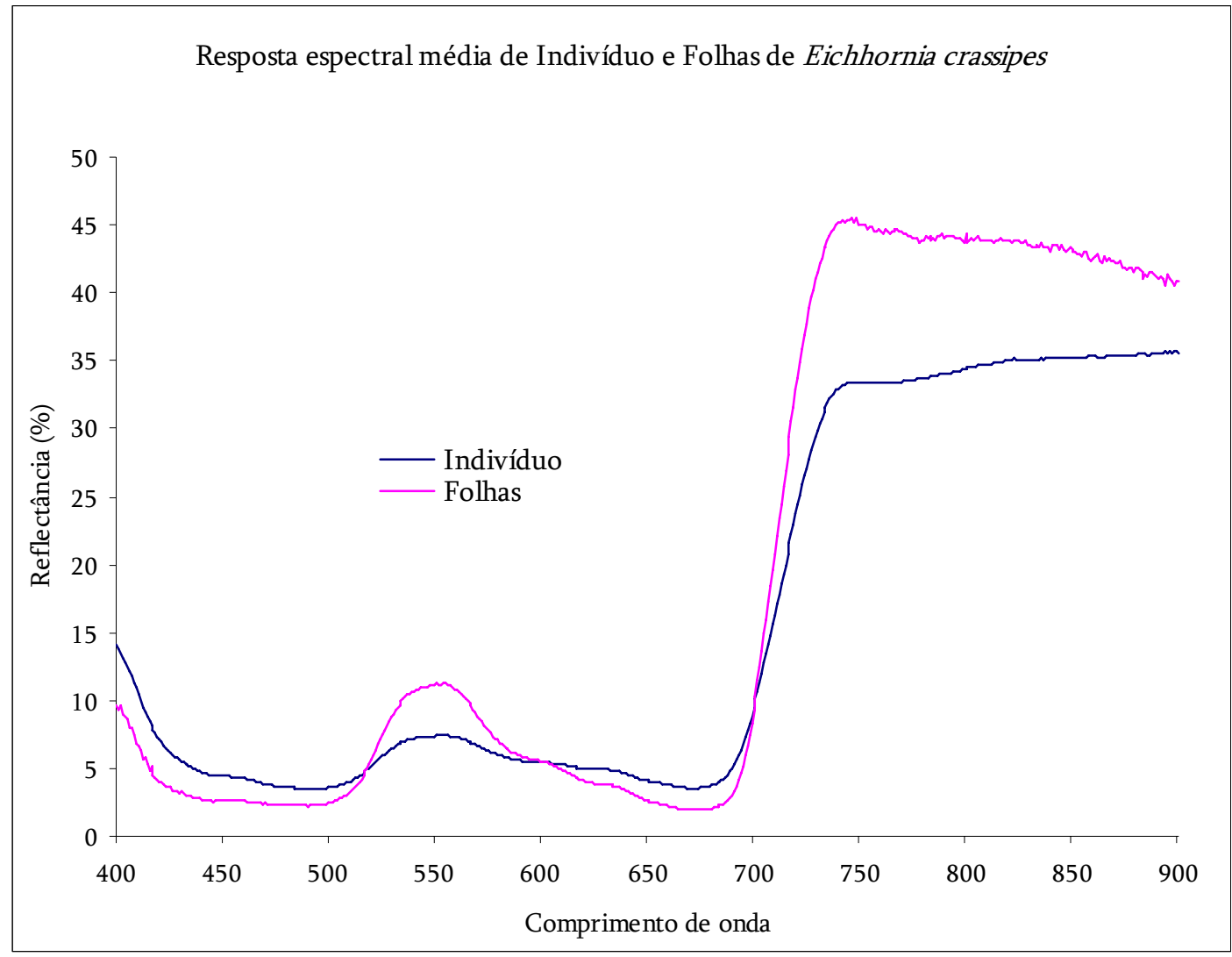

Figura II.8: Comparação das respostas espectrais de Eichhornia crassipes, obtidas a partir de folhas (média de 10 folhas) e de um mesmo indivíduo (média de quatro ângulos diferentes).

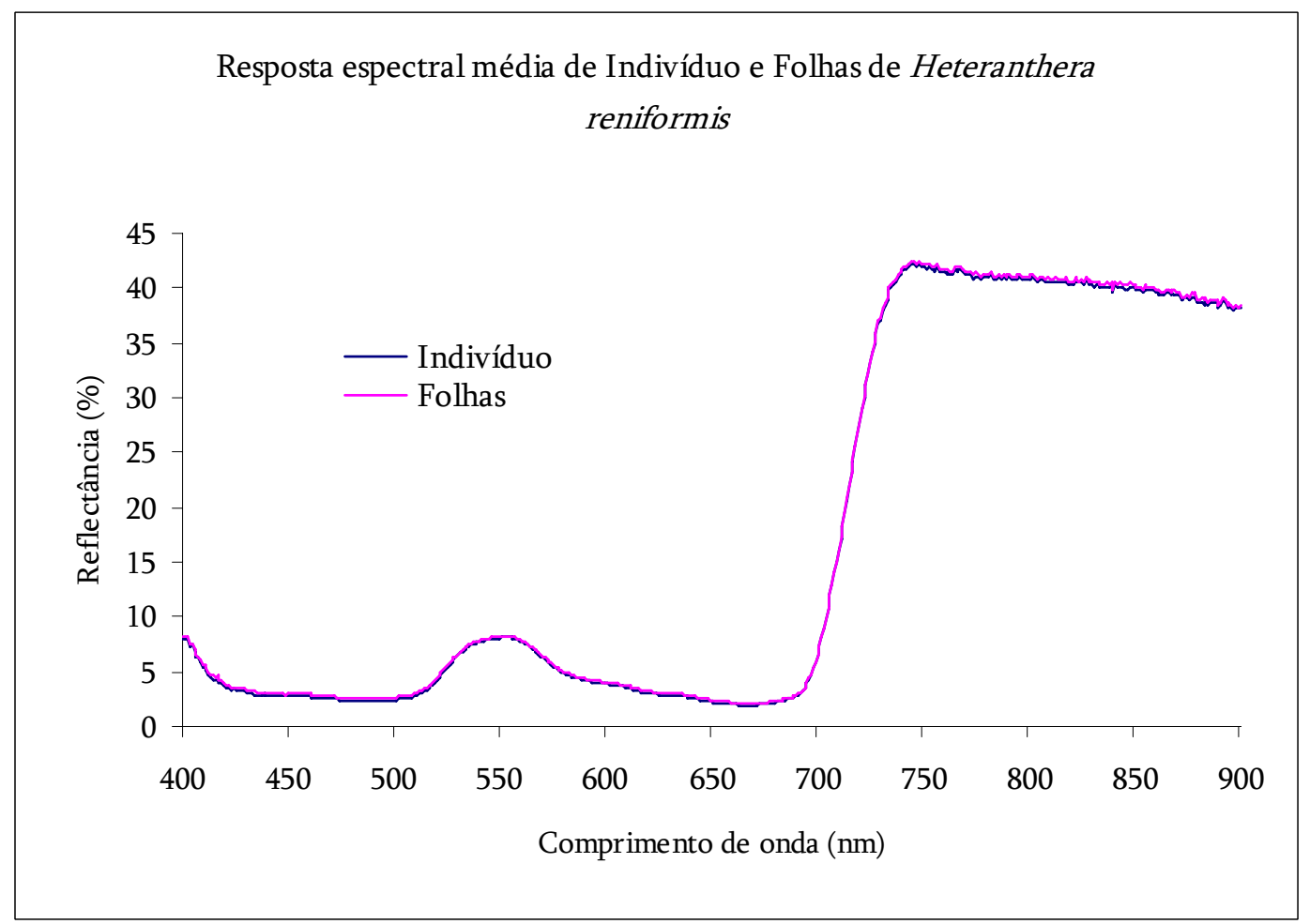

Figura II.9: Comparação das respostas espectrais de He. reniformis obtidas a partir de folhas (média de 10 folhas) e de um mesmo indivíduo (média de quatro ângulos diferentes). 


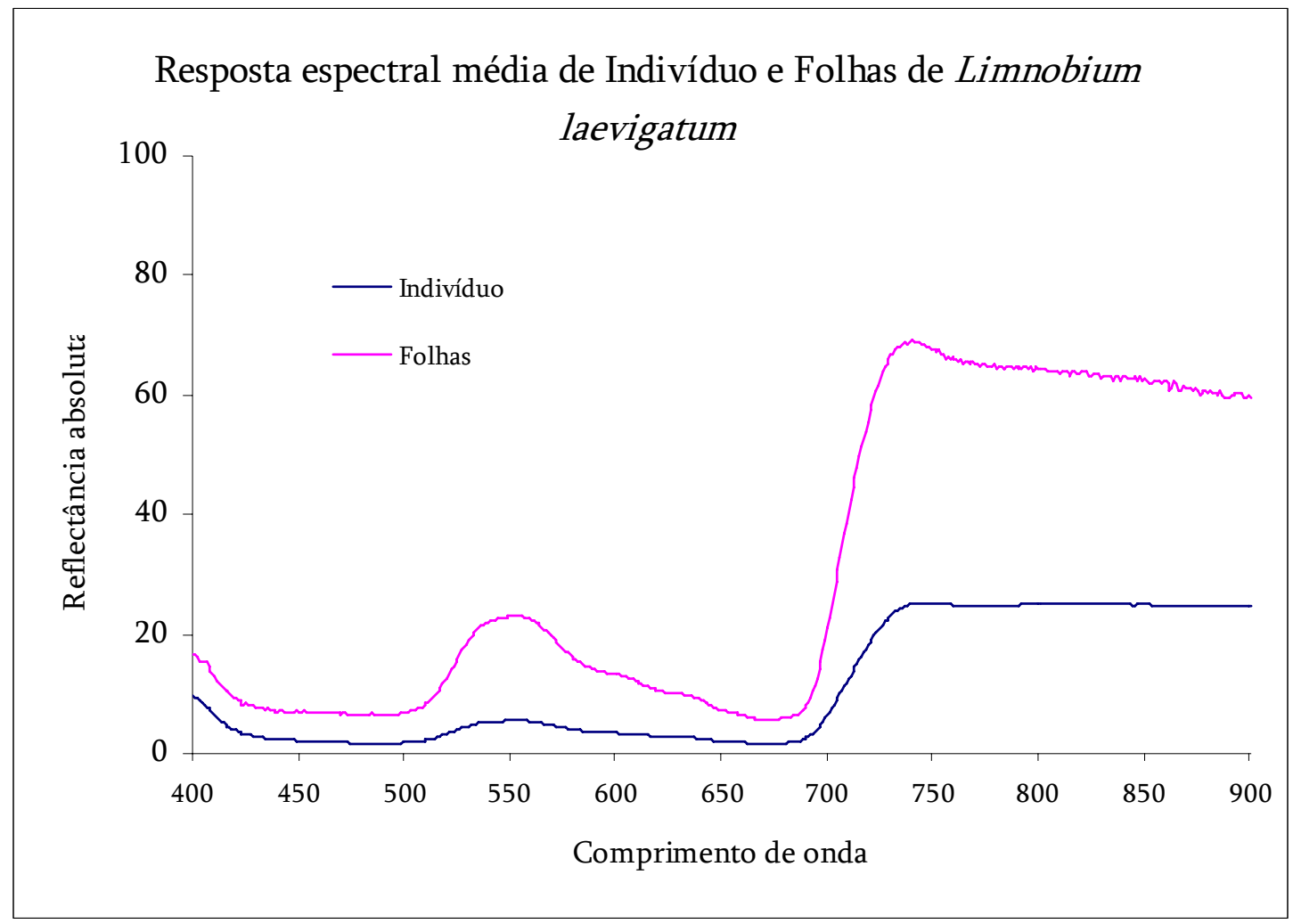

Figura II.10: Comparação das respostas espectrais de L. laevigatum obtidas a partir de folhas (média de 10 folhas) e de um mesmo indivíduo (média de quatro ângulos diferentes).

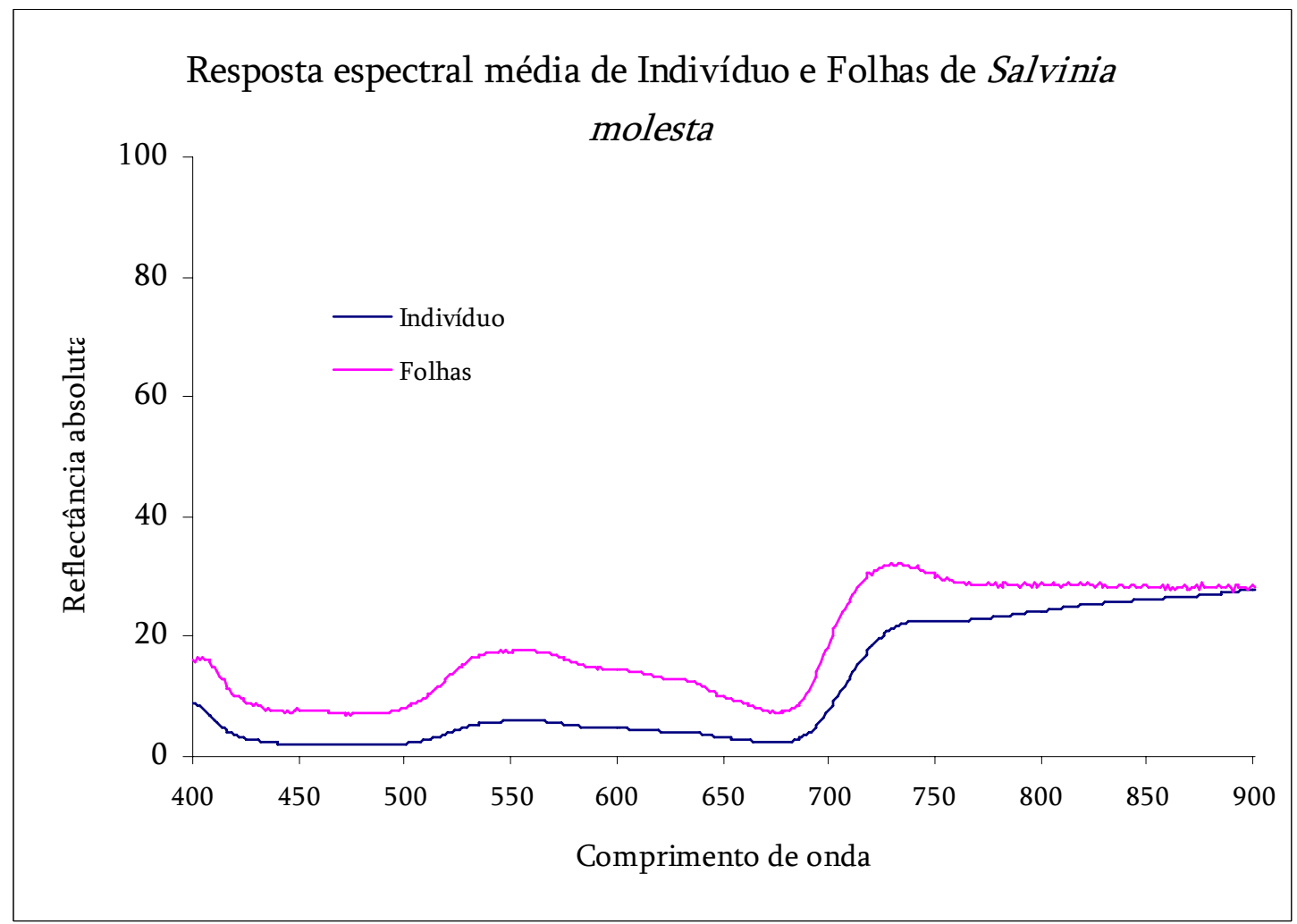

Figura II.11: Comparação das respostas espectrais de L. laevigatum obtidas a partir de folhas (média de 10 folhas) e de um mesmo indivíduo (média de quatro ângulos diferentes). 


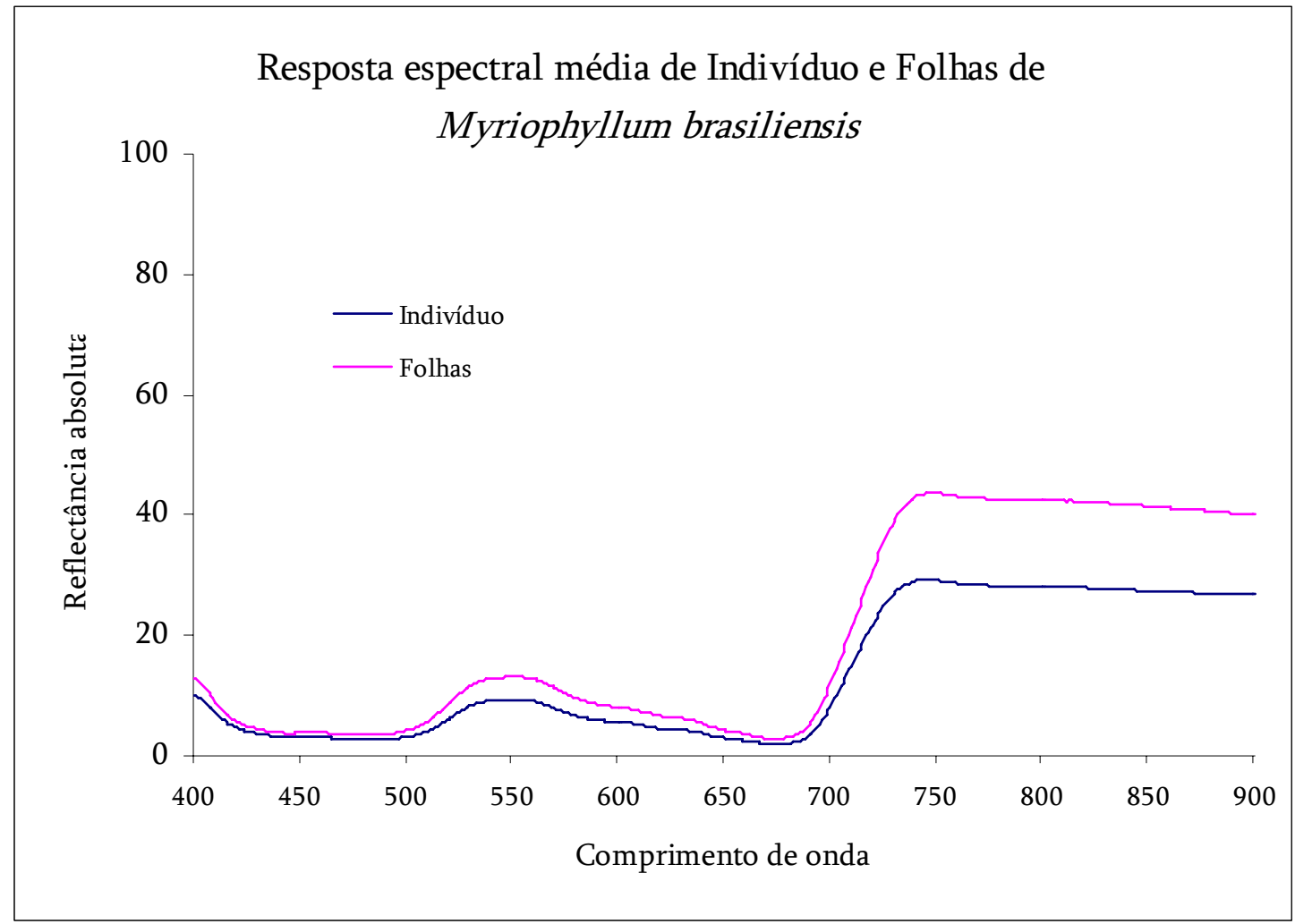

Figura II.12: Comparação das respostas espectrais de $M$. brasiliense obtidas a partir de folhas agrupadas horizontalmente (medidas em diferentes posições) e de um mesmo indivíduo (visto de cima).

Observando as figuras comparativas entre as amostragens de folhas apenas e do indivíduo como um todo, nota-se que, com exceção de Eichhornia crassipes, a reflectância das folhas foi maior ou igual em todos os comprimentos de onda do que a reflectância do indivíduo nos mesmos comprimentos de onda. Isso se explica porque quando a medida é tomada do indivíduo como um todo, há menos área coberta por vegetação na área de visada. No caso de Ei. crassipes, que pode apresentar pecíolos inflados, pode ter havido maior influência dessas partes na reflectância do indivíduo. 


\section{4 - CONCLUSÕES}

Foi coletada a resposta espectral de doze espécies de macrófitas, significantemente distintas entre si nas quatro faixas do espectro de maior interesse para o Sensoriamento Remoto Orbital, as quais são Azul, Verde, Vermelho e Infra-Vermelho Próximo (IVP).

As análises das respostas espectrais mostraram variações de intensidade de reflectância no caso intra-específico, mas também nos picos de reflectância no caso interespecífico. Inter-especificamente, o coeficiente de variação mostrou que há maior variação dos valores de reflectância no Azul e no Vermelho. Intra-especificamente, a variância mínima entre as amostras (folhas) variou conforme a faixa espectral. No azul, a variância mínima das amostras foi a de $N$. mexicana, e a máxima foi a de $P$. stratiotes. No verde a mínima foi de $E g$. Densa, e a máxima foi de $E i$. azurea. No vermelho a mínima foi de $H$. reniformis e a máxima foi de $P$. stratiotes. No IVP a menor variância foi a de $P$. stratiotes e a máxima foi de L. laevigatum.

Da comparação entre indivíduos e folhas notou-se que a resposta espectral das folhas é mais intensa que a do indivíduo completo, com exceção de Eichhornia crassipes. 


\section{II.5 - CONSIDERAÇÕES FINAIS}

Podem ser sugeridos como estudos futuros a comparação da estrutura anatômica e da pigmentação de folhas de macrófitas em relação à sua reflectância; estudos sobre a resposta espectral resultante da mistura entre espécies diferentes no campo de visada; estudos onde se analise a resposta espectral em função da idade das folhas, da angulação típica da folha, da reflexão especular de tricomas presentes na epiderme de alguns gêneros (como Salvinia sp. e Pistia stratiotes); e maiores estudos sobre outros fatores que possam influenciar na resposta espectral de macrófitas. 


\section{II.6 - APÊNDICE}

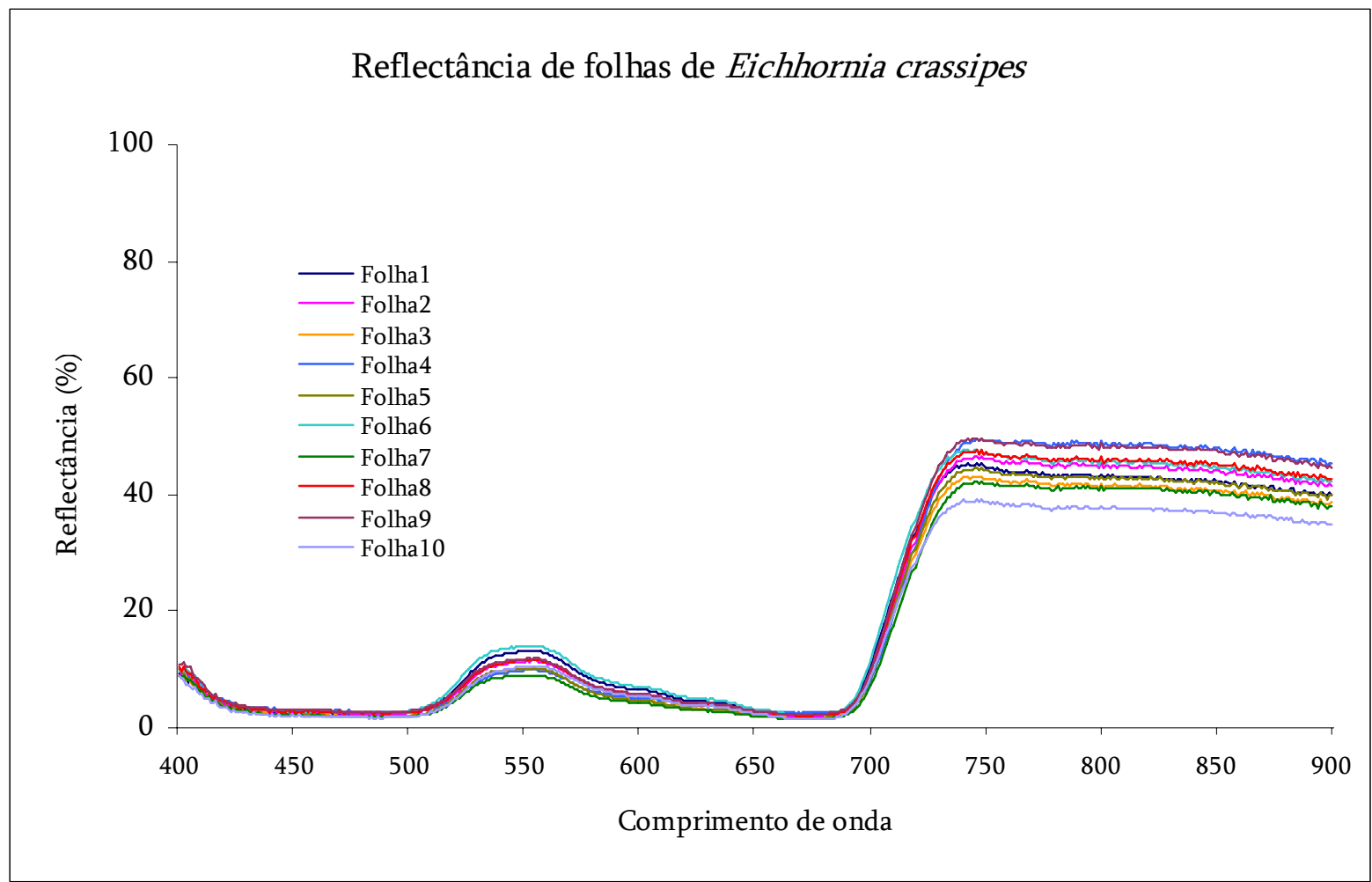

Figura II.13: Reflectância Absoluta de folhas de Eichhornia crassipes.

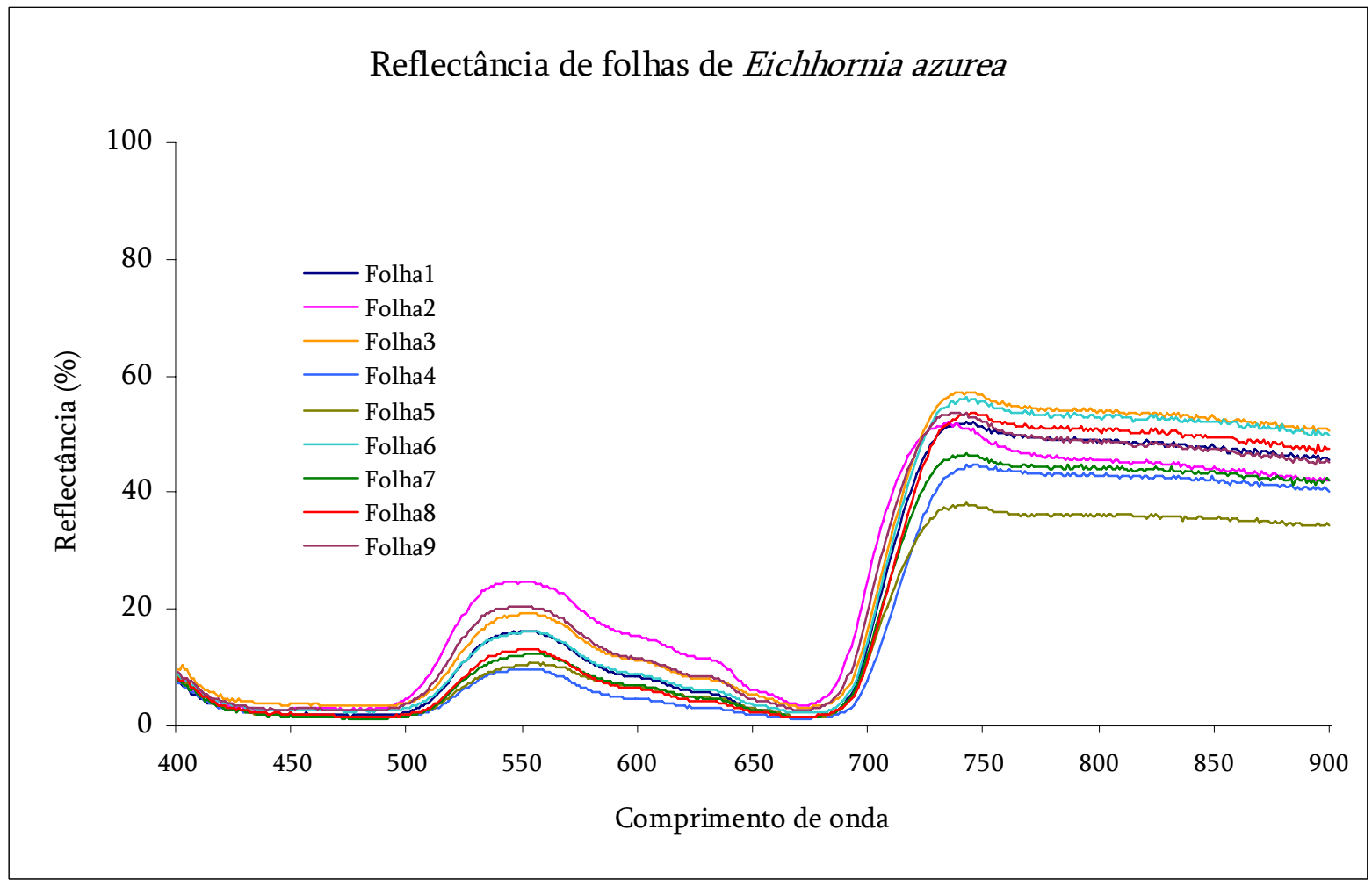

Figura II.14: Reflectância Absoluta de folhas de Eichhornia azurea. 


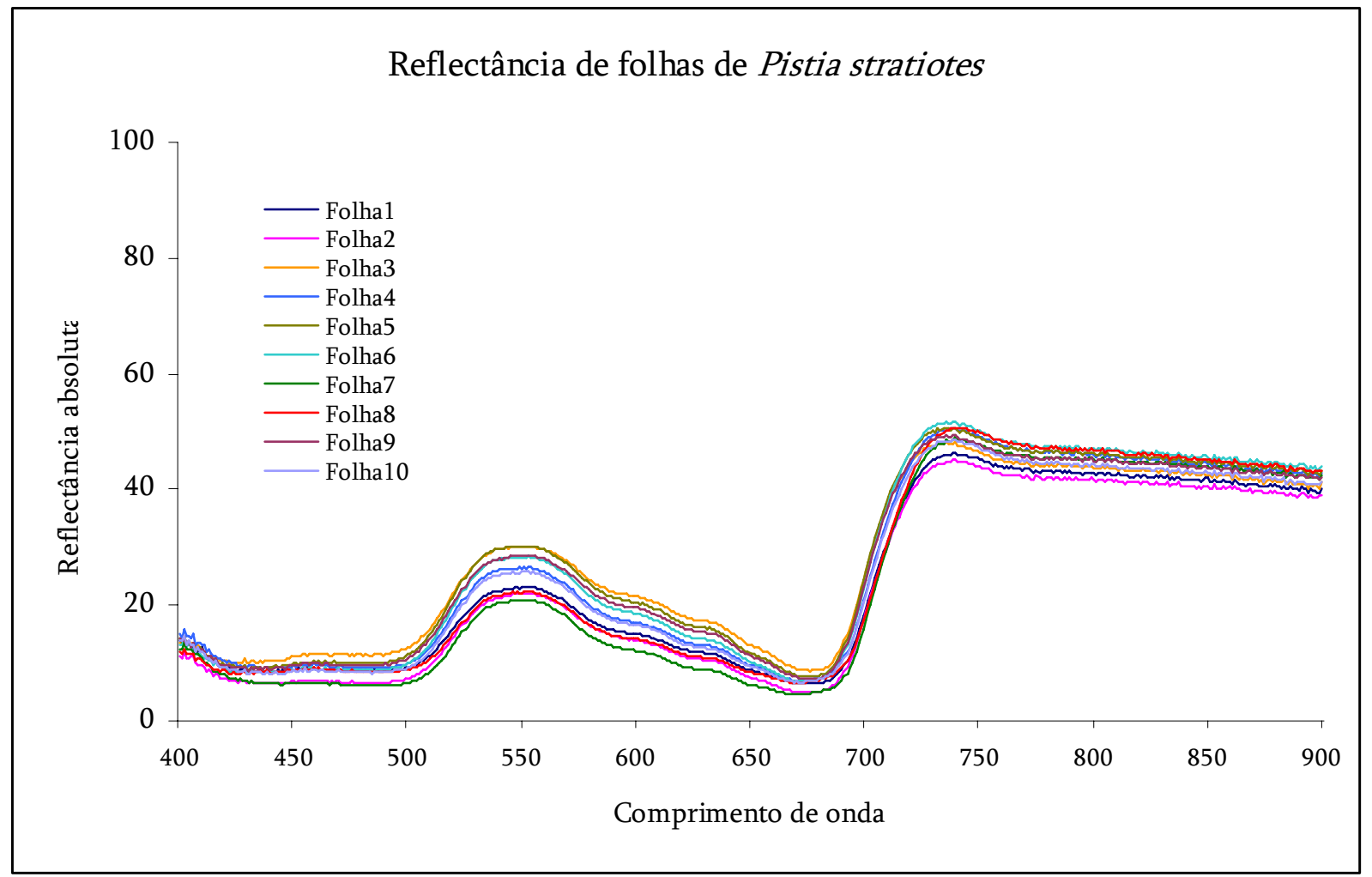

Figura II.15: Reflectância Absoluta de Pistia stratiotes.

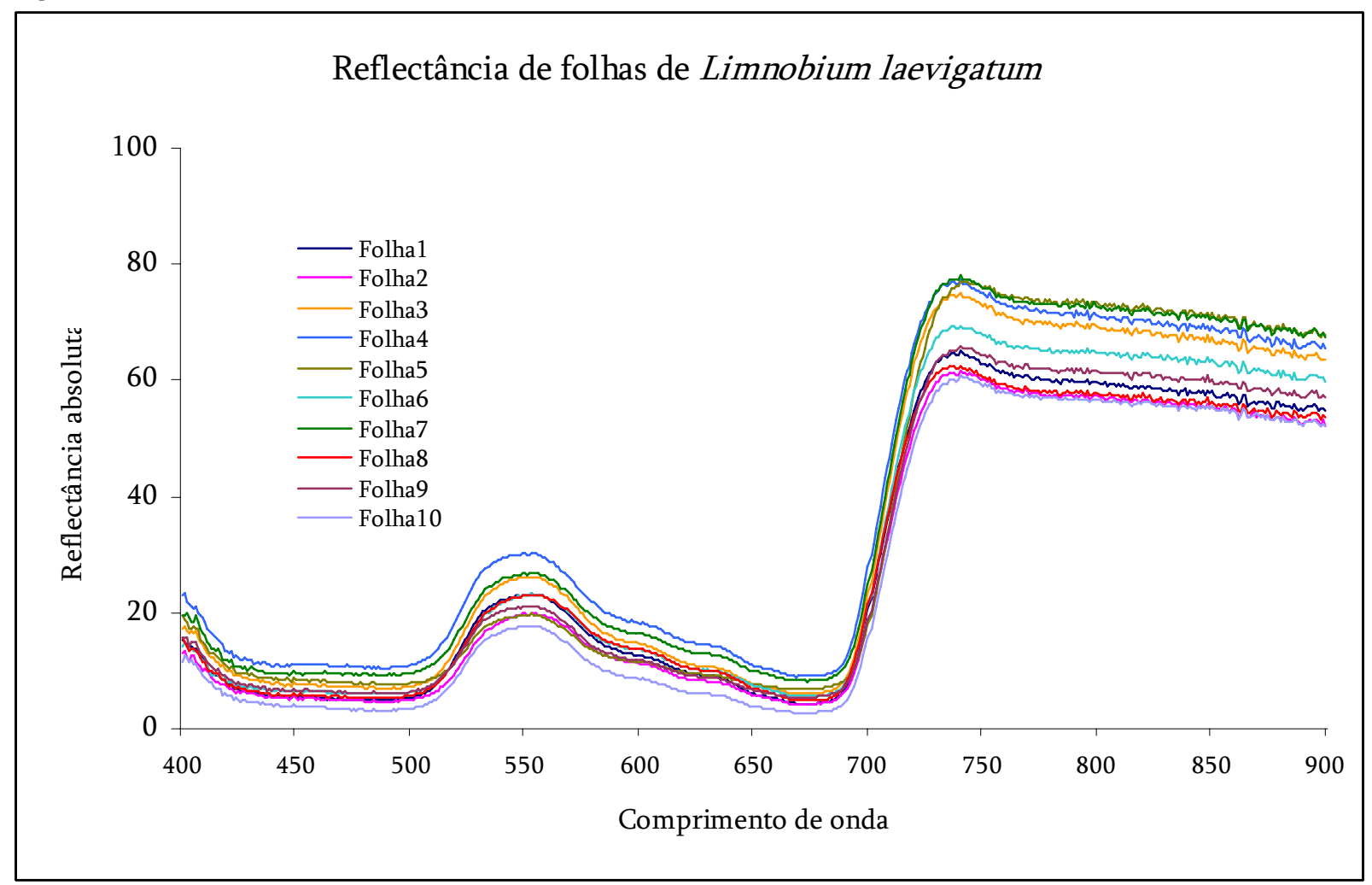

Figura II.16: Reflectância Absoluta de folhas de Limnobium laevigatum. 


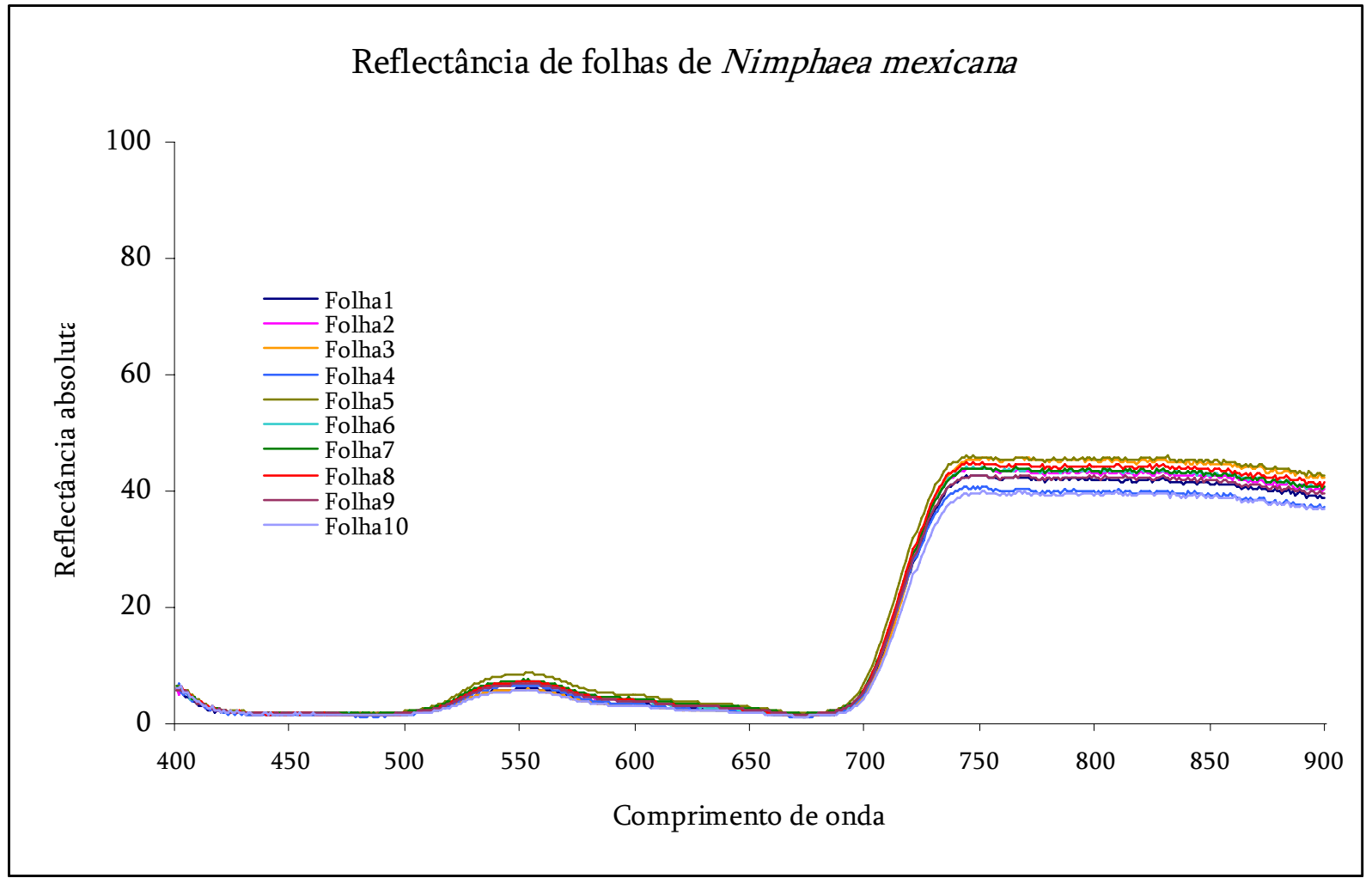

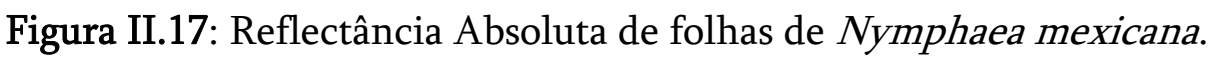

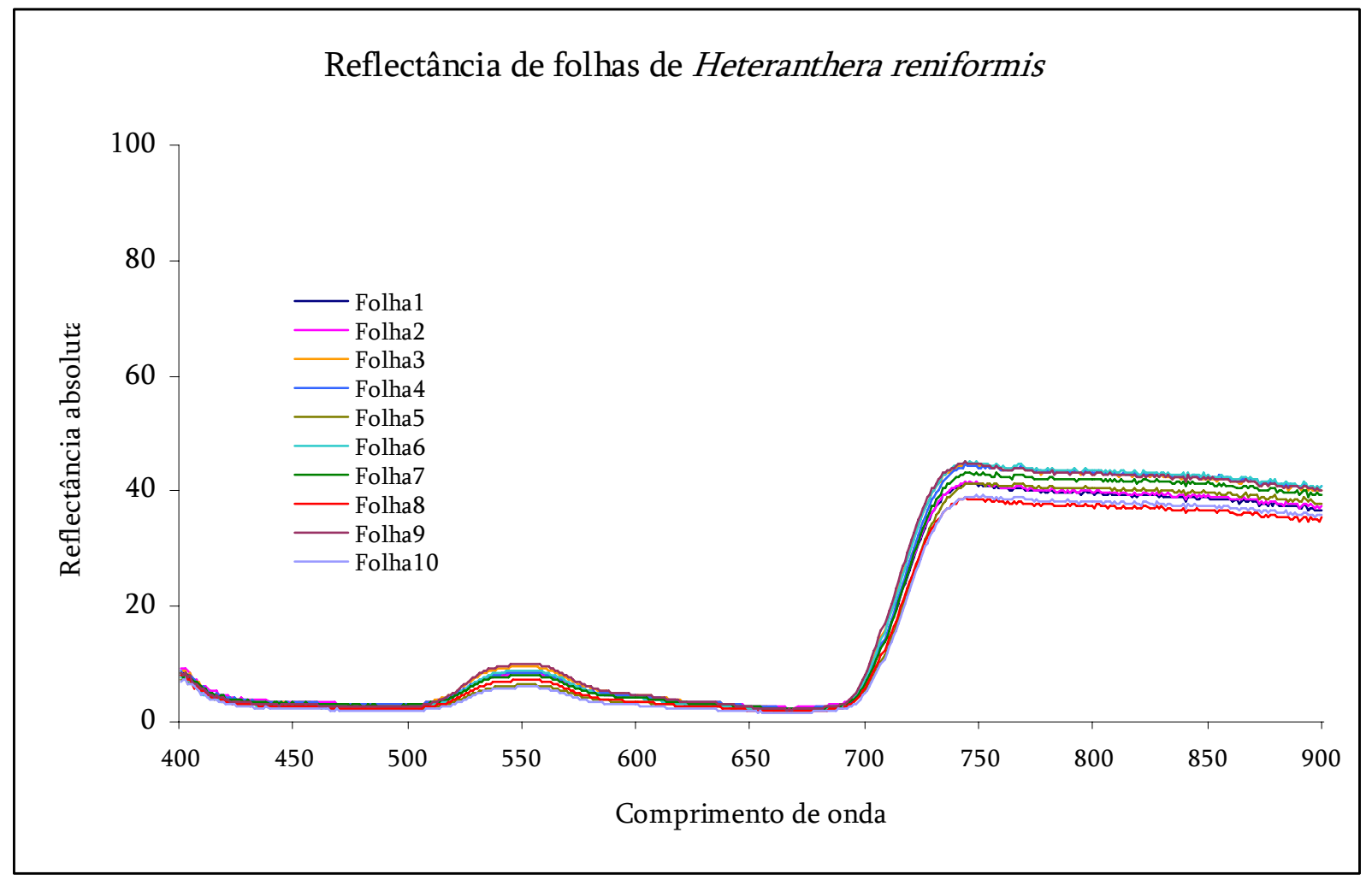

Figura II.18: Reflectância Absoluta de folhas de Heteranthera reniformis. 


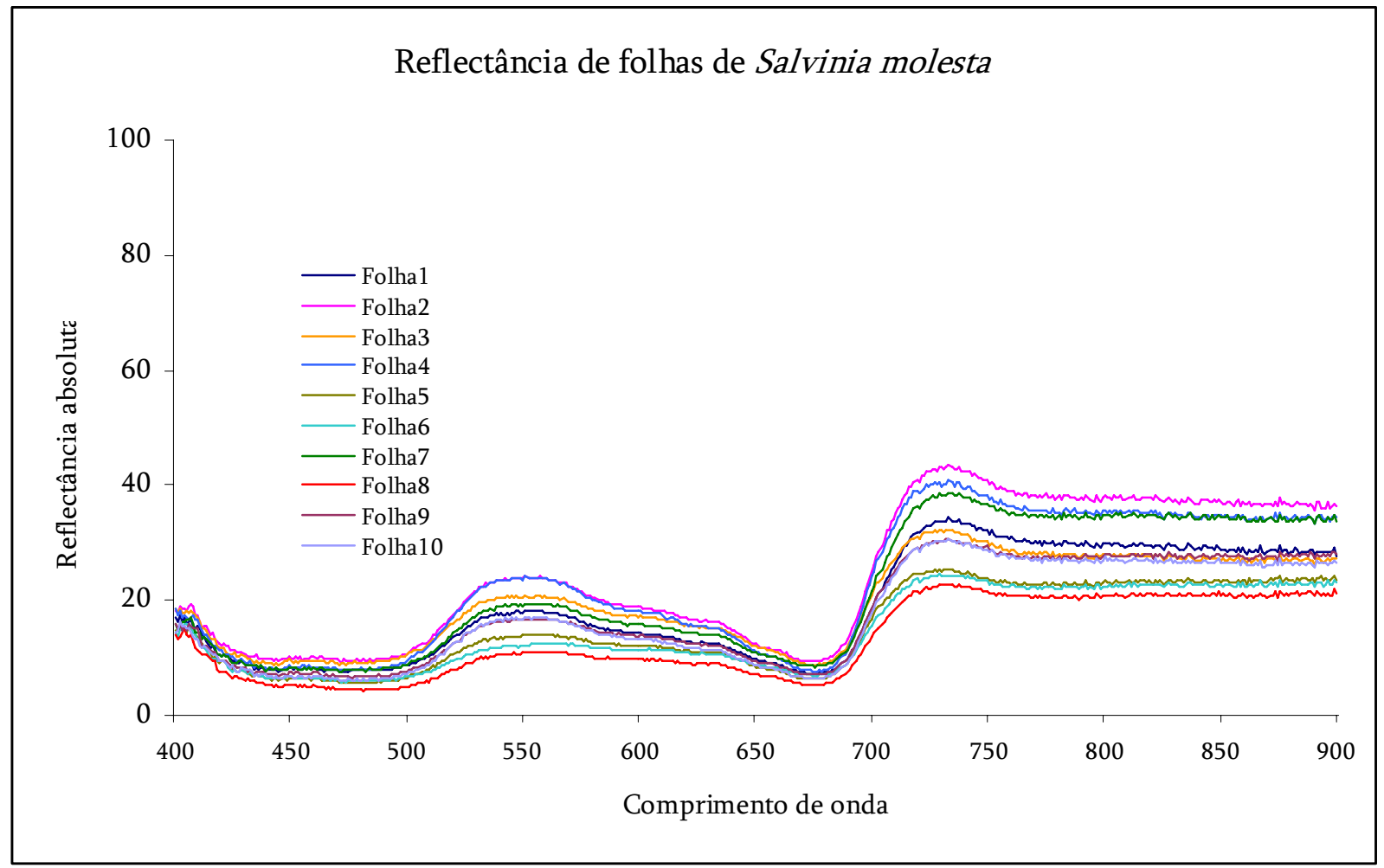

Figura II.19: Reflectância Absoluta de folhas de Salvinia molesta.

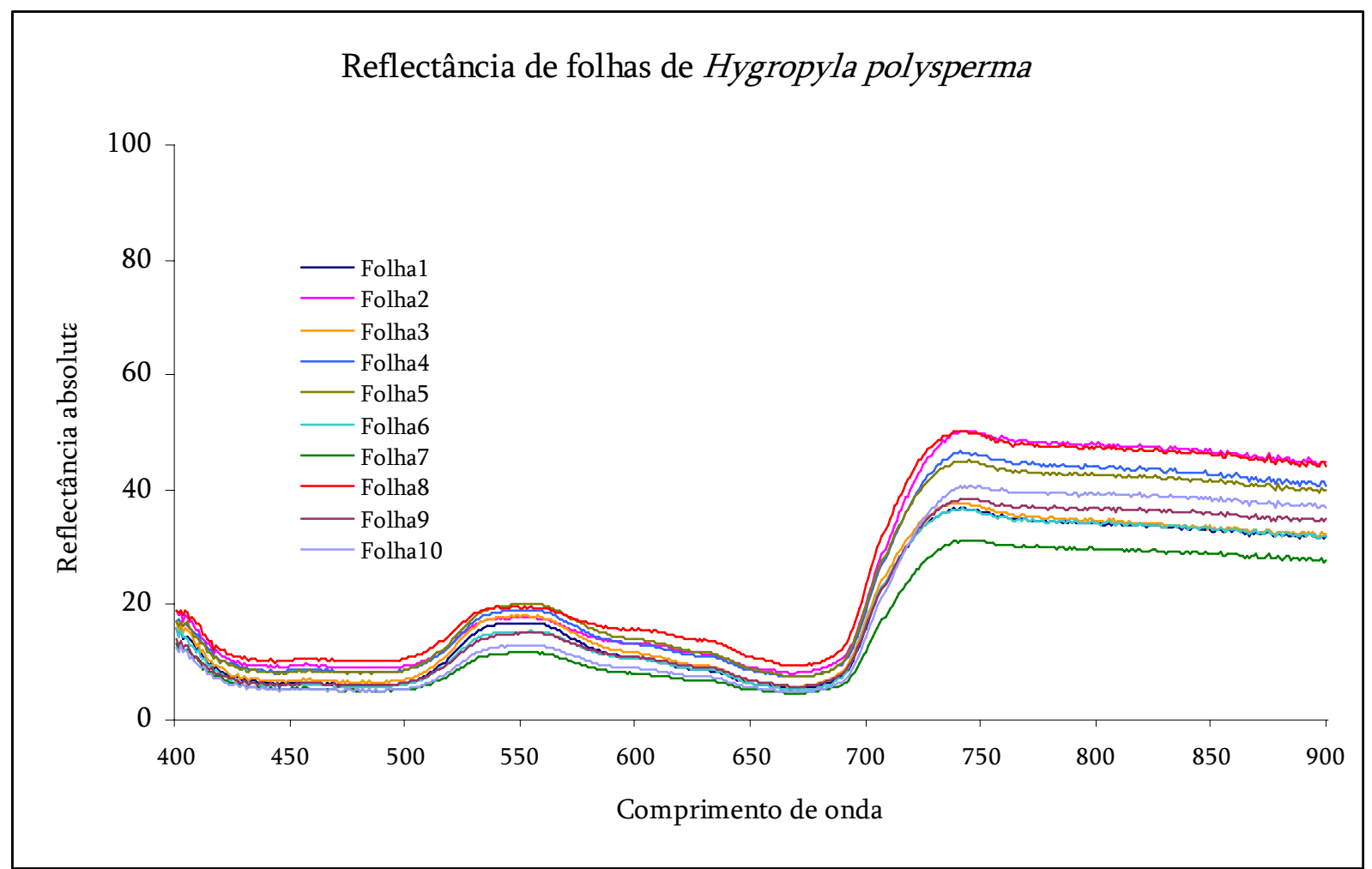

Figura II.20: Reflectância Absoluta de folhas de Hygrophila polysperma. 


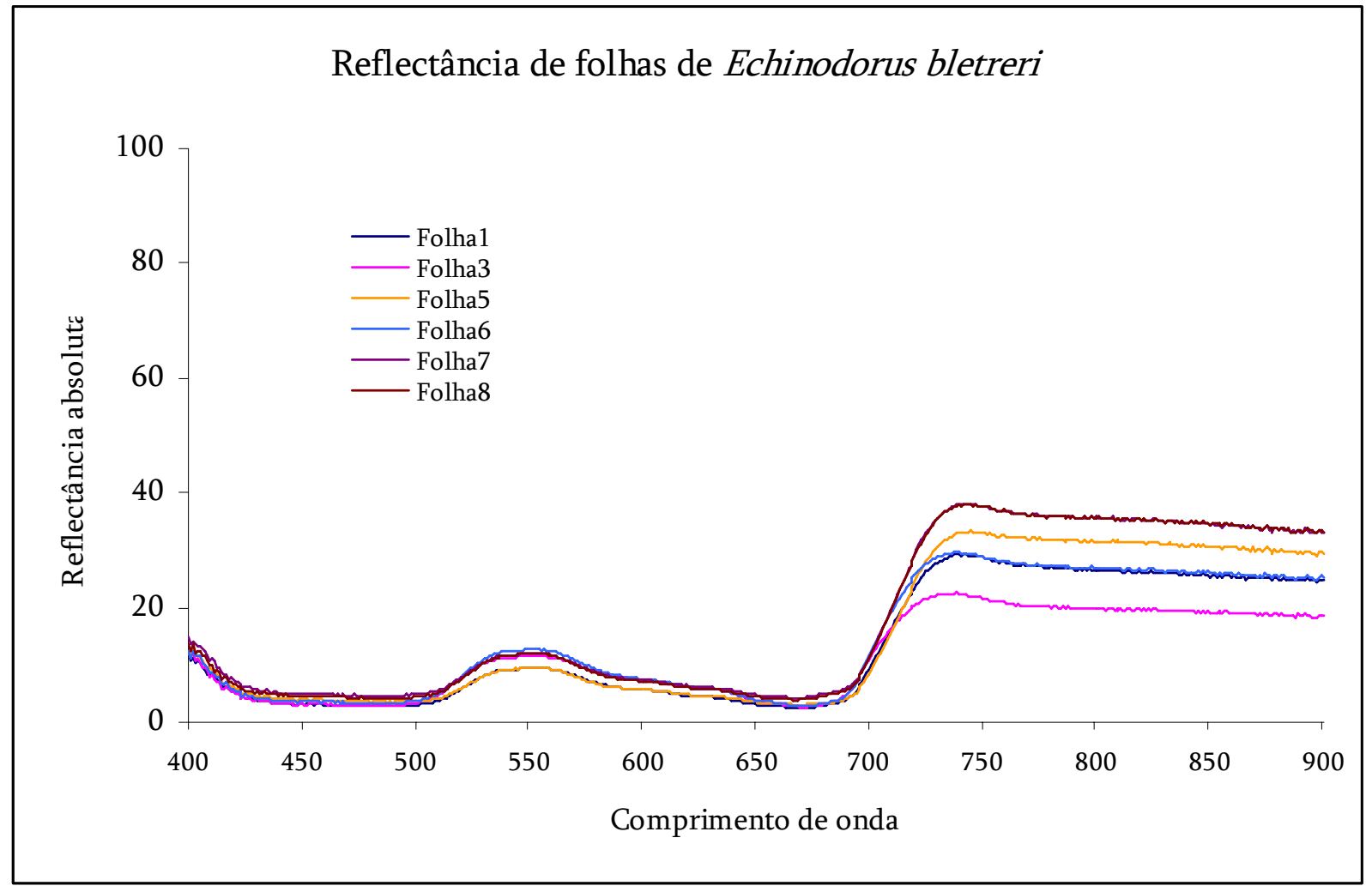

Figura II.21: Reflectância Absoluta de folhas de Echinodorus bleheri.

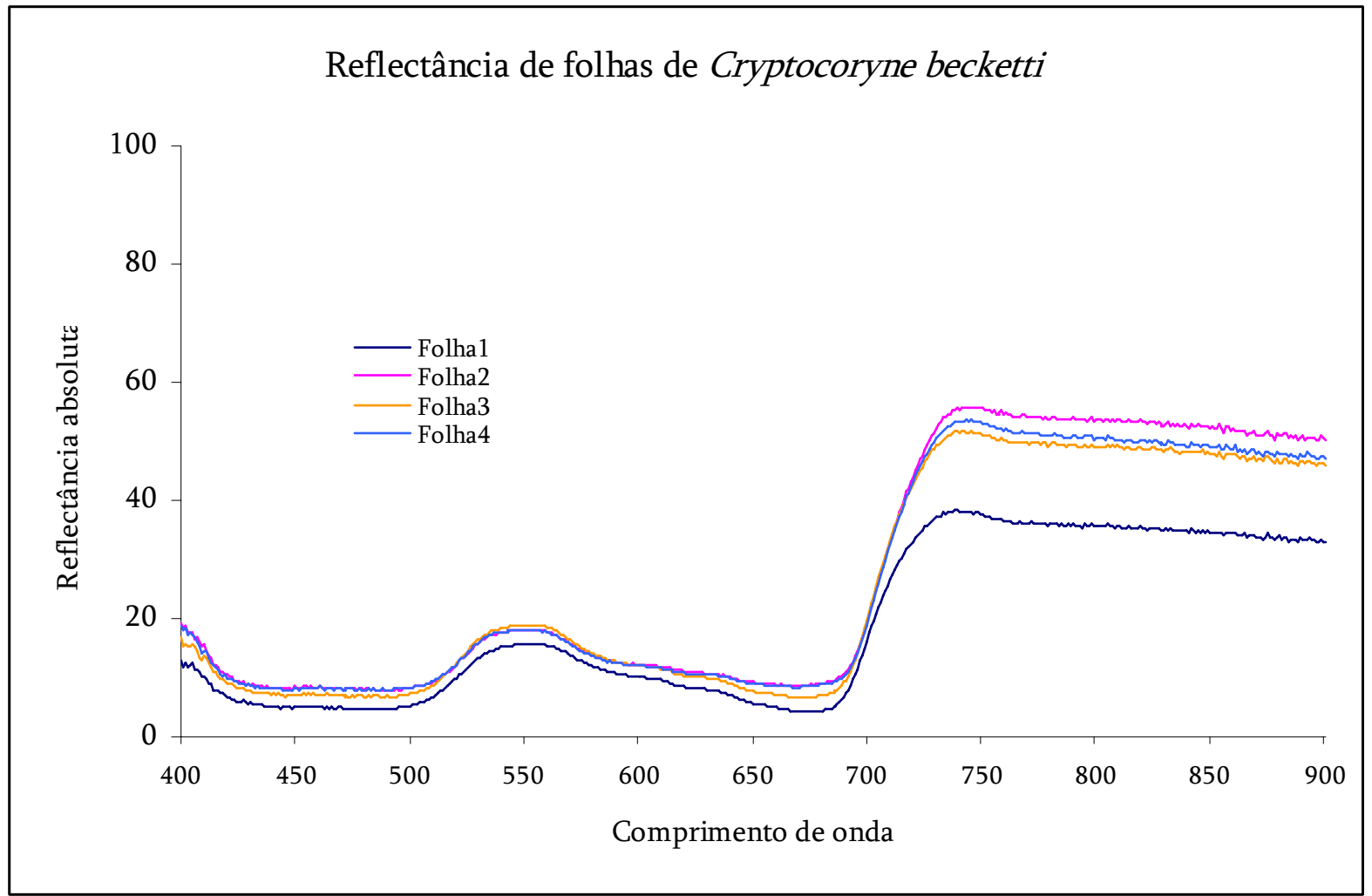

Figura II.22: Reflectância Absoluta de folhas de Cryptocoryne beckettiii. 


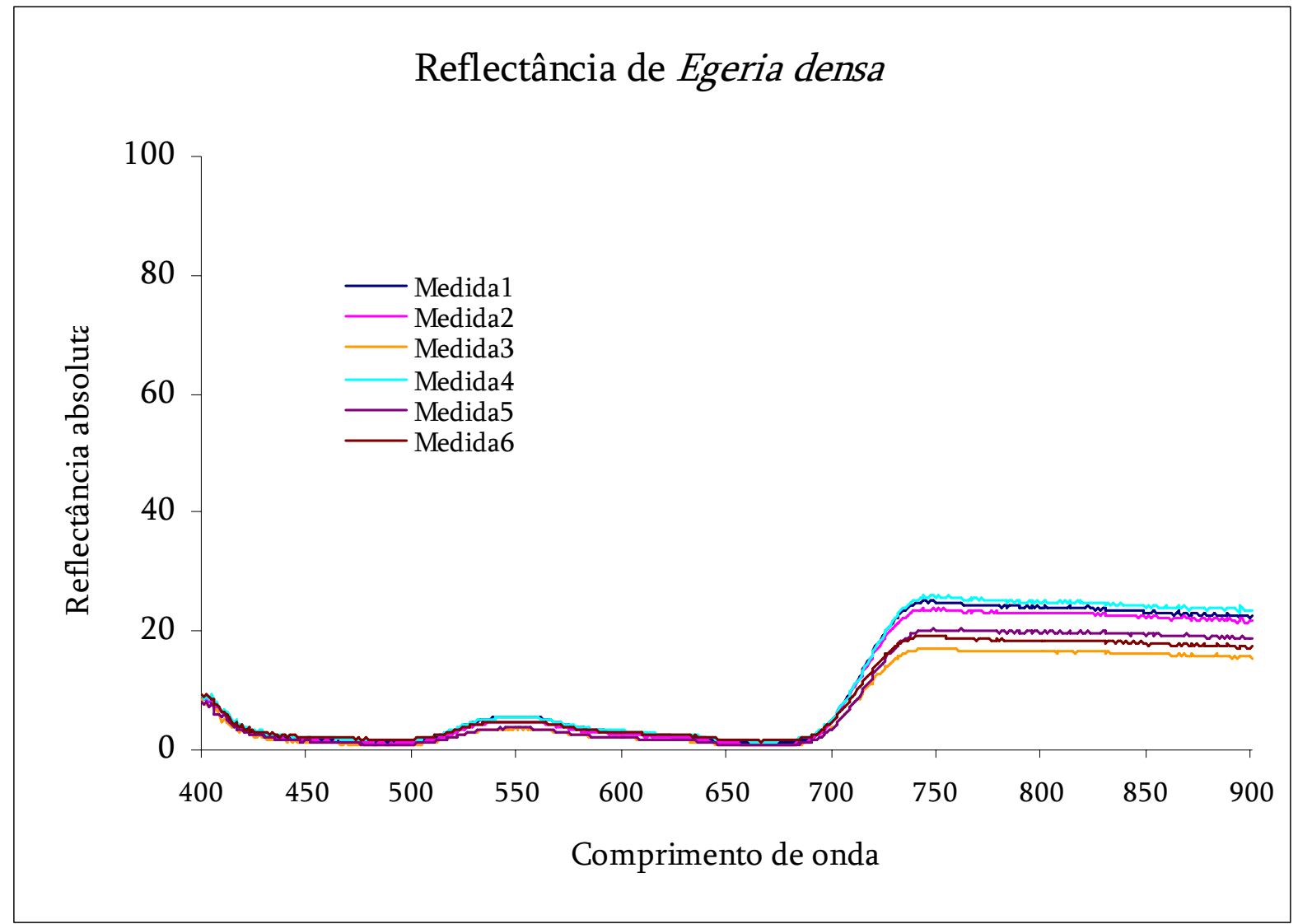

Figura II.23: Reflectância Absoluta de folhas de Egeria densa.

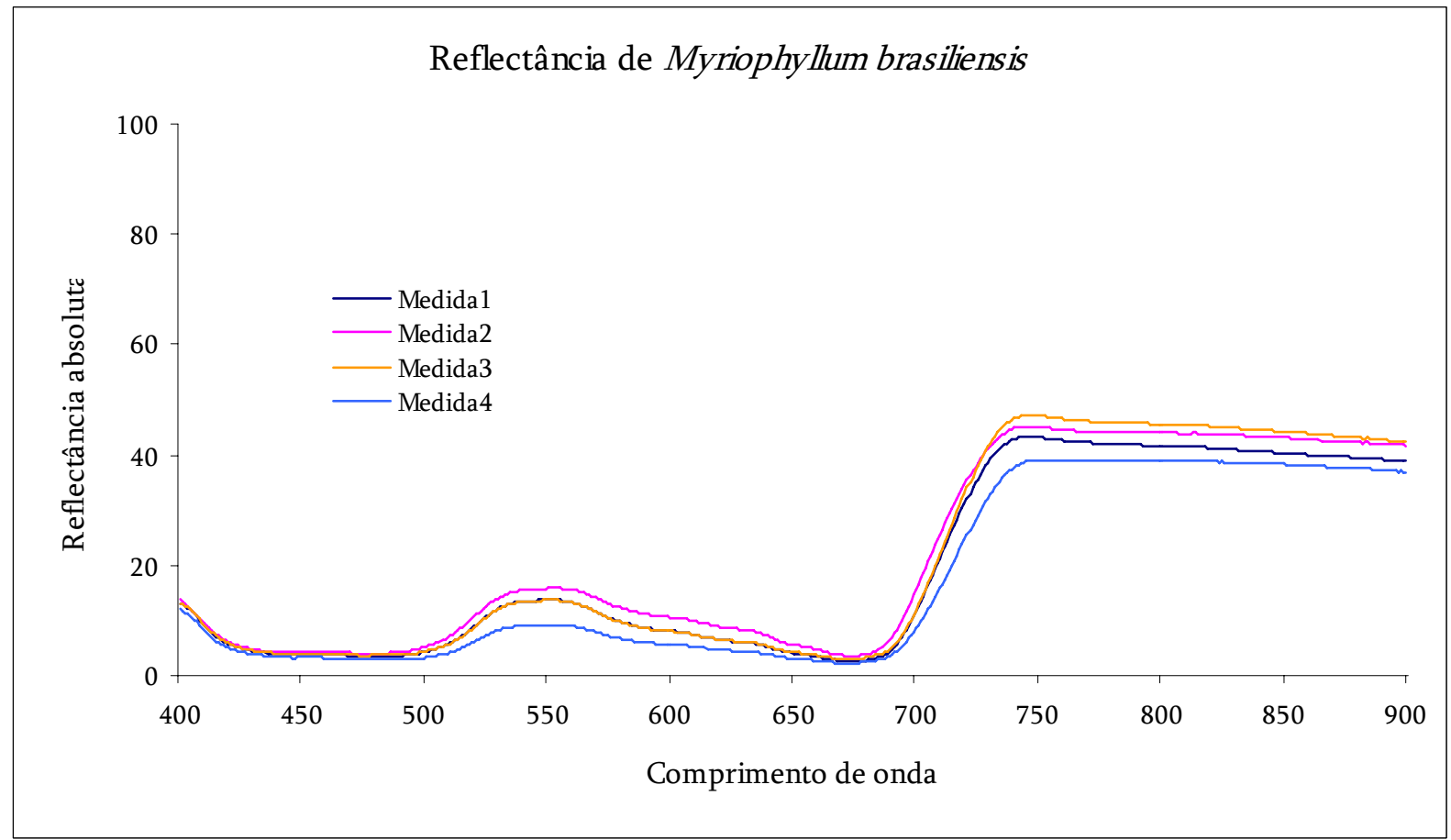

Figura II.24: Resposta espectral de Myriophyllum brasiliense, medida em 3 posições diferentes. 


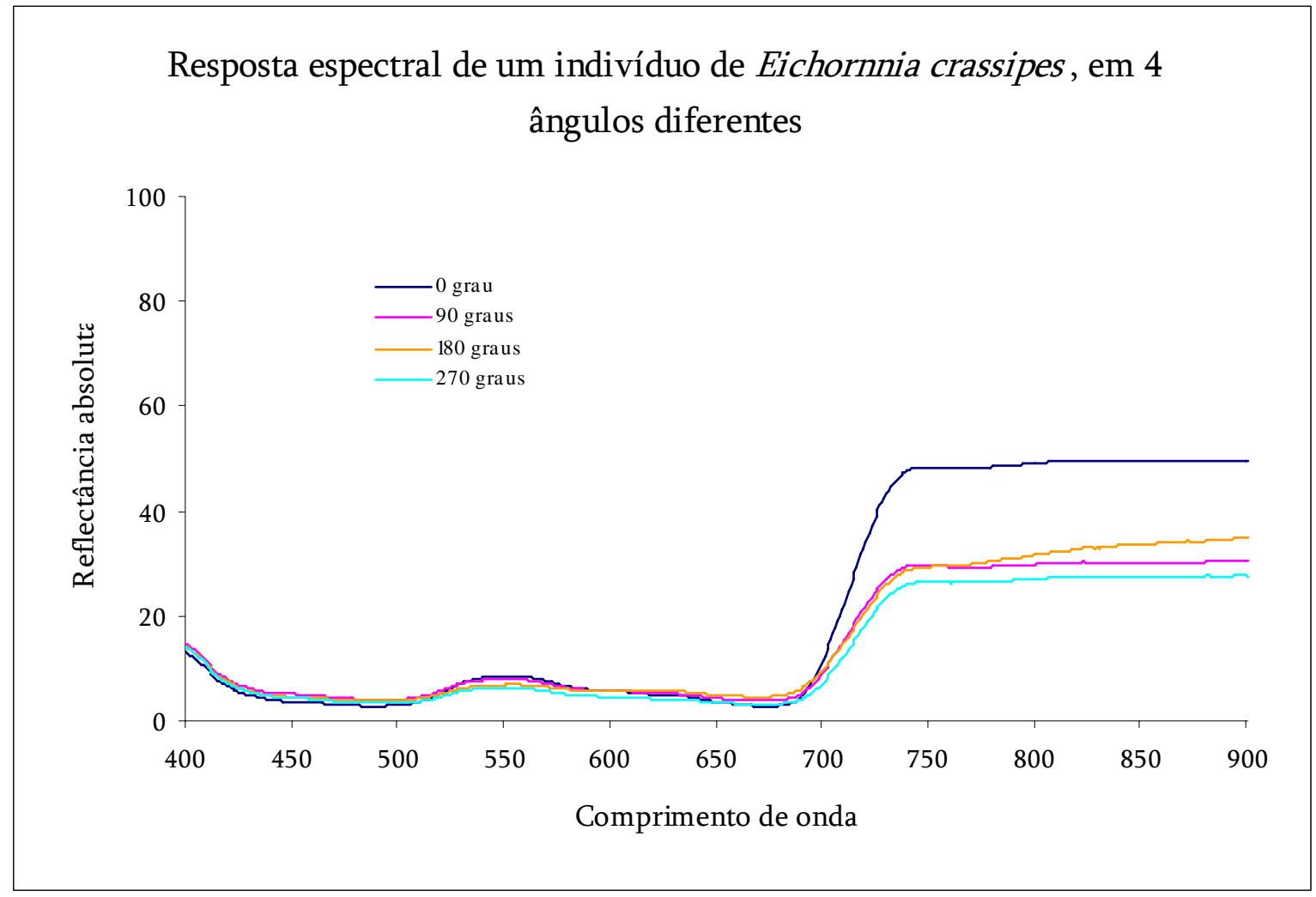

Figura II.25: Resposta espectral de Eichhornia crassipes, medida a partir de um mesmo indivíduo, em quatro ângulos diferentes.

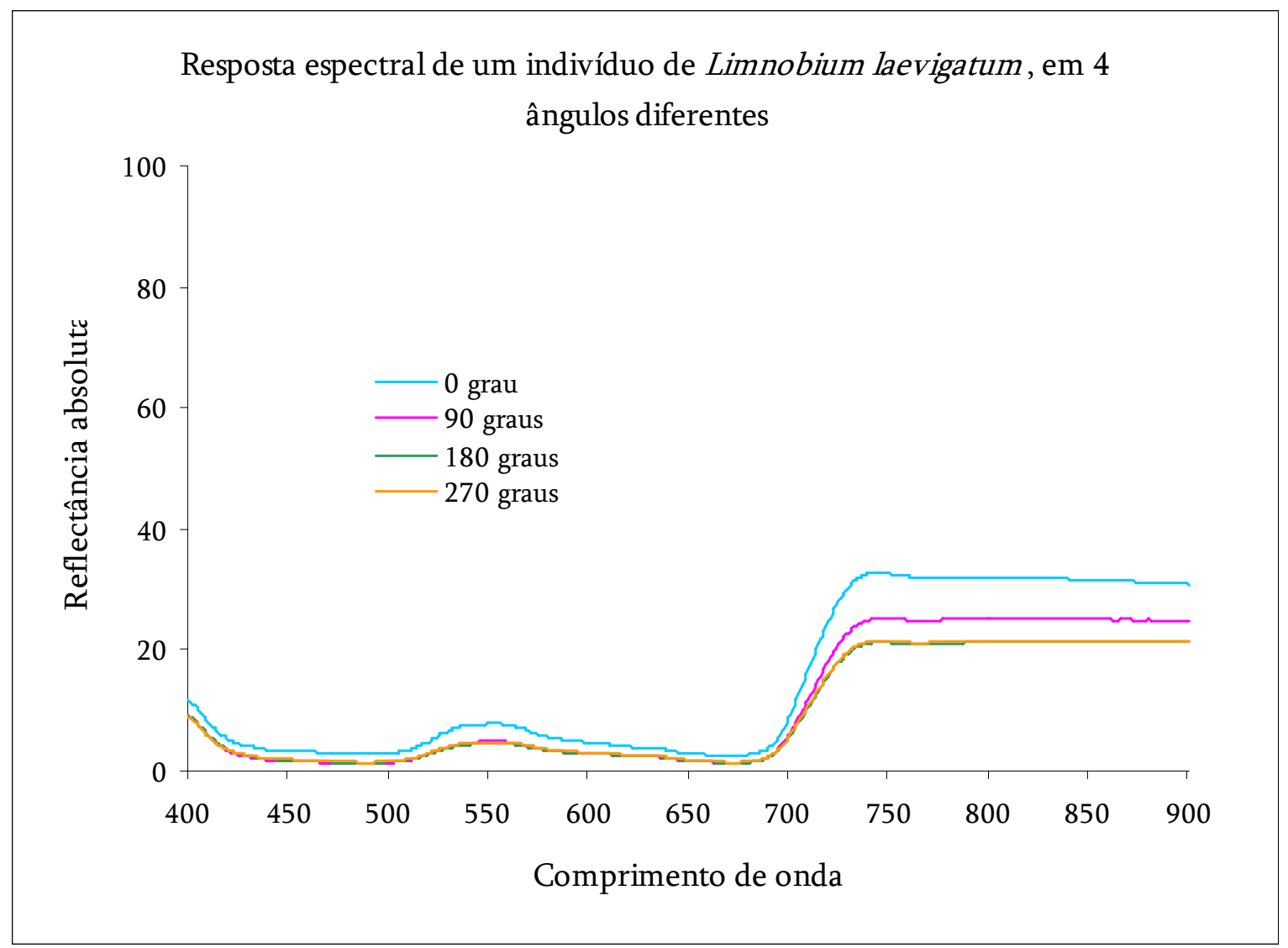

Figura II.26: Resposta espectral de Limnobium laevigatum, medida a partir de um mesmo indivíduo, em quatro ângulos diferentes. 


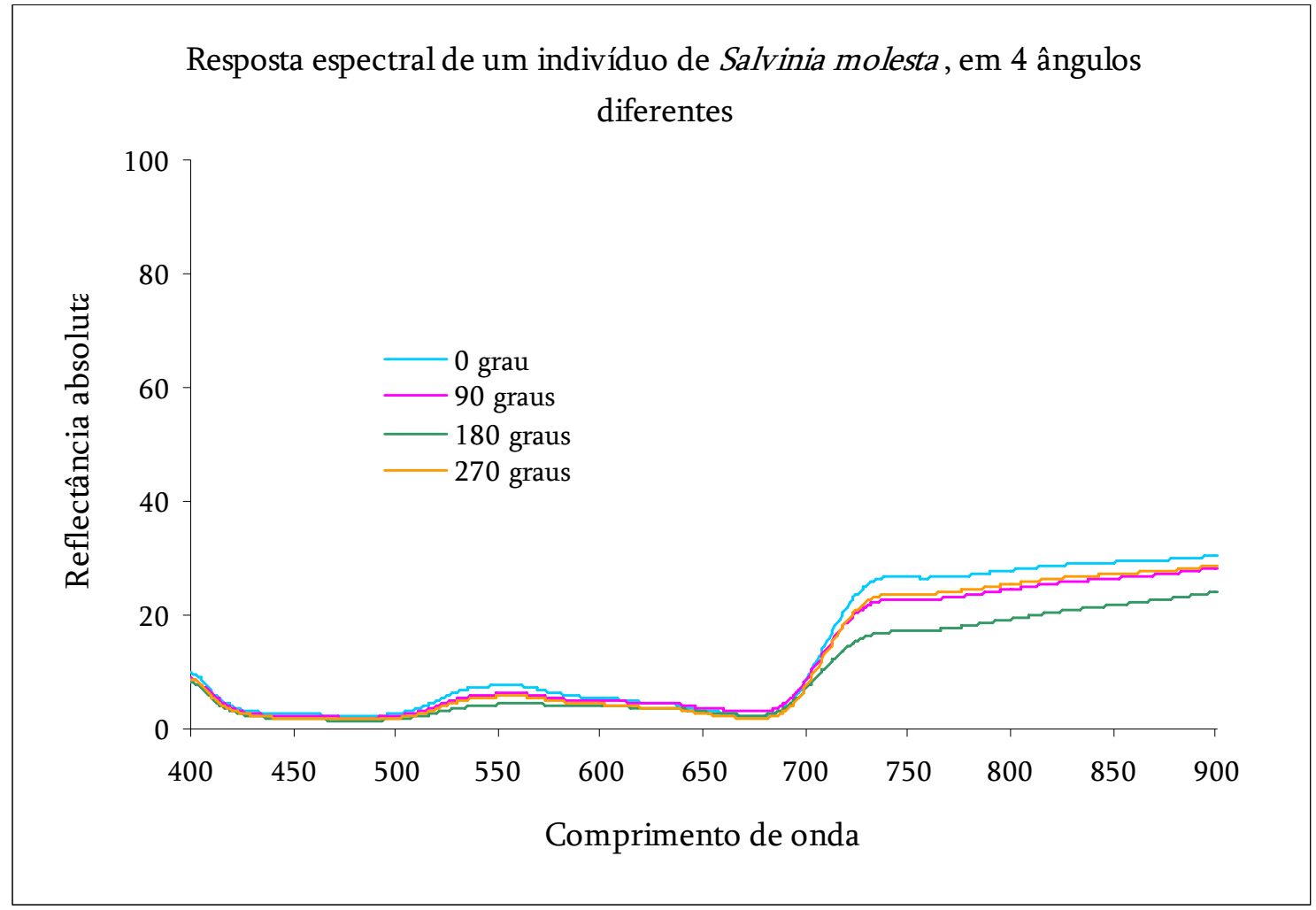

Figura II.27: Resposta espectral de Salvinia molesta, medida a partir de um mesmo grupo de indivíduos, em quatro ângulos diferentes.

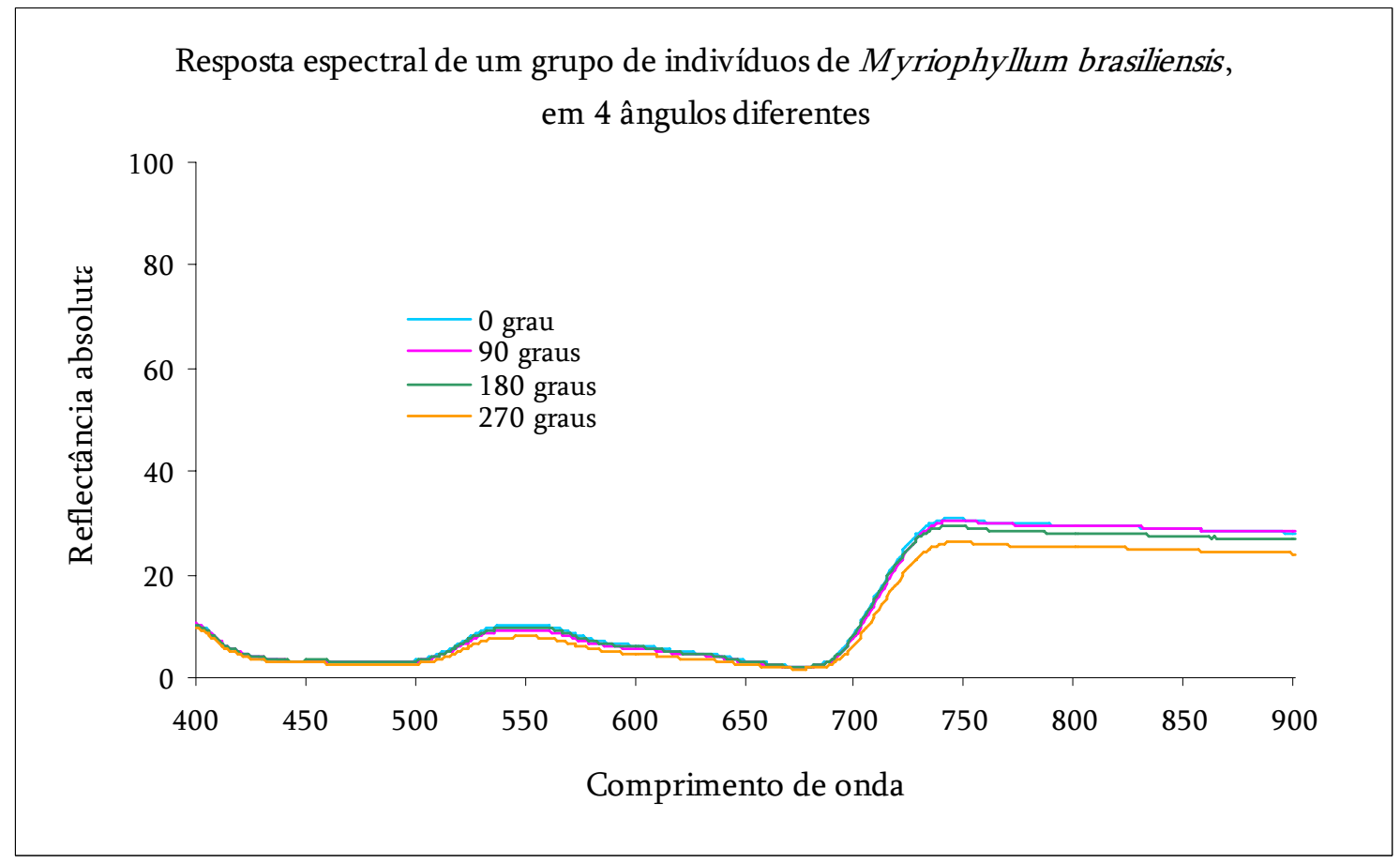

Figura II.28: Resposta espectral de Myriophyllum brasiliense, vista de cima, em quatro ângulos diferentes. 


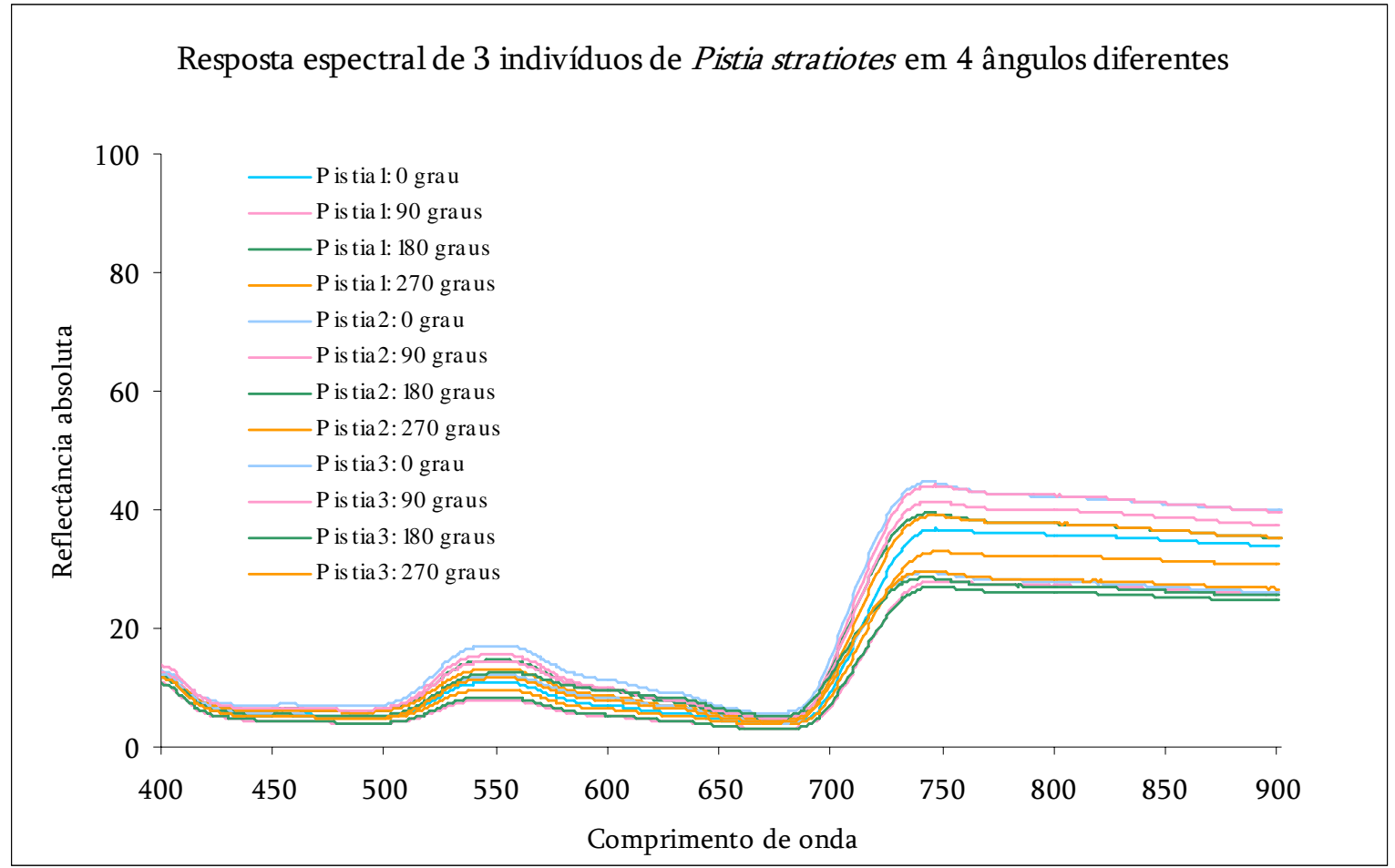

Figura II.29: Resposta espectral de Pistia stratiotes, medida a partir de três indivíduos, em quatro ângulos diferentes.

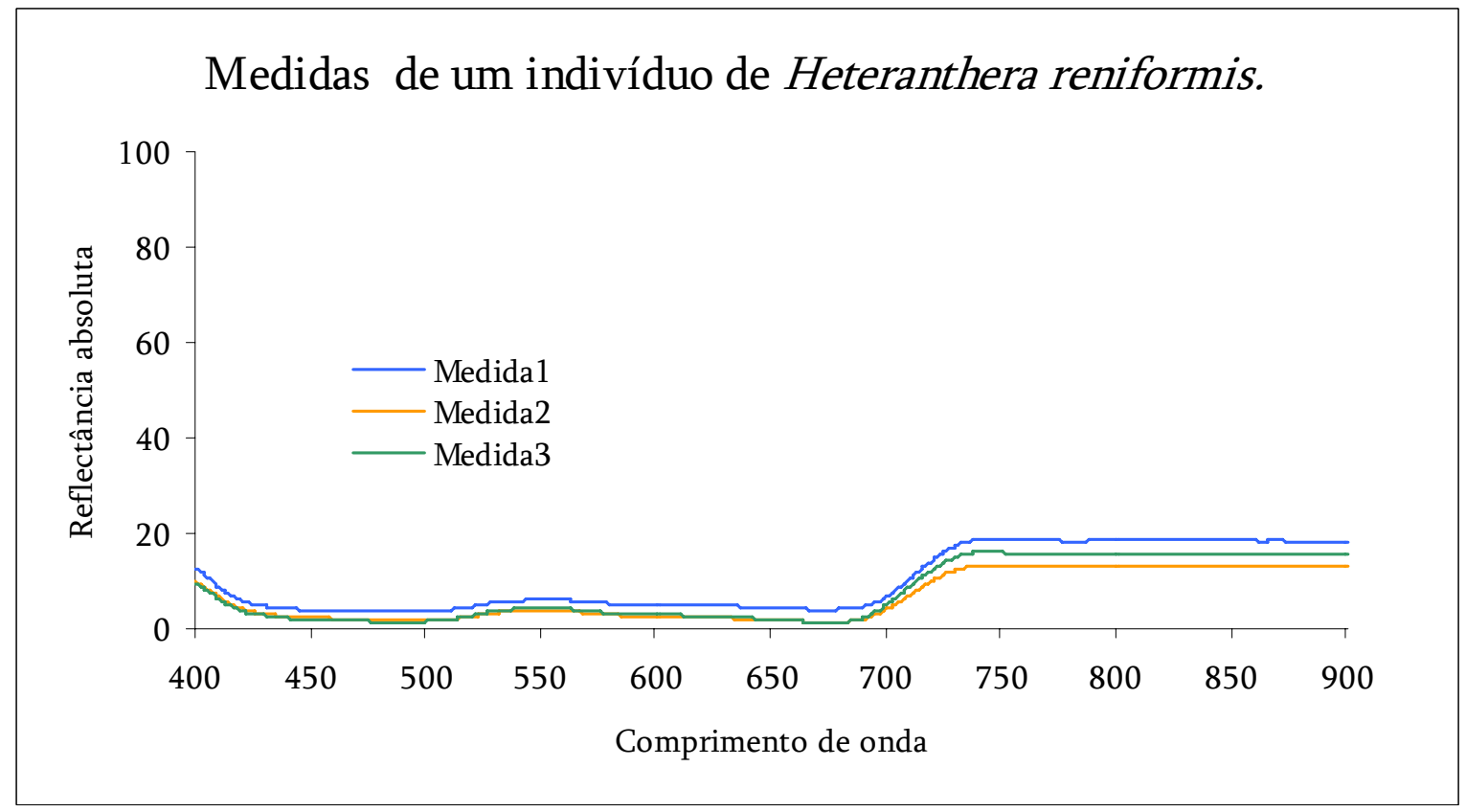

Figura II.30: Resposta espectral de Heteranthera reniformis, medida a partir de um mesmo indivíduo, em três diferentes posições. 


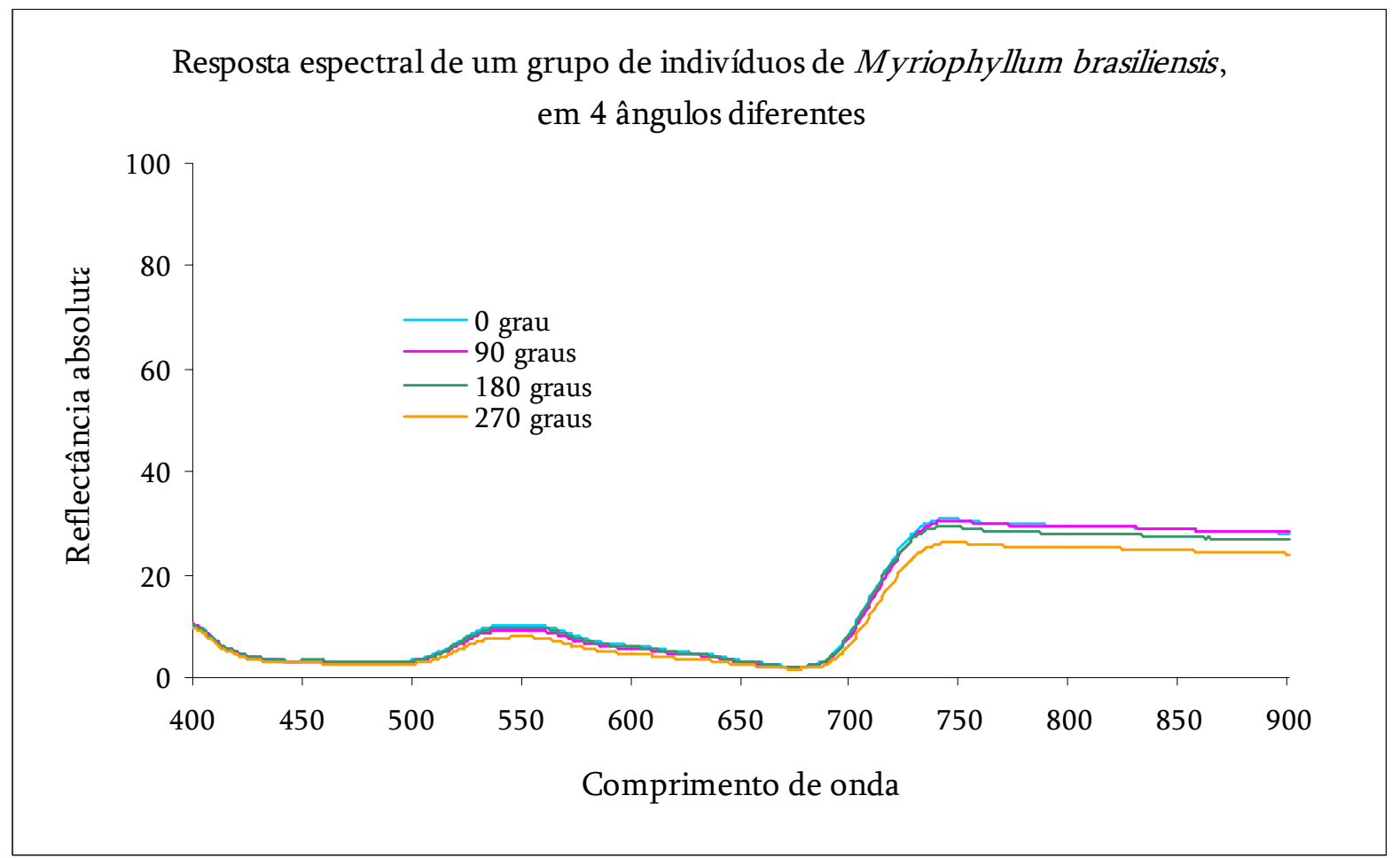

Figura II.31: Reflectância Absoluta de um grupo de indivíduos de Myriophyllum brasiliense. 


\section{CAPÍTULO III - ESTUDO DO ESTRESSE HÍDRICO DE FOLHAS DE MACRÓFITAS QUANDO SUBMETIDAS}

A EXPERIMENTOS DE LABORATÓRIO.

\section{III.1 - INTRODUÇÃO}

A resposta espectral típica de uma espécie vegetal pode exibir variações em função de diferentes fatores, incluindo estresses hídricos, nutricionais e luminosos (Smith et al. 1998). Carter (1993) estudou a reflectância de folhas em função de diferentes tipos de estresse, incluindo senescência e desidratação. Intervalos de comprimentos de onda foram selecionados onde se encontrou diferenças significantes na reflectância entre as folhas saudáveis e as submetidas a estresse. No caso de senescência o intervalo foi de 498-715 e no caso da desidratação os intervalos foram de 506-519 e 571-708.

Um outro experimento mostra a importância dos espaços aéreos na resposta espectral. DeLucia et al. (1996) fizeram um experimento no qual óleo mineral foi infiltrado no espaço intercelular de folhas (Figura III.1) com o objetivo de investigar a contribuição da reflectância da luz intercelular na fotossíntese. Pela figura pode-se observar que quando o óleo foi infiltrado na folha, preenchendo os espaços aéreos do parênquima esponjoso, a reflectância teve redução na região do visível e especialmente no IVP. No mesmo artigo foi realizada a comparação entre folhas de sombra e de sol, as quais mostraram também uma grande diferença da reflectância especialmente no IVP. 


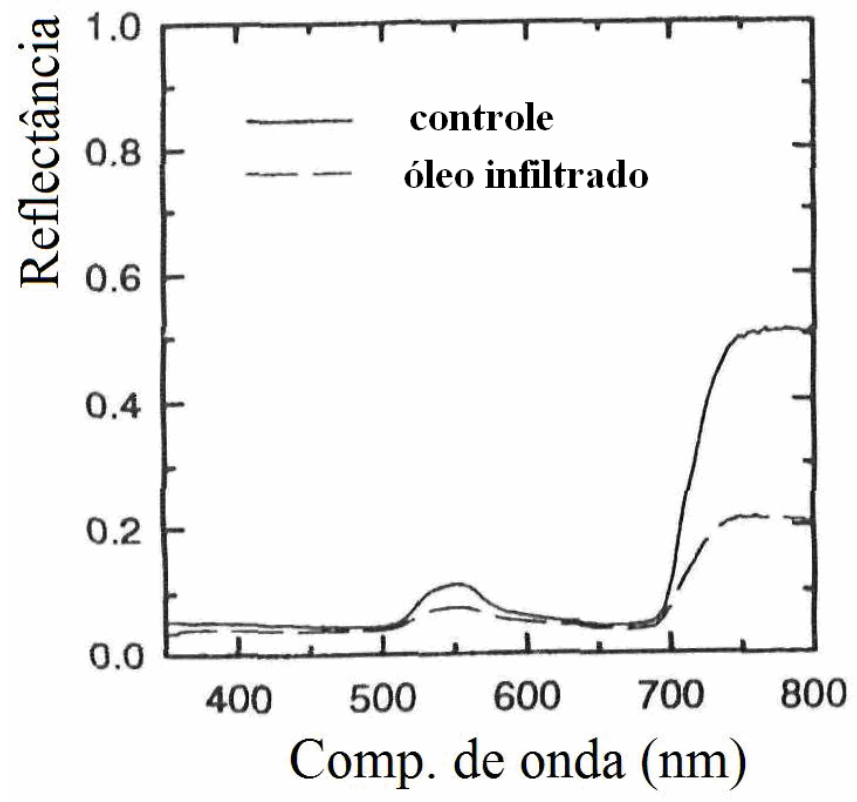

Figura III.1: Espectro de reflectância da superfície adaxial de Hitydrophyllym canadetise. Cada linha representa a media de 3-5 espectros, com coeficiente de variação menos que 5\%. (In: Delucia et al. 1996).

A resposta espectral depende também do arranjo dos elementos na área de visada. Por exemplo, em relação à cobertura de folhas por área de corpo d’ água, Jakubauskas et al. (2000) mostraram que quanto maior a cobertura de folhas de macrófitas por área, maior é a reflectância.

Os experimentos realizados em laboratório submetem as folhas a um estresse principalmente hídrico. O dessecamento das folhas durante as medições também podem interferir, principalmente na resposta na região do IVP (Turrel 1936, Gausman et al. 1969).

O objetivo desse capítulo foi o de verificar possíveis interferências do dessecamento nos resultados espectroradiométricos obtidos em laboratório. 


\section{III.2 - PROCEDIMENTOS METODOLÓGICOS}

As espécies utilizadas neste experimento foram Eichhornia crassipes, Heteranthera reniformis, Nimphea mexicana e Limnobium laevigatum. Os cortes dos pecíolos foram feitos o mais próximo possível às raízes e as folhas foram mantidas na sombra nos períodos em que não estavam sendo realizadas medidas. As medidas foram realizadas com a lâmpada de 1000 W (tungstênio-halógena) a 160 cm (altura) e 80 cm (distância horizontal) do alvo, e inclinada em 45 graus. A fibra óptica utilizada foi de $200 \mu \mathrm{m}$, e as medidas foram realizadas aproximadamente na área central do limbo foliar.

Devido ao calor provocado pela emissão de luz da lâmpada de $1000 \mathrm{~W}$, ela foi acesa apenas para a tomada de medidas, respeitando um tempo de estabilização da lâmpada de aproximadamente 10 segundos a cada vez que era ligada. Deve ser observado que nesse caso pode ter havido pequenas variações na área de visada e na interferência da reflexão especular, a cada medida. Desse modo, pequenas variações na reflectância espectral da mesma folha eram esperadas entre uma medida e outra.

As medidas das folhas maiores foram feitas a $5 \mathrm{~cm}$ de distância e das folhas menores foram feitas a 2 cm de distância do alvo. 


\section{III.3 - RESULTADOS E DISCUSSÕES}

Em relação ao estudo sobre dessecação, os resultados obtidos podem ser observados nas Figuras a seguir.

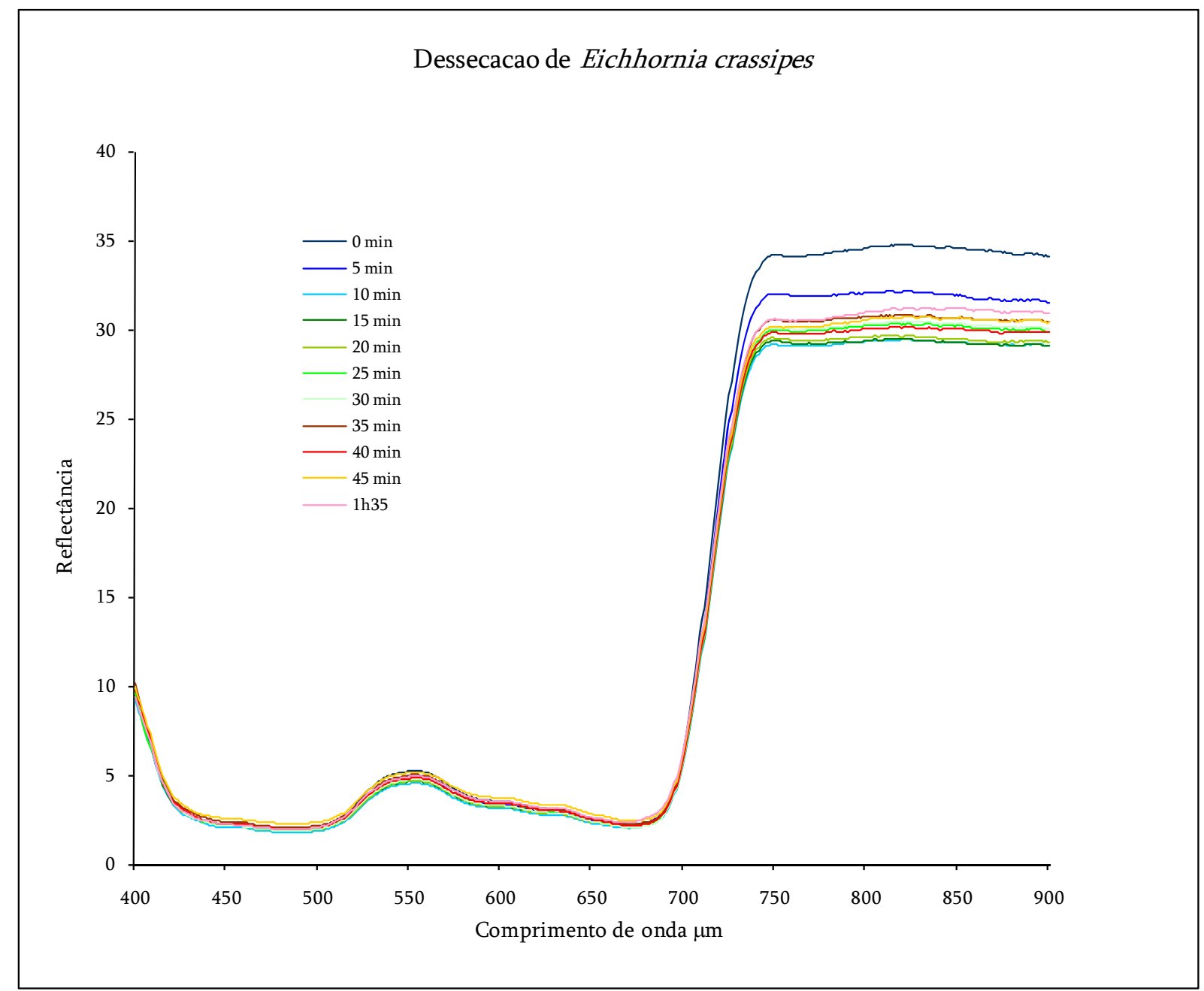

Figura III.1: Respostas espectrais referentes ao experimento de dessecação de Eichhornia crassipes.

Apesar de ter sido notada uma diminuição da resposta na faixa do IVP, entre 0 e 10 min, após esse período a resposta obtida não foi proporcional à diminuição da reflectância no IVP para Eichhornia crassipes. 


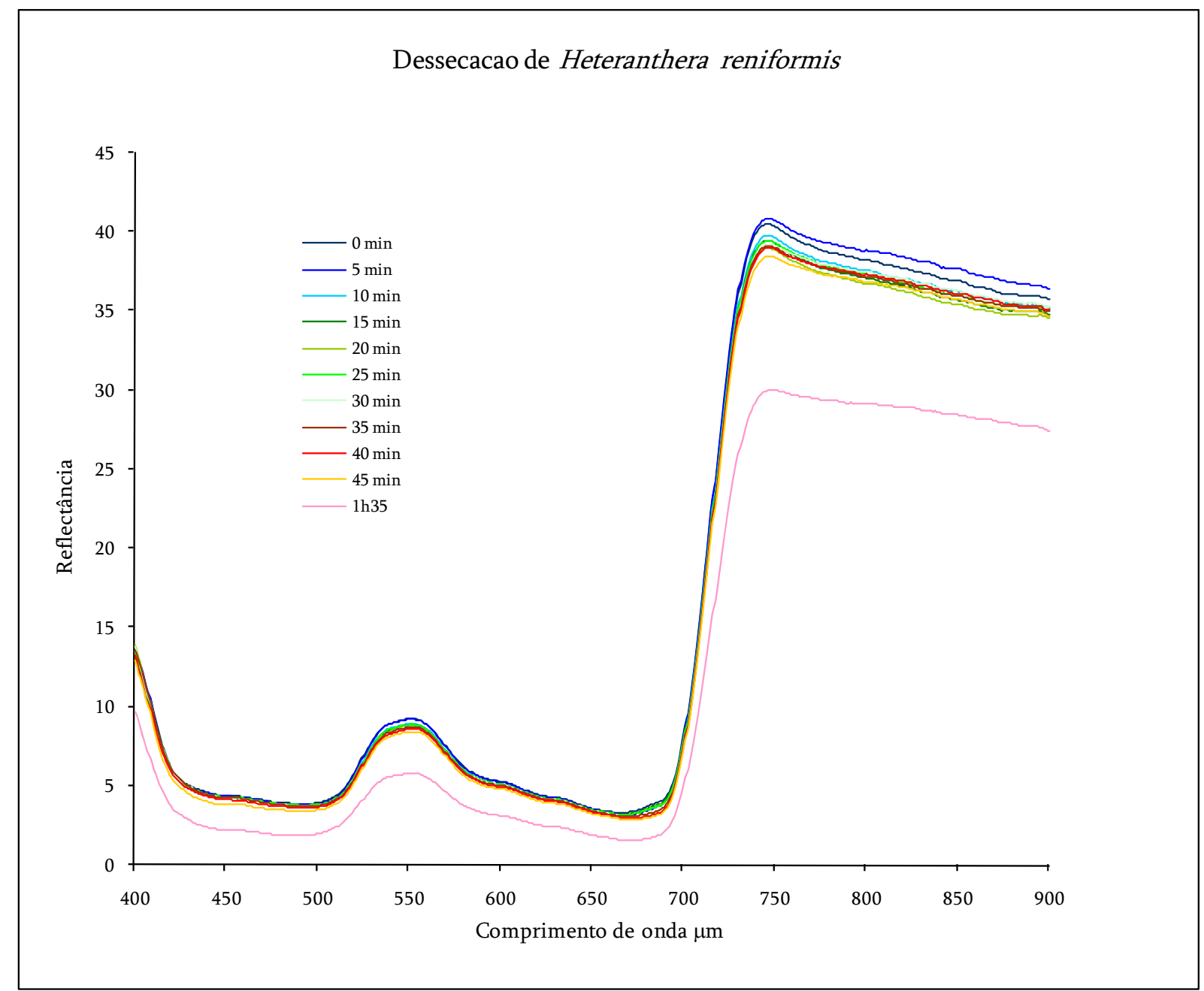

Figura III.2: Respostas espectrais referentes ao experimento de dessecação de Heteranthera reniformis.

Nesse caso (Fig. III.2) nota-se uma grande variação na resposta espectral após 1 hora e 35 minutos do corte da folha, ao longo de todo o espectro, não havendo variações proporcionais à diminuição da reflectância entre 0 e 45 minutos. 


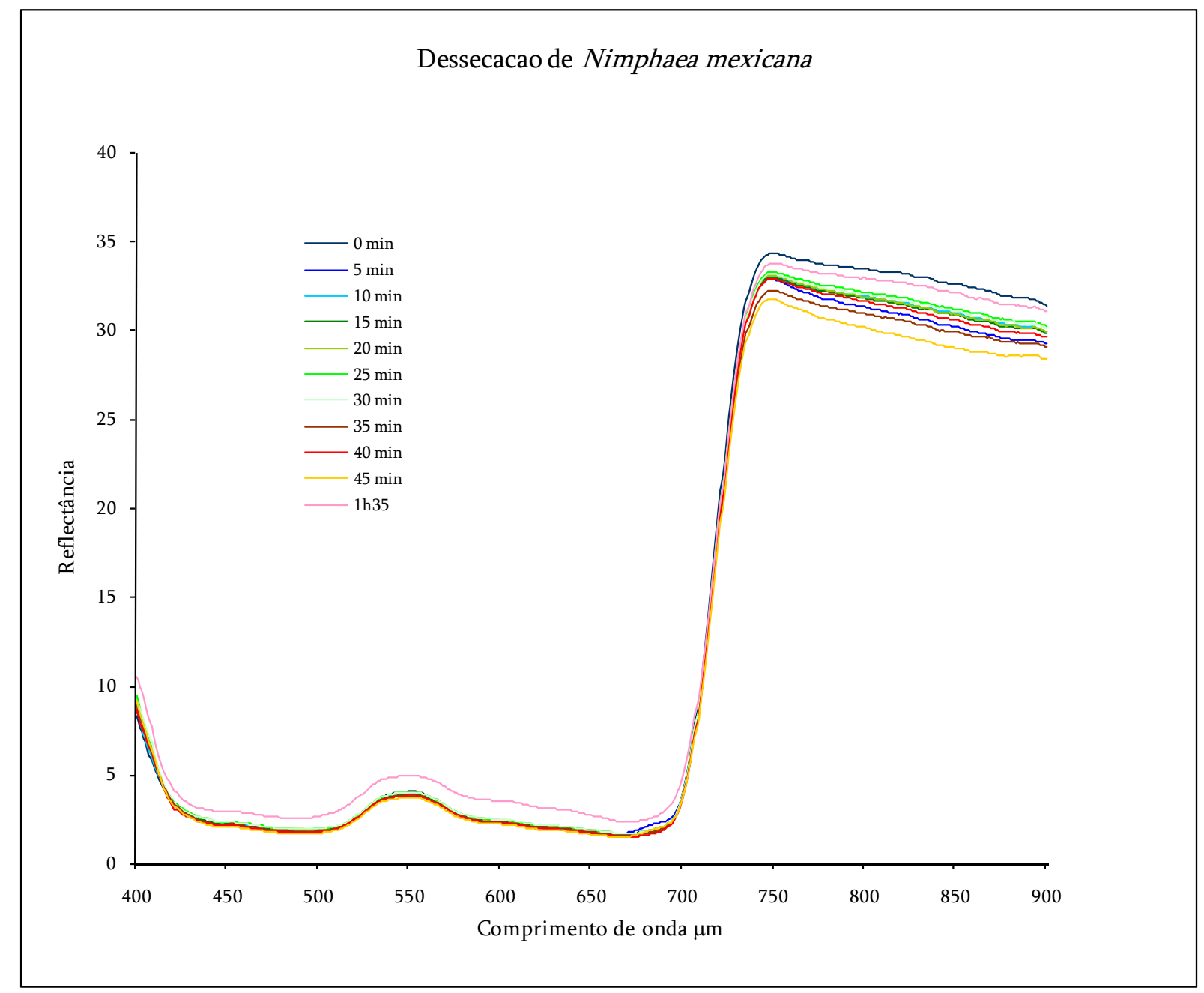

Figura III.3: Respostas espectrais referentes ao experimento de dessecação de Nymphaea mexicana.

Nymphaea mexicana não mostrou diminuição proporcional da reflectância em função do aumento do tempo de dessecação. Pode-se notar, no entanto, valores maiores de reflectância na faixa do visível, após 1 hora e 35 minutos, o que não pode ser considerado padrão para a espécie, já que não foram realizados outros experimentos para diagnosticar essa variação. O mesmo vale para Ei. crassipes. 


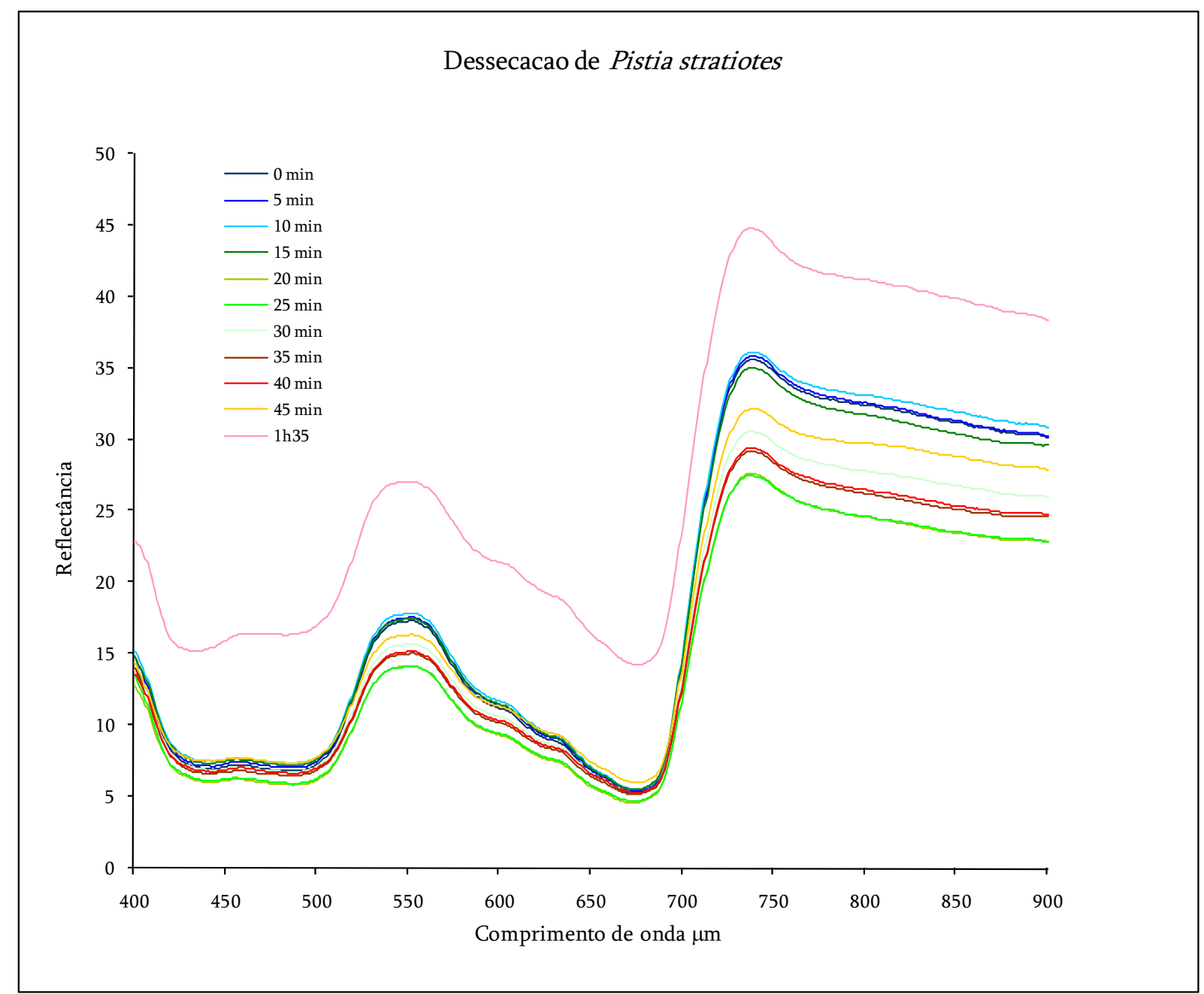

Figura III.4: Respostas espectrais referentes ao experimento de dessecação de Pistia stratiotes.

Como no caso anterior, Pistia stratiotes mostrou um aumento da reflectância na faixa do Visível, mas agora também no IVP, após 1 hora e 35 minutos. Também não seria possível afirmar que esse é um padrão da espécie. 


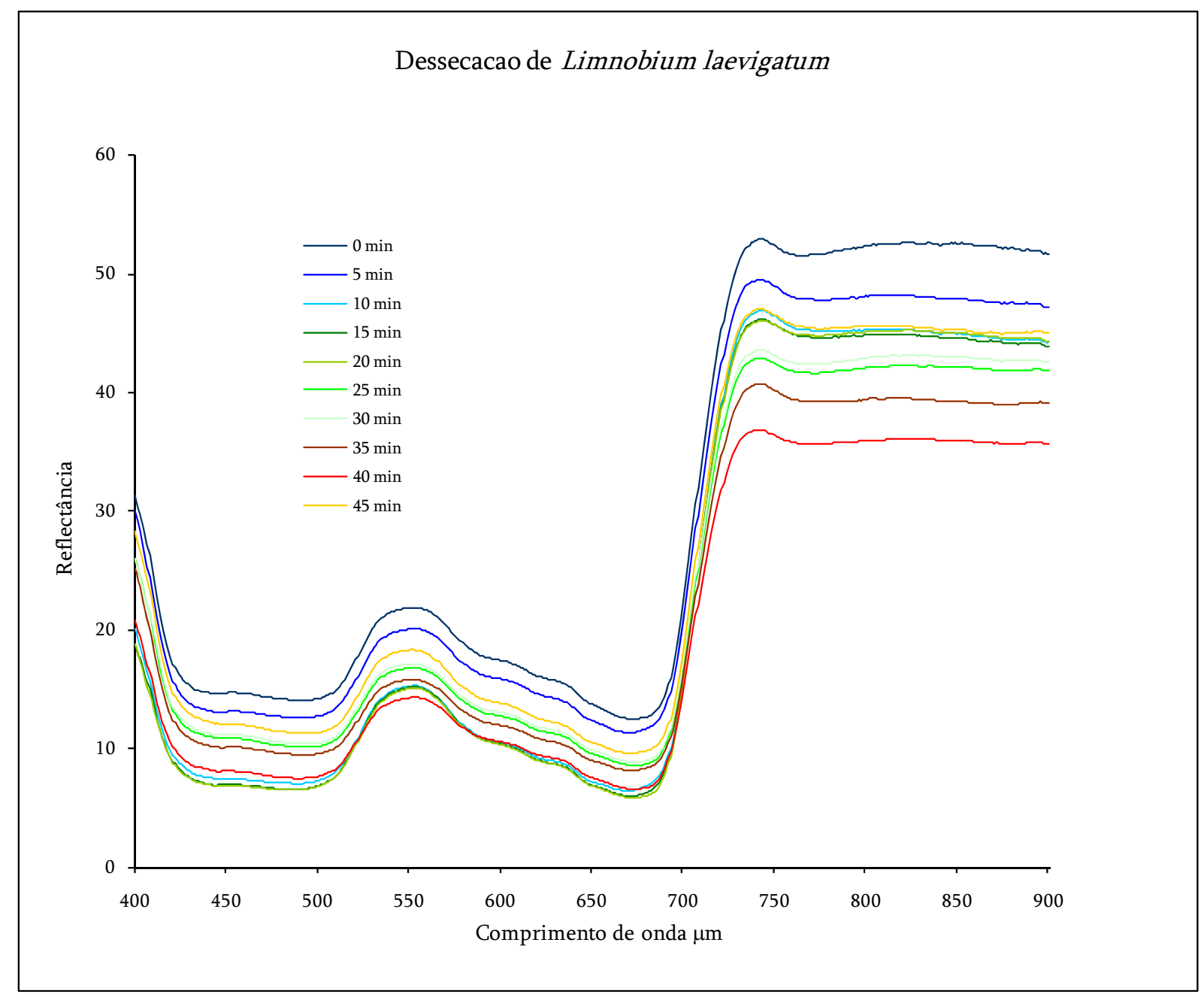

Figura III.5: Respostas espectrais referentes ao experimento de dessecação de Limnobium laevigatum mantida fora d'água.

Para L. laevigatum pode-se notar a diminuição da reflectância com o aumento do tempode dessecamento, com exceção das medidas para 25 e 45 minutos. Nesse caso, pode-se afirmar que há influência da dessecação na resposta espectral ao longo do tempo. 


\section{4 - CONCLUSÕES}

Em relação a essa tese os experimentos mostraram que o tempo de realização das medidas tomadas não comprometeu os resultados obtidos referentes às respostas espectrais.

Os resultados relativos à dessecação das espécies analisadas em laboratório mostraram a necessidade de maiores estudos sobre dessecação de espécies de macrófitas, se possível estudos diferenciados para cada uma das espécies. Entretanto,. 
CAPÍTULO IV - DISTINÇÃO ENTRE ESPÉCIES DE MACRÓFITAS ATRAVÉS DO ESTUDO DE SUAS

RESPOSTAS ESPECTRAIS.

IV. 1 - INTRODUÇÃO

Uma das razões de se estudar a resposta espectral de alvos terrestres é formar uma base sólida de conhecimento para a análise destes mesmos alvos em imagens orbitais. No caso das macrófitas, a importância de se diferenciar espécies vem de encontro às necessidades atuais relacionadas principalmente ao consumo energético e saneamento básico, que são prejudicados quando da infestação dessas plantas. A diferenciação de espécies nesses casos possibilita o melhor controle das infestações, já que para cada uma, tanto o controle (principalmente o biológico (Mendes et al. 2004)) como a densidade (Thomaz e Bini 2003), variam conforme a espécie. A análise das respostas espectrais das espécies pode indicar por quais descritores é possível diferenciá-las.

Em análises com imagens orbitais, o descritor mais importante pode ser a intensidade da reflectância, que varia muito principalmente entre as faixas do Vermelho e do IVP, em função especialmente de suas características pigmentares e anatômicas, respectivamente. Mas este não é o único descritor, especialmente se forem considerados os sensores hiperspectrais. Num futuro próximo espera-se que os sensores hiperspectrais atuem com detectores de maior resolução espacial, que propiciarão uma melhor 
delimitação do alvo de estudo. Assim, outros descritores dever ser estudados para comparar matematicamente as respostas espectrais, tais como os picos de intensidade em cada faixa, a Posição do Limite Vermelho e os Índices entre faixas.

Os picos de intensidade são os pontos de inflexão da curva espectroradiométrica de cada espécie, que ocorrem em função das características da vegetação mencionadas nos capítulos anteriores. Já o Limite Vermelho é encontrado na região entre as faixas do Vermelho e do IVP.

A região onde ocorre a principal inversão na intensidade da reflectância está situada entre a região do Vermelho e do IVP e um descritor que tem sido cada vez mais utilizado para delimitá-la é o chamado Limite Vermelho, mais conhecido como "Red edge" (Dawson e Curran 1988, Curran et al. 1991, Clevers 1999 e 2001, Baranoski e Rokne, 2005) ou “Red edge position”(REP). A posição do Limite Vermelho é definida como a posição do ponto de inflexão máximo na curva do vermelho ao IVP. Essa posição é chamada de Índice do Limite Vermelho e pode auxiliar a agrupar ou diferenciar espécies de plantas através de seus pontos típicos de inversão nessa região. Curran et al. (1991) verificaram que o Limite Vermelho varia em função da concentração e tipo de pigmentos na folha. Recentemente, em 2005, Baranoski e Rokne publicaram um artigo mostrando os diferentes modos de se calcular o Limite Vermelho, dois dos quais foram aplicados nesta tese. Em 2006, Cho e Skidmore publicaram um artigo onde mostram ainda um outro modo de calcular o Limite Vermelho. 
Os outros descritores são os índices de diferenças normalizadas entre faixas espectrais definidas. Em Lillesand e Kieffer (2000) encontra-se uma breve explanação de como índices entre faixas podem auxiliar na análise e compreensão de espectros radiométricos. Índices entre faixas são comuns no estudo de vegetação. A normalização dos dados coloca-os numa mesma escala, gerando resultados comparáveis em qualquer situação, pois variam sempre de -1 a 1 . O Índice de Vegetação com Diferença Normalizada (IVDN), por exemplo, é gerado a partir da normalização entre a diferença das respostas espectrais no Vermelho e no IVP.

Alguns estudos sobre a distinção de espécies já foram realizados, como o de Price, em 1994, que discutiu a possibilidade de assinaturas espectrais permitirem discriminar alvos, reconhecendo as dificuldades envolvidas nesses estudos especialmente no caso de sensores orbitais. Fyfe (2003), também buscando identificar espécies através de suas respostas espectrais, tentou distinguir espectralmente diversas espécies de macroalgas marinhas, chegando à conclusão de que isso é possível, em determinadas faixas do espectro e utilizando sensores hiper-espectrais. Entretanto, como mencionado anteriormente, não foram encontrados estudos sobre a distinção espectral de macrófitas.

Assim, o objetivo deste Capítulo é analisar matematicamente os espectros obtidos para as espécies de macrófitas, buscando os melhores descritores para diferenciá-las. Foram utilizados quatro descritores para essa análise, que são: a intensidade média na faixa 
espectral, os pontos de inversão em cada faixa, o ponto do Limite Vermelho (explicações ainda neste capítulo) e Índices entre faixas.

\section{IV.2 - PROCEDIMENTOS METODOLÓGICOS}

As respostas espectrais das espécies foram obtidas conforme visto no Capítulo II. Os dados foram utilizados para calcular: a intensidade média na faixa espectral, os pontos de inversão em cada faixa, o ponto do Limite Vermelho (explicações ainda neste capítulo) e os índices normalizados entre as faixas de interesse. Os procedimentos para realizar as análises individuais encontram-se a seguir. Análises estatísticas foram realizadas para verificar se as diferenças encontradas são significativas.

As respostas espectrais obtidas foram agrupadas em faixas espectrais correspondentes àquelas encontradas nos satélites LANDSAT-5 e 7, CBERS-2 e IKONOS2, SPOT, ALOS, de modo que possam ser úteis em estudos com sensores multiespectrais. São elas:

Azul: $450-520 \mathrm{~nm}$

Verde: 520 - $590 \mathrm{~nm}$

Vermelho: $630-690 \mathrm{~nm}$

Infravermelho Próximo (IVP): 770 - 790 nm 
IV.2.1 - Intensidade média nas Faixas espectrais de interesse

Foi calculada a Reflectância Absoluta Média das folhas das macrófitas nos intervalos correspondentes às faixas espectrais do Visível (Azul, Verde e Vermelho) e Infravermelho próximo (IVP).

Foi medida a Reflectância de cada uma das 10 folhas, pertencentes a 10 indivíduos diferentes, de cada espécie estudada. Para a medida de intensidade foi utilizado o valor médio das 10 folhas nas Faixas espectrais citadas. Na impossibilidade de realizar as medidas para 10 folhas, foram feitas as medidas para o número de folhas disponíveis.

IV.2.2 - Comprimentos de onda nos picos de reflectância dentro das faixas

Os pontos de inflexão (picos) das curvas médias das folhas foram detectados dentro dos intervalos de faixas espectrais mencionados anteriormente. Também foram analisados os picos de reflectância na região conhecida como Red Edge, que se refere a 690 - 770 nm.

Foram calculados os picos para cada folha e em seguida a média dos picos para as folhas amostradas, sendo esse valor considerado o representativo para a espécie. 
IV.2.3 - Posição do Limite Vermelho ou REP (Red Edge Position)

O Limite Vermelho foi calculado segundo dois procedimentos diferentes: pelo Método Linear de (Guyot e Baret1988 apud Clevers et al. 2001), e pela análise da primeira derivada da curva de Reflectância, de modo que pudesse ser verificado se haveria variação de resultados entre ambos.

Segundo Clevers et al. (2001), o método de interpolação linear descrito assume que a curva espectral no Limite Vermelho pode ser simplificada a uma linha centrada em um ponto médio entre a reflectância no IVP (cerca de $780 \mathrm{~nm}$ ) e a reflectância mínima na faixa de absorção da clorofila (em torno de $670 \mathrm{~nm}$ ). O valor de reflectância no ponto de inflexão ou no Red edge position ( $\left.\mathrm{R}_{\mathrm{REP}}\right)$ pode ser estimado pela seguinte equação:

$R_{R E P}=\left(R_{670}+R_{780}\right) / 2$

Para encontrar o comprimento de onda correspondente ao valor de reflectância no ponto de inflexão, é utilizado um método linear de interpolação, descrito como se segue:

$$
R E P=700+40 \bullet\left(\left(R_{R E P}-R_{700}\right) /\left(R_{740}-R_{700}\right)\right)
$$

onde $\mathrm{R}_{670}, \mathrm{R}_{700}, \mathrm{R}_{740}$ e $\mathrm{R}_{780}$ são os valores de reflectância nos comprimentos de onda 670 , 700, 740 e $780 \mathrm{~nm}$, respectivamente, e as constantes 700 e 40 são resultantes da interpolação no intervalo 700 a $740 \mathrm{~nm}$. 
Um outro método de calcular o Limite Vermelho (Baranoski e Rokne 2005) é através do uso do valor máximo da curva de primeira derivada do espectro de reflectância na região do Limite Vermelho. Quando o valor da derivada é máximo, tem-se o ponto de máxima modificação na orientação da curva espectral.

IV.2.4 - Índices entre faixas

Foram calculados diferentes possíveis Índices de diferença normalizada entre diferentes faixas, seguindo a fórmula:

Índice $=\frac{\text { FaixaA }- \text { FaixaB }}{\text { FaixaA }+ \text { FaixaB }}$

Assim, os índices incluídos na análise apresentam as seguintes fórmulas:

$$
\begin{aligned}
& \text { IVP e Azul }=\frac{\text { Faixa4 }- \text { Faixa } 1}{\text { Faixa4 }+ \text { Faixa1 }} \\
& \text { Verde-Azul }=\frac{\text { Faixa } 2-\text { Faixa1 }}{\text { Faixa } 2+\text { Faixa1 }} \\
& \text { IVP e Verde }=\frac{\text { Faixa } 4-\text { Faixa2 }}{\text { Faixa4 }+ \text { Faixa2 }}
\end{aligned}
$$

Vermelho e Verde $=\frac{\text { Faixa } 3-\text { Faixa2 }}{\text { Faixa3 }+ \text { Faixa2 }}$

IVP e Vermelho $=\frac{\text { Faixa } 4-\text { Faixa3 }}{\text { Faixa } 4+\text { Faixa3 }}$

onde Faixa 1 = Azul, Faixa $2=$ Verde, Faixa $3=$ Vermelho, Faixa $4=$ IVP 


\section{IV.3 - RESULTADOS E DiSCUSSÕES}

Na Tabela IV.1 constam os valores do teste F obtido pela análise de variância ANOVA para as respostas espectrais das espécies analisadas dentro dos intervalos de comprimento de onda : Azul, Verde, Vermelho e IVP. Ao todo, para cada uma das doze espécies, foram 71 valores de reflectância no Azul, 70 no Verde, 61 no Vermelho e 121 no IVP,

Tabela IV.1: Resultados da análise de variância (nível de significância $=0,05$ ) entre os grupos de macrófitas, para as faixas de comprimento de onda Azul, Verde, Vermelho e IVP. Podem ser observados os valores do teste F experimental e do F crítico.

\begin{tabular}{|l|l|l|}
\cline { 2 - 3 } \multicolumn{1}{c|}{} & $F$ & F crítico \\
\hline Azul & 380,60 & 1,80 \\
\hline Verde & 683,11 & 1,80 \\
\hline Vermelho & 402,71 & 1,80 \\
\hline IVP & 18015,38 & 1,79 \\
\hline
\end{tabular}

Observando os valores de F em relação ao Fcrítico pode-se afirmar que em todas as faixas de comprimento de onda é possível diferenciar as espécies através dos valores intercalados dentro das quatro Faixas utilizadas. Entretanto, dentre elas é a faixa do IVP que possibilita melhor distinção entre as espécies. 
IV.3.1 - Intensidade média nas Faixas Espectrais de interesse

Na Figura IV.1 se encontram os valores da intensidade da média de Reflectância Absoluta para as macrófitas estudadas em função da faixa espectral. Esses valores foram calculados a partir dos dados de reflectância dentro das faixas espectrais de interesse.

No IVP a maior diferença foi entre L. laevigatum e Salvinia molesta, esta última tendo o menor valor observado para essa faixa. Analisando agora apenas as espécies com valor de Reflectância no IVP menor que de L. laevigatum, temos que Pistia stratiotes, Eichhornia crassipes e Nimphea mexicana apresentam valores semelhantes na média, nesta faixa de comprimento de onda. 


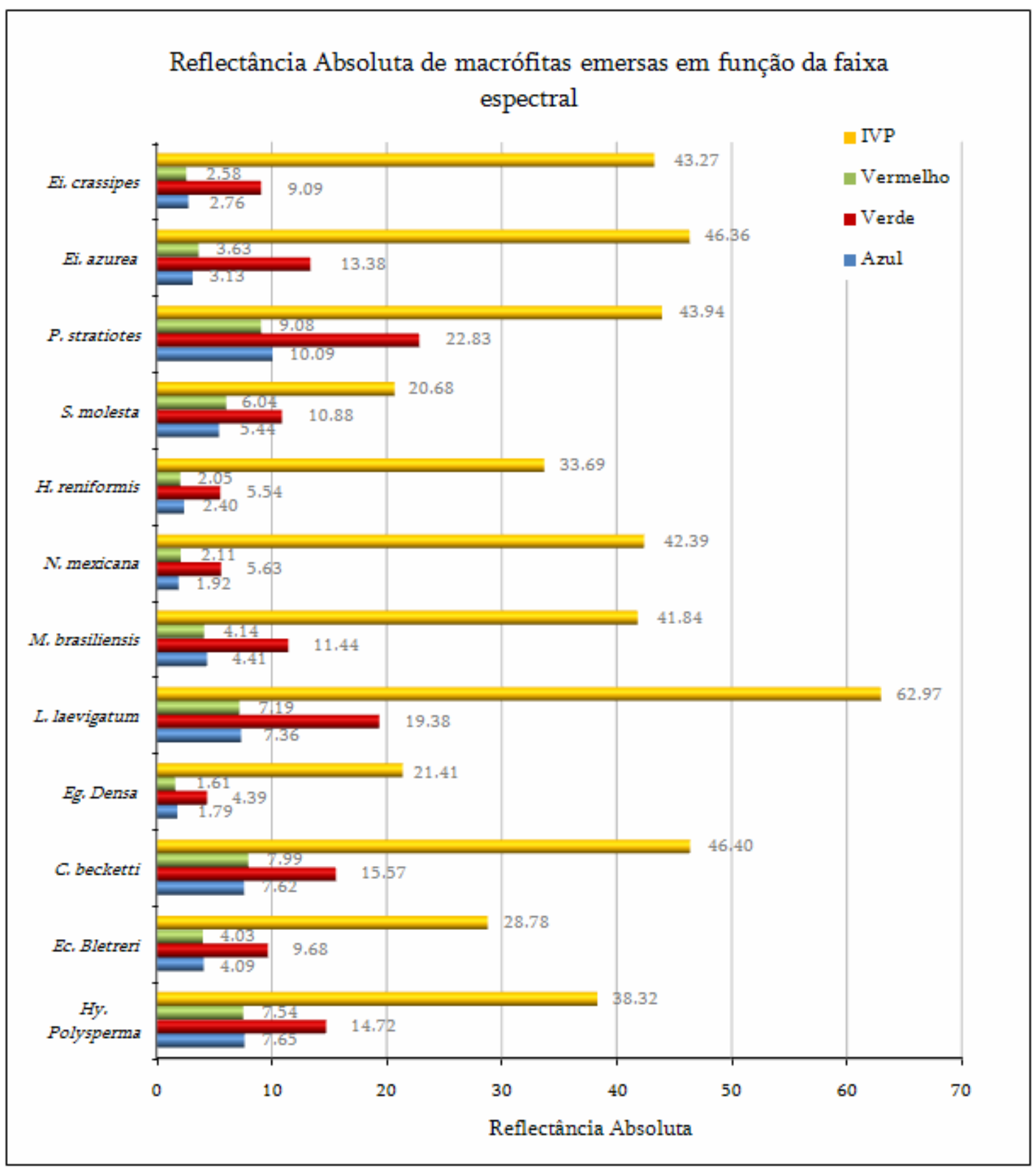

Figura IV.1: Reflectância absoluta de espécies de macrófitas dentro da faixa espectral. As espécies analisadas foram: Eichhornia crassipes, Eichhornia azurea, Pistia stratiotes, Salvinia molesta, Hetheranthera reniformis, Nimphea mexicana, Myriophyllum brasiliense, Limnobium laevigatum, Egeria densa, Cryptocoryne beckettii, Echinodorus bleheri e Hygrophila polysperma . 
Os dados também podem ser agrupados de modo a facilitar a comparação com resultados obtidos a partir de imagens de satélite (Figura IV.2).

\section{Reflectância média nas Faixas espectrais}

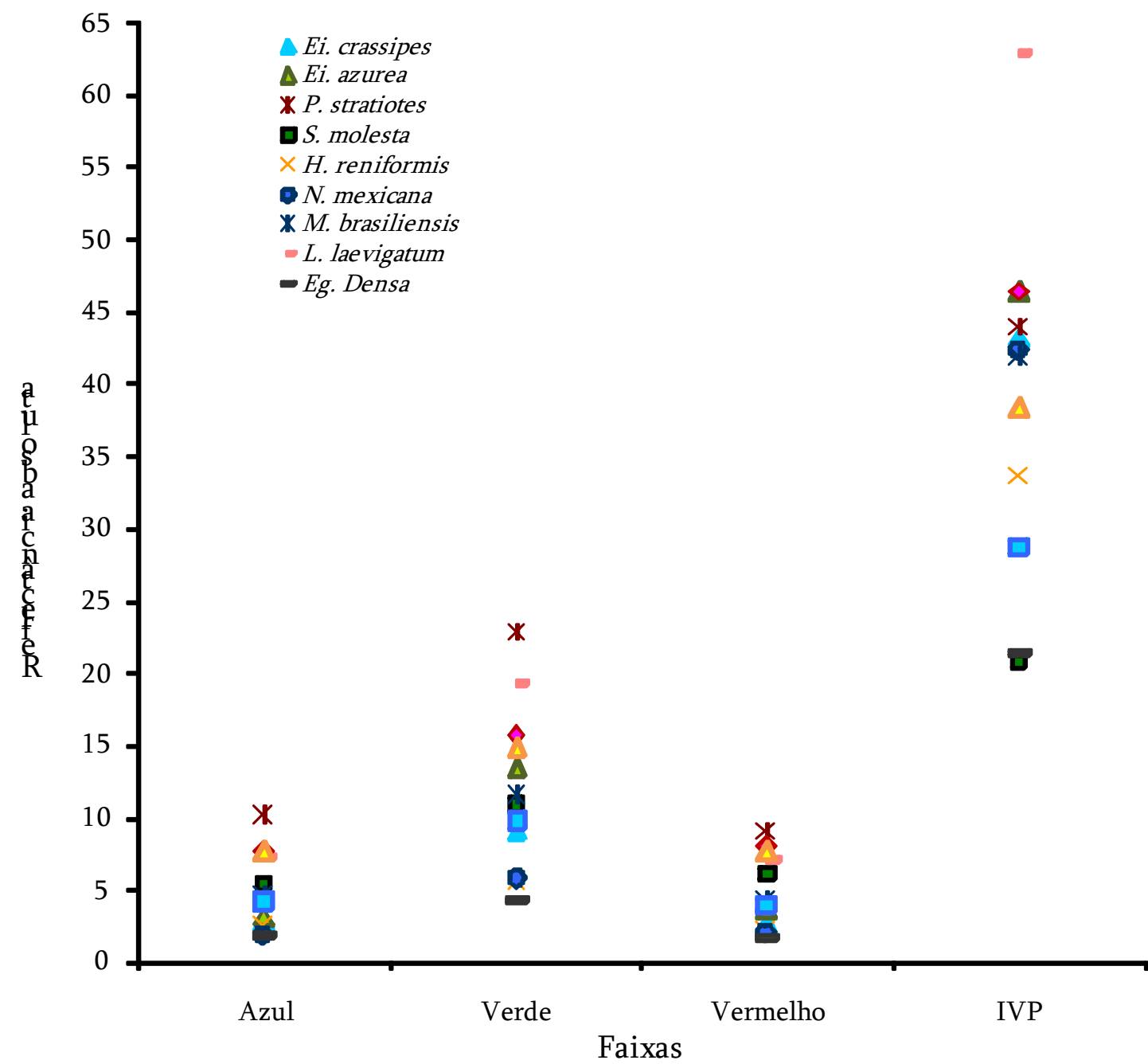

Figura IV.2: Reflectância média das espécies de macrófitas nas faixas espectrais correspondentes à obtida através do uso dos satélites CBERS-2, SPOT, IKONOS, ALOS e LANDSAT-5 e 7. As espécies analisadas foram: Eichhornia crassipes, Eichhornia azurea, Pistia stratiotes, Salvinia molesta, Hetheranthera reniformis, Nimphea mexicana, Myriophyllum brasiliense, Limnobium laevigatum, Egeria densa, Cryptocoryne beckettii, Echinodorus bleheri e Hygrophila polysperma . 
Com esses dados foi realizada a análise de variância ANOVA, com nível de significância 0,05, cujos resultados se encontram na Tabela IV.2.

Tabela IV.2: Resultado da ANOVA entre valores médios de reflectância das espécies analisadas.

\begin{tabular}{lccccc}
\hline Fonte da variação & $S Q$ & $M Q$ & $f$ & valor-P & fcrítico \\
\hline Entre grupos & 9592,63 & 3197,54 & 69,31 & 0,00 & 2,82 \\
Dentro dos grupos & 2030,03 & 46,14 & & & \\
Total & 11622,67 & & & & \\
\hline
\end{tabular}

SQ é a soma dos quadrados, MQ é a média dos Quadrados e fé obtido pela média dentro dos grupos, dividida pela média entre os grupos.

Sendo f maior que fcrítico, há portanto diferenças significativas entre os grupos, ou seja, a média das faixas auxilia a discriminar macrófitas. Observa-se que a Média dos Quadrados (MQ) entre os grupos é muito superior a MQ dentro dos grupos, indicando uma forte variância entre os grupos.

IV.3.2 - Comprimentos de onda nos Picos de Reflectância dentro das Faixas

Os picos de reflectância foram identificados nas Faixas espectrais de interesse, e então foram localizados os comprimentos de onda correspondentes a esses picos. Esses valores de comprimento de onda podem ser visualizados na Figura IV.3. 


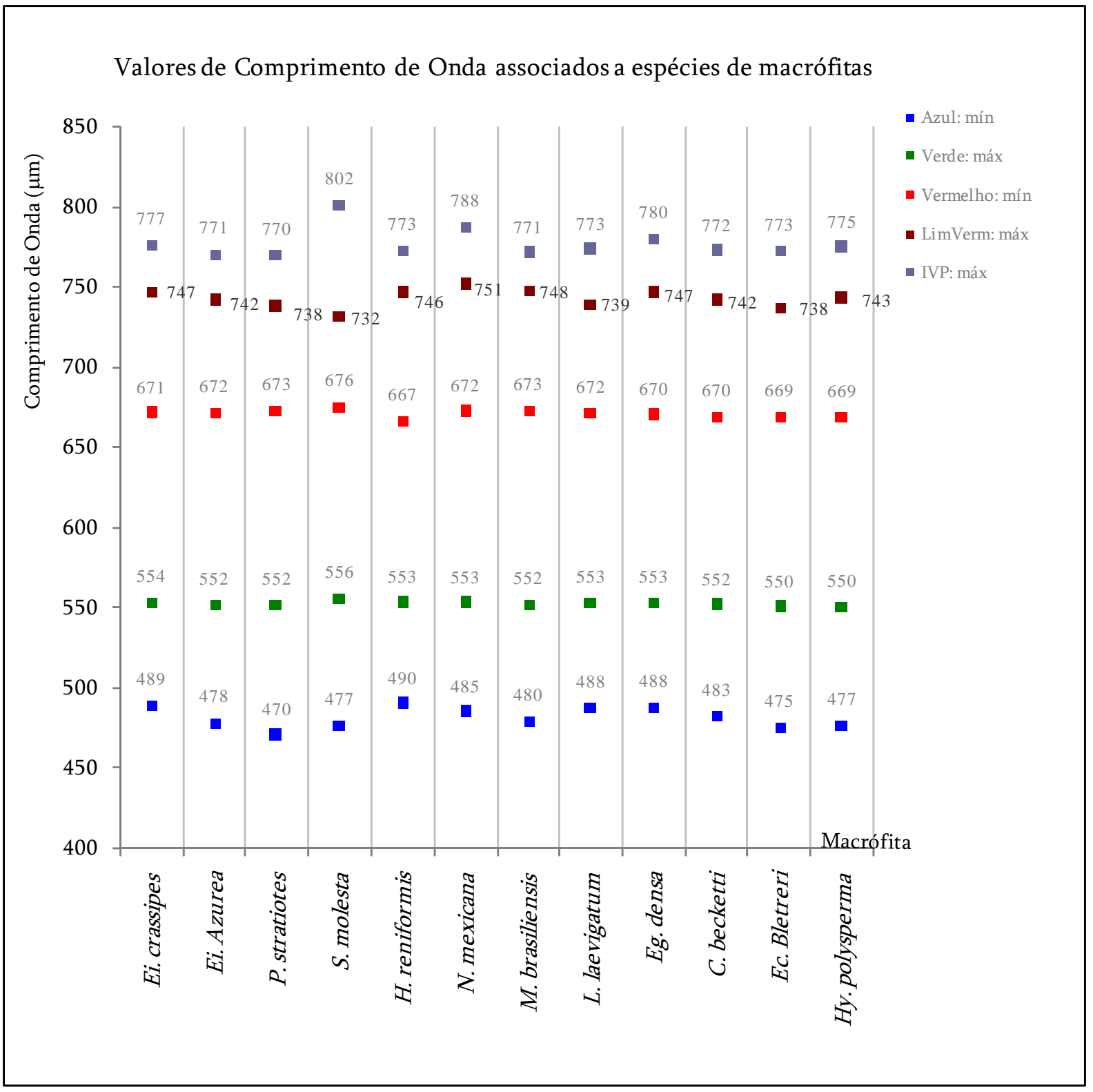

Figura IV.3: Valores de comprimento de onda nos pontos máximos das faixas espectrais Azul, Verde, Vermelho, IVP e também no Limite Vermelho. As espécies incluídas nesta análise foram: Salvinia molesta, Egeria densa, Hygrophila polysperma, Echinodorus bleheri, Pistia stratiotes, Limnobium laevigatum, Eichhornia crassipes, Eichhornia azurea, Hetheranthera reniformis, Nimphea mexicana.

A análise de variância ANOVA mostrou que as diferenças entre as médias são significativas (vide resultados na Tabela IV.3) para alfa igual a 0,05. 
Tabela IV.3: Resultado da ANOVA para os picos de reflectância utilizados.

\begin{tabular}{lccccc}
\hline Fonte da variação & $S Q$ & $M Q$ & $F$ & valor-P & F crítico \\
\hline Entre grupos & 755370,64 & 188842,66 & 5840,54 & 0,00 & 2,54 \\
Dentro dos grupos & 1778,32 & 32,33 & & & \\
Total & 757148,96 & & & & \\
\hline
\end{tabular}

$S Q$ é a soma dos quadrados, MQ é a média dos Quadrados e f é obtido pela média dentro dos grupos, dividida pela média entre os grupos.

IV.3.3 - Posição do Limite Vermelho

A - Método Linear, por Interpolação

Na Figura IV.4 pode-se observar a variação dos Limites vermelhos calculados por interpolação, dentro das espécies de macrófitas estudadas. Neste gráfico podem ser observados os Limites Vermelhos referentes a Macrófitas submersas (Eg. densa, C. beckettii, Ec. bleheri e H. polysperma) e emersas (as demais). 


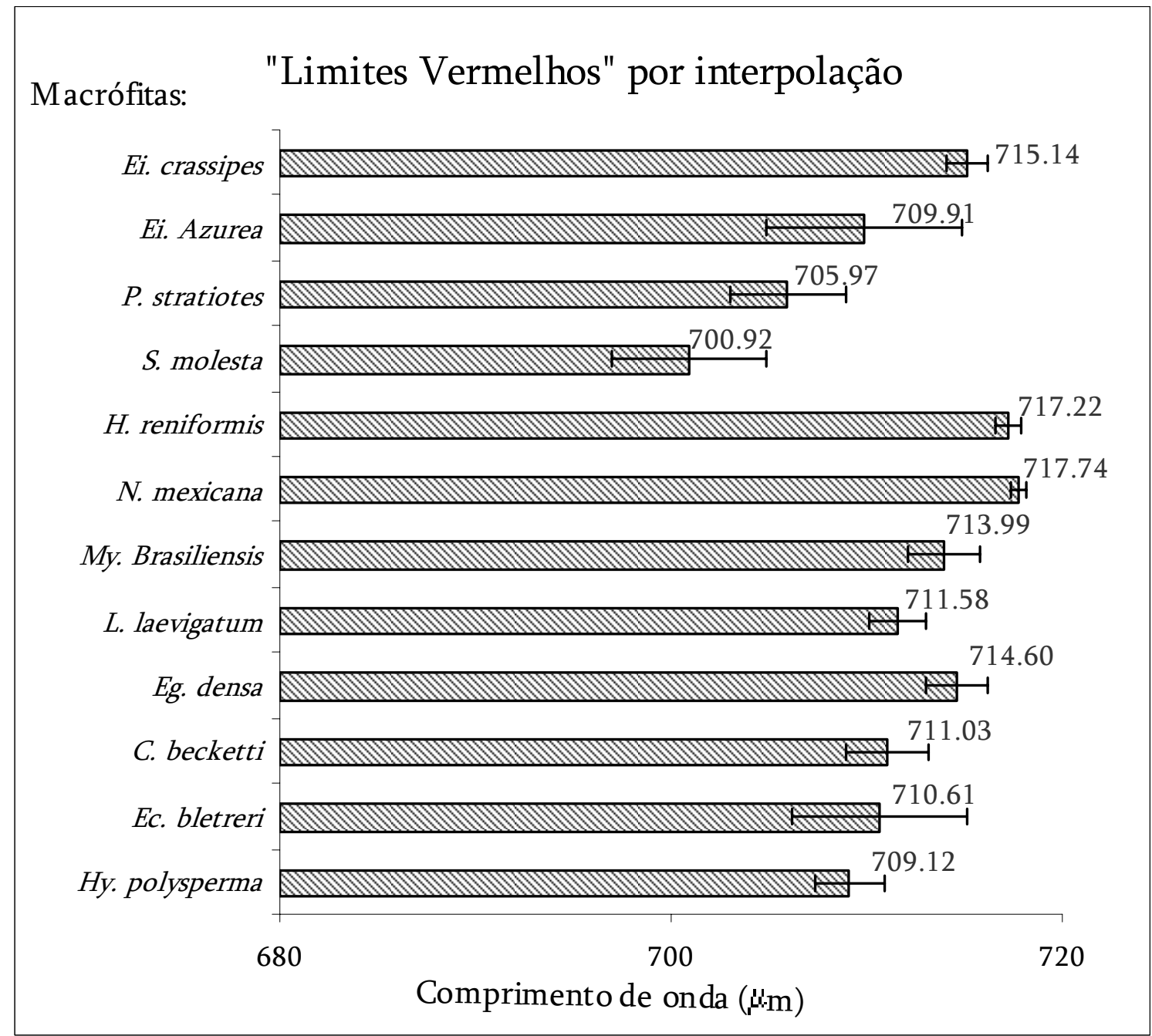

Figura IV.4: Limites vermelhos das espécies de macrófitas, obtidos por interpolação. As espécies incluídas nesta análise foram: Salvinia molesta, Egeria densa, Hygrophila polysperma, Echinodorus bleheri, Pistia stratiotes, Limnobium laevigatum, Eichhornia crassipes, Eichhornia azurea, Hetheranthera reniformis, Myriophyllum brasiliense, Nimphea mexicana. As barras mostradas são os desvio padrão correspondentes.

\section{$B$ - Método da Primeira derivada}

Ao final do capítulo, no Apêndice, encontram-se os gráficos relativos às funções derivativas das espécies estudadas. 
A partir dos dados numéricos obtidos, foram calculados os valores derivativos máximos em cada intervalo de comprimento de onda mencionado. Foram então calculados os pontos de inflexão referentes ao Limite Vermelho. O resultado pode ser observado na Figura IV.5.

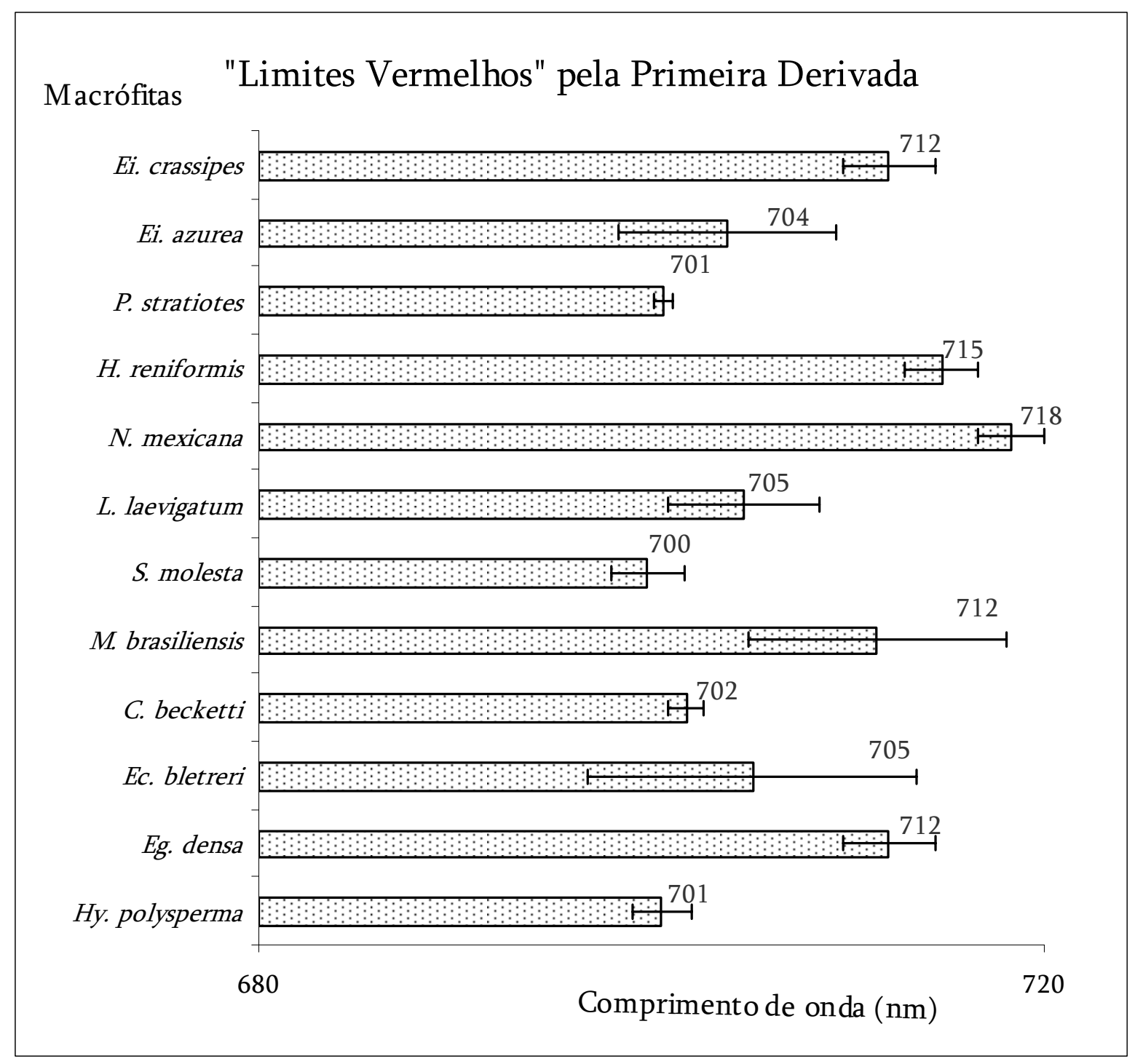

Figura IV.5: Limites vermelhos das espécies de macrófitas, obtidos pelo método da primeira derivada. As espécies analisadas foram: Eichhornia crassipes, Eichhornia azurea, Pistia stratiotes, Salvinia molesta, Hetheranthera reniformis, Nimphea mexicana, Myriophyllum brasiliense, Limnobium laevigatum, Egeria densa, Cryptocoryne beckettii, Echinodorus bleheri e Hygrophila polysperma. 
Comparando os valores dos Limites Vermelhos obtidos por Interpolação e por derivada, pode-se observar na Tabela IV.4 os resultados obtidos. Considerando-se os desvios padrão associados a cada caso, os Limites Vermelhos calculados mostraram valores semelhantes para as duas técnicas de cálculo, com as maiores diferenças tendo sido encontradas em $P$. stratiotes e L. laevigatum.

Tabela IV.4: Comparação entre os Limites Vermelhos obtidos por Interpolação e por Derivada. As espécies analisadas foram: Eichhornia crassipes, Eichhornia azurea, Pistia stratiotes, Salvinia molesta, Hetheranthera reniformis, Nimphea mexicana, Myriophyllum brasiliense, Limnobium laevigatum, Egeria densa, Cryptocoryne beckettii, Echinodorus bleheri e Hygrophila polysperma .

\begin{tabular}{|l|c|c|c|c|}
\cline { 2 - 5 } \multicolumn{1}{l|}{} & $\begin{array}{c}\text { Limites Vermelhos por } \\
\text { Interpolação }\end{array}$ & $\begin{array}{c}\text { Desvio } \\
\text { Padrão }\end{array}$ & $\begin{array}{c}\text { Limites Vermelhos por } \\
\text { Derivada }\end{array}$ & $\begin{array}{c}\text { Desvio } \\
\text { Padrão }\end{array}$ \\
\hline Ei. crassipes & 715 & 1,00 & 712 & 2,33 \\
\hline Ei. azurea & 710 & 5,01 & 704 & 5,53 \\
\hline P. stratiotes & 706 & 2,97 & 701 & 0,52 \\
\hline H. reniformis & 717 & 0,63 & 715 & 1,87 \\
\hline N. mexicana & 718 & 0,44 & 718 & 3,83 \\
\hline L. laevigatum & 712 & 1,45 & 705 & 1,87 \\
\hline S. molesta & 701 & 3,89 & 700 & 6,56 \\
\hline M. brasiliense & 714 & 1,84 & 712 & 0,96 \\
\hline C. becketti & 711 & 2,13 & 702 & 8,36 \\
\hline Ec. bletreri & 711 & 4,45 & 705 & 2,33 \\
\hline Eg. densa & 715 & 1,63 & 712 & 1,51 \\
\hline Hy. polysperma & 709 & 1,81 & 701 & \\
\hline
\end{tabular}


Pode-se observar, pela tabela, que esse descritor propiciou a separação das espécies estudadas. A ANOVA (Tabela IV.5) mostrou que a separação é significativa para um Alfa de 0,08 .

Tabela IV.5: Resultado da ANOVA para os limites vermelhos utilizados na diferenciação entre espécies de macrófitas.

\begin{tabular}{lccccc}
\hline \multicolumn{1}{c}{ Fonte da variação } & $S Q$ & $M Q$ & $F$ & valor- $P$ & F crítico \\
\hline Entre grupos & 112,67 & 112,67 & 3,67 & 0,07 & 3,37 \\
Dentro dos grupos & 675,17 & 30,69 & & & \\
Total & 787,83 & & & & \\
\hline
\end{tabular}

SQ é a soma dos quadrados, MQ é a média dos Quadrados e fé obtido pela média dentro dos grupos, dividida pela média entre os grupos.

Sendo f maior que fcrítico, há diferenças significativas entre as médias, mostrando portanto que o Limite Vermelho pode ser utilizado como diferenciador. Em relação ao cálculo por interpolação ou por derivada o resultado mostrou que não há diferença significativa entre o método de Interpolação e o de Derivada. (Tabela IV.6).

Tabela IV.6: Diferenças entre grupos, obtidas a partir da ANOVA.

\begin{tabular}{lrrrrr}
\hline \multicolumn{1}{c}{ Grupo } & Contagem & Média & ld & \multicolumn{2}{c}{ Diferenças } \\
\hline Limites Vermelhos & 12 & 711,58 & 4,80 & 4,33 (Interpolação e derivada) \\
por Interpolação & 12 & 707,25 & 4,80 & & \\
Limites Vermelhos por Derivada & & & & & \\
\hline
\end{tabular}

ld = limite de decisão 
IV.3.4 - Índices entre faixas

Os índices entre faixas calculados para as espécies estudadas se encontram na Figura IV.6. Pode-se observar pela figura que há grandes variações nos índices. Os resultados dos dados submetidos ao teste ANOVA estão na Tabela IV.7.

Tabela IV.7: Resultado da ANOVA para a diferenciação entre as espécies utilizando os índices entre faixas como descritores.

\begin{tabular}{lccccc}
\hline \multicolumn{1}{c}{ Fonte da variação } & $S Q$ & $M Q$ & $F$ & valor-P & F crítico \\
\hline Entre grupos & 1.48 & 0.37 & 30.62 & 0.00 & 2.54 \\
Dentro dos grupos & 0.66 & 0.01 & & & \\
Total & 2.14 & & & & \\
\hline
\end{tabular}

SQ é a soma dos quadrados, MQ é a média dos Quadrados e fé obtido pela média dentro dos grupos, dividida pela média entre os grupos.

O teste de variância mostrou que os índices utilizados são suficientemente significativos para a diferenciação das espécies estudadas, para alfa igual a 0,5. 


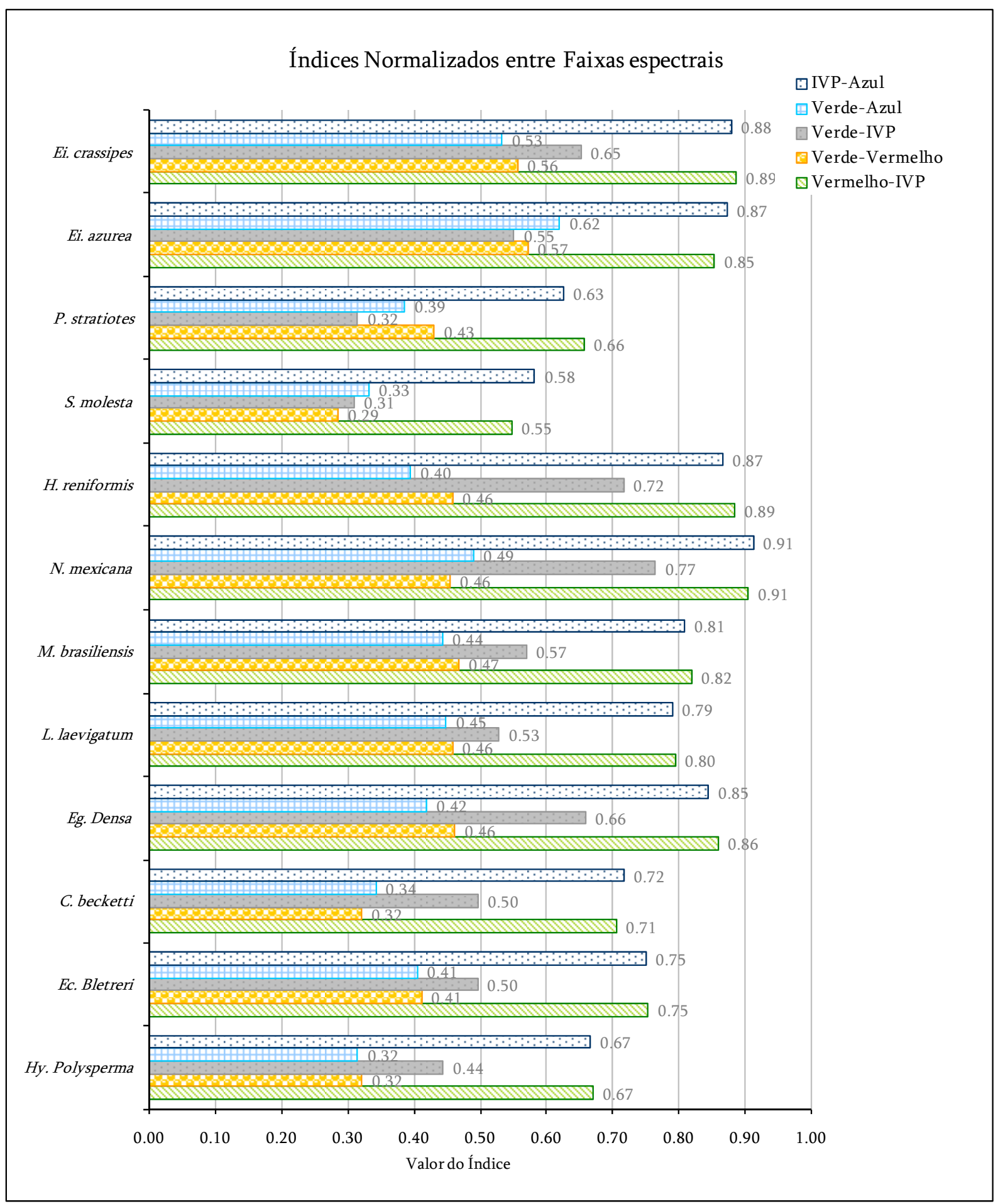

Figura IV.6: Na figura podem ser observados os resultados referentes aos índices entre Faixas utilizados neste estudo. As espécies analisadas foram: Eichhornia crassipes, Eichhornia azurea, Pistia stratiotes, Salvinia molesta, Hetheranthera reniformis, Nimphea mexicana, Myriophyllum brasiliense, Limnobium laevigatum, Egeria densa, Cryptocoryne beckettii, Echinodorus bleheri e Hygrophila polysperma. 


\section{IV.4-CONCLUSÕES}

Efetivamente é no IVP (Infravermelho próximo) que as doze espécies de macrófitas analisadas podem ser melhor distinguidas espectralmente.

Os descritores: Intensidade média na faixa espectral, Pontos de inversão em cada faixa, Posição do Limite Vermelho e Índices entre faixas, se mostraram eficientes na separação entre as espécies de macrófitas estudadas.

Pode ocorrer alteração nos valores desses descritores em função de diferentes variáveis, que devem ser levadas em consideração. Algumas delas são variações no ângulo de visada, na escala (quando se passa a estudar os indivíduos incluindo folhas e raízes, ou populações), e nas próprias características intrínsecas da espécie (presença de tricoma, cutícula espessada, entre outros).

Por esse motivo os dados devem ser conferidos em campo, sendo necessária a tomada de medidas in situ que possam ser comparáveis às aqui obtidas. 


\section{IV.5 - APÊNDICE}

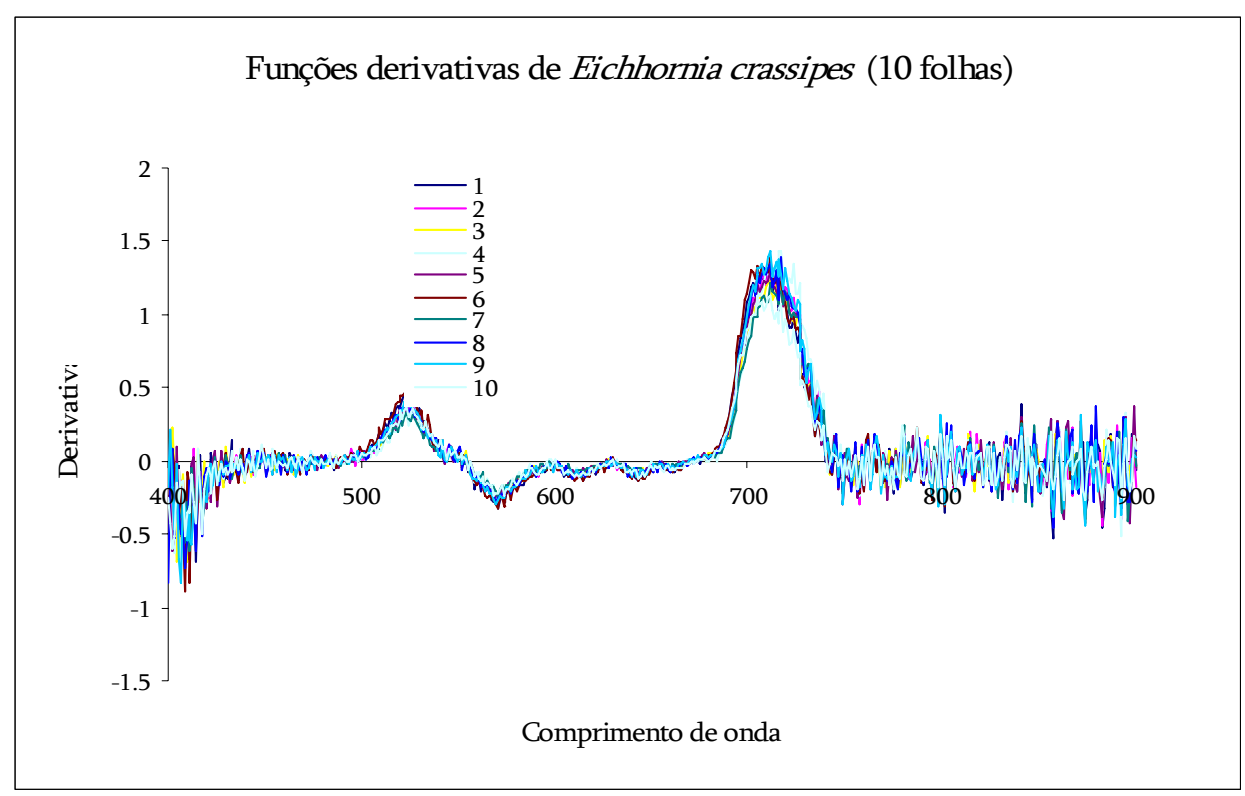

Figura IV.7: Função derivativa da resposta espectral de folhas de Eichhornia crassipes.

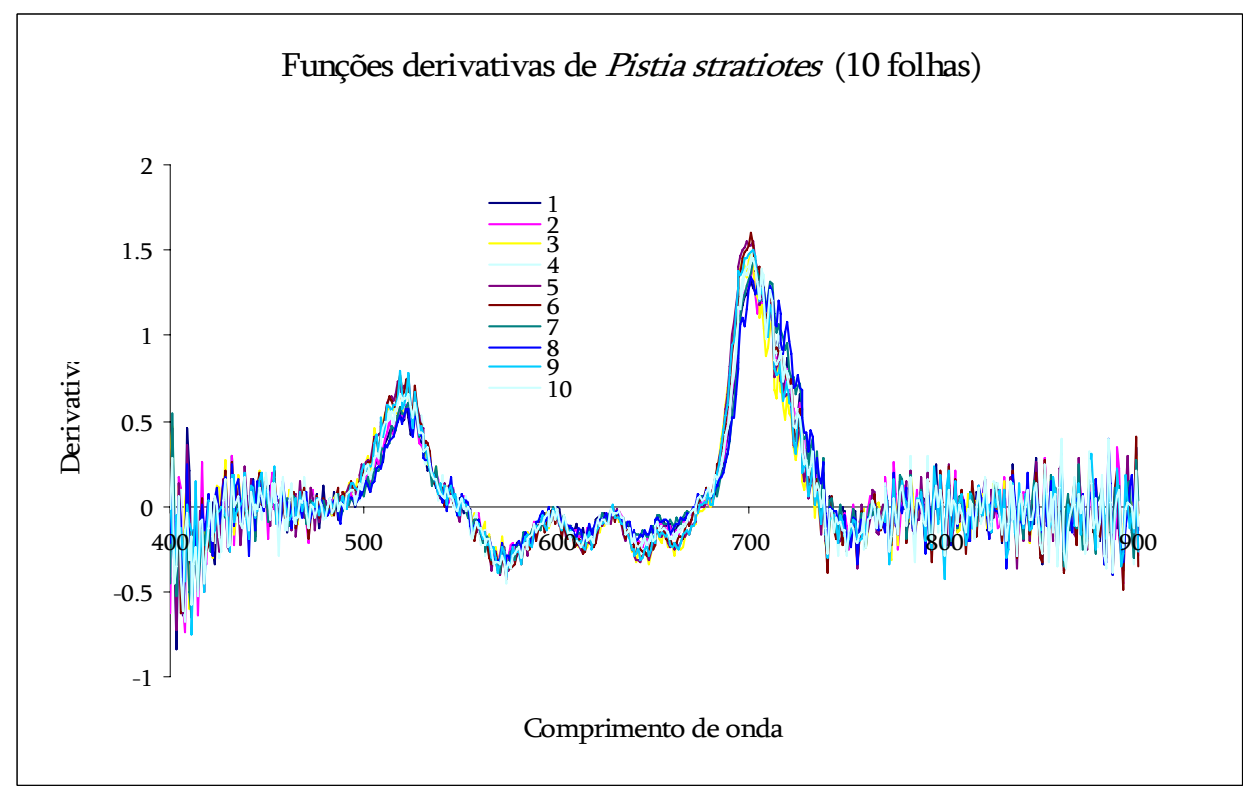

Figura IV.8: Função derivativa da resposta espectral de folhas de Pistia stratiotes. 


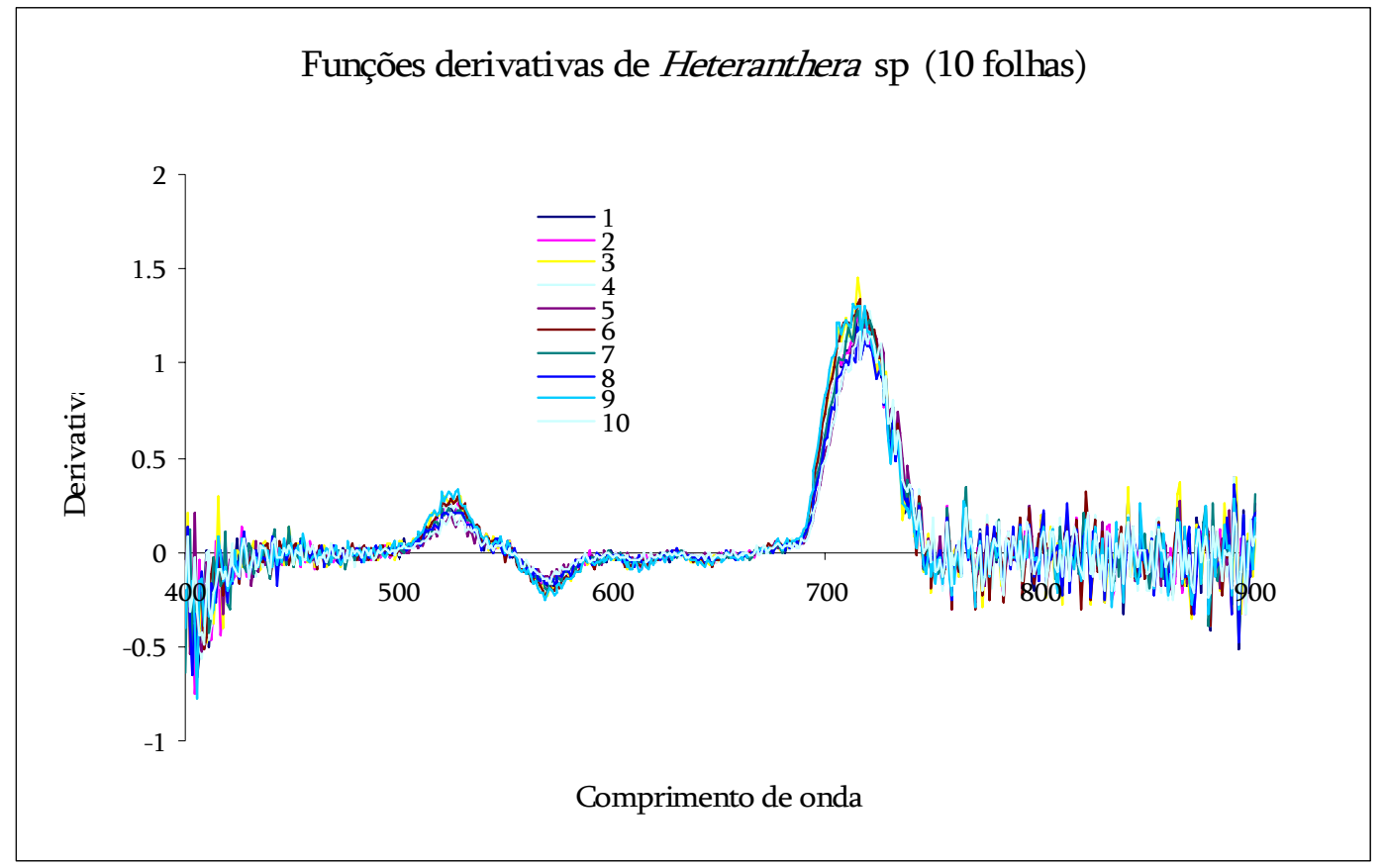

Figura IV. 9: Função derivativa da resposta espectral de folhas de Heteranthera sp.

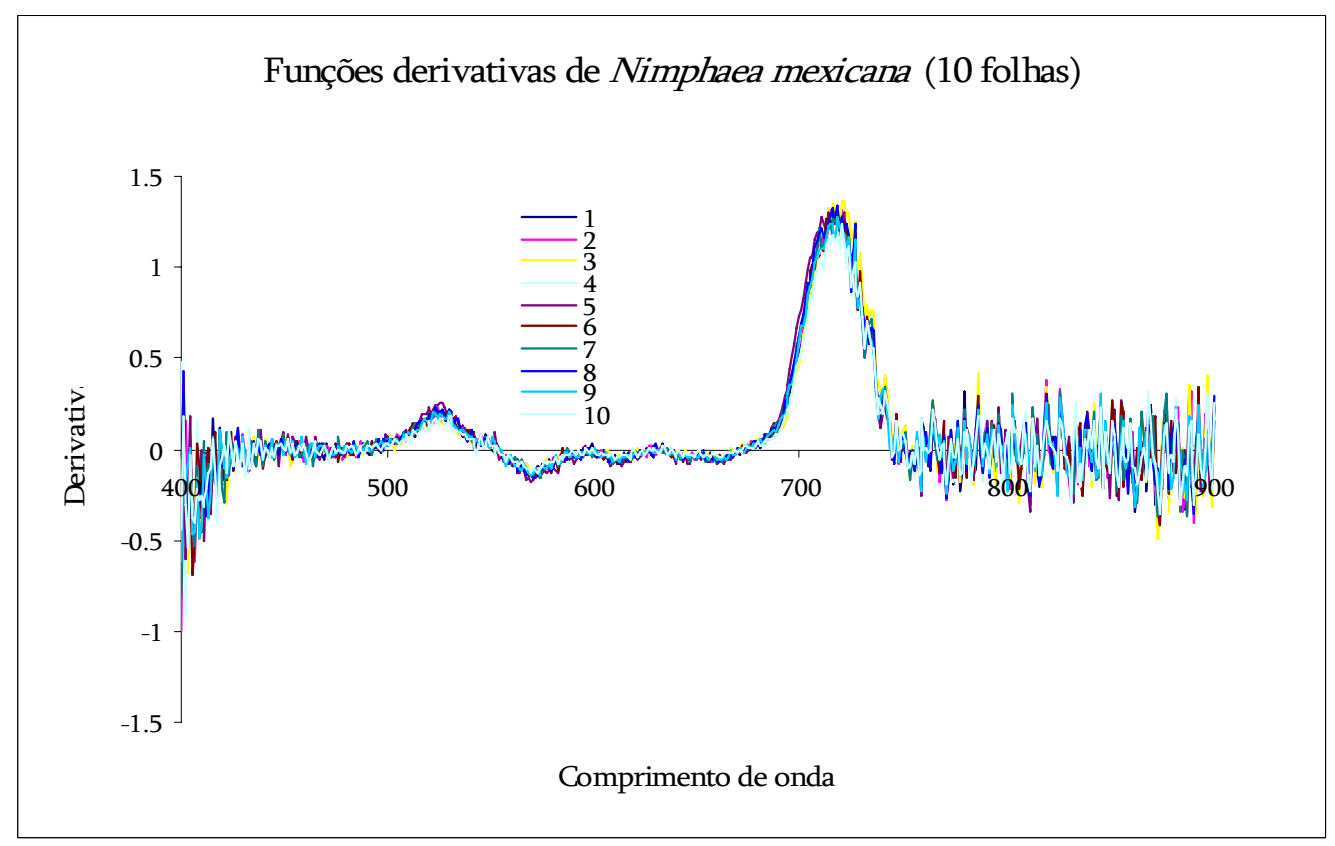

Figura IV.10: Função derivativa da resposta espectral de folhas de Nymphaea mexicana. 


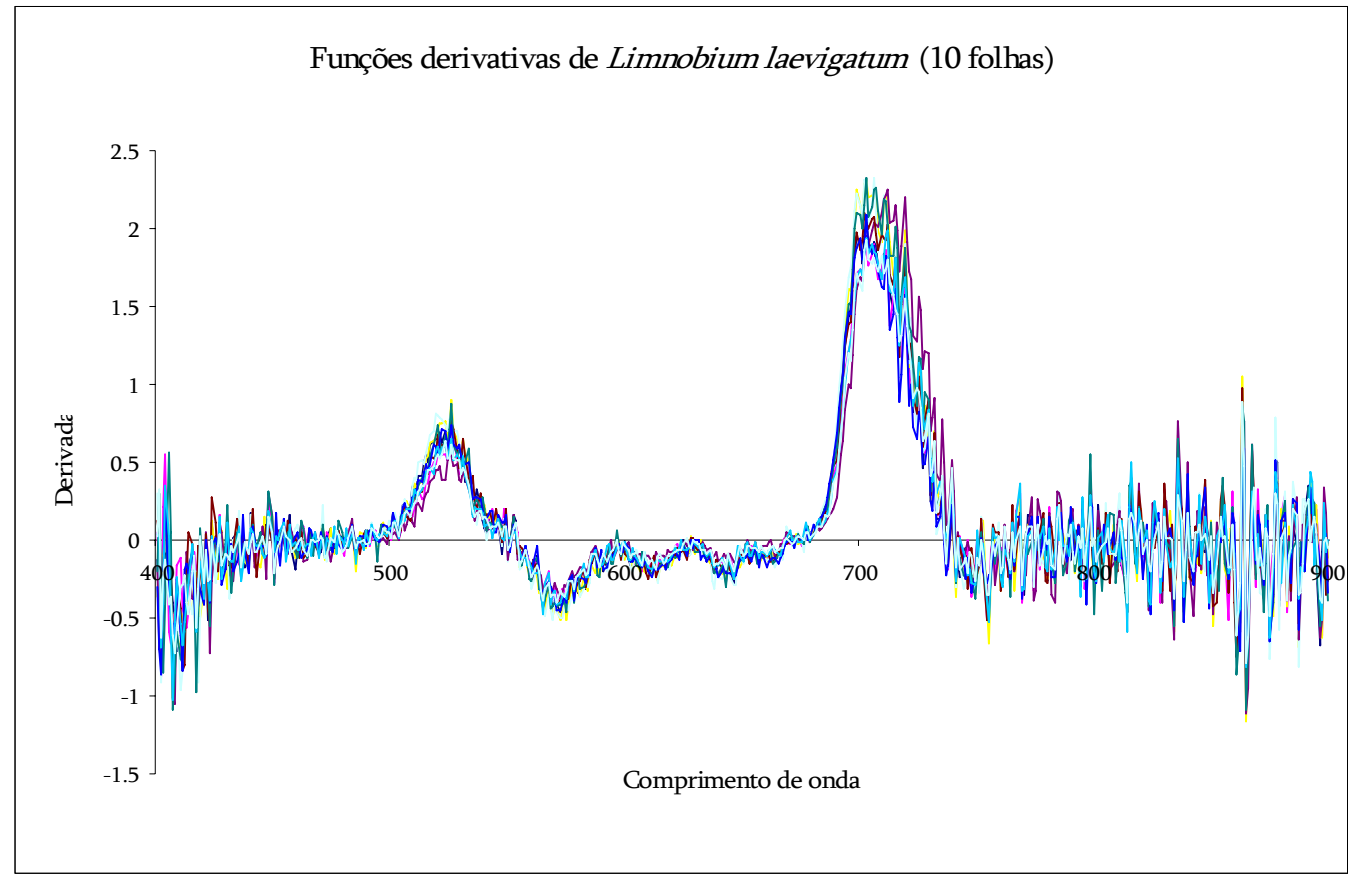

Figura IV.11: Função derivativa da resposta espectral de folhas de Limnobium laevigatum.

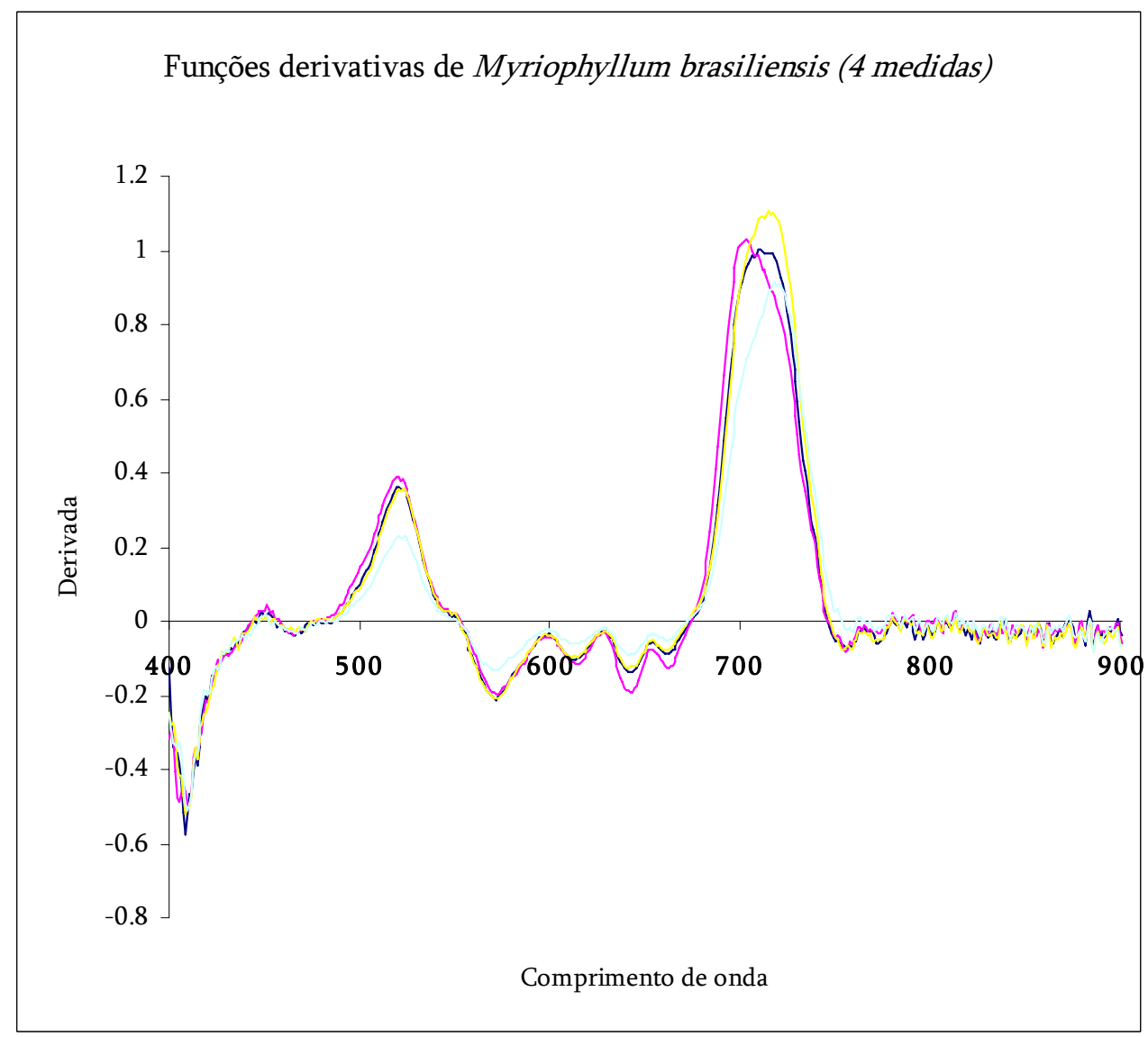

Figura IV.12: Função derivativa da resposta espectral de Myriophyllum brasiliense. 


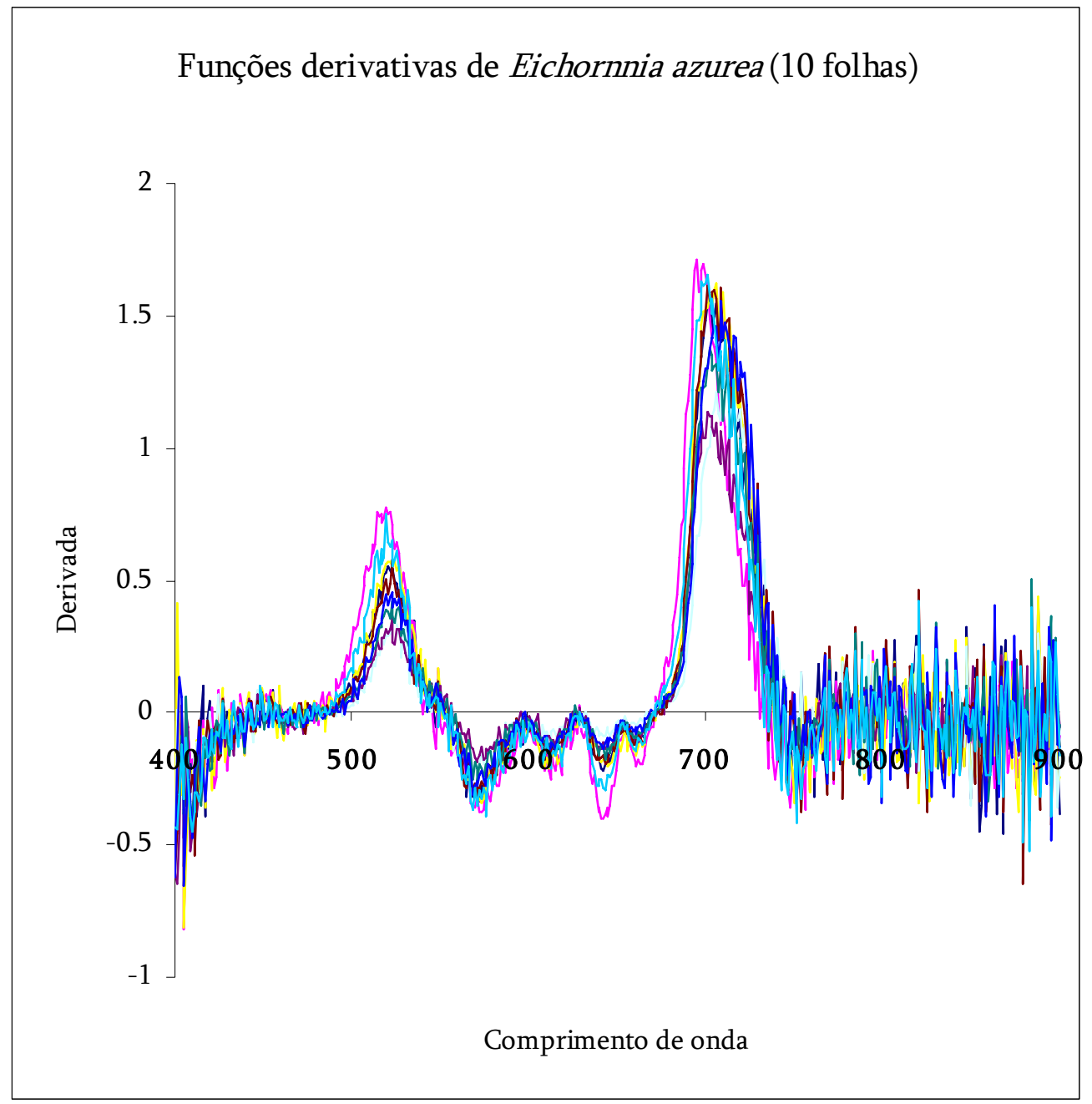

Figura IV.13: Função derivativa da resposta espectral de Eichhornia azurea. 


\section{CAPÍTULO V - UTILIZAÇÃO DE ANÁLISES ANATÔMICAS MICROSCÓPICAS PARA EXPLICAR}

ALTERAÇÕES NA RESPOSTA ESPECTRAL DE ESPÉCIES DE MACRÓFITAS.

\section{V.1 - INTRODUÇÃO}

A estrutura anatômica das folhas e sua relação com suas respostas espectrais é o foco deste capítulo. Há um aumento súbito de reflectância entre o Vermelho e o Infravermelho Próximo (IVP). A explicação para o fato é dada em função da presença da Clorofila, que absorve fortemente no Vermelho, e da estrutura interna das folhas, onde a variação entre os espaços aéreos e celulares são diretamente proporcionais à reflectância na faixa do IVP. O antagonismo entre a reflectância observada no Vermelho e no IVP tem levado os pesquisadores a buscar parâmetros de descrição das espécies, como visto no Capítulo anterior.

A Figura V.1 mostra a estrutura interna típica da folha de uma dicotiledônea. Nela pode ser observado o parênquima esponjoso, onde ocorre o retroespalhamento. 


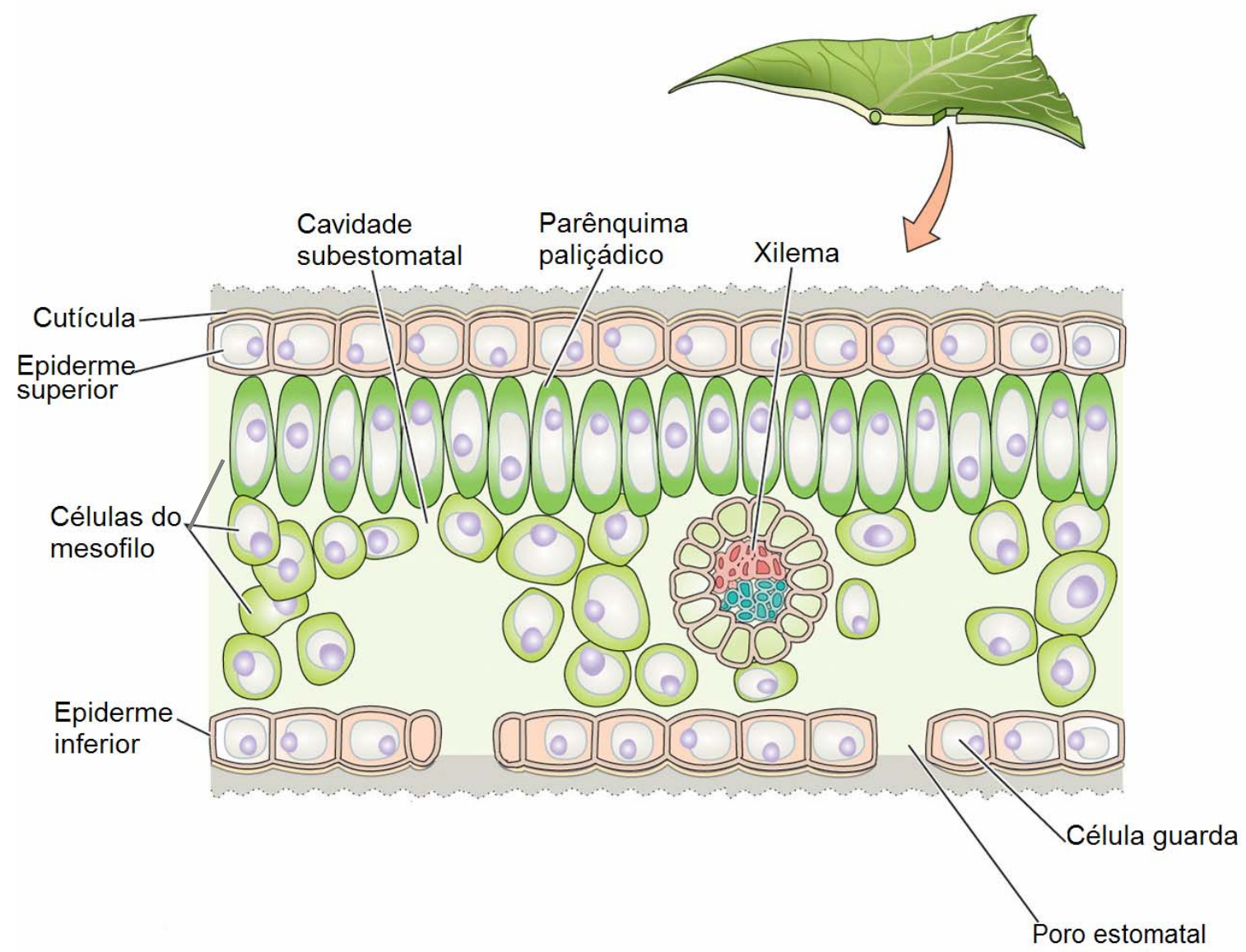

PLANT PHYSIOLOGY, Third Edition, Figure $4.10 @ 2002$ Sinauer Associates, Inc.

Figura V.1: Estrutura anatômica típica de uma folha dicotiledônea. In: Taiz e Zeiger 2002.

Esse retroespalhamento pode ocorrer em diferentes caminhos dentro do parênquima esponjoso, e esse foi o tema de um dos mais conhecidos estudos nesta área, feito por Gates et al. (1965), mostrado na Figura V.2, onde se pode observar os prováveis caminhos da luz no interior de uma folha. 


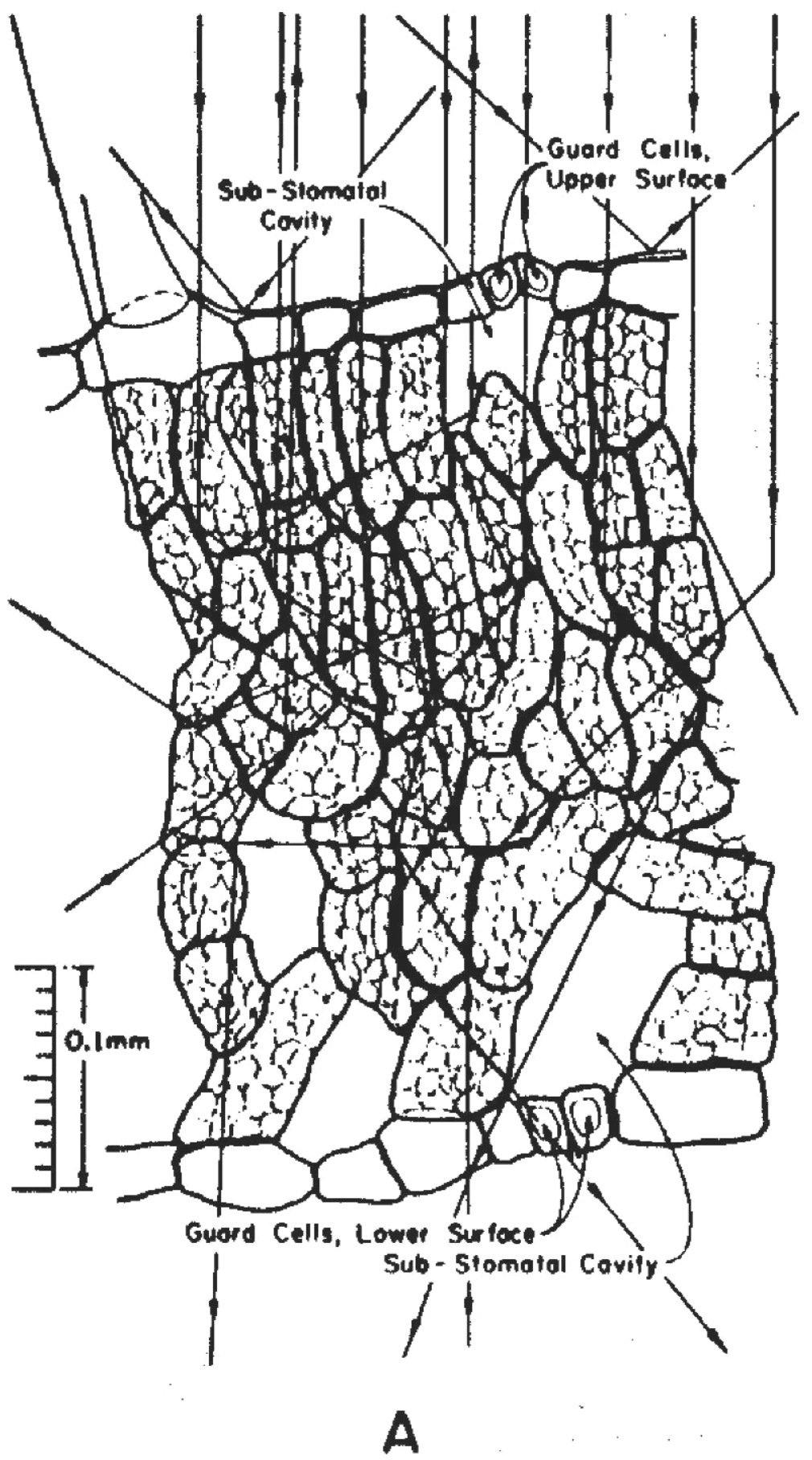

Figura V.2: Possíveis trajetos da luz no interior de uma folha de Mimulus cardinalis, segundo Gates et al. (1965).

Após este estudo foram desenvolvidos outros estudos para tentar elucidar como ocorre esse retroespalhamento, como o de Govaerts et al. (1996), que desenvolveram um modelo tridimensional de transferência radiativa para uma folha de dicotiledônea, 
Ourcival et al. (1999) que discutiram as relações entre as propriedades bioquímicas, anatômicas e de reflectância das folhas do carvalho Quercus ilex mostrando a participação da anatomia na refletância e Slaton et al. (2001), que estudaram a reflectância do IVP a partir de características estruturais das folhas. O tecido paliçádico também pode influenciar na distribuição uniforme dos comprimentos de onda para os cloroplastos dentro da folha, como mostraram Vogelmann e Martin (1993). Eles estudaram folhas com conteúdos pigmentares similares, mas diferentes tipos de desenvolvimento anatômico do parênquima.

Gausman et al. (1969) citaram quatro explicações possíveis para relacionar a estrutura interna das folhas à sua reflectância: 1) o espalhamento interno da luz pode ser causado por estruturas subcelulares com dimensões aproximadas dos comprimentos de onda da radiação; 2) a reflecção da luz pode ocorrer nas interfaces das cavidades intercelulares do parênquima esponjoso; 3) o arranjo das células do parênquima pode alterar a reflectância; 4) a orientação horizontal das paredes celulares tem sido também relacionada com o aumento da reflectância. A maioria dos estudos realizados nessa área considera a segunda explicação como a mais influente no caso da reflectância no IVP. Tem-se, portanto, o conhecimento de que a reflectância das espécies no IVP corresponde em sua maioria ao retroespalhamento resultante das variações nos índices de refração no interior do parênquima, que podem ser indiretamente mensuradas pela quantidade de ar presente nos espaços intercelulares do parênquima. 
Em função da ausência de publicações relacionadas diretamente com a resposta espectral de macrófitas, outros estudos com plantas terrestres contribuíram para auxiliar na compreensão dos fatores envolvidos no Sensoriamento Remoto de macrófitas. Em 1936, Turrel já discutia a diferenciação de tipos vegetais através das superfícies expostas ao ar no interior de folhas dicotiledôneas. Gates et al., em 1965, publicaram um artigo onde discutiam de modo geral as propriedades espectrais das plantas. Alguns anos depois, em 1969, Gausman et al. relacionaram a reflectância de folhas de algodão com sua estrutura interna. Nesse caso foi verificado que quando cultivadas com água de baixa salinidade, tanto a espessura da folha como sua reflectância eram menores quando comparadas a condições de alta salinidade. $\mathrm{O}$ autor também menciona que folhas jovens são mais compactas e têm menos espaços intercelulares do que as folhas mais velhas, e que folhas mais suculentas têm um arranjo de parênquima mais desorganizado (Hayward e Long 1941 apud Gausman et al. 1969). Um ano depois, em 1970, Knipling mostrou que quando infiltrados com água, os espaços intercelulares das folhas provocam uma maior absorção (e, portanto, menor reflectância) dos comprimentos de onda da região do Visível e principalmente do IVP, resultado semelhante ao obtido por DeLucia et al. (1996).

A estrutura foliar é, portanto, o principal determinante da intensidade da reflectância na faixa do IVP. Assim, a hipótese desse capítulo é de que a análise de variáveis micro-anatômicas das folhas de macrófitas, sendo elas a espessura da folha, a espessura do parênquima esponjoso e especialmente a área dos espaços aéreos, pode auxiliar a explicar e conduzir a distinção entre as espécies. 
O objetivo deste capítulo foi, portanto, o de obter e comparar essas características (espessura foliar, espessura da câmara do parênquima esponjoso, e áreas preenchidas por ar dentro dessas câmaras) com a resposta espectral das folhas das espécies estudadas nas diferentes faixas do espectro, buscando verificar a possibilidade de diferenciação entre as espécies.

\section{V.2 - PROCEDIMENTOS METOdOLÓGICOS}

\section{V.2.1 - Medidas radiométricas}

Inicialmente foram medidas as respostas espectrais das folhas das espécies estudadas, em câmara escura, de acordo com os procedimentos descritos no Capítulo II, e calculados os Índices descritores (Capítulo IV). Foram escolhidas cinco espécies para as quais foi possível preparar as lâminas para as análises anatômicas. As folhas foram enumeradas, tiveram sua reflectância medida conforme explicado no Cap. II, e foram cortadas transversalmente. Foram então separadas para as análises anatômicas as folhas com respostas espectrais mínima, média e máxima na faixa do IVP, de modo a comparar suas anatomias com a resposta espectral nesta faixa espectral. Para escolher quais as folhas com Máxima, Média e Mínima Reflectância, foram comparados os valores MÉDIOS de cada folha no IVP com o valor MÉDIO da espécie no IVP. As espécies utilizadas nestas análises foram: Eichhornia crassipes, Pistia stratiotes, Nymphaea mexicana, Heteranthera reniformis. e Limnobium laevigatum 
V.2.2 - Medidas anatômicas

Para o cálculo das medidas anatômicas foi utilizada microscopia confocal e óptica. O funcionamento do microscópio confocal é baseado na microscopia por laser, como mostram Rowland e Nickless (2000). Sua maior vantagem é permitir que o pesquisador observe o objeto de interesse de um modo tridimensional, possibilitando calcular variáveis como espessura, área e volume de estruturas celulares em alguns casos. Neste estudo, o microscópio confocal foi utilizado porque facilita os procedimentos envolvidos na analise das estruturas foliares sem necessidade de que sejam feitos cortes em micrótomos.

As folhas foram fixadas em solução Karnovsky (Karnovksy 1965), composto de glutaraldeído, formaldeído e tampão cacodilato de sódio 0,1 M, e FAA (formaldeído, ácido acético e álcool etílico 70\%) por 72 horas, seguindo a metodologia de Johansen (1940), sendo o estudo anatômico baseado no exame microscópico de seções obtidas à mão livre.

O tipo de corte também foi importante na preparação para análise no Microscópio Confocal. Inicialmente foi feita a tentativa de se analisar os cortes em profundidade, a partir da epiderme foliar, ou seja, da superfície adaxial para a abaxial. Entretanto a espessura das folhas das macrófitas não possibilitou o alcance do laser do microscópio confocal até a região do parênquima esponjoso (vide Figura V.3). 

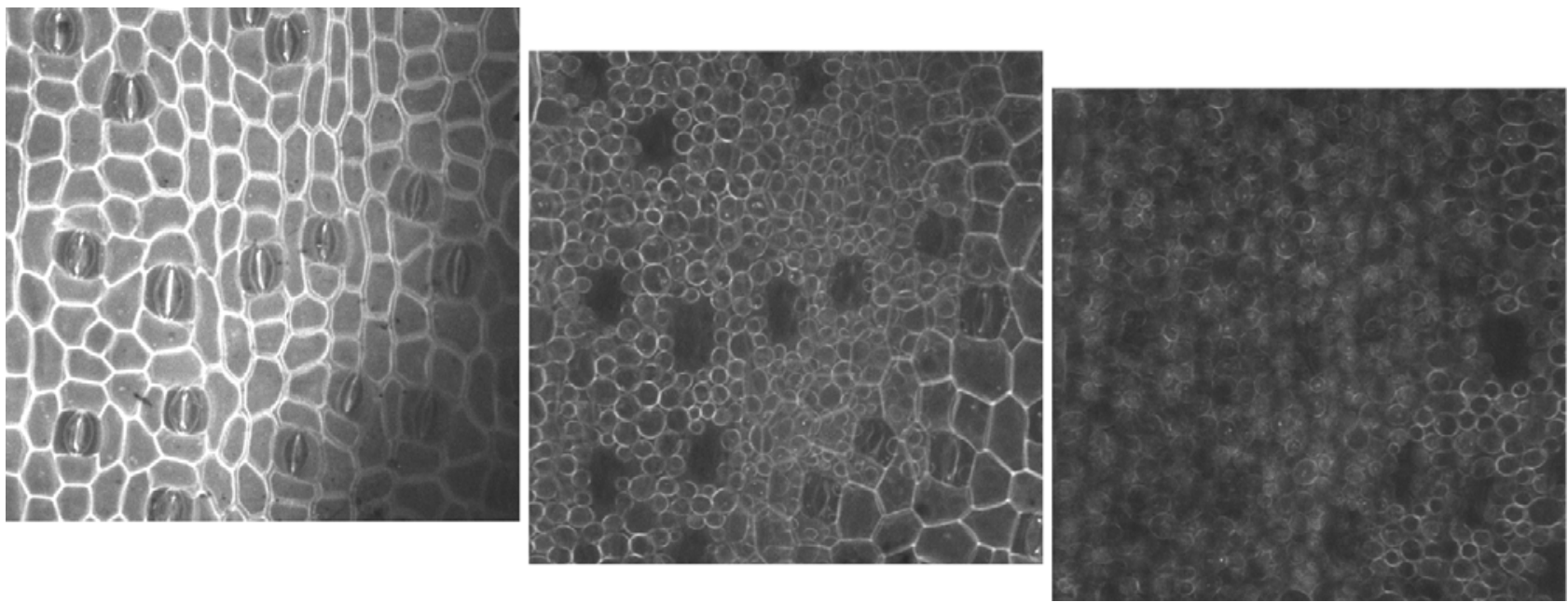

Figura V.3: Análise de folha de Eichhornia crassipes no Microscópio Confocal, vista da superfície adaxial em direção à adaxial. Observe que o laser alcançou apenas até o parênquima paliçádico.

Por esta razão, optou-se por realizar cortes transversais das folhas e obter imagens em áreas similares para cada folha e espécie. Das cinco espécies estudadas, apenas Limnobium laevigatum foi analisada com microscópio óptico, em função de apresentar um parênquima esponjoso demasiado espesso para a área de visada do microscópio confocal.

As áreas dos espaços aéreos para as folhas de maior, média e menor reflectância, foram calculadas em cinco profundidades do microscópio confocal para cada folha, a partir da qual foi feita uma média representativa da espécie. Tanto os valores da proporção de espaços aéreos das três folhas como a média das espécies foram comparados com as respostas espectrais na região do IVP.

Os volumes e áreas das estruturas internas das folhas têm sido calculados de diferentes modos, incluindo modelos matemáticos. Para o presente estudo, os cálculos 
realizados foram bidimensionais, pois houve muita imprecisão durante o corte das folhas para que se pudesse calcular de modo adequado os volumes referentes aos espaços aéreos das folhas. Há imprecisão envolvida durante o corte da folha, por vezes alterando a forma e o tamanho da câmara aérea de uma camada para a outra, tornando impreciso o cálculo do volume por integração de área. Por esse motivo especialmente, os volumes poderiam ser então considerados como os de cilindros regulares, cujas bases seriam iguais à área da câmara superior do cilindro. Assim, considerando-se áreas de 3 câmaras distintas A, B e C, o volume total poderia ser calculado conforme ilustrado na Figura V.4.

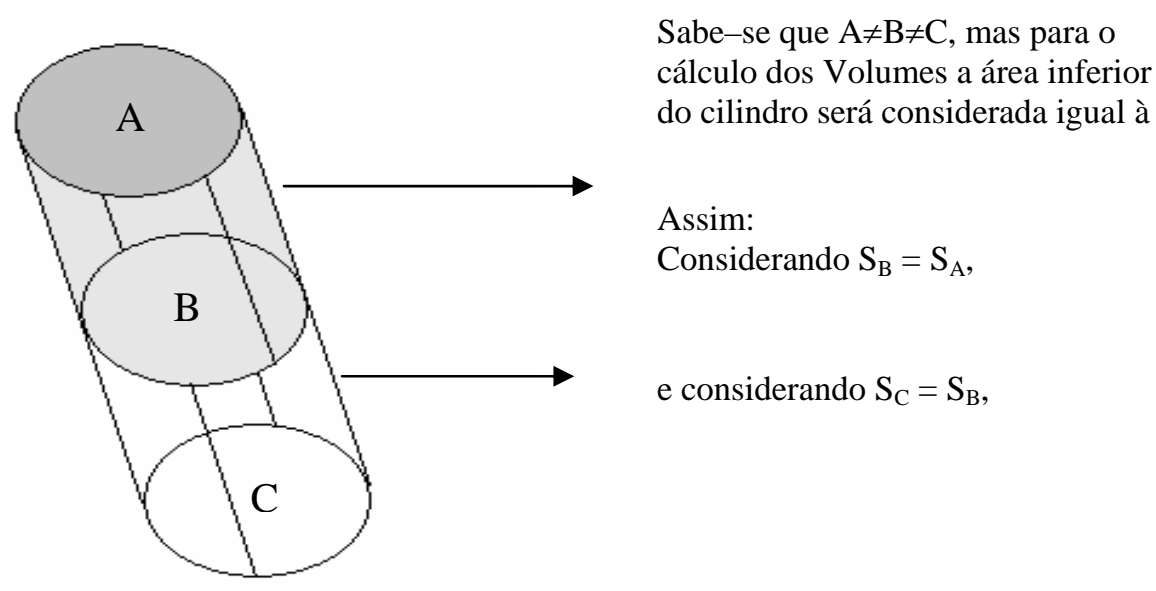

Figura V.4: Cálculo de volume, onde Volume total $=$ Vol a $+\operatorname{Vol} b=\left(A^{*} H\right)+\left(B^{*} H\right)$, onde $\mathrm{S}=$ Área, $\mathrm{H}$ = altura, e Vol = Volume.

Sabendo que no microscópio confocal H é a distância entre as seções, e que essa distância corresponde a $4 \mu \mathrm{m}$ : Volume total $=4^{*}(\mathrm{~A}+\mathrm{B})$

Assim, como o Volume estipulado é diretamente proporcional às áreas envolvidas, optou-se por utilizar as áreas para os cálculos de espaços aéreos na comparação entre folhas e espécies diferentes. 
Os dados anatômicos calculados são referentes ao esquema foliar da Figura V.5.

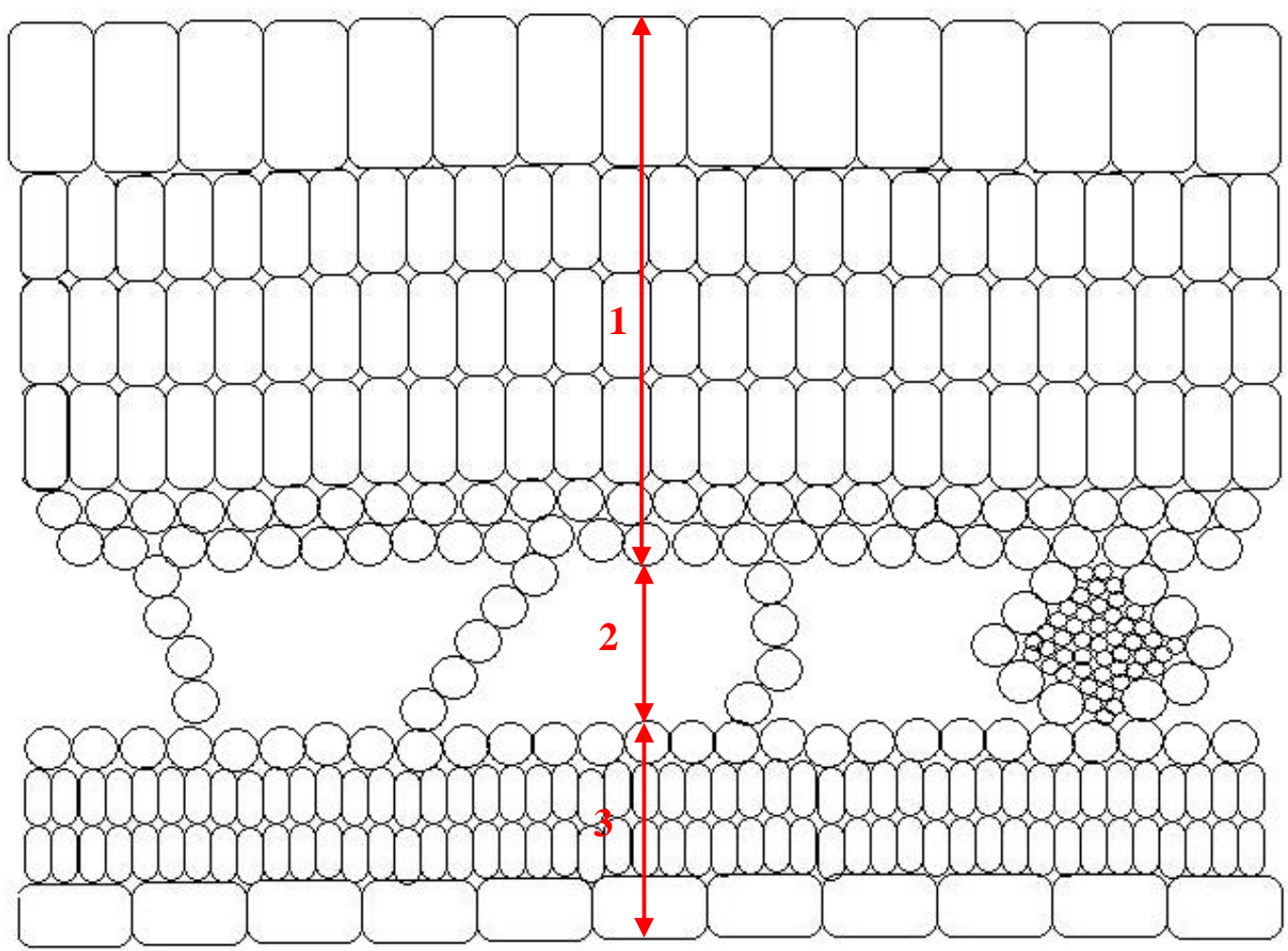

Figura V.5: Variáveis anatômicas no estudo:

1-Espessura adaxial

2-Espessura da câmara

3-Espessura abaxial

Uma análise multivariada de Correspondência foi realizada incluindo os valores das variáveis anatômicas: espessura da folha, da câmara e espaços aéreos, com a finalidade de verificar o quanto eles influenciam na diferenciação entre as espécies estudadas. 


\section{V.3 - RESULTADOS E DisCUSSÕES}

\section{V.3.1 - Análises anatômicas}

A seguir encontram-se exemplos das imagens tridimensionais obtidas para cada espécie (Figuras V.6 a V.10). Nestas imagens a escala mostra que as regiões vermelhas representam as áreas mais próximas da lente do microscópio, enquanto que as azuis representam as mais profundas. Pôde-se observar que as espécies apresentaram grandes variações no número e área dos espaços aéreos especialmente na região do parênquima esponjoso.

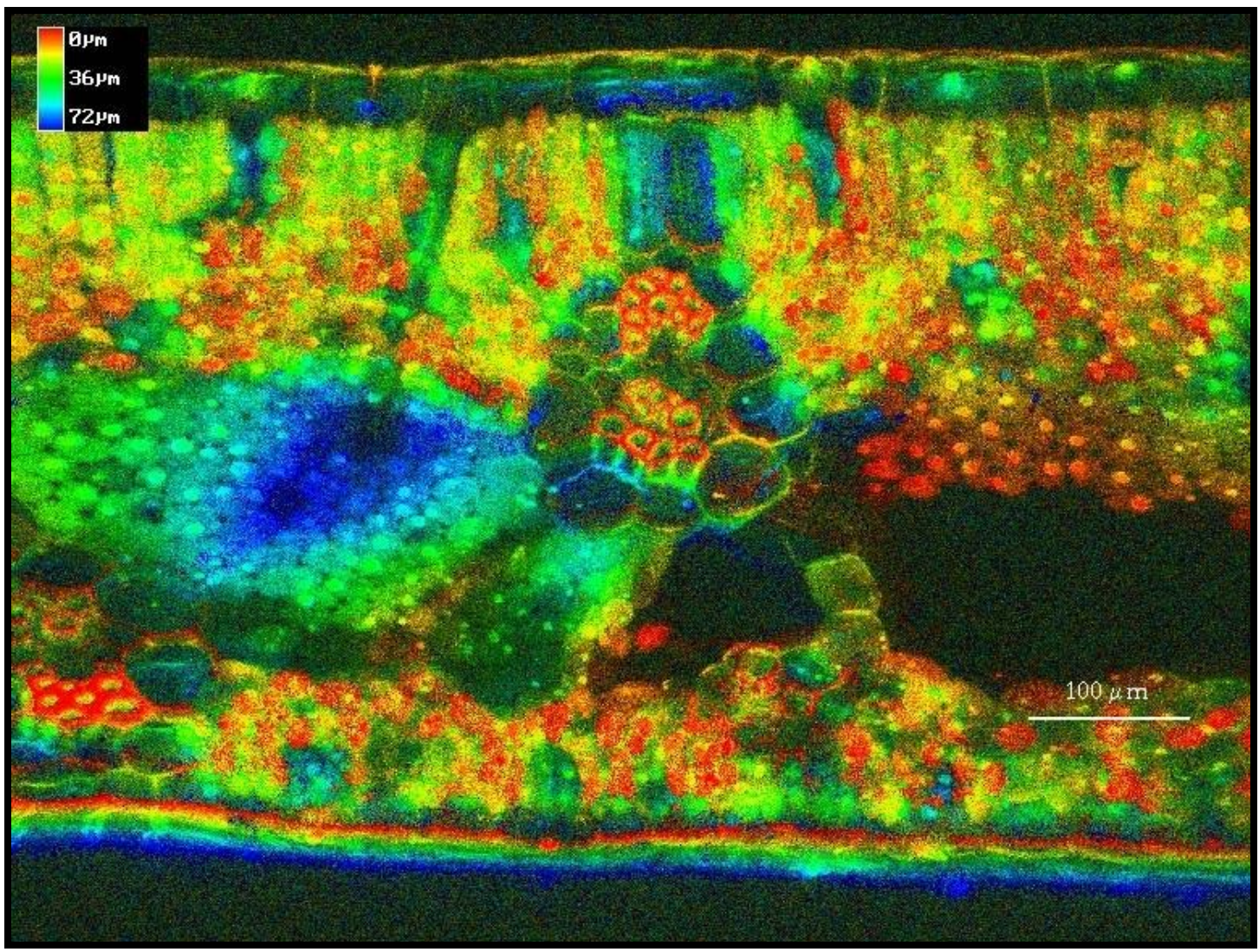

Figura V.6: Imagem tridimensional do microscópio Confocal para Eichhornia crassipes. 


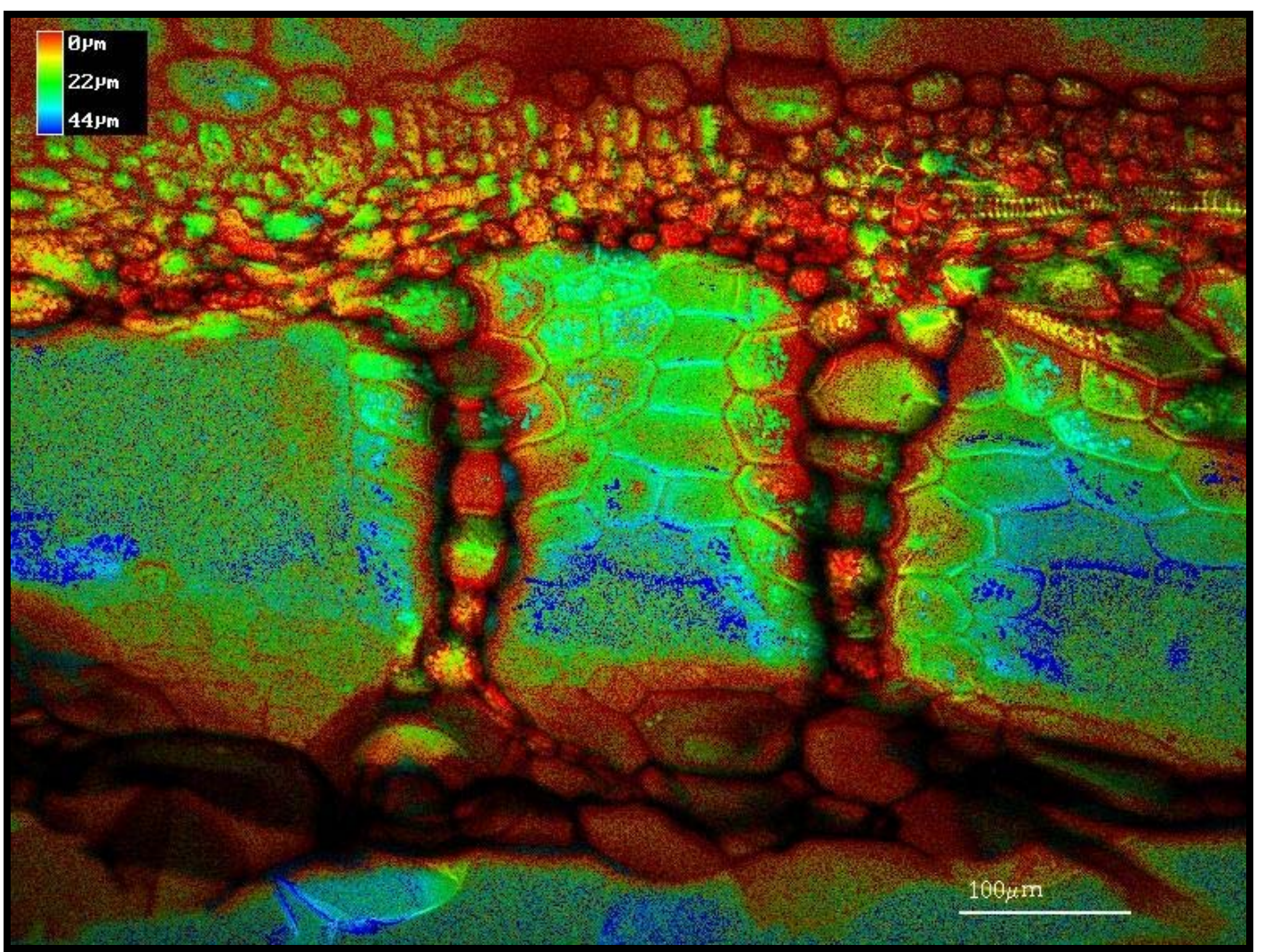

Figura V.7: Imagem tridimensional do microscópio Confocal para Pistia stratiotes..

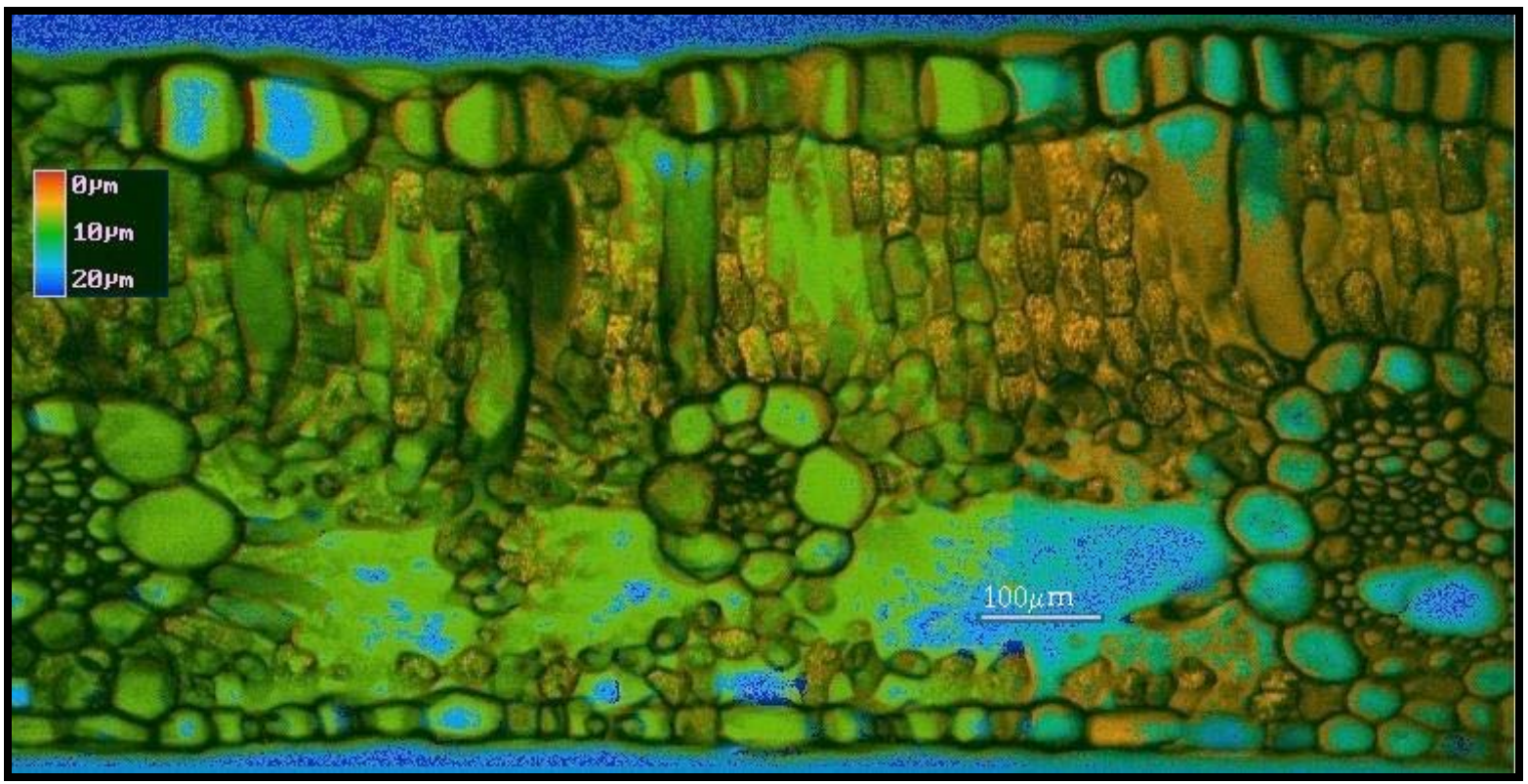

Figura V.8: Imagem tridimensional do microscópio Confocal para Heteranthera sp. 


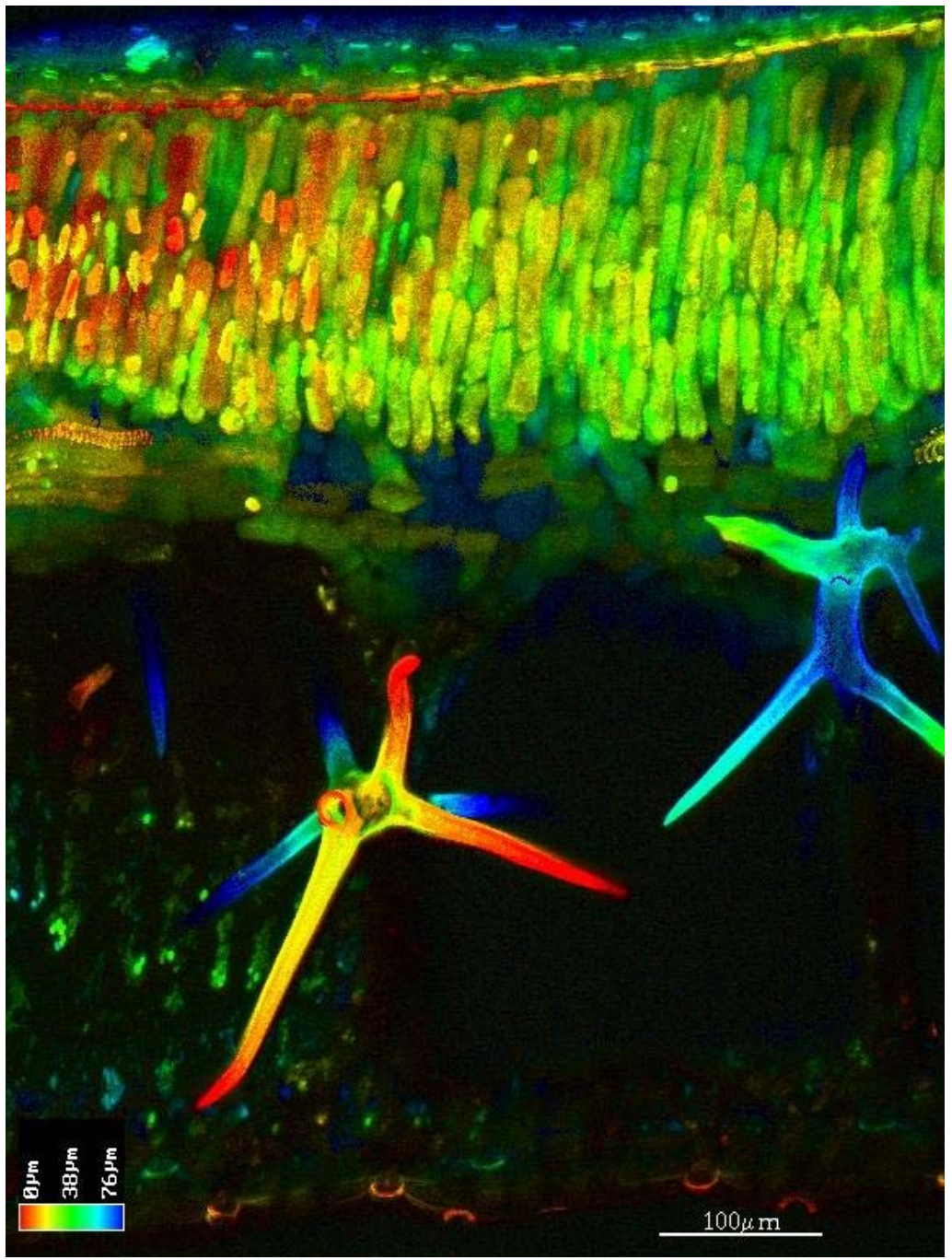

Figura V.9: Imagem tridimensional do microscópio Confocal para Nymphaea mexicana.

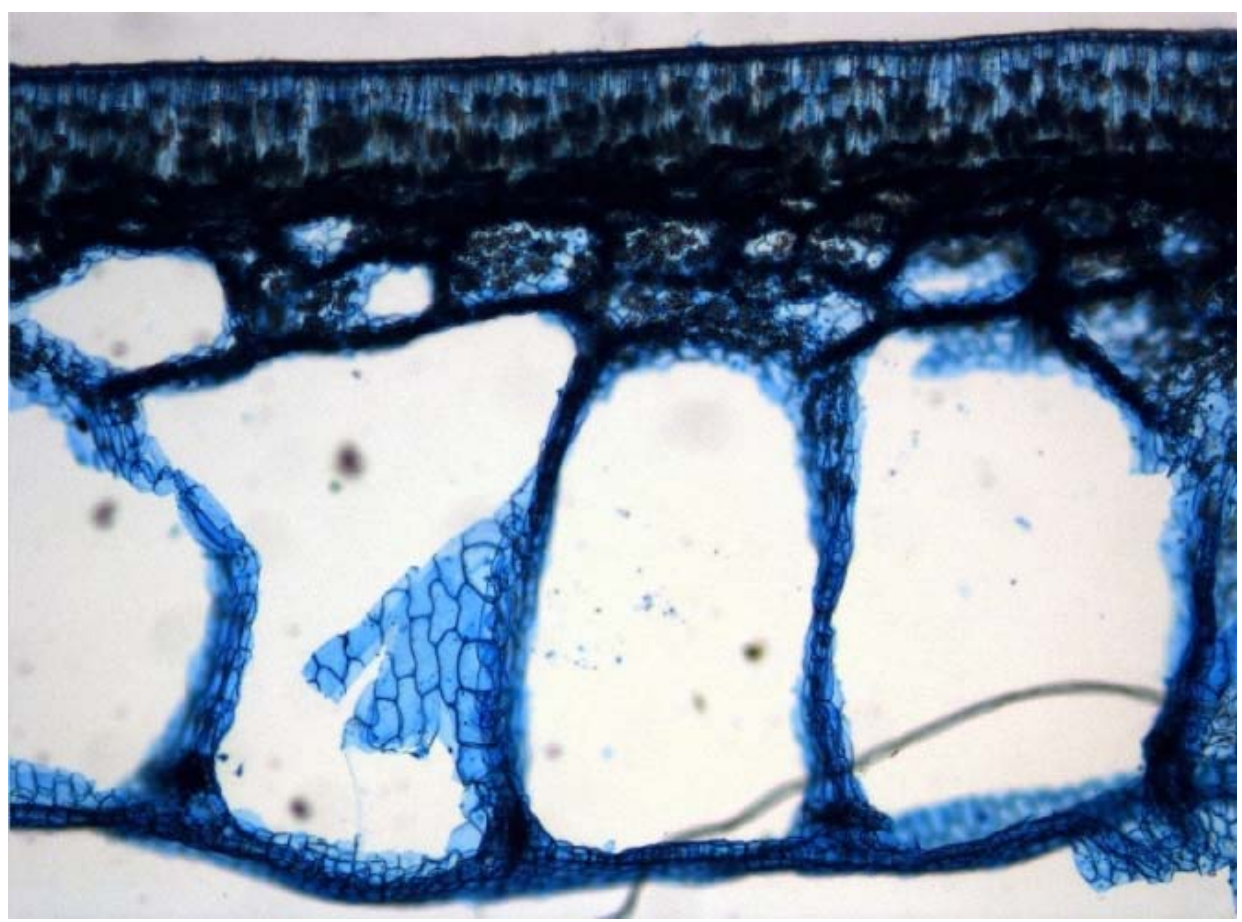

Figura V.10: Imagem do microscópio óptico para Limnobium laevigatum. 
Após as análises das imagens obtidas para as três folhas de cada espécie, foi possível calcular as proporções de espaços aéreos no parênquima esponjoso, através da confecção de vetores manuais referentes às áreas de ar (Figura V.11). Foram feitos cálculos para cinco diferentes seções da mesma folha, e os resultados para cada espécie podem ser observados no Apêndice, ao final da tese. A proporção dos espaços aéreos (\%) foi calculada a partir da razão entre os valores de área $\left(\mu^{2}\right)$ superficial das cavidades aéreas do Parênquima esponjoso em relação à área total da seção utilizada em cada caso:

Proporção de espaço aéreo $=($ Área de ar $/$ Área total do corte $){ }^{*} 100$

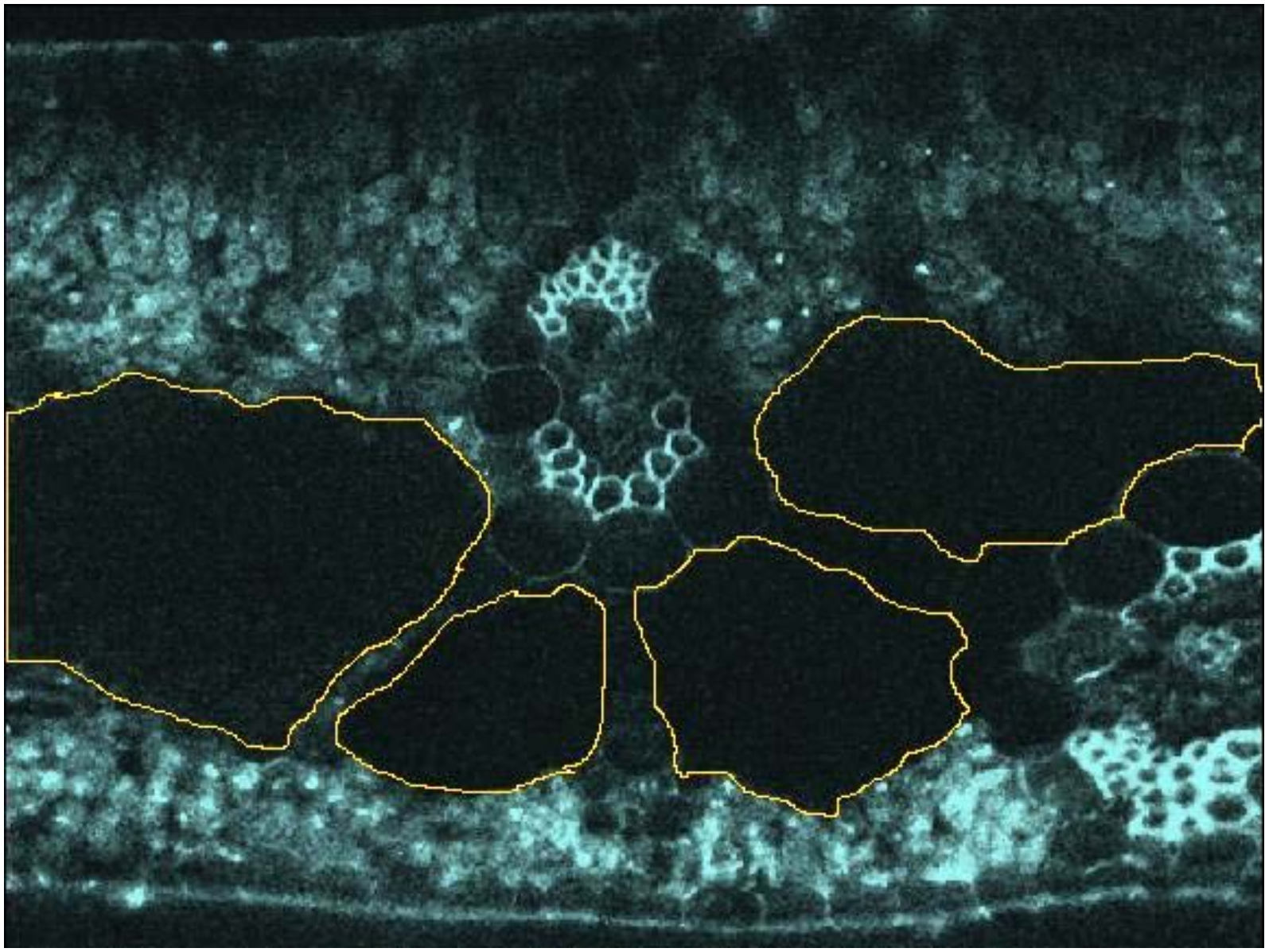

Figura V.11: Seção transversal obtida pelo microscópio confocal para uma das folhas de Eichhornia crassipes. Em amarelo podem ser observados os vetores desenhados sobre as porções aéreas encontradas no parênquima esponjoso. 
Os valores médios das cinco seções referentes à proporção de espaços aéreos para as folhas de máxima, média, e mínima reflectância no IVP, e a média para cada espécie estudada se encontram na Tabela V.1.

Tabela V.1: Proporção de espaços aéreos (\%) dentro das espécies estudadas, onde se observam as folhas com Máxima (Max), Média (Med) e Mínima (Min) Reflectâncias absolutas no IVP, e as médias das folhas, gerando valores representativos para espécie.

\begin{tabular}{|c|c|c|c|c|}
\cline { 2 - 5 } \multicolumn{1}{c|}{} & $\begin{array}{c}\text { Proporção (\%) } \\
\text { Max IVP }\end{array}$ & $\begin{array}{c}\text { Proporção (\%) } \\
\text { Med IVP }\end{array}$ & $\begin{array}{c}\text { Proporção (\%) } \\
\text { Min IVP }\end{array}$ & $\begin{array}{c}\text { Proporção (\%) } \\
\text { Média }\end{array}$ \\
\hline Eichhornia crassipes & 23,58 & 27,45 & 18,31 & 23,11 \\
\hline Pistia stratiotes & 35,53 & 32,29 & 41,63 & 36,48 \\
\hline Nymphaea mexicana & 41,85 & 38,92 & 36,52 & 39,10 \\
\hline Heteranthera reniformis & 12,66 & 11,085 & 8,43 & 10,72 \\
\hline Limnobium laevigatum & 63,67 & 57,82 & 43,59 & 55,027 \\
\hline
\end{tabular}

Na Figura V.12 podem ser observados o valor médio da Proporção de espaços aéreos encontrado para cada espécie de macrófita analisada. 
Proporções de espaços aéreos em macrófitas

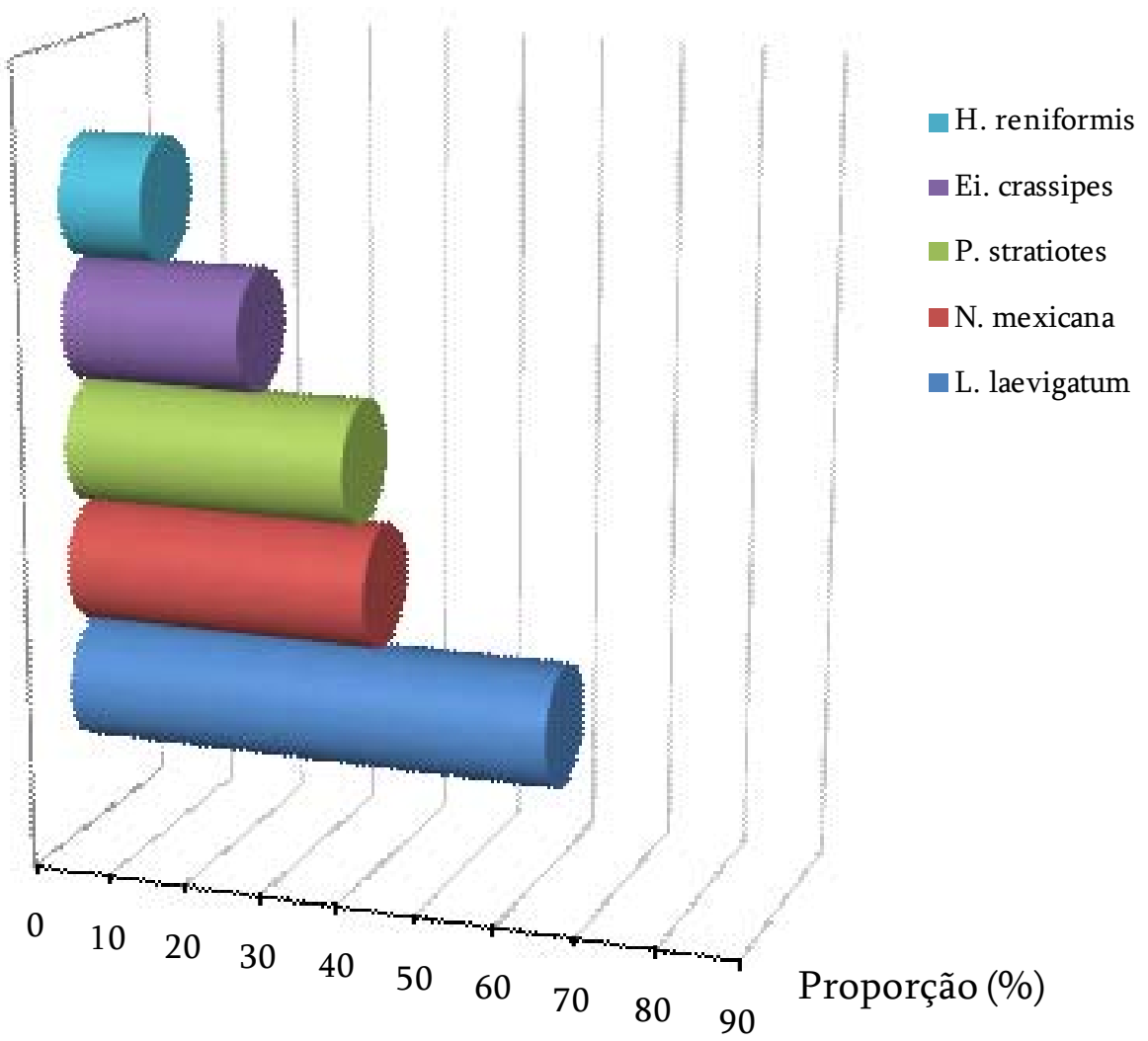

Figura V.12: Proporções de espaços aéreos (\%) médios no parênquima esponjoso em relação à área total de corte histológico em seções transversais de folhas de macrófitas. As barras representam os desvios padrão respectivos.

Observa-se que em Limnobium laevigatum a proporção de espaços aéreos no parênquima esponjoso foi de mais de 50\%, enquanto que em Heteranthera reniformis foi de cerca de 10\%, estando as outras espécies em valores intermediários. 
VI.3.2 - Análises conjuntas dos dados anatômicos e espectroradiométricos

No apêndice se encontram as pranchas representando a espécie, um corte histológico de uma das folhas da espécie de modo a mostrar sua estrutura do parênquima especialmente, e as respostas espectrais de cada uma. Em seguida de cada figura são resumidos os dados obtidos para cada espécie, incluindo os anatômicos e os espectroradiométricos.

Os resultados de reflectância no IVP, para as 10 folhas de cada espécie estudada são mostrados na Tabela V.2, onde também estão indicadas (sublinhadas) as folhas que apresentaram valores de Reflectância Absoluta máxima, média e mínima para cada espécie estudada.

Tabela V.2: Valores de Reflectância no IVP para as espécies analisadas - valor para cada folha e média dos valores. Os valores mínimos, médios e máximos para cada espécie estão sublinhados.

\begin{tabular}{|l|r|r|r|r|r|r|r|r|r|r|r|}
\cline { 2 - 12 } & Folha 1 & $\mathbf{2}$ & 3 & 4 & $\mathbf{5}$ & $\mathbf{6}$ & $\mathbf{7}$ & $\mathbf{8}$ & $\mathbf{9}$ & 10 & Média \\
\hline Eichhornia crassipes & $\underline{42,39}$ & 44,15 & 40,87 & $\underline{47,97}$ & 42,14 & 44,89 & 40,40 & 45,25 & 47,53 & $\underline{37,07}$ & 43,27 \\
\hline Pistia stratiotes & 41,96 & $\underline{40,82}$ & 42,92 & 44,94 & 45,21 & $\underline{46,06}$ & 44,33 & 45,69 & $\underline{44,18}$ & 43,28 & 43,94 \\
\hline Nymphaea mexicana & 41,43 & $\underline{42,60}$ & 44,77 & 39,43 & $\underline{45,10}$ & 42,96 & 43,02 & 43,71 & 41,81 & $\underline{39,06}$ & 42,39 \\
\hline Heteranthera reniformis & 38,97 & 39,29 & 42,39 & 42,61 & $\underline{39,91}$ & $\underline{42,88}$ & 41,40 & $\underline{36,84}$ & 42,40 & 37,59 & 40,43 \\
\hline Limnobium laevigatum & 58,19 & 55,79 & 67,61 & 69,54 & $\underline{71,66}$ & $\underline{63,51}$ & 71,26 & 56,47 & 60,27 & $\underline{55,43}$ & 62,97 \\
\hline
\end{tabular}


Os valores da figura a seguir (Figura V.13), mostram as diferenças interespecíficas, onde $L$. laevigatum foi a espécie com maior valor no IVP, seguida por $P$. stratiotes, $E$. crassipes, $N$. mexicana, e Heteranthera reniformis.

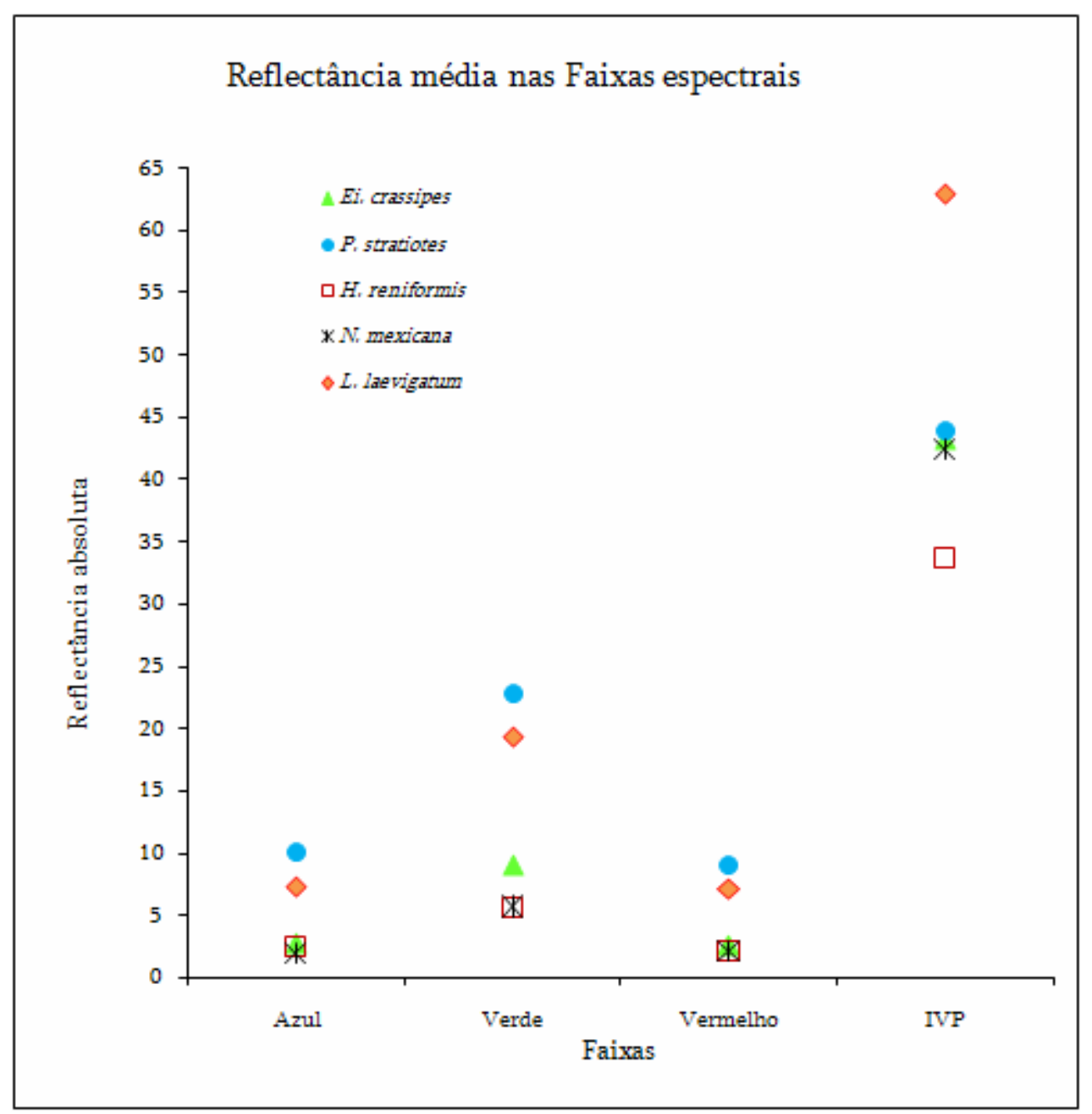

Figura V.13: Reflectância absoluta média das espécies nas faixas espectrais de interesse.

As proporções de espaços aéreos calculadas para as folhas de Máxima, Média e Mínima Reflectância das espécies estudadas se encontra na Tabela V.1 pôde ser comparada com os valores de reflectância no IVP. Observou-se que em Limnobium laevigatum a proporção de espaços aéreos no parênquima esponjoso foi de mais de $50 \%$, enquanto que 
em Heteranthera reniformis foi de cerca de 10\%, estando as outras espécies em valores intermediários, tendo o mesmo ocorrido quando da análise da resposta espectral dessas espécies no IVP (Figura V.14), o que corrobora os estudos citados anteriormente.

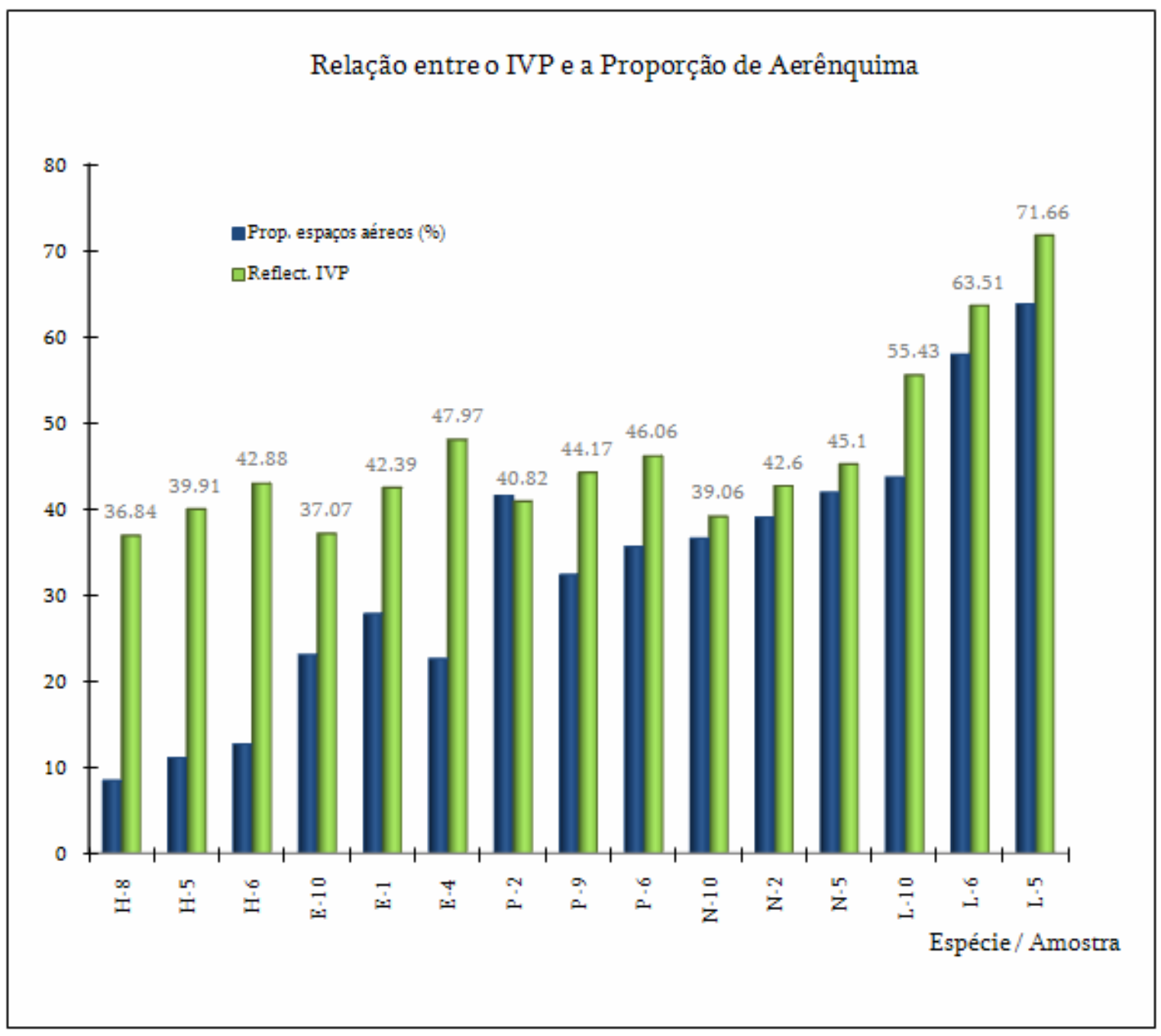

Figura V.14: Relação entre a Reflectância de espécies de macrófitas no IVP para as folhas com máxima, média e mínima reflectância de cada espécie, em relação à Proporção de Aerênquima. No eixo x se encontra a espécie e o número da folha analisada, em ordem crescente dos valores no IVP, sendo: $\mathrm{H}=$ Heteranthera sp., $\mathrm{E}=$ Eichhornia crassipes, $\mathrm{N}=$ Nymphaea mexicana, $\mathrm{P}=$ Pistia stratiotes, e $\mathrm{L}=$ Limnobium laevigatum. A coluna de reflectância no IVP tem os valores destacados, para maior compreensão. 
A relação entre as variáveis anatômicas para cada espécie também foi analisada

(Figura V.15).

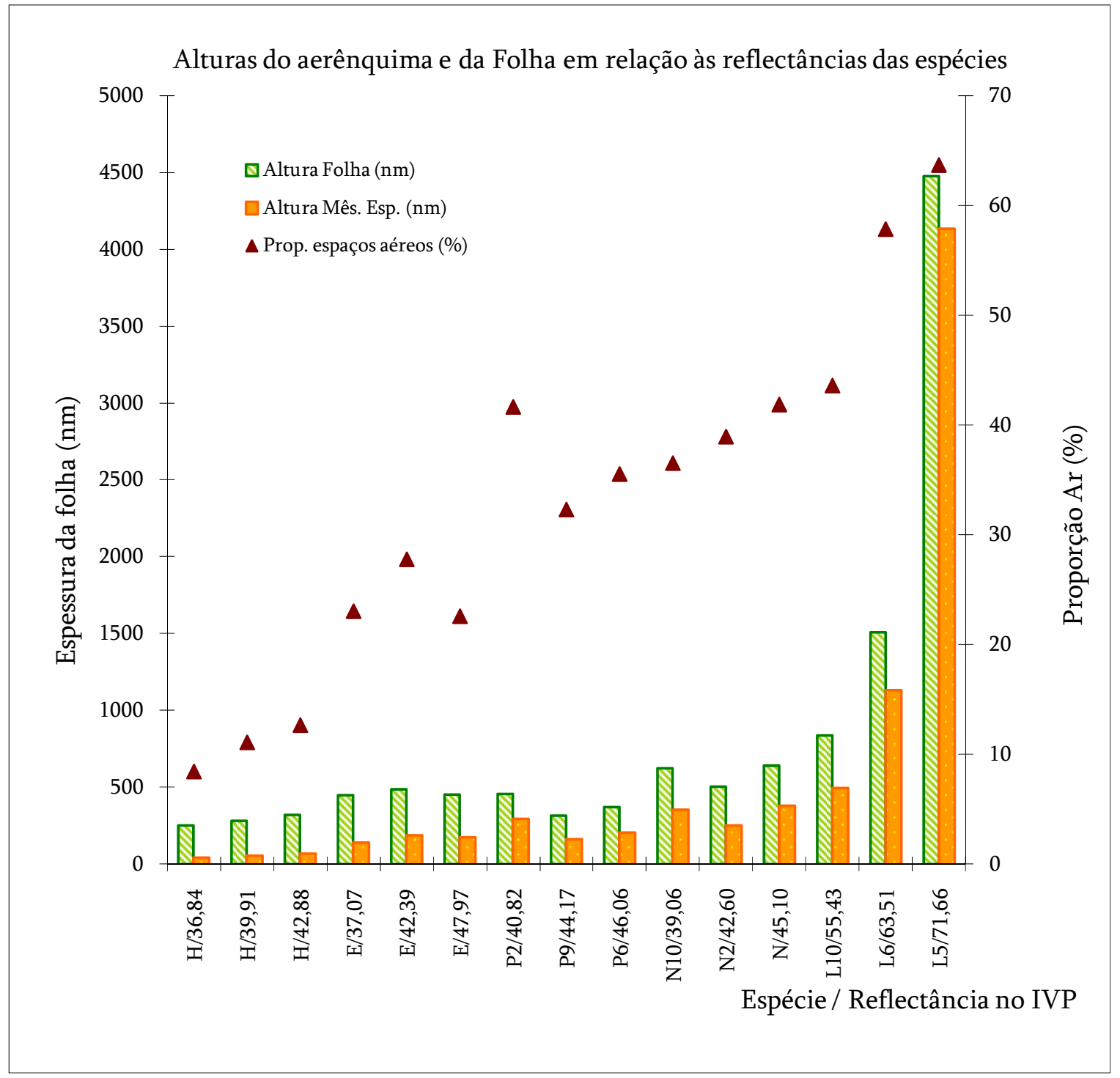

Figura V.15: Relação entre a Reflectância de espécies de macrófitas no IVP (eixo X - em ordem crescente para a espécie) em relação às variáveis: Espessura da folha, Espessura do Parênquima esponjoso, e Proporção de Ar presente no parênquima. No eixo X se encontra a espécie e seu respectivo valor médio no IVP, sendo: $\mathrm{H}=$ Heteranthera sp., $\mathrm{E}=$ Eichhornia crassipes, $\mathrm{N}=$ Nymphaea mexicana, $\mathrm{P}=$ Pistia stratiotes, e L = Limnobium laevigatum. 
Sabendo-se que a maior diferença entre as espécies foi indicada na faixa do IVP, foram plotados os dados anatômicos em relação ao valor médio nesta faixa (Figura V.16), onde se pode observar o aumento do IVP em função das variáveis anatômicas analisadas, o que também pode ser observado através dos valores de Correlação (Tabela V.29).

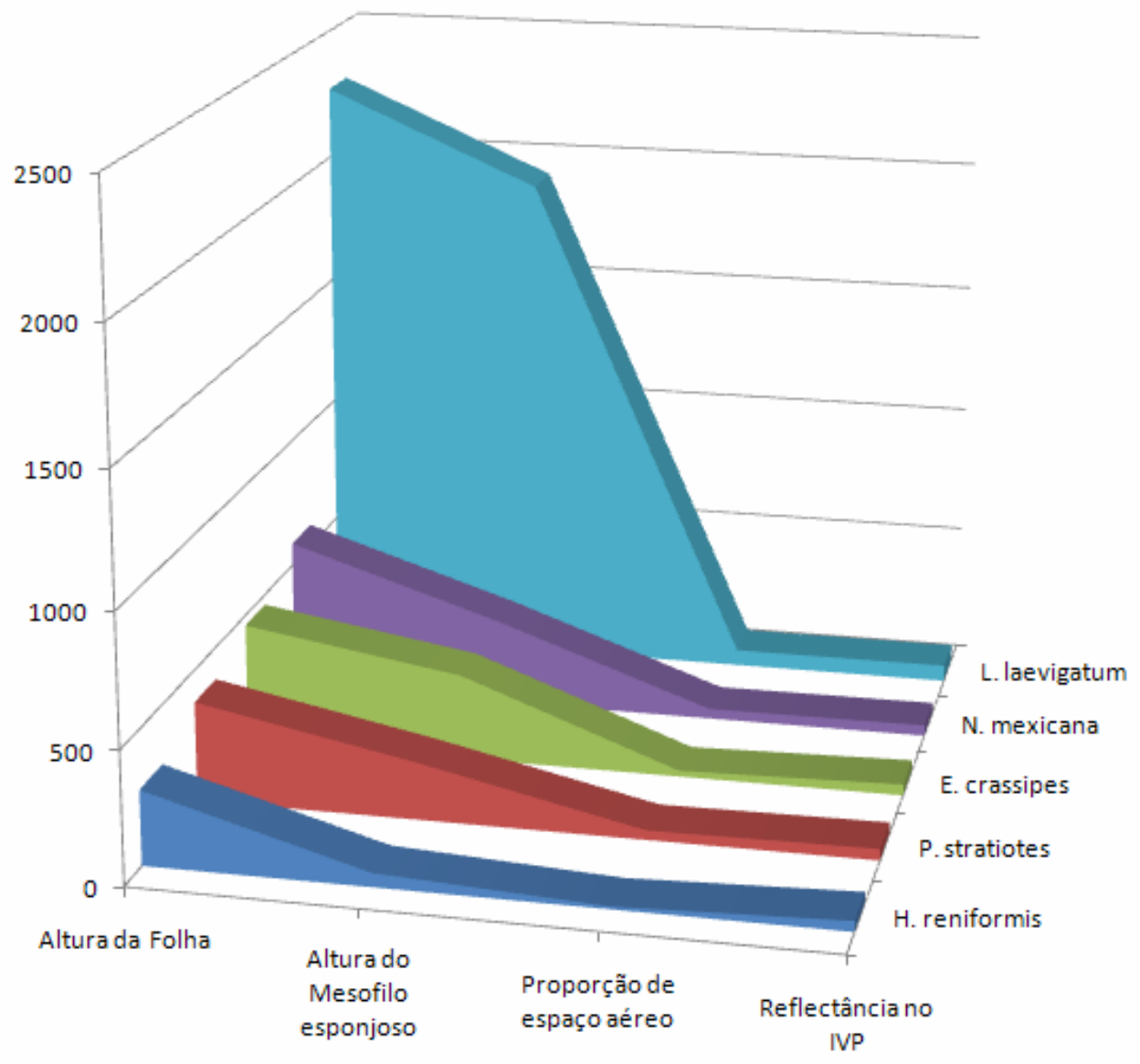

Figura V.16: Variáveis anatômicas em função da reflectância média no IVP para as espécies estudadas.

A análise de variância ANOVA foi realizada com os dados da Tabela V.3. 
Tabela V.3: Valores das variáveis utilizadas para a análise de variância, para as espécies estudadas.

\begin{tabular}{cccccc}
\hline & $\begin{array}{c}\text { Espessura da } \\
\text { Folha }\end{array}$ & $\begin{array}{c}\text { Espessura do Mesofilo } \\
\text { esponjoso }\end{array}$ & $\begin{array}{c}\text { Proporção de } \\
\text { espaço aéreo }\end{array}$ & IVP & $\begin{array}{c}\text { Proporção da } \\
\text { Câmara }\end{array}$ \\
\hline H. reniformis & 283,71 & 52,95 & 10,73 & 39,68 & 18.66 \\
P. stratiotes & 379,75 & 218,35 & 36,48 & 43,68 & 57.50 \\
E. crassipes & 460,84 & 329,00 & 23,12 & 42,48 & 71.39 \\
N. mexicana & 587,90 & 329,00 & 39,10 & 42,25 & 55.96 \\
L. laevigatum & 2271,28 & 1918,70 & 62,35 & 63,53 & 84.48 \\
\hline
\end{tabular}

Para um nível de significância igual a 0,08, os resultados da ANOVA aplicada à essas variáveis se encontra na Tabela V.4.

Tabela V.4: Resultado da ANOVA para a diferenciação entre as espécies utilizando as medidas anatômicas e de reflectância média no IVP.

\begin{tabular}{clllll}
\hline Fonte da variação & $S Q$ & $M Q$ & $f$ & valor- $P$ & fcrítico \\
\hline Entre grupos & 2565332.8 & 641333.2 & 2.515896 & 0.073812 & 2.444636 \\
Dentro dos grupos & 5098248.7 & 254912.4 & & & \\
Total & 7663581.5 & & & & \\
\hline
\end{tabular}

SQ é a soma dos quadrados, MQ é a média dos Quadrados e fé obtido pela média dentro dos grupos, dividida pela média entre os grupos.

Sendo f maior que fcrítico, há portanto diferenças significativas na discriminação de macrófitas. Assim, o teste de variância mostrou que as medidas utilizadas são suficientemente significativas para a diferenciação das espécies estudadas, para alfa igual a 
0,8. Para verificar quais variáveis mais influenciaram na discriminação das espécies, foi realizada a Análise de Correspondência com os dados.

A Análise de Correspondência mostrou ser possível representar todos os dados amostrais em apenas dois eixos (mais de 98\% do total de variação das amostras), como pode ser observado na Tabela V.5.

Tabela V.5: Resultado referente à análise de correspondência, onde se observa a representatividade de cada eixo gerado pela análise.

\begin{tabular}{|c|c|}
\hline Eixo & Percentagem cumulativa \\
\hline 1 & 88,51 \\
\hline 2 & 98,64 \\
\hline 3 & 100,000 \\
\hline 4 & 100,000 \\
\hline
\end{tabular}

Utilizando os dados dos Eixos 1 e 2, foi possível identificar se havia associação entre as variáveis anatômicas (Figura V.18). 


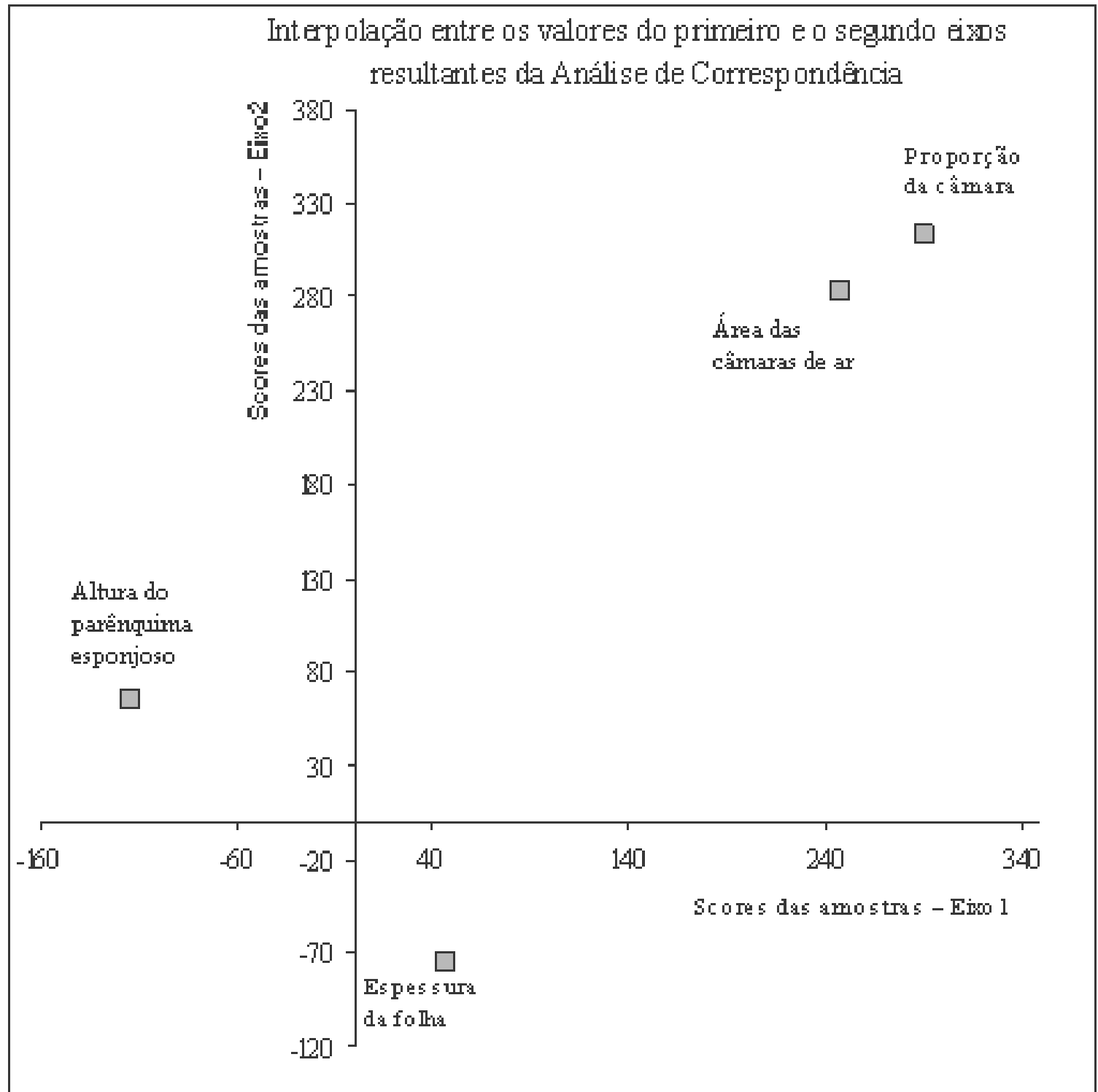

Figura V.18: Resultado da interpolação entre os eixos resultantes da análise de correspondência entre variáveis.

O resultado mostrou que há grande correlação entre a proporção da câmara de ar e a proporção de espaços aéreos. Também foi possível verificar que as espécies de macrófitas puderam ser agrupadas (Figura V.19) baseando-se nas variáveis anatômicas utilizadas. Houve a formação de quatro grupos distintos de amostras. 


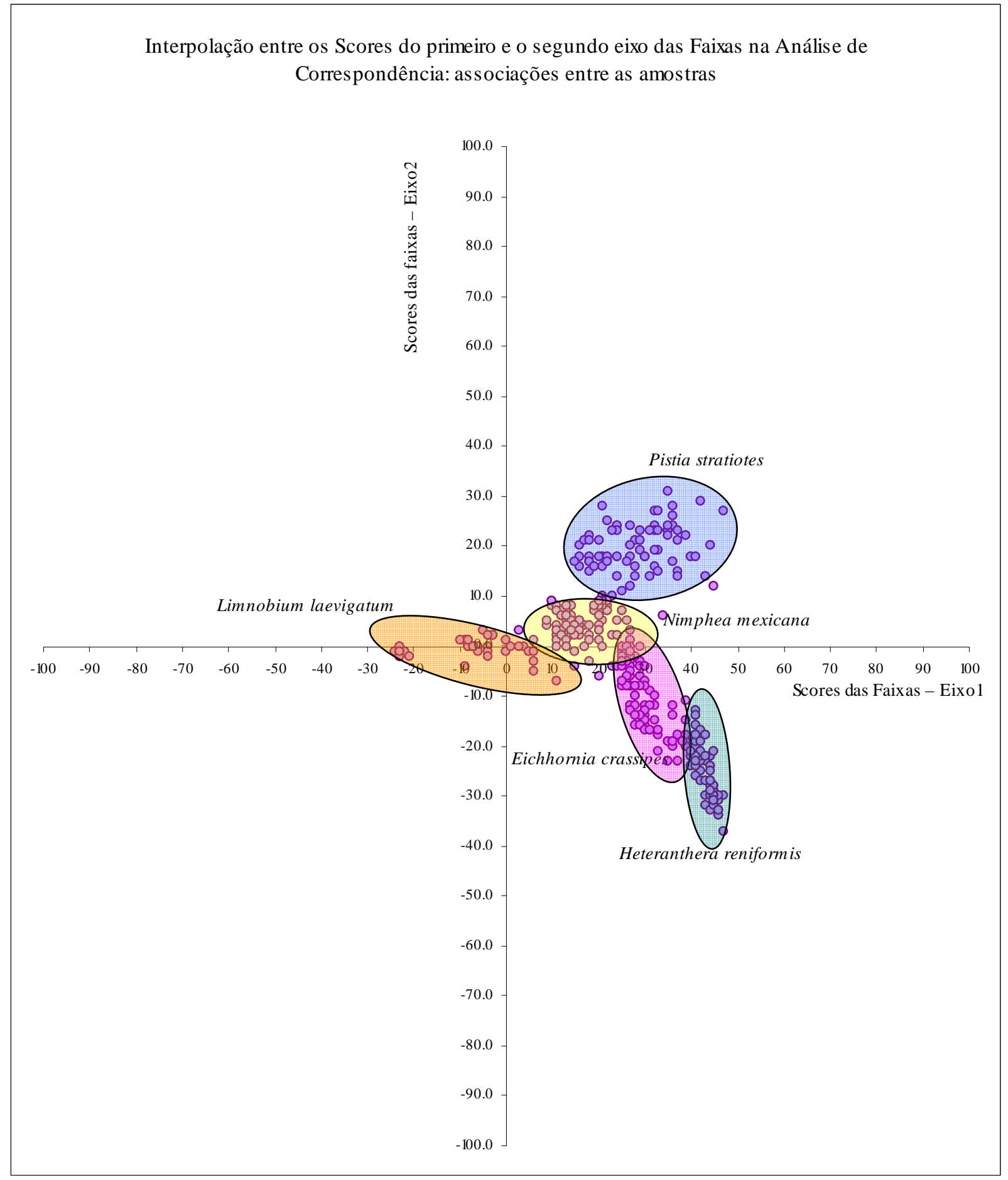

Figura V.19 : Associações entre amostras, resultantes da análise de correspondência.

Para verificar qual das variáveis influenciou mais na discriminação de cada espécie, foram sobrepostos os gráficos das figuras. O resultado (Figura V.20) mostrou que, em 
relação às variáveis anatômicas, as espécies são distinguíveis principalmente pelas variáveis espessura da folha e altura do mesofilo esponjoso.

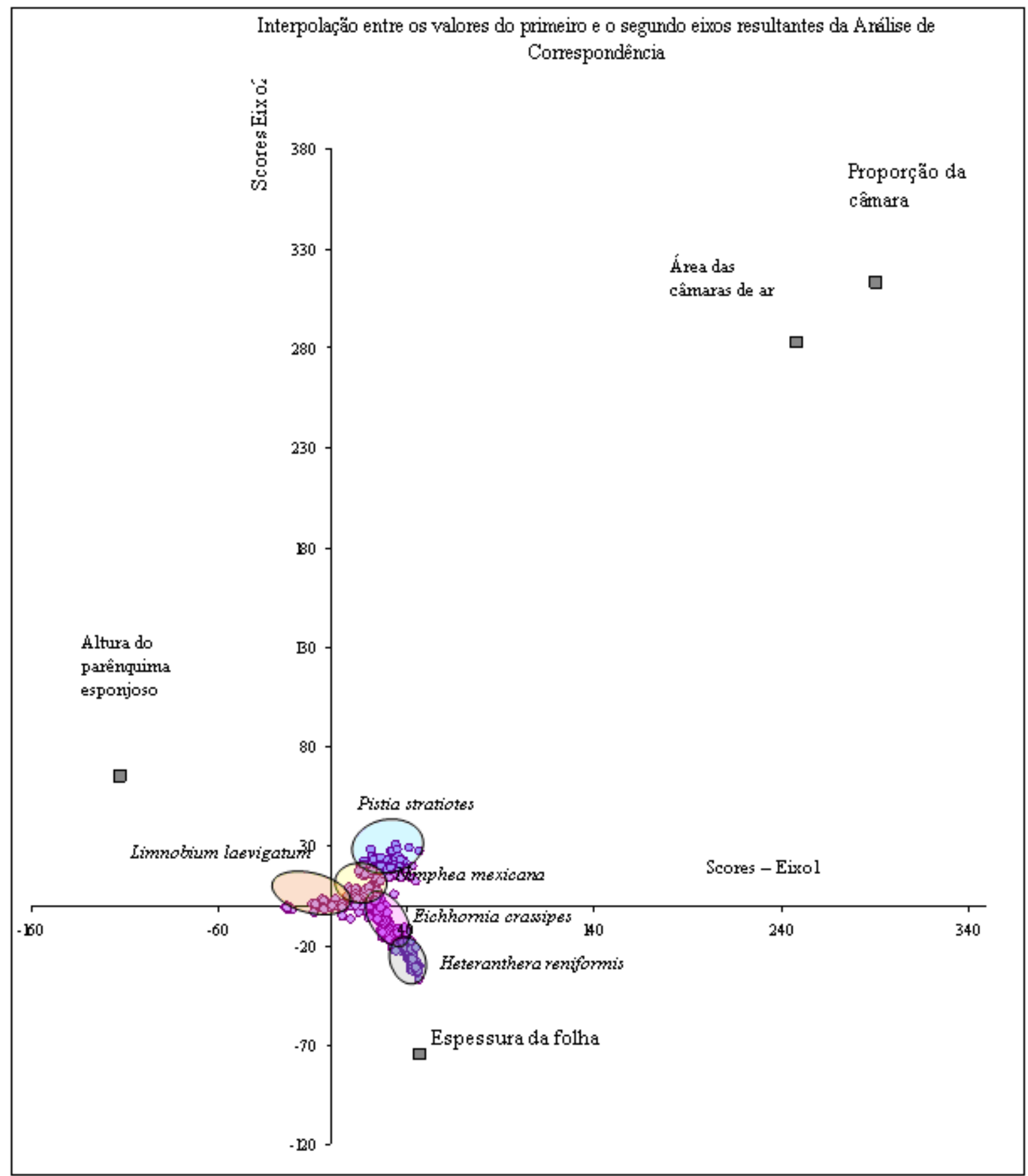

Figura V.20: Associação entre variáveis e amostras, resultante da Análise de Correspondência. 


\section{V.4 - CONCLUSÕES}

O uso do microscópio confocal mostrou-se muito útil, na medida em que simula o corte histológico, fazendo isso em tempo mais rápido, e a um custo mais baixo. Entretanto este microscópio ainda não resolve à questão de cálculo de volume do aerênquima, pois há ainda muita imprecisão em diversas fases da preparação anatômica, desde o corte das folhas até o cálculo das áreas das câmaras de ar.

Os resultados mostraram que as características anatômicas utilizadas corroboraram as premissas de que os parâmetros anatômicos estão relacionados especialmente com a resposta espectral no IVP.

Espectralmente, a faixa que melhor possibilitou distinguir as espécies estudadas foi a IVP, seguida dos índices entre Verde e IVP, Vermelho e IVP e IVP e Azul.

Limnobium laevigatum foi a espécie com maior valor no IVP, seguida por Pistia stratiotes, Eichhornia crassipes, Nymphaea mexicana, e Heteranthera reniformis.

Os resultados mostraram que não foi possível relacionar a reflectância à proporção de espaços aéreos dentro da espécie, mas foi possível relacionar a reflectância de diferentes espécies à proporção média de espaços aéreos de cada uma. 
Observou-se também que em Limnobium laevigatum a proporção de espaços aéreos no parênquima esponjoso foi de mais de $50 \%$, enquanto que em Heteranthera reniformis foi de cerca de $10 \%$, estando as outras espécies em valores intermediários. O mesmo ocorreu quando da análise da resposta espectral dessas espécies no IVP.

A proporção de espaços aéreos, juntamente com a espessura da folha e a espessura do parênquima esponjoso mostraram correlação maior que $85 \%$ com os valores de IVP das espécies.

\section{V.5 - AGRADECIMENTOS ESPECIAIS}

Ao Prof. Gregório Cardoso Tápias Ceccantini, Giuliano Maselli Locosselli, Waldir Caldeira e Márcio Valentim Cruz, que auxiliaram nas análises anatômicas e de microscopia confocal e óptico. 


\section{V.6 - CONSIDERAÇÕES FINAIS}

Estudos anteriores já relacionavam o aumento dos espaços aéreos com aumento no IVP. Entretanto, outros fatores devem ser levados em consideração nesta reflectância como aspectos relacionados à espessura da folha (presença de cutícula, espessura da epiderme, espaços aéreos no parênquima) e ao parênquima esponjoso (dimensões e número dos espaços aéreos), e podem ser sugeridos como hipóteses de estudos futuros. 


\section{V.6-APÊNDICE}

Tabela V.6: Número da folha para valores de reflectância para Eichhornia crassipes.

\begin{tabular}{|l|r|r|r|}
\cline { 2 - 4 } \multicolumn{1}{l|}{} & Máx = Folha 4 & Médio = Folha 1 & Mínimo = Folha 10 \\
\hline Amostra 1 & 22.79057 & 25.99418 & 18.84647 \\
\hline Amostra 2 & 23.76843 & 29.28216 & 18.32998 \\
\hline Amostra 3 & 23.89238 & 27.1507 & 18.1966 \\
\hline Amostra 4 & 23.87892 & 27.49432 & 18.0689 \\
\hline Amostra 5 & 23.56944 & 27.35405 & 18.11408 \\
\hline Média: & 23.57995 & 27.45508 & 18.31121 \\
\hline Desvio: & 0.459821 & 1.18077 & 0.315264 \\
\hline
\end{tabular}

Tabela V.7: Número da folha para valores de reflectância para Pistia stratiotes.

\begin{tabular}{|l|r|r|r|}
\cline { 2 - 4 } \multicolumn{1}{c|}{} & Máx = Folha 6 & Médio = Folha 9 & Mínimo = Folha 2 \\
\hline Amostra 1 & 38.18396 & 33.52764 & 45.62091 \\
\hline Amostra 2 & 37.45136 & 34.15513 & 43.66267 \\
\hline Amostra 3 & 34.71851 & 30.63628 & 40.8551 \\
\hline Amostra 4 & 33.42282 & 30.94341 & 39.27974 \\
\hline Amostra 5 & 33.8586 & 32.19558 & 38.75051 \\
\hline Média: & 35.52705 & 32.29161 & 41.63379 \\
\hline Desvio: & 2.157972 & 1.546568 & 2.935756 \\
\hline
\end{tabular}

Tabela V.8: Número da folha para valores de reflectância para Nymphaea mexicana:

\begin{tabular}{|l|r|r|r|}
\cline { 2 - 4 } \multicolumn{1}{c|}{} & Máx = Folha 5 & Médio = Folha 2 & Mínimo = Folha 10 \\
\hline Amostra 1 & 43.09247 & 37.29672 & 32.72346 \\
\hline Amostra 2 & 42.3818 & 38.81892 & 38.07396 \\
\hline Amostra 3 & 42.07076 & 40.56296 & 38.10143 \\
\hline
\end{tabular}




\begin{tabular}{|l|r|r|r|}
\hline Amostra 4 & 40.73297 & 38.884 & 37.87537 \\
\hline Amostra 5 & 40.98903 & 39.06133 & 35.83306 \\
\hline Média: & 41.85341 & 38.92479 & 36.52146 \\
\hline Desvio: & 0.982885 & 1.158202 & 2.325852 \\
\hline
\end{tabular}

Tabela V.9: Número da folha para valores de reflectância para Heteranthera reniformis.

\begin{tabular}{|l|r|r|r|}
\cline { 2 - 4 } \multicolumn{1}{l|}{} & Máx = Folha 6 & Médio = Folha 5 & Mínimo = Folha 8 \\
\hline Amostra 1 & 14.33527 & 13.88654 & 10.20403 \\
\hline Amostra 2 & 13.01892 & 12.49572 & 9.823539 \\
\hline Amostra 3 & 15.00747 & 11.89116 & 8.327367 \\
\hline Amostra 4 & 11.49562 & 8.724817 & 7.241479 \\
\hline Amostra 5 & 9.453802 & 8.428485 & 6.544382 \\
\hline Média: & 12.66222 & 11.08535 & 8.42816 \\
\hline Desvio: & 2.240616 & 2.403966 & 1.586489 \\
\hline
\end{tabular}

Tabela V.10: Número da folha para valores de reflectância para Limnobium laevigatum:

\begin{tabular}{|l|r|r|r|}
\cline { 2 - 4 } \multicolumn{1}{c|}{} & Máx = Folha 5 & Médio = Folha 6 & Mínimo = Folha 10 \\
\hline Amostra 1 & 85.63661 & 58.56633 & 45.81231 \\
\hline Amostra 2 & 83.40751 & 58.29579 & 39.22094 \\
\hline Amostra 3 & 86.87425 & 55.77175 & 45.32017 \\
\hline Amostra 4 & 84.34766 & 57.75411 & 43.99391 \\
\hline Amostra 5 & 85.82052 & 58.72021 & 43.58683 \\
\hline Média: & 85.63661 & 57.82164 & 3.010198 \\
\hline Desvio: & 1.352478 & 1.203474 & \\
\hline
\end{tabular}


Análises conjuntas dos dados anatômicos e espectroradiométricos

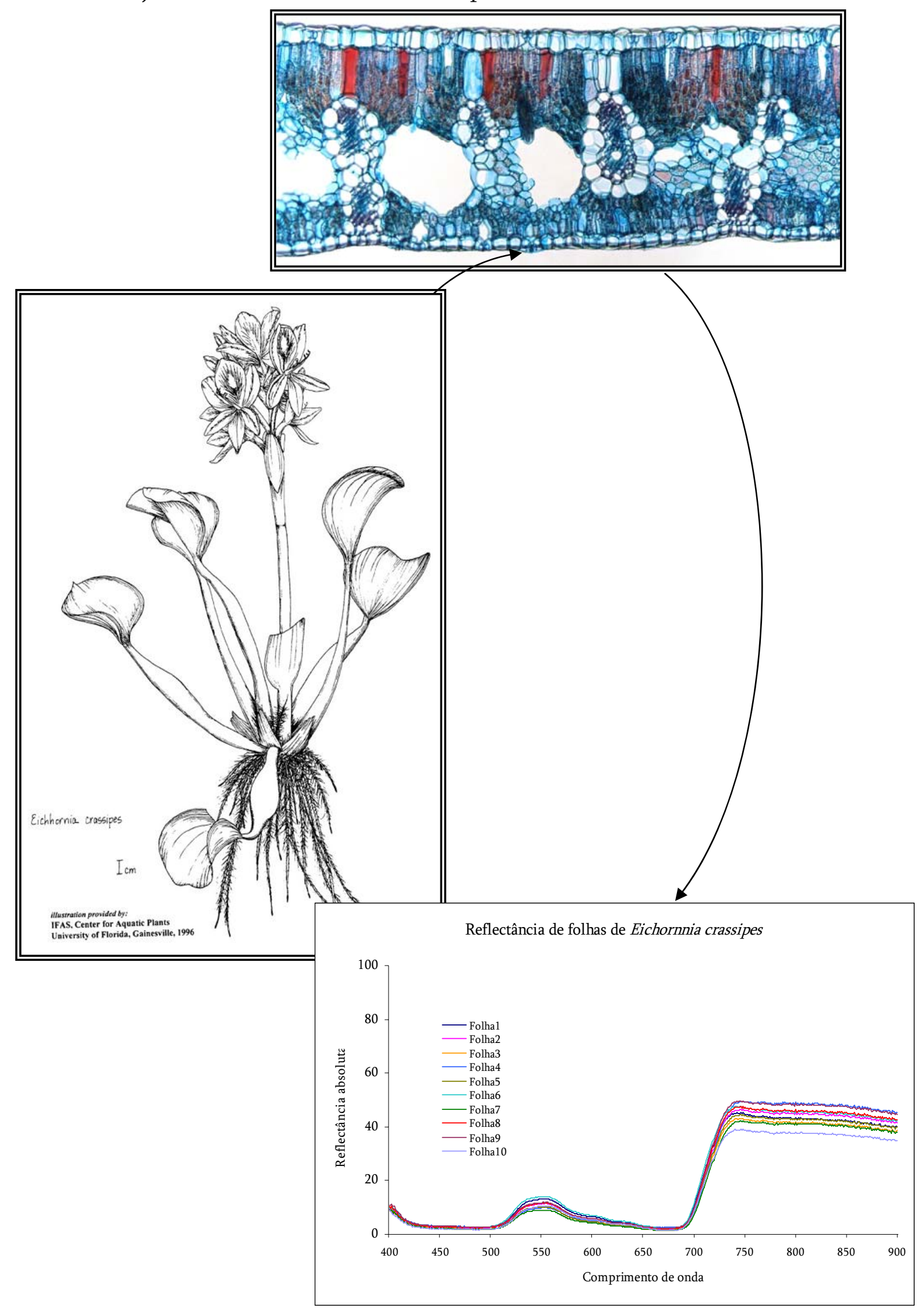

Figura V.17: Análise conjunta de Eichhornia crassipes 
Tabela V.11: Médias de reflectância absoluta nas faixas espectrais para as folhas de Eichhornia crassipes.

\begin{tabular}{|l|r|}
\hline Médias & \\
\hline Azul & 2.76226 \\
\hline Verde & 9.090533 \\
\hline Vermelho & 2.583198 \\
\hline IVP & 43.26656 \\
\hline
\end{tabular}

Tabela V.12: Índices entre as faixas espectrais para as folhas de Eichhornia crassipes.

\begin{tabular}{|l|l|}
\hline Índices & \multicolumn{1}{|l}{} \\
\hline Vermelho-IVP & 0.887319 \\
\hline Verde-Vermelho & 0.557434 \\
\hline Verde-IVP & 0.652749 \\
\hline Verde-Azul & 0.533906 \\
\hline IVP-Azul & 0.879977 \\
\hline
\end{tabular}

Tabela V.13: Valores de pico de comprimento de onda nas faixas espectrais para as folhas de Eichhornia crassipes.

\begin{tabular}{|l|l|}
\hline Picos & \\
\hline Azul & 489 \\
\hline Verde & 554 \\
\hline Vermelho & 671 \\
\hline Red Edge & 747 \\
\hline IVP & 777 \\
\hline
\end{tabular}

Tabela V.14: Valores dos Limites Vermelhos para as folhas de Eichhornia crassipes.

\begin{tabular}{|l|l|}
\hline Limites Vermelhos & \multicolumn{1}{|l}{} \\
\hline Limites Vermelhos por Interpolação & 715 \\
\hline Desvio Padrão & 1,00 \\
\hline Limites Vermelhos por Derivada & 712 \\
\hline Desvio Padrão & 2,33 \\
\hline
\end{tabular}

Tabela V.15: Proporção de espaços aéreos (\%) em relação ao número da folha para valores de reflectância para Eichhornia crassipes.

\begin{tabular}{|l|r|r|r|}
\cline { 2 - 4 } \multicolumn{1}{c|}{} & Máx = Folha 4 & Médio = Folha 1 & Mínimo = Folha 10 \\
\hline Amostra 1 & 22.79057 & 25.99418 & 18.84647 \\
\hline Amostra 2 & 23.76843 & 29.28216 & 18.32998 \\
\hline Amostra 3 & 23.89238 & 27.1507 & 18.1966 \\
\hline Amostra 4 & 23.87892 & 27.49432 & 18.0689 \\
\hline Amostra 5 & 23.56944 & 27.35405 & 18.11408 \\
\hline Média: & 23.57995 & 27.45508 & 18.31121 \\
\hline Desvio: & 0.459821 & 1.18077 & 0.315264 \\
\hline
\end{tabular}




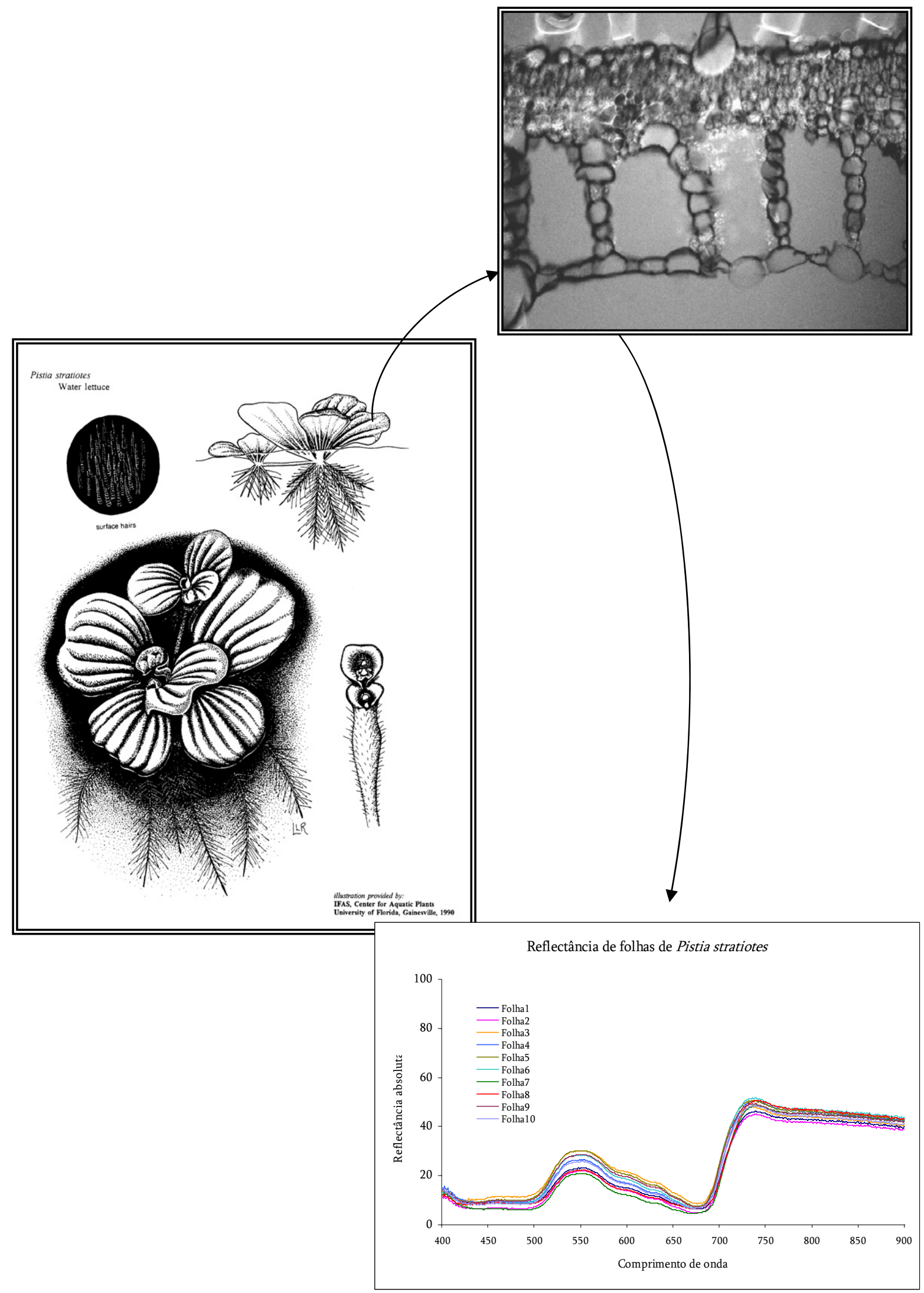

Figura V.18 - Análise conjunta de Pistia stratiotes 
Tabela V.16: Médias de reflectância absoluta nas faixas espectrais para as folhas de Pistia stratiotes.

\begin{tabular}{|l|l|}
\hline Médias & \multicolumn{1}{|l}{} \\
\hline Azul & 10.08838 \\
\hline Verde & 22.83325 \\
\hline Vermelho & 9.077627 \\
\hline IVP & 43.93981 \\
\hline
\end{tabular}

Tabela V.17: Índices entre as faixas espectrais para as folhas de Pistia stratiotes.

\begin{tabular}{|l|l|}
\hline Índices & \multicolumn{1}{|l}{} \\
\hline Vermelho-IVP & 0.657561 \\
\hline Verde-Vermelho & 0.431064 \\
\hline Verde-IVP & 0.316094 \\
\hline Verde-Azul & 0.387127 \\
\hline IVP-Azul & 0.626551 \\
\hline
\end{tabular}

Tabela V.18: Valores de pico de comprimento de onda nas faixas espectrais para as folhas de Pistia stratiotes.

\begin{tabular}{|l|l|}
\hline Picos & \\
\hline Azul & 470 \\
\hline Verde & 552 \\
\hline Vermelho & 673 \\
\hline Red Edge & 738 \\
\hline IVP & 770 \\
\hline
\end{tabular}

Tabela V.19: Valores dos Limites Vermelhos para as folhas de Pistia stratiotes.

\begin{tabular}{|l|l|}
\hline Limites Vermelhos & \multicolumn{1}{|l}{} \\
\cline { 1 - 1 } Limites Vermelhos por & 706 \\
\hline Interpolação & 2,97 \\
\hline Desvio Padrão & 701 \\
\hline Limites Vermelhos por Derivada & 0,52 \\
\hline Desvio Padrão &
\end{tabular}

Tabela V.20: Proporção de espaços aéreos (\%) em relação ao número da folha para valores de reflectância para Pistia stratiotes.

\begin{tabular}{|l|r|r|r|}
\cline { 2 - 4 } \multicolumn{1}{c|}{} & Máx = Folha 4 & Médio = Folha 1 & Mínimo = Folha 10 \\
\hline Amostra 1 & 38.18396 & 33.52764 & 45.62091 \\
\hline Amostra 2 & 37.45136 & 34.15513 & 43.66267 \\
\hline Amostra 3 & 34.71851 & 30.63628 & 40.8551 \\
\hline Amostra 4 & 33.42282 & 30.94341 & 39.27974 \\
\hline Amostra 5 & 33.8586 & 32.19558 & 38.75051 \\
\hline Média: & 35.52705 & 32.29161 & 41.63379 \\
\hline Desvio: & 2.157972 & 1.546568 & 2.935756 \\
\hline
\end{tabular}




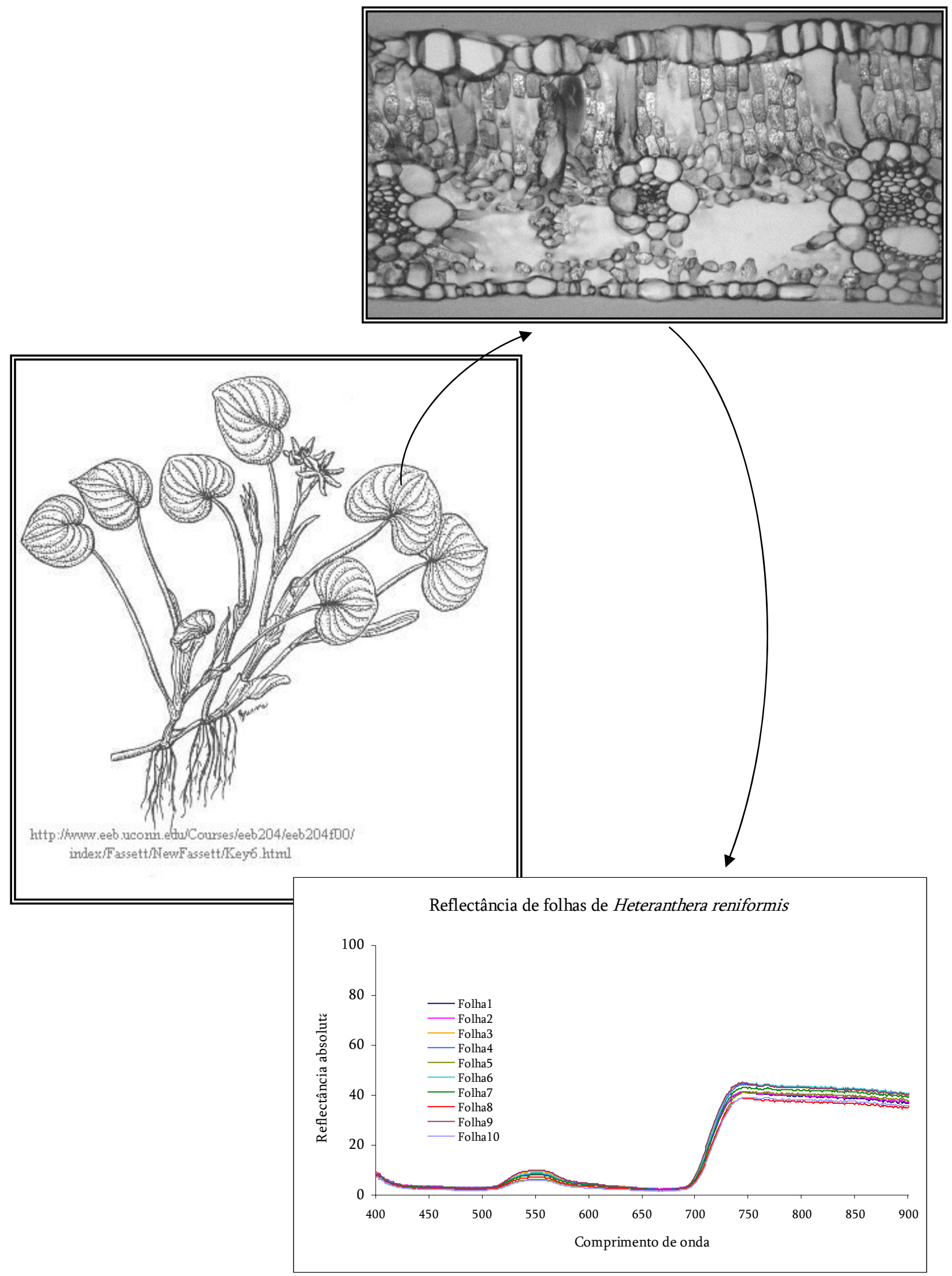

Figura V.19 - Análise conjunta de Heteranthera reniformis 
Tabela V.21: Médias de reflectância absoluta nas faixas espectrais para as folhas de Heteranthera reniformis.

\begin{tabular}{|l|l|}
\hline Médias & \multicolumn{1}{|l}{} \\
\hline Azul & 2.398937 \\
\hline Verde & 5.543287 \\
\hline Vermelho & 2.054551 \\
\hline IVP & 33.69133 \\
\hline
\end{tabular}

Tabela V.22: Índices entre as faixas espectrais para as folhas de Heteranthera reniformis.

\begin{tabular}{|l|l|}
\hline Índices & \multicolumn{1}{|l}{} \\
\hline Vermelho-IVP & 0.885047 \\
\hline Verde-Vermelho & 0.459175 \\
\hline Verde-IVP & 0.717429 \\
\hline Verde-Azul & 0.395903 \\
\hline IVP-Azul & 0.867059 \\
\hline
\end{tabular}

Tabela V.23: Valores de pico de comprimento de onda nas faixas espectrais para as folhas de Heteranthera reniformis.

\begin{tabular}{|l|l|}
\hline Picos & \\
\hline Azul & 490 \\
\hline Verde & 553 \\
\hline Vermelho & 667 \\
\hline Red Edge & 746 \\
\hline IVP & 773 \\
\hline
\end{tabular}

Tabela V.24: Valores dos Limites Vermelhos para as folhas de Heteranthera reniformis.

\begin{tabular}{|l|l|}
\hline Limites Vermelhos & \multicolumn{1}{|l}{} \\
\cline { 1 - 1 } Limites Vermelhos por & 717 \\
\hline Interpolação & 0,63 \\
\hline Desvio Padrão & 715 \\
\hline Limites Vermelhos por Derivada & 1,87 \\
\hline
\end{tabular}

Tabela V.25: Proporção de espaços aéreos (\%) em relação ao número da folha para valores de reflectância para Heteranthera reniformis.

\begin{tabular}{|l|r|r|r|}
\cline { 2 - 4 } \multicolumn{1}{c|}{} & Máx = Folha 6 & Médio = Folha 5 & Mínimo = Folha 8 \\
\hline Amostra 1 & 14.33527 & 13.88654 & 10.20403 \\
\hline Amostra 2 & 13.01892 & 12.49572 & 9.823539 \\
\hline Amostra 3 & 15.00747 & 11.89116 & 8.327367 \\
\hline Amostra 4 & 11.49562 & 8.724817 & 7.241479 \\
\hline Amostra 5 & 9.453802 & 8.428485 & 6.544382 \\
\hline Média: & 12.66222 & 11.08535 & 8.42816 \\
\hline Desvio: & 2.240616 & 2.403966 & 1.586489 \\
\hline
\end{tabular}




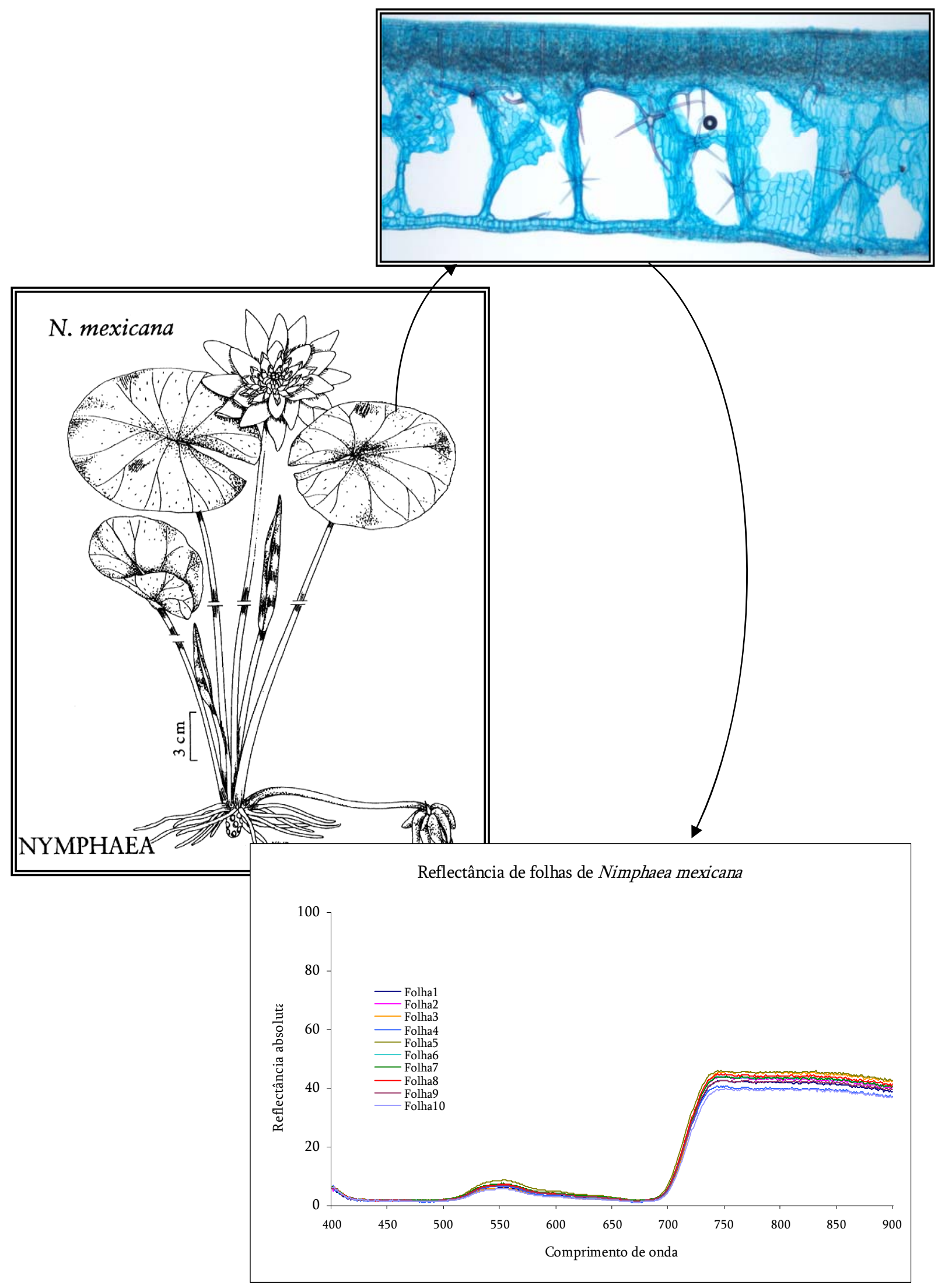

Figura V.20 - Análise conjunta de Nymphaea mexicana 
Tabela V.26: Médias de reflectância absoluta nas faixas espectrais para as folhas de Nymphaea mexicana.

\begin{tabular}{|l|r|}
\hline Médias & \\
\hline Azul & 1.921729 \\
\hline Verde & 5.625911 \\
\hline Vermelho & 2.10528 \\
\hline IVP & 42.38837 \\
\hline
\end{tabular}

Tabela V.27: Índices entre as faixas espectrais para as folhas de Nymphaea mexicana.

\begin{tabular}{|l|r|}
\hline Índices & \multicolumn{1}{|r}{ Vermelho-IVP } \\
\hline Verde-Vermelho & 0.405367 \\
\hline Verde-IVP & 0.765657 \\
\hline Verde-Azul & 0.490773 \\
\hline IVP-Azul & 0.91326 \\
\hline
\end{tabular}

Tabela V.28: Valores de pico de comprimento de onda nas faixas espectrais para as folhas de Nymphaea mexicana.

\begin{tabular}{|l|l|}
\hline Picos & \\
\hline Azul & 485 \\
\hline Verde & 553 \\
\hline Vermelho & 672 \\
\hline Red Edge & 751 \\
\hline IVP & 788 \\
\hline
\end{tabular}

Tabela V.29: Valores dos Limites Vermelhos para as folhas de Heteranthera reniformis.

\begin{tabular}{|l|l|}
\hline Limites Vermelhos & \multicolumn{1}{|l}{} \\
\cline { 1 - 1 } Limites Vermelhos por & 718 \\
\hline Interpolação & 0,44 \\
\hline Desvio Padrão & 718 \\
\hline Limites Vermelhos por Derivada & 1,73 \\
\hline Desvio Padrão &
\end{tabular}

Tabela V.30: Proporção de espaços aéreos (\%) em relação ao número da folha para valores de reflectância para Heteranthera reniformis.

\begin{tabular}{|l|r|r|r|}
\cline { 2 - 4 } \multicolumn{1}{c|}{} & Máx = Folha 6 & Médio = Folha 5 & Mínimo = Folha 8 \\
\hline Amostra 1 & 43.09247 & 37.29672 & 32.72346 \\
\hline Amostra 2 & 42.3818 & 38.81892 & 38.07396 \\
\hline Amostra 3 & 42.07076 & 40.56296 & 38.10143 \\
\hline Amostra 4 & 40.73297 & 38.884 & 37.87537 \\
\hline Amostra 5 & 40.98903 & 39.06133 & 35.83306 \\
\hline Média: & 41.85341 & 38.92479 & 36.52146 \\
\hline Desvio: & 0.982885 & 1.158202 & 2.325852 \\
\hline
\end{tabular}




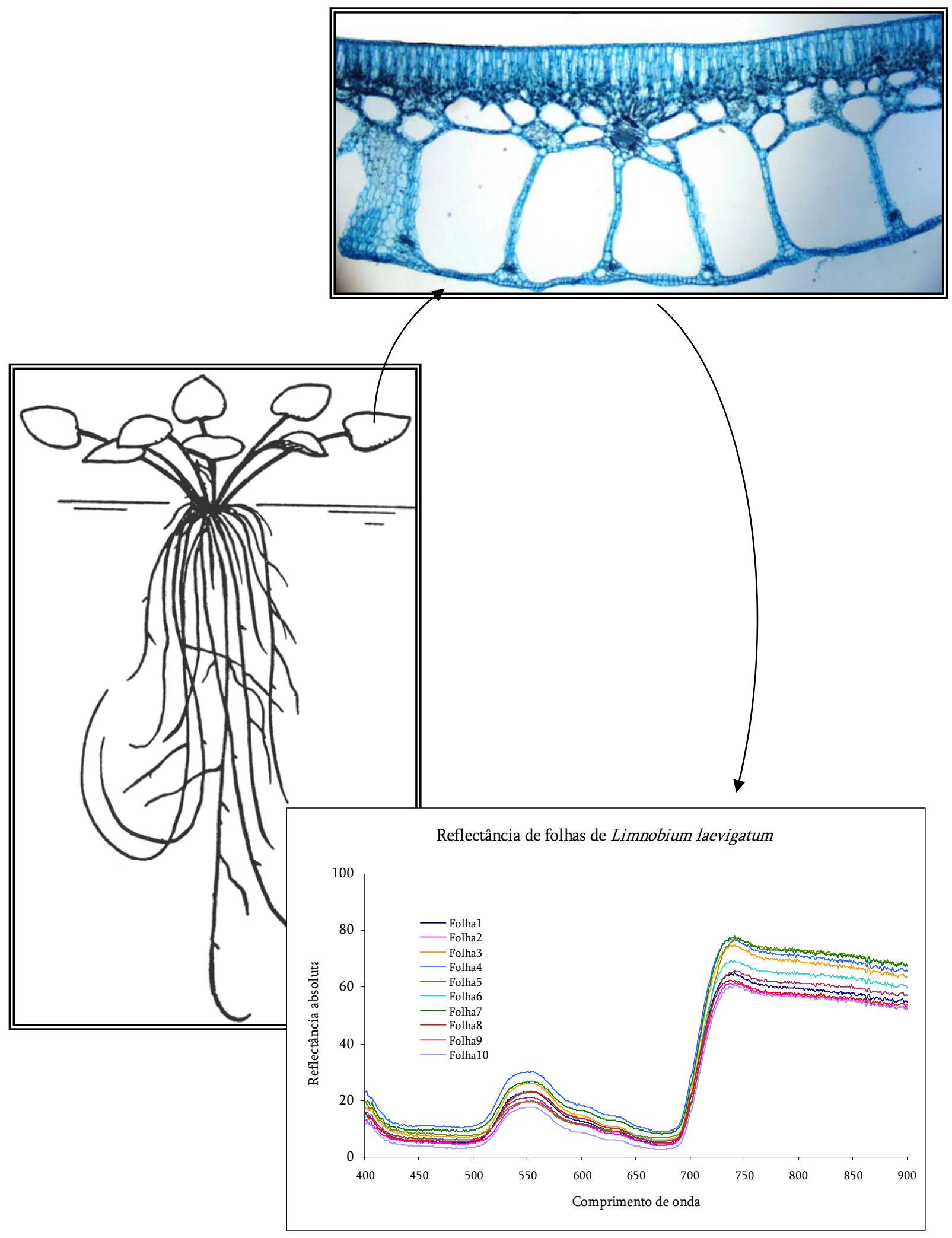

Figura V.21 - Análise conjunta de Limnobium laevigatum 
Tabela V.31: Médias de reflectância absoluta nas faixas espectrais para as folhas de Limnobium laevigatum.

\begin{tabular}{|l|l|}
\hline Médias & \\
\hline Azul & 7.356802 \\
\hline Verde & 19.37792 \\
\hline Vermelho & 7.186608 \\
\hline IVP & 62.97451 \\
\hline
\end{tabular}

Tabela V.32: Índices entre as faixas espectrais para as folhas de Limnobium laevigatum.

\begin{tabular}{|l|r|}
\hline Índices & \multicolumn{1}{|r}{} \\
\hline Vermelho-IVP & 0.79514 \\
\hline Verde-Vermelho & 0.458932 \\
\hline Verde-IVP & 0.52939 \\
\hline Verde-Azul & 0.449644 \\
\hline IVP-Azul & 0.790796 \\
\hline
\end{tabular}

Tabela V.33: Valores de pico de comprimento de onda nas faixas espectrais para as folhas de Limnobium laevigatum.

\begin{tabular}{|l|l|}
\hline Picos & \\
\hline Azul & 488 \\
\hline Verde & 553 \\
\hline Vermelho & 672 \\
\hline Red Edge & 739 \\
\hline IVP & 773 \\
\hline
\end{tabular}

Tabela V.34: Valores dos Limites Vermelhos para as folhas de Limnobium laevigatum.

\begin{tabular}{|l|l|}
\hline Limites Vermelhos & \multicolumn{1}{|l}{} \\
\cline { 1 - 1 } Limites Vermelhos por & 712 \\
\hline Interpolação & 1,45 \\
\hline Desvio Padrão & 705 \\
\hline Limites Vermelhos por Derivada & 3,83 \\
\hline Desvio Padrão &
\end{tabular}

Tabela V.35: Proporção de espaços aéreos (\%) em relação ao número da folha para valores de reflectância para Limnobium laevigatum.

\begin{tabular}{|l|r|r|r|}
\cline { 2 - 4 } \multicolumn{1}{c|}{} & Máx = Folha 5 & Médio = Folha 6 & Mínimo = Folha 10 \\
\hline Amostra 1 & 85.63661 & 58.56633 & 45.81231 \\
\hline Amostra 2 & 83.40751 & 58.29579 & 39.22094 \\
\hline Amostra 3 & 86.87425 & 55.77175 & 45.32017 \\
\hline Amostra 4 & 84.34766 & 57.75411 & 43.99391 \\
\hline Amostra 5 & 85.82052 & 58.72021 & \\
\hline Média: & 85.63661 & 57.82164 & 43.58683 \\
\hline Desvio: & 1.352478 & 1.203474 & 3.010198 \\
\hline
\end{tabular}


CAPÍTULO VI - UTILIZAÇÃO DE MODELAGEM PARA SIMULAR A RESPOSTA ESPECTRAL DE EGERIA

DENSA DE ACORDO COM A PROFUNDIDADE.

\section{VI.1 - INTRODUÇÃO}

Estudos sobre a resposta espectral de macrófitas submersas são bastante raros, e o único que pode ser mencionado aqui é o de Han e Rundquist (2003) que verificaram experimentalmente as respostas espectrais de Ceratophyllum demersum a profundidades variáveis, mostrando que a reflectância diminui conforme a profundidade, principalmente na faixa do Infravermelho Próximo, onde a água absorve fortemente.

Para simular respostas espectrais das macrófitas submersas em corpos d'água com diferentes componentes opticamente ativos, têm sido desenvolvidos programas de computador baseados nas Propriedades Ópticas da água. Esses são modelos que simulam o comportamento da luz na água conforme as diferentes concentrações de elementos dissolvidos e em suspensão. As equações relacionadas às Propriedades Ópticas da água vêm sendo aperfeiçoadas há décadas e têm sido utilizadas para gerar esses modelos que prevêem o comportamento da luz na água (Plass e Kattawar, 1969 e 1972; Gordon et al. 1974; Kirk 1981a e 1981b). A maioria dos estudos, entretanto, foi desenvolvida para ser aplicada em corpos d'água oceânicos, como o fizeram Malthus et al. (1997), que utilizaram um método estatístico (Monte Carlo) de simulação de fótons para simular informações sobre dosséis de plantas submersas, enfatizando algas marinhas. Kirk (1981a) foi o primeiro a desenvolver 
um programa de computador que utilizava o Monte Carlo para simular a penetração da luz em corpos d'água naturais. $\mathrm{O}$ modelo pode ser também adaptado para simular dados sobre a resposta espectral de macrófitas de águas continentais, imersas ou não. Essas simulações são importantes especialmente no caso das macrófitas submersas. No Brasil não foram encontrados artigos publicados envolvendo o Monte Carlo aplicado a corpos d'água naturais.

Os procedimentos envolvidos para determinar as respostas espectrais das submersas devem ainda considerar a influência da profundidade e dos vários elementos dispersos na camada de água que se encontra sobre elas. Para facilitar a análise da influência de tantos fatores concomitantemente é necessário o uso de modelos que simulem a reflectância das macrófitas de acordo com as alterações das variáveis de profundidade e de concentração de elementos opticamente ativos na água (Malthus et al. (1997). Tais modelos podem ser aplicados às respostas espectrais das macrófitas submersas, para simular as variações na reflectância, de acordo com as variáveis mencionadas. Essa é a função do modelo Quantum, que será utilizado nesta tese.

Como mencionado anteriormente, a resposta espectral das macrófitas pode ser afetada significantemente pela presença de variáveis como as substâncias opticamente ativas na coluna d'água, a profundidade em que se encontram na coluna d'água ou a influência do fundo. Atualmente é possível inferir a resposta espectral das macrófitas em ambientes onde há alterações dessas variáveis. Para que isso seja possível, foram 
desenvolvidos modelos matemáticos que possibilitam a simulação das respostas espectrais em diferentes condições.

Um dos principais modelos, denominado Quantum, é baseado no modelo Monte Carlo. O Monte Carlo é um método estatístico que auxilia na simulação de variáveis. Este método tem sido utilizado em diferentes áreas do conhecimento, e mais recentemente tem sido aplicado à Oceanografia e Limnologia.

O modelo Quantum foi desenvolvido pelo professor Timothy J. Malthus e colaboradores para simular informações espectrais de dosséis de plantas submersas, particularmente algas (Malthus et al. 1997). Ele é baseado na simulação da propagação de fótons em corpos d'água, envolvendo as Propriedades Ópticas da água e simulando as relações entre essas propriedades. Através dos resultados é possível investigar a extensão na qual a informação espectral atribuída às macrófitas é influenciada pelas várias substâncias ópticas ativas na coluna de água onde elas vivem, pela profundidade variável dessa coluna e pela influência do fundo em alguns casos.

Para descrever as Propriedades Ópticas dos corpos d’água, têm sido utilizadas funções matemáticas e suas inter-relações (Zimmerman, 2003; Ammenberg, 2002; Dekker et al., 2001a e 2001b; Effler, 2001; Kutser, 2001; Strombeck e Pierson, 2001; Morel e Loisel, 1998; Sathe e Sathyendranath, 1990 e 1992; Gallegos, 1990; Kirk, 1981a). Essas propriedades podem ser divididas em Propriedades Ópticas Aparentes e Propriedades 
Ópticas Inerentes. Vários autores as têm examinado, como Preisendorf (1961) e Kirk (1981b), por exemplo. Resumidamente define-se que as Inerentes são aquelas cujos valores em um determinado ponto do corpo d'água independem das mudanças na distribuição do campo de luz, enquanto que as Aparentes não são independentes do campo de luz.

As propriedades ópticas consideradas como Inerentes são: o coeficiente de absorção (a), coeficiente de espalhamento (b), a partir dos quais é definido o coeficiente de atenuação do feixe $(c=a+b)$, e a função volumétrica de espalhamento. As propriedades ópticas consideradas como Aparentes incluem a Irradiância (fluxo radiante por unidade de área horizontal), o Coeficiente de Atenuação Vertical para a Irradiância (derivada logarítmica, com respeito à profundidade, da Irradiância ascendente e descendente), e a Reflectância (razão entre a Irradiância ascendente e descendente ao corpo d'água).

A função dos modelos ópticos é, portanto, gerar valores referentes às Propriedades Ópticas Aparentes do corpo d'água a partir das Propriedades Ópticas Inerentes. Assim ele propicia tanto o entendimento do que acontece com a radiação solar quando ela passa para corpos d'água com características continentais, quanto ajuda a predizer como a disponibilidade de luz para a fotossíntese nesses meios será afetada pelas mudanças na composição da água que alteram suas Propriedades Ópticas Inerentes (Kirk, 1981a). A partir do conhecimento das Propriedades Ópticas Aparentes é possível validar dados de imagens obtidas por Sensoriamento Remoto. 
O modelo Quantum foi escrito em linguagem Pascal e seu objetivo é simular a resposta espectral de macrófitas. As variáveis de entrada são:

1. Ângulo de elevação solar

3. Profundidade da coluna d'água a ser modelada $(\mathrm{cm})$

4. Índice de Área Foliar da planta

5. Nove colunas de dados contendo as seguintes medidas, registradas a cada $4 \eta \mathrm{m}$, no intervalo de $400 \eta \mathrm{m}$ a $750 \eta \mathrm{m}:$

a. Comprimento de onda

b. Absorção da água

c. Espalhamento da água

d. Absorção do húmus aquático

e. Absorção do Seston (Orgânico + Inorgânico)

f. Espalhamento do Seston (Orgânico + Inorgânico)

g. Reflectância da folha da planta

h. Transmitância da folha da planta

i. Reflectância do fundo do corpo d'água (\%)

O Índice de área foliar, a absorção do Húmus, a Reflectância e Transmitância da folha e a Reflectância do fundo do corpo d'água são valores que devem ser alterados conforme o alvo e o local de estudo. Essas variáveis devem ser alteradas conforme sua concentração (Húmus), composição (fundo do corpo d'água) ou espécie (no caso das 
folhas). Outros valores são fixos, como a Absorção e o Espalhamento da Água, que foram obtidos a partir de Smith e Baker (1981).

A metodologia para calcular a absorção do Húmus aquático foi descrita em Kirk (1983). Segundo o autor ela pode ser indicada pelo coeficiente de absorção em 440 ๆm (denominada g440), que pode ser medido conforme a equação:

$\mathrm{a}(\lambda)=\mathrm{a}\left(\lambda_{0}\right) \mathrm{e}^{-\mathrm{S}\left(\lambda-\lambda_{0}\right)}$

onde a é o Coeficiente de absorção e S é o coeficiente de inclinação da curva (derivado da regressão do logaritmo de a pelo comprimento de onda) que deve variar conforme o ambiente a ser estudado.

A absorção pelo fitoplâncton foi empiricamente modelada por Harwar et al. (1995), e varia em função da concentração de clorofila. O espalhamento pelo fitoplâncton varia conforme o espalhamento em 550 ๆm, que pode ser calculado segundo Gordon e Morel (1983) e Morel (1987) que sugerem que B550 = 0,3 [Chl] ${ }^{0,62}$, onde B550 é o espalhamento em 550 ๆm e [Chl] é a concentração de clorofila. O espalhamento do fitoplâncton pode ser então calculado pela equação $B(\lambda)=B 550(550 / \lambda)$.

O cálculo para a absorção do Tripton orgânico ou (ad) e para o espalhamento do Tripton inorgânico foram obtidos de Pierson e Strömbeck (2001). Uma análise de 
Regressão Linear dos dados fornecidos pelos autores possibilitou inferir a equação final para os cálculos das variáveis. O pesquisador necessita apenas entrar com as concentrações das substâncias em uma planilha do Excel, e depois rodar o Modelo com os valores obtidos então. No caso da absorção, a regressão foi feita a partir da equação $a_{d}(400)=a_{d}^{*}(400) C_{\text {Triptorg }}+e_{* a d}$ para obter o valor de $a_{d}^{*}(400)$, onde $e$ é um erro aproximadamente igual à zero. Obtido o valor de $a_{d}^{*}(400)$, o cálculo da absorção pôde ser feito para todos os comprimentos de onda utilizando a equação $a_{d}(\lambda)=a_{d}^{*}(400) e^{-S_{d}(\lambda-400)}$, onde S é o coeficiente da equação e varia conforme o local de estudo. No caso do espalhamento, o procedimento foi semelhante e as equações utilizadas foram:

$$
b_{b S P I M}(442)=[\text { TriptonInorganico }] b_{b S P I M}^{*}(442)+e_{b S P M}^{*}
$$

e

$$
b_{b \text { Triptinorg }}(\lambda)=\frac{b_{b \text { Triptinorg }}(442) \lambda^{-B b_{b}}}{442^{-B b_{b}}}
$$

O produto final do modelo é uma curva que indica a reflectância da espécie sob diferentes condições ecológicas.

A partir do conhecimento de que a água absorve fortemente no IVP, espera-se que com o aumento da profundidade, mesmo em águas claras, haja diminuição drástica da reflectância das plantas submersas no IVP. Nas outras faixas do espectro a diminuição também ocorre, mas principalmente em função de outros componentes opticamente ativos 
que provocam absorção ou reflexão especular da radiação incidente, de modo que a resposta espectral emergente do corpo d'água com plantas submersas seja uma mistura de todos esses elementos. Por este e outros motivos as simulações são importantes, pois permitem verificar o quanto uma variável influencia mais que a outra na resposta espectral emergente do corpo d'água.

O objetivo deste capítulo é demonstrar o potencial de simulação do programa Quantum, utilizando para tanto a resposta espectral da espécie de macrófita submersa Egeria densa.

\section{VI.2 - ProcediMENTOS METODOLÓGICOS}

Para se analisar Egeria densa, foi medida a resposta espectral da espécie como visto nos Capítulo II. Sabe-se que a reflectância para as espécies submersas varia conforme a profundidade em que se encontram no corpo d'água e conforme as substâncias opticamente ativas suspensas na coluna dágua. Para simular a variação da resposta espectral conforme a alteração dessas variáveis pode ser aplicada uma modelagem Monte Carlo. Um dos modelos é denominado Modelo Quantum, desenvolvido pelo professor Timothy Malthus e colaboradores, que pode gerar os resultados em função da profundidade e também em função da variação das concentrações de elementos opticamente ativos na água. 
Assim, os dados de resposta espectral da espécie Egeria densa serão adicionados no modelo e serão calculadas as respostas espectrais em função de algumas modificações nas variáveis: A uma profundidade de $10 \mathrm{~cm}$ com três concentrações diferentes de clorofila, à profundidade de $20 \mathrm{~cm}$ e concentração de clorofila em $10 \mathrm{mg} / \mathrm{m}^{3}$, e à profundidade de 100 $\mathrm{cm}$ e clorofila em $10 \mathrm{mg} / \mathrm{m}^{3}$.

\section{VI.3 - RESULTADOS E DISCUSSÕES}

A resposta espectral da espécie obtida em câmara escura, fora da água, se encontra na Figura VI.1.

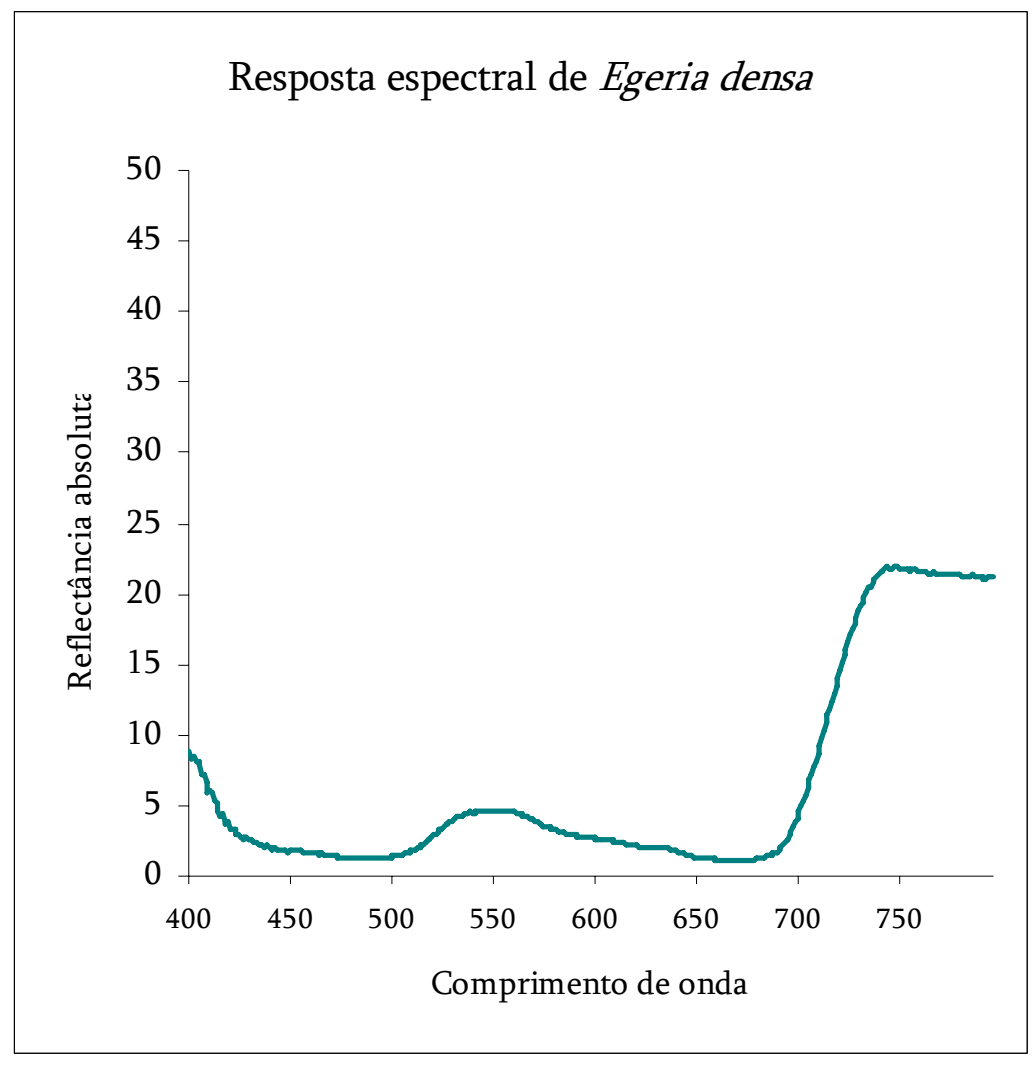

Figura VI.1: Resposta espectral de Egeria densa obtida em laboratório. 
Para uma profundidade de $10 \mathrm{~cm}$ e concentração de clorofila de $10 \mathrm{mg} / \mathrm{m}^{3}$, a curva resultante da simulação de 1.000 .000 de fótons interagindo na coluna d'água pode ser observada na Figura VI.2. Pode-se observar a forte reflectância na faixa do IVP.

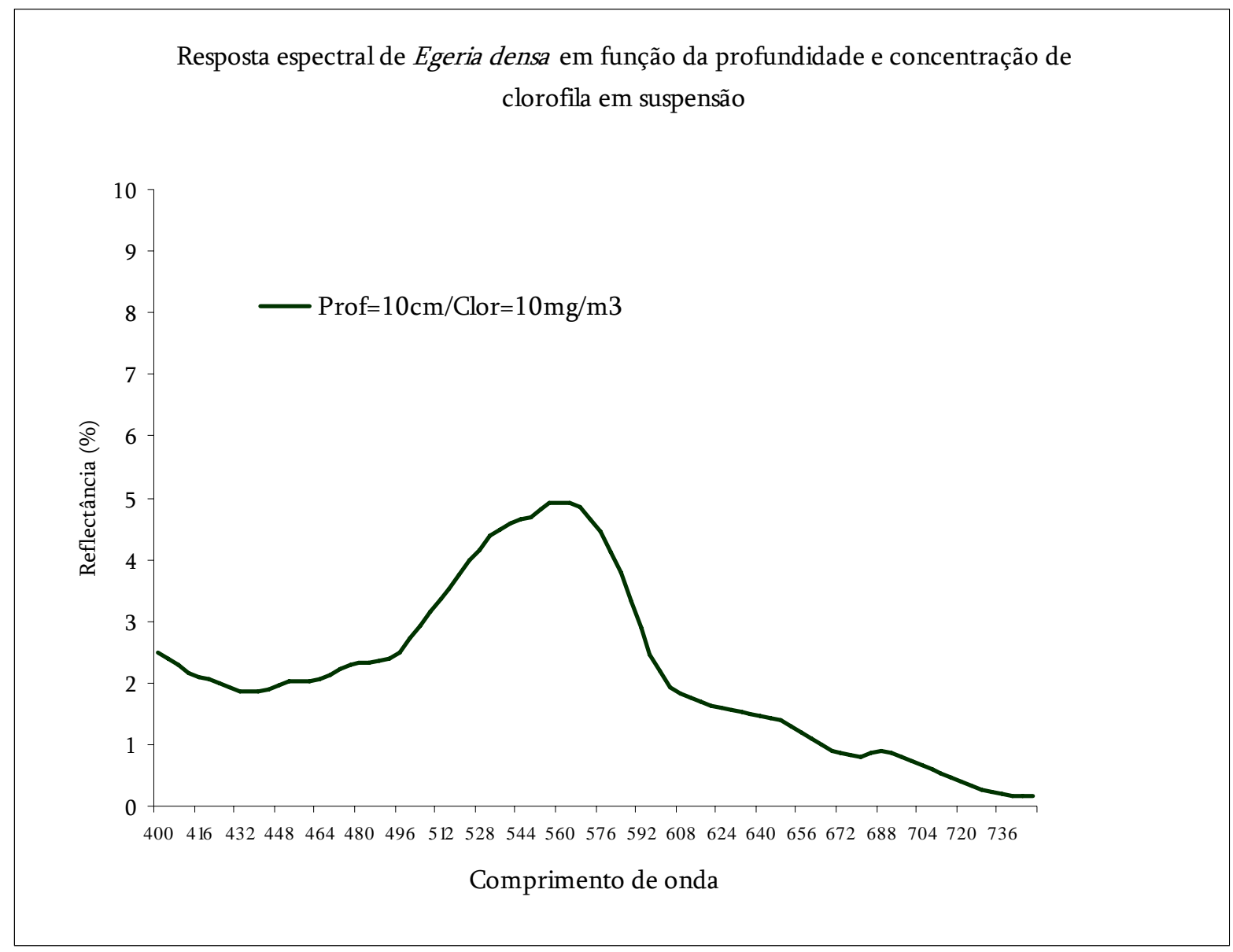

Figura VI.2: Simulação da resposta espectral de Egeria densa em uma coluna com concentração de clorofila igual a $10 \mathrm{mg} / \mathrm{m}^{3}$ e a uma profundidade de $10 \mathrm{~cm}$.

Neste caso a coluna d'água provocou a absorção na faixa do IVP, que se refletiu em reflectância muito baixa na região do IVP.

Mantendo a concentração de clorofila na água e aumentando a profundidade para $20 \mathrm{~cm}$ e depois para $100 \mathrm{~cm}$, as curvas resultantes da simulação de 1.000 .000 de fótons 
interagindo na coluna d'água podem ser observadas na Figuras VI.3 e VI.4 respectivamente.

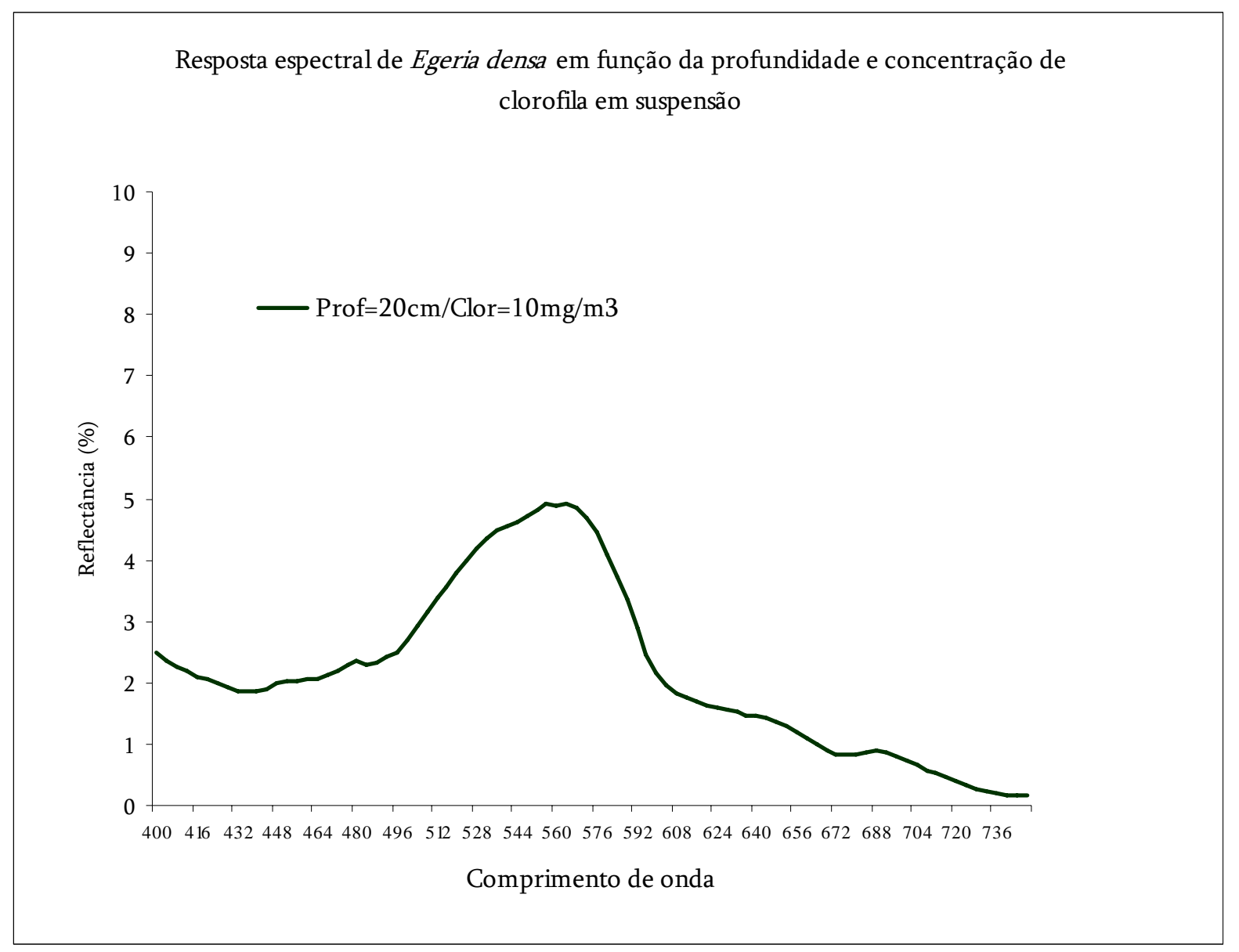

Figura VI.3: Simulação da resposta espectral de Egeria densa em uma coluna com concentração de clorofila igual a $10 \mathrm{mg} / \mathrm{m}^{3}$ e a uma profundidade de $20 \mathrm{~cm}$.

Neste caso a simulação mostrou praticamente os mesmos resultados da anterior, mostrando que pequenas variações na profundidade não alteram a resposta espectral significativamente nas faixas do visível. 


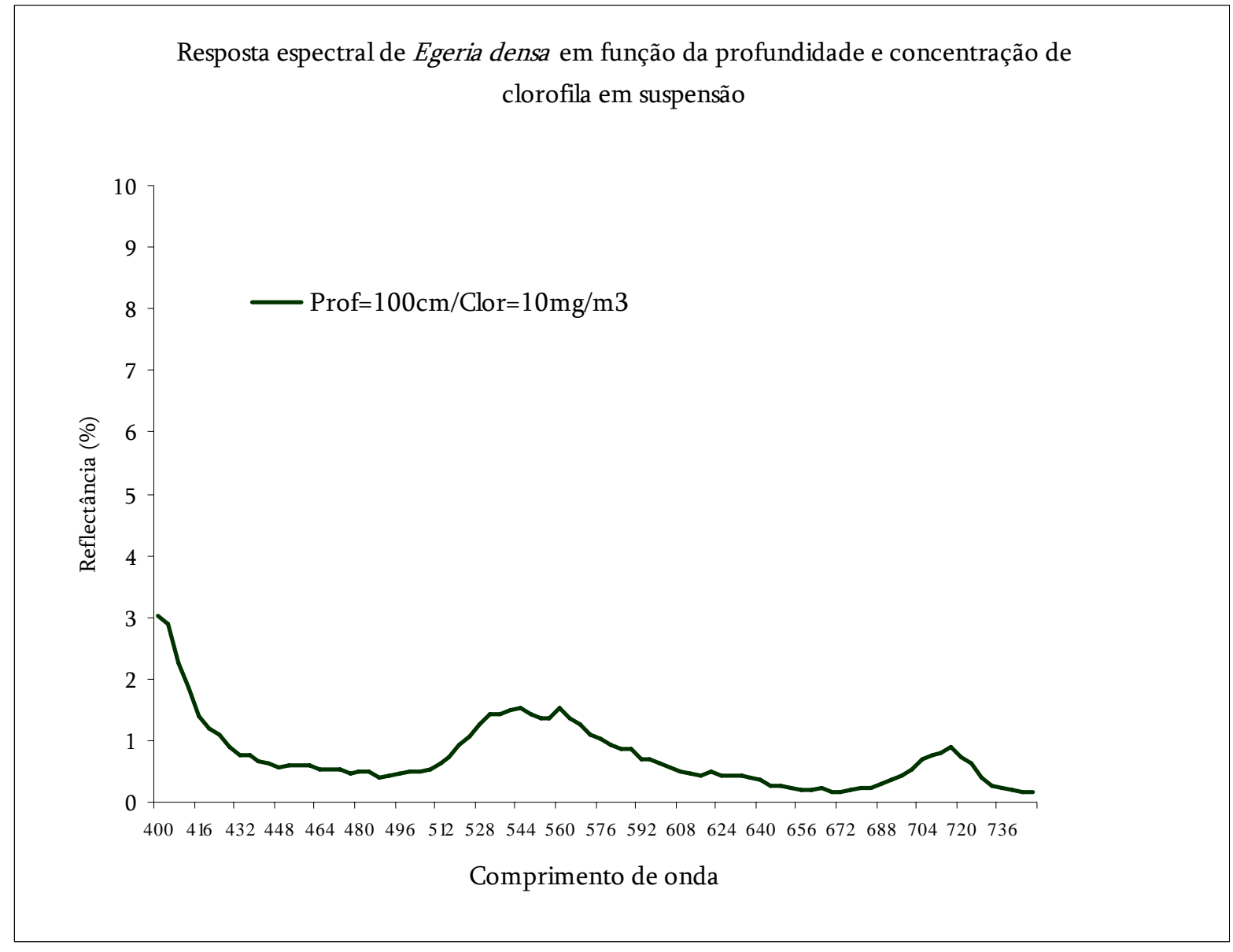

Figura VI.4: Simulação da resposta espectral de Egeria densa em uma coluna com concentração de clorofila igual a $10 \mathrm{mg} / \mathrm{m}^{3}$ e a uma profundidade de $100 \mathrm{~cm}$.

Neste caso observa-se que a reflectância diminuiu em todas as faixas, mas teve um pequeno aumento na região do IVP. Isso ocorre porque o programa utiliza um número fixo de camadas de plantas, e a 10 e $20 \mathrm{~cm}$ havia apenas 2 camas de folhas, enquanto que a $100 \mathrm{~cm}$ havia 10 camadas de folhas, indicando maior infestação do corpo d’água.

A comparação entre as curvas se encontra na Figura VI.5. 


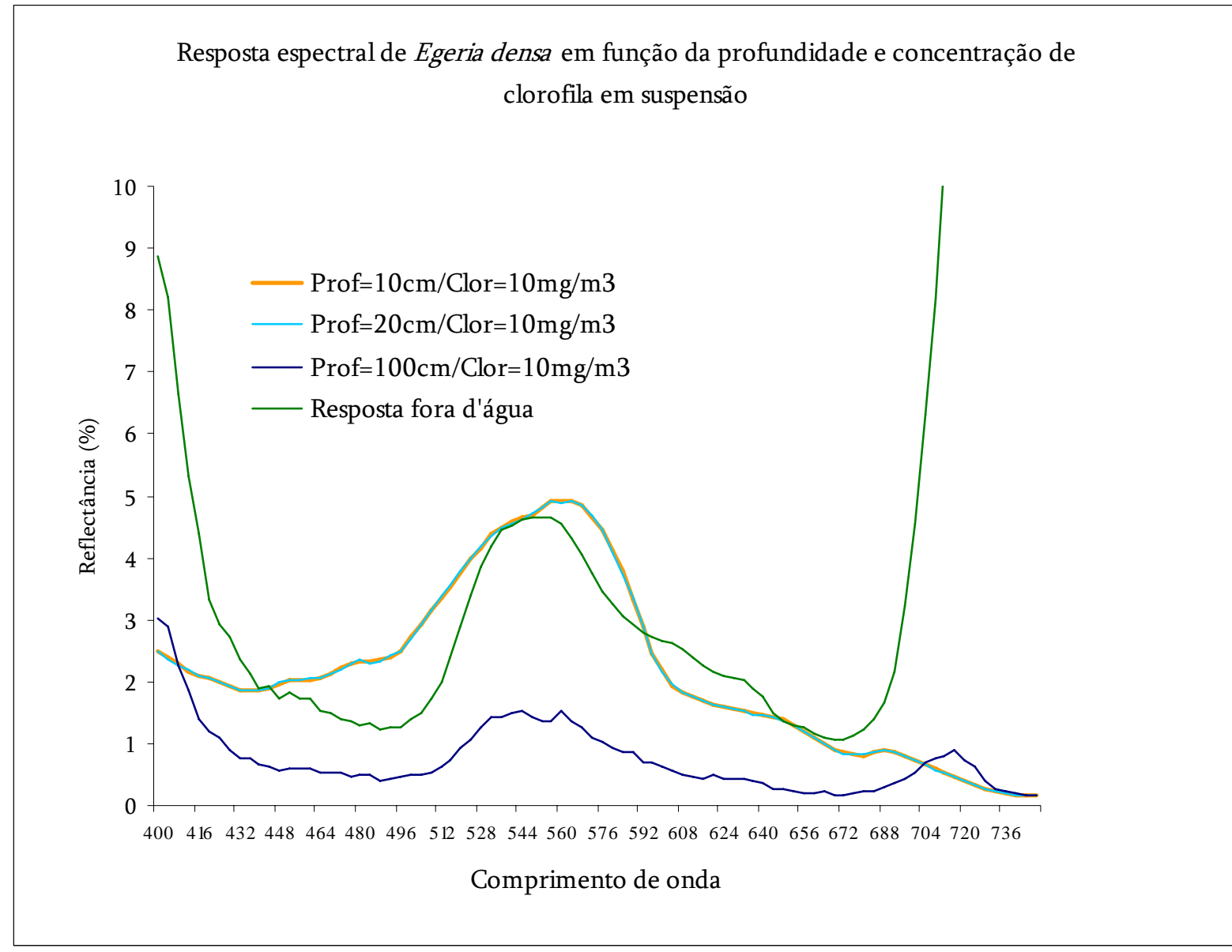

Figura VI.5: Simulação da resposta espectral de Egeria densa obtida em diferentes profundidades e concentração de clorofila igual a $10 \mathrm{mg} / \mathrm{m}^{3}$.

Pela figura observa-se que as curvas simuladas a 10 e $20 \mathrm{~cm}$ possuem formas bastante diferentes da resposta espectral da espécie fora d'água e a $100 \mathrm{~cm}$. Isso ocorre porque, como mencionado anteriormente, nas profundidades de 10 e $20 \mathrm{~cm}$ as camadas de folhas de Egeria densa são poucas, e se observa mais as variações devidas à concentração de clorofila na coluna d'água do que da macrófita. 


\section{VI.4 - CONCLUSÕES}

De acordo com as simulações do modelo Quantum utilizado, as curvas de Egeria densa simuladas a 10 e $20 \mathrm{~cm}$ de profundidade não mostraram diferenças significativas, mas a uma profundidade de $100 \mathrm{~cm}$ houve diferença significativa daquela observada fora d'água.

Programas de simulação podem ser muito úteis para explicar as variações das respostas espectrais de plantas submersas. Pelo fato de o Quantum ter sido desenvolvido para ser utilizado com uma espécie de alga marinha, ele necessita ainda ser submetido a novas alterações para poder ser aplicado às enumeras espécies de macrófitas encontradas nas regiões tropicais. 


\section{CAPÍTULO VII - CONCLUSÕES E CONSIDERAÇÕES FINAIS}

Ao longo da tese foi possível demonstrar que a espectroradiometria possibilita efetivamente a distinção entre espécies de macrófitas, sob determinadas condições. Sensores orbitais multiespectrais são usualmente utilizados para mapeamento e monitoramento de áreas com grande cobertura homogênea de macrófitas, enquanto que Sensores hiperespectrais com boa resolução espacial podem ser utilizados para diferenciar macrófitas em todas as escalas de análise. Os resultados aqui apresentados contribuíram para a melhor compreensão da utilização de Sensoriamento Remoto em análises com macrófitas. Especialmente quando os sensores são orbitais, as necessidades de maior conhecimento prévio das características espectrais dos alvos é importante para que se possam reduzir as incertezas de interpretação.

As respostas espectrais das espécies estudadas, que foram obtidas com o uso de um sensor hiperespectral em laboratório, possibilitaram a construção de um banco espectral inicial de macrófitas, ao qual poderão ser adicionadas novas espécies em estudos futuros.

A diferenciação das espécies foi possível através da utilização dos descritores testados (a intensidade média na faixa espectral, os pontos de inversão em cada faixa, o ponto do Limite Vermelho e Índices entre faixas).

As cinco espécies de macrófitas para as quais foi possível realizar a análise microscópica mostraram-se diferentes em questões anatômicas e espectroradiométricas. Em relação à análise com dados anatômicos, foi constatado que a espessura da folha e espessura do parênquima esponjoso foram as variáveis mais importantes para a discriminação das 
espécies estudadas. Em relação à análise conjunta com a reflectância no IVP, foi constatado que ela está diretamente relacionada principalmente à proporção de espaços aéreos e espessura do parênquima esponjoso das espécies.

A simulação da resposta espectral de Egeria densa, conforme a profundidade e a concentração de clorofila, mostrou o potencial de utilização do modelo Quantum para esse tipo de estudo. O modelo propicia a simulação da resposta de plantas submersas em ambientes aquáticos com a variação das substâncias opticamente ativas presentes na coluna d’água, o que pode ser extremamente útil no caso de monitoramento de infestações com Sensoriamento Remoto Orbital, por exemplo. 


\section{REFERÊNCIAS BIBLIOGRÁFICAS}

Abdon, M. M.; Meyer, M.. Variação Temporal de Áreas Ocupadas por Macrófitas Aquáticas no Reservatório de Tucuruí Através de Dados do Satélite Landsat/TM. IV Simpósio Latinoamericano de Percepción Remota. San Carlos de Bariloche, 20-24 Nov. 1989. Anais: SELPER. Buenos Aires. Vol. I, pp. 545-548.

ACKLESON, S. G. ; KLEMAS, V.. 2-flow simulation of the natural light-field within a canopy of submerged aquatic plants. Applied Optics, 25 (7): 1129-36. 1986.

AlberotanZA, L.; BRANDO, V.E.; RAVAgnAN, G.; ZANDONELlA, A.. Hyperspectral aerial images. A valuable tool for submerged vegetation recognition in the Orbetello Lagoons, Italy. Int. J. Remote Sensing, 20 (3): 523-533. 1999.

Ammenberg, P.; Flink, P.; Lindell, T.; Pierson, D.; Strombeck, N.. Bio-optical modelling combined with remote sensing to assess water quality. Int. J. Remote Sensing 23(8): 1621-1638. 2002.

BARANOSKI, G.V.G.; ROKNE, J.G.. A practical approach for estimating the red edge position of plant leaf reflectance. Int. J. Remote Sensing 26(3):503-321. 2005.

BitenCOURT-PEREIRA, M.D.. "Parâmetros limnológicos passíveis de serem monitorados através de sensores remotos orbitais". Tese de Doutorado pelo Programa de Ecologia e Recursos Naturais UFSCar - Universidade Federal de São Carlos, São Carlos - SP - 1992.

BOWEN, H.S.. ABSOlUte RADIOMETRIC CALIBRATION OF THE IKONOS SENSOR Using Radiometrically Characterized Stellar SourCes. Pecora 15/Land Satellite Information IV/ISPRS Commission I/FIEOS 2002 Conference Proceedings.

BUKATA, R.P.; BRUTON, J.E.; JEROME, J.H.. Use of Chromaticity in Remote Measurements of Water Quality. Remote Sensing of Environment 13: 161-177.

CARTER, G.A.. Responses of Leaf Spectral Reflectance to Plant Stress. American Journal of Botany, 80(3): 239-243. 1993.

CARVAlHo, J.C.; Barbosa, C.; Novo, E.M.; MANTOVANI, J.E.; Melack, J.; FIlHO, W.P.. Applications of Quantitative Analysis Techniques to Monitor Water Quality of Curuai Lake, Brazil. International Geoscience and Remote Sensing Symposium. IEEE 2003.

CASTRO-ESAU, K.L.; SÁNCHEZ-AZOFEIFA, G.A.; RIVARD, B.; WRIGHT, S.J.; QUESADA, M.. Variability in leaf optical properties of Mesoamerican trees and the potential for species classification. American Journal of Botany, 93(4): 517-530. 2006.

CHO, M.A.; SKIDMORE, A.K.. A new technique for extracting the red edge position from hyperspectral data: The linear extrapolation method. Remote Sens. Environ., 101:181-193. 2006. 
CleVERS, J.G.P.W.; JONG, S.M.; EPEMA, G.F.; MEER, F. VAN DER; BAKKER, W.H.; SKIDMORE, A.K.; ADDINK, E.A.. MERIS and the red-edge position. JAG (3), 4:313-320. 2001.

CURRAN, P.J.; DUNGAN, J.L.; MACLER, B.A.; PlUMMER, S.E.. The effect of a red leaf pigment on the relationship between Red Edge and chlorophyll concentration. Remote Sens. Environ., 35:69-76. 1991.

DAVIS, G.J.; BRINSON, M.M.. Responses of submersed vascular plant communities to environmental change. URL: http://www.aquabotani.com/paper2.html, 1980. Acesso em fevereiro/2005.

DEKKER, A.G.; MALTHUS, T.J.; SEYHAN, E.. Quantitative modeling of inland water quality for Highresolution MSS Systems. IEEE Transactions on Geoscience and Remote Sensing 29(1). 1991.

DeKKer, A.G.; Bukata, R.P.; Jerome, J.H.; PozDNYAKOV, D.V.. 2001. Remote Sensing of Inland and Coastal Waters: 1: Twenty-eight years of technology push but still waiting for end-user pull. Proc. Workshop on RS and resource mgmt in nearshore and inland waters, Wolfville, Nova Scotia. 2001a.

DEKKER, A.G.; VOS, R.J.; PETERS, S.W.M.. Comparision of Remote sensing data, model results and in situ data for total suspended matter (TSM) in the southern Frisian lakes. The Science of the Total Environment, 268: 197-214. 2001b

DeLUCiA, E.H.; NELSON, K.; VOGELMANN, T.C.; SMITH, W.K.. Contribution of intercellular reflectance to photosynthesis in shade leaves. Plant, Cell and Environment 19: 159-170. 1996.

EFFLER, S.W.; GELDA, R.K.; BLOOMFIELD, J.A.; QUINN, S.O.; JOHNSON, D.L.. Modeling the effects of tripton on water clarity: Lake Champlain. Journal of WaterResources Planning and Management 127(4):224-234. 2001.

ESTEVES, F. A.. Fundamentos de Limnologia. Editora Interciência Rio de Janeiro/RJ 602 pp. 1998.

EVERITT, J.H.; YANG, C.; EsCOBAR, D.E.; WEBSTER, C.F.; LONARD, R.I.; DAVIS, M.R.. Using Remote Sensing and Spatial Information Technologies to Detect and Map Two Aquatic Macrophytes. J. Aquat. Plant Manage. 37:71-80. 1999

FYFE, S.K.. Spatial and temporal variation in spectral reflectance: Are seagrass species spectrally distinct? Limnol. Oceanogr., 48 (1, part 2): 464-479. 2003

Gallegos, C.L.; CORRELl, D.L.; PierCE, J.W.. Modeling Spectral Diffuse Attenuation, Absorption, and Scattering Coefficients in a Turbid Estuary. Limnology and Oceanography 35(7): 1486-1502. 1990.

GAteS, D.M.; KEEGAN, H.J.; SCHLETER, J.C.; WeIDNER, V.R.. Spectral Properties of plants. Applied Optics 4(1): 11-20, 1965.

GAUSMAN, H.W.; ALLEN, W.A.; CARDENAS, R.. Reflectance of cotton leaves and their structure. 
Remote Sensing of Environment, 1:19-22. 1969.

GOODIN, D.G.; HAN, L.; FRASER, R.N.; RUNDQUIST, D.C.; STEBBINS, W.A.; SCHALLES, J.F.. Analysis of Suspended Solids in Water Using Remotely Sensed High Resolution Derivative Spectra. Photogramm. Eng. Remote Sens.. 59: 505-510. 1993.

GORDON, H.R. E MOREL, A. Lectures Notes on Coastal and Estuarine Studies. Springer-Verlag, NY. 1983.

GORDON, H.R.; BROWN, O.B.. Influence of Bottom depth and Albedo on the Diffuse Reflectance of a Flat Homogeneous Ocean. Applied Optics 13(9):2153-2159. 1974

GOVAERTS, Y.M.; JACQUEMOUD, S.; VERSTRAETE, M.M.; USTIN, S.L.. Three-dimensional radiation transfer modeling in a dicotyledon leaf. Applied Optics, 35(33): 6585-6598. 1996.

GracianI, S. D.; NovO, E.M.L.M.. Determinação da cobertura de macrófitas aquáticas em reservatórios tropicais. Anais XI SBSR, Belo Horizonte, Brasil, 05 - 10 abril 2003, INPE, p. 2509 2516.

HAN, L.; RUNDQUIST, D.C.; LIU, L.L.; FRASER, R.N.; SCHALLES, J.F.. The spectral responses of algal chlorophyll in water with varying levels of suspended sediment. Int. J. Remote Sensing 15(18): 3707-3718. 1994.

HAN, L.; RUNDQUIST, D.C.. The spectral responses of Ceratophyllum demersum at varying depths in an experimental tank. Int. J. Remote Sensing, 24 (4): 859-864. 2003.

Harwar, M.D.; Malthus, T.J.; DeKKer, A.G.; E Trueman, I.C.. Reflectance from inland waters: Modelling the position of the chlorophyll a peak as a function of chlorophyll concentration. Proceedings of the Remote Sensing Society One Day Student Meeting, 1995.

HENRY, R.. Ecologia de Reservatórios - Estrutura, Função e Aspectos Sociais. Editor: Raoul Henry - Botucatu: FUNDIBIO: FAPESP, 1999.

JAGO, R. A.; CUTLER, M. E. J.; CURRAN, P. J.. Estimating Canopy Chlorophyll Concentration from Field and Airborne Spectra. Remote Sens. Environ. 68:217-224. 1999.

Jakubauskas, M.; Kindscher, K.; Fraser, A.; Debinski, D.; Price, K. P.. Close-range Remote Sensing of Aquatic Macrophyte Vegetation Cover. Int. J. Remote Sensing, 21(18): 3533-3538. 2000.

JAKUBAUSKAS, M.E.; PETERSON, D.L.. Mapping and monitoring invasive aquatic plant obstructions in navigable waterways using satellite mulstispectral imagery. Apresentado em Pecora 15/Land Satellite Information IV/ISPRS Comission I/FIEOS, 2002, Conference Proceedings.

KARNOVSKY, M.J. 1965. A formaldehyde-glutaraldehyde fixative of high osmolarity for use in electron microscopy. J. Cell Biol. 27:137A. 
KIRK, J.T.O.. Monte Carlo Procedure for Simulating the Penetration of light into Natural waters. CSIRO Aust. Div. Plant Ind. Tech. Pap. 36:1-16. 1981a

KIRK, J.T.O.. Monte Carlo Study of the nature of the Underwater Light Field in, and the relationships between Optical Properties of, Turbid Yellow Waters. Aust. J. Mar. Freshwater Res., 32:517-32. 1981b

KIRK , J.T.O.. Light and photosysthesis in aquatic ecosystems. Cambridge Univ. Press, Cambridge, 1983.

KIRK, J.T.O.; TYLLER, P.A.. The spectral absorption and scattering proprieties of dissolved and particulate components in relation to the underwater light field of some tropical Australian freshwaters. Freshwater biology, 1986; 16: 573-583.

KNIPLING, E.B.. Physical and physiological basis for the reflectance of visible and Near-infrared radiation from vegetation. Remote Sens. Environ., 1: 155-159. 1970.

KUMAR, R.; SilVA, L.. Light ray tracing through a leaf cross section. Applied Optics, 12: 2950-2954. 1973.

KUTSER, T.; HeRleVI, A.; KAllio, K.; ARST, H.. A hyperspectral model for interpretation of passive optical remote sensing data from turbid lakes. The Science of the Total Environment 268:47-58. 2001.

LEHMANN, A.; JAQUET, J. M.; et al. "Contribution of GIS to submerged macrophyte biomass estimation and community structure modeling, Lake Geneva, Switzerland." Aquatic Botany,1994. 47: 99-117.

LEHMANN, A., JAQUET, J.M.; LACHAVANNE, J.B.. A GIS approach of aquatic plant spatial heterogeneity in relation to sediment and depth gradient, Lake Geneva, Switzerland. Aquat. Bot. special issue, 58: 347-361. 1997.

LEHMANN, A.; LACHAVANNE, J.-B.. Geographic information systems and remote sensing in aquatic botany. Aquatic Botany, 1997, 58(1997): 195-207.

LILLESAND, T.M.; KIEFER, R.W.. Remote Sensing and image interpretation. $4^{\text {rd }}$. Ed. John Wiley \& Sons, NY, 2000.

LIMA, I. B. T; NOVO, E. M. L. M.; BINS, L.. Multitemporal TM image analysis to assess the spatial and temporal dispersion of floating macrophytes in Brazilian hydroelectric reservoirs. SBSR, 2003.

MALTHUS, T.J.; DEKKER, A.G. First Derivative Indices for the Remote Sensing of Inland Water Quality Using High Spectral Resolution Reflectance. Environment International, 21(2): 221-232. 1995.

MALTHUS, T.J.; GEORGE, D.G.. Airborne remote sensing of macrophytes in Cefni Reservoir, Anglesey, UK. Aquatic Botany, 1997; 58(1997): 317-332. 
Malthus, T.J.; GiraOlo, G.; Laloggia, G.; Clark, C.D.; Plummer, S.E.; Calvo, S.; TOMASello, A.. Can Biophysical Properties of Submersed Macrophytes be determined by Remote Sensing? Fourth International Conference on Remote Sensing for Marine and Coastal Environments, Orlando, Florida, 17-19 Março. 1997.

Martins, D.; Velini, E. D.; Pitelli, R. A.; TOMAZella, M. S.; Negrisoli, E.. Ocorrência de Plantas Aquáticas nos Reservatórios da Light-RJ. Planta Daninha, Viçosa-MG, 21: 105-108. Edição Especial. 2003.

MATHEW, S.; SCHMieder, K.; BOCKER, R.. Application of Remote Sensing and GIS in the Classification of Submerged Macrophytes as an Indicator of Nutrient Load in Lake Constance, Germany. Canadian Coastal Conference, 2003.

Mendes, D.; Pitelli, R.A.; Coelho, L.. Efeito de concentrações de herbicidas sobre aspectos biológicos de Fusarium sp. (Isolado FCAV\#940). Planta Daninha, Viçosa-MG, v.22, n.1, p.85-93, 2004.

Milton, E.. Principles of field spectroscopy. International Journal of Remote Sensing 8 (12), 18071827. 1987.

MOREL, A. Chlorophyll-specific scattering coefficient of phytoplankton. A simplified theoretical approach. Deep-Sea Research, 34(7): 1093-1105. 1987.

MOREL, A.; LOISEL, H.. Apparent Optical properties of Oceanic water: dependence on the molecular scattering contribution. Applied Optics 37(21): 4765-4776. 1998.

OURCIVAL, J.M.; JOFFRE, R.; RAMBAL, S.. Exploring the relationships between reflectance and anatomical and biochemical properties in Quercus ilex leaves. New Phytol., 143:351-364. 1999.

PALOMBO, C.R.; BITENCOURT-PEREIRA, M.D.. Monitoramento de infestação de macrófitas aquáticas através de satélite. Ambiente, 6(1):49-54. 1992.

Peñuelas, J.; Filella, I.; Gamon, J. A.; Field, C.. Assessing Photosynthetic Radiation-use Efficiency of Emergent Aquatic Vegetation from Spectral Reflectance. Aquatic Botany, 58: 307315. 1997.

PIERSON, D.; STRÖMBECK, N.. Estimation of radiance reflectance and the concentrations of optically active substances in Lake Mälaren, Sweden, based on direct and inverse solutions of a simple model. The Science of the Total Environment 268:171-188. 2001.

Plass, G.N.; Kattawar, W.. Monte Carlo Calculations of Radiative Transfer in the Earth's Atmosphere-Ocean System: I. Flux in the Atmosphere and Ocean. Journal of Physical Oceanography, 2: 139-145. 1972.

Plass, G.N.; KatTAWAR, W.. Radiative Transfer in an atmosphere-ocean system. Appl. Opt. 8:455466. 1969. 
PREISENDORFER, R.W.. Application of Radiative Transfer Theory to light measurements in the sea. In: Radiant Energy in the sea. Int. Union Géod. Géophys. Geod. Monogr. No. 10, pp. 11-29. 1961.

PRICE, J.C.. How unique are spectral signatures? Remote Sens. Environ. 49: 181-186. 1994.

REMILLARD, M.M.; WELCH, R.A.. GIS technologies for aquatic macrophyte studies: I. Database development and changes in the aquatic environment. Landscape Ecology, 1992; 7(3):151-162.

Ritchie, J.C.; COOPER, C.M.. Remote sensing techniques for determining water quality: Application to TMDLs, pp. 367-374. In: TMDL Science Issues Conference, Water Environment Federation, Alexandria, VA, 2001.

RowlAND, R.E.; NiCKLESS, E.M.. Confocal Microscopy Opens the Door 3-Dimensional Analysis of Cells. Bioscene, 26(3). 2000.

SATHE, P.V.; SATHYENDRANATH, S.. A Fortran programs for computation of Optical Properties of the sea from Radiation data collected by in situ spectrometers. Computers \& Geosciences 16(8):1085-1103. 1990.

SATHE, P.V.; SATHYENDRANATH, S.. A Fortran-77 program for Monte Carlo simulation of upwelling light from the sea. Computers \& Geosciences 18(5):487-507. 1992.

SCHMIDT, K.S.; SKIDMORE, A.K.. Spectral discrimination of vegetation types in a coastal wetland. Remote Sens. Environ. 85 (2003) 92-108.

SLATON, M.R.; HUNT, E.R.JR.; SMITH, W.K.. Estimating Near-infrared reflectance from leaf structure characteristics. American Journal of Botany 88(2): 278-284. 2001.

Smith, R. C.; BAKeR, K. S.. Optical Properties of the Clearest Natural Waters (200-800 nm). ). Applied Optics, 20 (2): 177-184. 1981.

SMITH, W.K.; BELL, D.T.; SHEPHERD, K.A.. Associations between leaf structure, orientation, and sunlight exposure in five Western Australian Communities. American Journal of Botany, 85(1): 5663. 1988.

SMITH, S.M.; GARRET, P.B.; LEEDS, J.A.; MCCORMICK, P.V.. Evaluation of digital photography for estimating live and dead aboveground biomass in monospecific macrophyte stands. Aquatic Botany 67: 69-77. 2000.

STROMBECK, N.; PIERSON, D.C.. The effects of variability in the inherent optical properties on estimations of chlorophyll $a$ by remote sensing in Swedish freshwaters. The Science of the Total Environment, 268: 123-137. 2001

TAiZ, L.; Zeiger, E.. Plant Physiology (3ª edição), Sinauer Associates, Inc. Publishers, Sunderland MA, USA. 2002.

THOMAZ, S. M.; BINI, L. M.. Ecologia e manejo de macrófitas aquáticas. Editora UEM, Maringá, 
2003.

TURRELL, F.M.. The area of the internal exposed surface of dicotyledon leaves. American Journal of Botany, 23: 255-264. 1936.

VASCONCELOS, C.H.; NOvO, E.M.L.M.. Mapeamento de macrófitas e paliteiros do Reservatório de Tucuruí (Pará), utilizando imagens RADARSAT. Anais XI SBSR, Belo Horizonte, Brasil, 05 - 10 abril 2003, INPE, p. 2633 - 2638.

VOGELMAN, T.C.; MARTIN, G.. The functional significance of palisade tissue: penetration of directional versus diffuse light. Plant, Cell and Environment, 16: 65-72. 1993.

WALDRON, M. C.; STEEVES P. A.; FINN J. T.. Use of thematic mapper imagery to assess water quality, trophic state, and macrophyte distributions in Massachusetts lakes. WRI (Water Resource Investigations report) 01-4016, preparado em cooperação com o Massachusetts Department of Environmental Management, 2001; 40 p.. Disponível na URL:

http://water.usgs.gov/pubs/wri/wri014016/ (28/09/2002).

WelCH, R.A.; RemilLaRD, M.M.. Remote Sensing and Geographic Information System for Aquatic Resource Evaluation. Photogrammetric Engineering and Remote Sensing, 1988; 54(2):177-185.

ZHENG, X.; DiCKEY, T.; CHANG, G.. Variability of the downwelling diffuse attenuation coefficient with consideration of inelastic scattering. Applied Optics, 41(30):6477. 2002.

Zimmerman, R.C.. A biooptical model of irradiance distribution and photosynthesis in seagrass canopies. Limnol. Oceanogr., 48 (1, parte 2): 568-585. 2003. 